\title{
Climate change and health : consequences and adaptation in Europe
}

Citation for published version (APA):

Akin, S. M. F. (2015). Climate change and health : consequences and adaptation in Europe. [Doctoral Thesis, Maastricht University]. Datawyse / Universitaire Pers Maastricht. https://doi.org/10.26481/dis.20151217sa

Document status and date:

Published: 01/01/2015

DOI:

10.26481/dis.20151217sa

Document Version:

Publisher's PDF, also known as Version of record

\section{Please check the document version of this publication:}

- A submitted manuscript is the version of the article upon submission and before peer-review. There can be important differences between the submitted version and the official published version of record.

People interested in the research are advised to contact the author for the final version of the publication, or visit the DOI to the publisher's website.

- The final author version and the galley proof are versions of the publication after peer review.

- The final published version features the final layout of the paper including the volume, issue and page numbers.

Link to publication

\footnotetext{
General rights rights.

- You may freely distribute the URL identifying the publication in the public portal. please follow below link for the End User Agreement:

www.umlib.nl/taverne-license

Take down policy

If you believe that this document breaches copyright please contact us at:

repository@maastrichtuniversity.nl

providing details and we will investigate your claim.
}

Copyright and moral rights for the publications made accessible in the public portal are retained by the authors and/or other copyright owners and it is a condition of accessing publications that users recognise and abide by the legal requirements associated with these

- Users may download and print one copy of any publication from the public portal for the purpose of private study or research.

- You may not further distribute the material or use it for any profit-making activity or commercial gain

If the publication is distributed under the terms of Article $25 \mathrm{fa}$ of the Dutch Copyright Act, indicated by the "Taverne" license above, 


\section{Climate change and health Consequences and adaptation in Europe}


ISBN 9789461595065

(c) copyright Su-Mia Fazilet Akin, Maastricht 2015

Printing: Datawyse / Universitaire Pers Maastricht 


\title{
CLIMATE CHANGE AND HEALTH \\ Consequences and adaptation in Europe
}

\author{
DISSERTATION \\ to obtain the degree of Doctor at the Maastricht University, \\ on the authority of the Rector Magnificus Prof. dr. L.L.P. Soete \\ in accordance with the decision of the Board of Deans, \\ to be defended in public on Thursday 17 December 2015, at 15:45 hours \\ by
}

Su-Mia Fazilet Akin

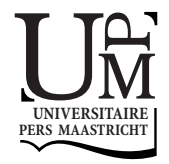




\section{Supervisor}

Prof. dr. Pim Martens

\section{Assessment Committee}

Prof. dr. Pieter Glasbergen (chairman)

Prof. dr. Matthew Baylis (Institute of Infection \& Global Health, University of Liverpool) Prof. dr. Martin Beniston (Institute for Environmental Sciences, University of Geneva) Prof. dr. Wim Passchier

This Ph.D. research was partly funded by VROM (the Dutch Ministry of Infrastructure and the Environment) as a part of the ENHanCE (ERA-NET Health and Climate in Europe) research project, under the ERA-ENVHEALTH project. 

Chapter 1 Introduction 9

1.1 Research context: Global change, climate change and human 10 health

1.2 Research objectives 13

1.3 Outline 13

Chapter 2 Research context, key concepts, and methodological approach 15

2.1 Global (environmental) change, globalisation, and human health 16

$\begin{array}{lll}2.2 & \text { Health } & 19\end{array}$

2.3 Climate change and health in Europe, and the ENHanCE 21 Research Project

2.4 Responses to climate change impacts on health: Adaptation and 25 mitigation

2.5 Participatory integrated assessment methods 30

$\begin{array}{lll}2.6 & \text { In summary } & 31\end{array}$

Chapter $3 \quad$ Globalisation and health: A statistical indicator analysis 33

$\begin{array}{lll}3.1 & \text { Introduction } & 35\end{array}$

$\begin{array}{lll}3.2 & \text { Methodology } & 37\end{array}$

$\begin{array}{lll}3.3 & \text { Results } & 46\end{array}$

$\begin{array}{lll}3.4 & \text { Discussion } & 51\end{array}$

3.5 Conclusion 53

Chapter $4 \quad$ A survey of Dutch expert opinion on climatic drivers of 57 infectious disease risk in Western Europe

$\begin{array}{lll}4.1 & 59\end{array}$

4.2 Methodology and research design 60

4.3 Results of the survey 63

$\begin{array}{lll}4.4 & \text { Discussion and conclusions } & 75\end{array}$ 
Chapter 5 Climate change and infectious disease risk in Western Europe: A 79 survey of Dutch expert opinion on adaptation responses and actors

5.1 Introduction $\quad 81$

5.2 Methodology 82

$\begin{array}{lll}5.3 & \text { Results } & 88\end{array}$

$\begin{array}{lll}5.4 & \text { Discussion and conclusions } & 105\end{array}$

Chapter $6 \quad$ Climate change adaptation for health in Europe 111

$\begin{array}{lll}6.1 & \text { Introduction } & 113\end{array}$

6.2 Conceptualization and research background 114

6.3 European Union climate change adaptation for health 116

6.4 A discussion on progress and mainstreaming of EU climate 120 change adaptation for health

$\begin{array}{lll}6.5 & \text { Conclusions } & 128\end{array}$

$\begin{array}{lll}\text { Chapter } 7 & \text { Conclusions and reflection } & 131\end{array}$

$\begin{array}{lll}7.1 & \text { The relationship between globalisation and health }\end{array}$

7.2 Climatic and non-climatic drivers of infectious disease risk in 134 Western Europe

7.3 Adaptation responses for climate change-induced infectious 136 disease risk in Western Europe

7.4 Adaptation to climate change and health in Europe 138

7.5 Global change, climate change, and health: Some final reflec- 139 tions

Valorisation Addendum 145

$\begin{array}{ll}\text { References } & 149\end{array}$

Appendix 1 Additional information stakeholder analysis and expert sample 161

$\begin{array}{ll}\text { Summary } & 169\end{array}$

$\begin{array}{ll}\text { Samenvatting } & 174\end{array}$

Acknowledgments 180

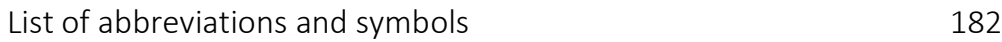

About the Author 184 
Ph.D. programme in Sustainability Science and Policy

(SSP) MUST Certificate 


\section{CHAPTER 1 INTRODUCTION}


This thesis focuses on global changes and in particular climate change, a global environmental change process, and its relations to health and infectious disease risk specifically, as well as how we can respond (adapt) to these challenges. A large part of the research presented in this dissertation was undertaken as a part of the ENHanCE (ERA-NET Health and Climate in Europe) research project part of the ERA-ENVHEALTH project, funded by VROM (Dutch Ministry of Infrastructure and the Environment). This chapter will introduce the research topic and context covered in this dissertation, thereafter introduce the main research objectives addressed, and finally provide an outline of this dissertation.

\subsection{Research context: Global change, climate change and human health}

Today, many interacting global changes are taking place at an unprecedented rate often related to human activities. These changes impact our ecological as well as societal systems. Climate change is one of the significant examples of such (mostly) human-induced global changes with already noticeable but also future consequences (IPCC, 2013; Scholte, 2000; Steffen et al., 2007). Globalisation or the global changes that are taking place create wide-ranging impacts on (public) health (Lee, 2009). Global changes and globalisation influence human health, and amongst these relevant global changes is also climate change as a driver for human health outcomes (McMichael, 2013).

The occurrence of human-induced global warming and climate change is a fact and its wide-ranging impacts in all regions of the world and in all sectors including health is acknowledged (EEA, 2012; IPCC, 2013; Kovats et al., 2014). Climate change is a threat to human health and well-being, including via its influence on infectious disease risk, at a global level, but also in the European region (EEA, 2012; Kovats et al., 2014; McMichael, 2013; Semenza \& Menne, 2009).

The relationships between climate change and health, or specifically infectious disease risk outcomes, are complex as they involve many climatic and non-climatic factors, which operate at different levels, and vary across geographical regions and are disease specific (Akin \& Martens, 2014; Füssel \& Klein, 2006; Semenza \& Menne, 2009; Sutherst, 2004). Some relevant mediating factors in this complex causal system are socioeconomic status, health system status and related vulnerability, and adaptive capacity (IPCC, 2014a; Menne et al., 2008). This thesis employs an integrated perspective on global change and climate change as it relates to health and infectious disease risk, in order to acknowledge and address the complexities at hand. Global changes as well as human health are viewed as holistic, integrated concepts, in line with this integrated approach. Moreover, not only the integration of various drivers is a central tenet of this approach, also the inclusion of multiple causal levels, and the use of integrated assess- 
ment methods, in this case participatory assessment methods, using stakeholders for the analyses.

The challenge climate change poses on our health, as well as socio-economic systems, requires an effective response. In this dissertation a focus is placed on adaptation responses to climate change impacts on health (rather than mitigation responses ${ }^{1}$ ) which can be defined as "the process of adjustment to actual or expected climate and its effects [...] (p.1) (IPCC, 2014d)". Based on this definition (IPCC, 2014d), adaptation for climate change-induced health outcomes specifically can be understood as the adjustment to actual or expected climate change effects on human health, where it is also aimed to moderate harm to health but to take advantage of beneficial opportunities (MEA, 2005a). Within a European context, such a response is developed and implemented, more so for mitigation response strategies, and more recently also a start for adaptation response strategies is made. The effectiveness of adaptation strategies for climate change is not evident, also not in the context of health outcomes, moreover, the full potential for risk reduction of adaptation measures is not reached (EC, 2009a, 2013a; IPCC, 2014b, 2014c; Smith et al., 2014). An accurate view on how much adaptation is undertaken at global, regional, national, and local levels, is at present not there or not complete. This complicates the assessment of the effectiveness of our response, the vulnerabilities and risks at hand from climate change for health, and what needs to still be done.

\subsubsection{The ENHanCE - ERA-NET Health and Climate in Europe - research project}

This dissertation has been partly based on the ENHanCE (ERA-NET Health and Climate in Europe) research project, part of the ERA-ENVHEALTH project. The project therefore is essential for understanding the context within which the research presented is placed. The ENHanCE project, which ran April 2009-March 2012, was an interdisciplinary project involving three partners in three countries: the University of Liverpool, in the United Kingdom (project leader); Centre de coopération internationale en recherché agronomique pour le développement (CIRAD)/University of Montpellier, in France; and Maastricht University, in the Netherlands. Each country partner was funded by a national funder. The research done at Maastricht University, at ICIS (the International Centre for Integrated assessment and Sustainable development) was funded by VROM (the Dutch Ministry of Infrastructure and the Environment).

\footnotetext{
${ }^{1}$ Mitigation of climate change can be defined as "a human intervention to reduce the sources or enhance the sinks of greenhouse gases (p.19) (IPCC, 2014d)". Mitigation policies can have co-benefits for health, e.g. changes to housing, energy, and/or transport policies can also indirectly improve overall population health and resilience (IPCC, 2014C). (In Chapter 2, 5, and 6 adaptation and mitigation responses are addressed).
} 
The ENHanCE project aimed to assess the potential impact of future climate change on infectious disease risk in Europe, and its outcomes for human health and well-being (the latter via effects of animal health). For the project the unit of analysis was "all those pathogens of humans and domestic animals that are known to occur in, or threaten, Western Europe; are of major impact to human health or well-being; and have epidemiological linkages to temperature or moisture levels in air or the environment and, hence, are expected to be most susceptible to the effects of climate change (ENHanCE project proposal (ENHanCE)". The geographical focus of the project is on Western Europe, with a strong emphasis on the partner countries involved in the project.

ICIS has lead two work packages for the ENHanCE project which in brief involved a participatory integrated assessment of responses to climate change-induced infectious disease risks, using expert opinion. And secondly, the participatory development of integrated assessment scenarios to visualize the future climate change impacts on human health \& well-being in Western Europe. The studies presented in Chapters 4 and 5 show the results of a large part of the integrated participatory assessment conducted for the ENHanCE project.

The ENHanCE research project will be discussed in more detail in Chapter 2. More information on the project can be found through the ENHanCE project website (ENHanCE).

\subsubsection{Point of departure of research approach and methods}

In Chapter 2 the research approach and methods used in the studies in this dissertation are explained, where attention is paid to the clarification of the context and key concepts to this dissertation. Overall, the studies presented in this dissertation can be characterized by an integrated approach to the analysis of the relationships between global change and/or climate change and health outcomes. Taking such an integrated perspective allows for the acknowledgement of the complexity of the relationships between global change/climate change and health. In order to examine and gain understanding of health threats from global environmental changes, and climate change in particular, in interaction with other change processes (socio-economic, institutional, demographic), a population-level research focus is taken on throughout the studies in this dissertation which is necessary to capture these dynamics. This focus also allows for the examination of the health of entire populations, or communities, which is the focus throughout the studies presented in this dissertation (McMichael, 2014b). Related to this perspective and inherent to this research approach also the key concepts used in this thesis, being health and global change/globalisation, are defined and understood as integrated holistic or pluralistic concepts. Another key characteristic of the research in this dissertation is that integrated participatory methods have been used to address the complexity of environmental problems such as climate change as well as the related policy field. This 
approach has allowed for the inclusion of stakeholder knowledge in the research, which can contribute to understanding complex issues (de Ridder et al., 2007; Füssel \& Klein, 2006; Kloprogge \& van der Sluijs, 2006). The research approach and methods used are elaborated on in Chapter 2.

\subsection{Research objectives}

The overall research aim of this thesis is to analyze the relationship between global change, specifically focusing on climate change as a global (environmental) change process, and health, and to assess the adaptation response to climatic consequences for health in Europe.

In order to address this research aim this thesis has the following research objectives:

1) To analyse the relationship between globalisation and health;

2) To explore expert views on the importance of climatic and non-climatic drivers for infectious disease risk in Western Europe and their uncertainty in terms of in their future development;

3) To explore expert views on adaptation responses to climate change-induced infectious disease risk in Western Europe, and the willingness and capacity of relevant actors in such a response;

4) To describe and reflect on current adaptation to climate change-induced health outcomes in Europe, mainstreaming efforts, and possible ways forward.

These objectives form a guide through this thesis, each treated in a separate chapter in this order and later all objectives return in Chapter 7 where a discussion and final conclusions are presented.

\subsection{Outline}

The dissertation first takes a closer look at some of the key concepts and methodological research approaches employed throughout the research presented in Chapter 2. Thereafter in Chapter 3, a study which analyzes the relationship between globalisation and population health, making use of the Maastricht Globalisation Index (MGI) as a measure for globalisation and examining its linkages to key mortality indicators by means of a statistical indicator analysis. Chapter 4 and 5 directly come from the research conducted as a part of the ENHanCE research project. In Chapter 4 a part of a survey of Dutch expert opinion on climatic and non-climatic drivers of infectious disease risk in Western Europe is presented. Thereafter, in Chapter 5, based on the same survey, the results of the expert opinions on adaptation to climate change-induced infectious disease risk in 
Western Europe is presented. As the response to climate change impacts on health is touched upon in Chapter 5, in Chapter 6 this topic is further explored in the context of the EU, focusing on governance of adaptation to climate change and health in Europe. Finally in Chapter 7, a discussion and final conclusions are given. Below in Table 1.1 a graphical representation of the outline of the dissertation can be found. The table also illustrates the geographical focus which is the global-level in Chapter 3, but then funnels in to the regional-level focusing on Western-Europe and the EU in Chapters 4, 5, and 6. Also it can be seen which chapters directly come from the research done for the ENHanCE research project.

\begin{tabular}{|c|c|c|}
\hline & Chapters & Geographical focus \\
\hline & Chapter 1 Introduction & \\
\hline & $\begin{array}{l}\text { Chapter } 2 \text { Clarification of key concepts and methodological } \\
\text { approach }\end{array}$ & \\
\hline & $\begin{array}{l}\text { Chapter } 3 \text { Globalisation and health: A statistical indicator analy- } \\
\text { sis }\end{array}$ & Global-level \\
\hline \multirow{4}{*}{$\begin{array}{l}\text { ENHanCE re- } \\
\text { search project }\end{array}$} & $\begin{array}{l}\text { Chapter } 4 \text { A survey of Dutch expert opinion on climatic drivers } \\
\text { of infectious disease risk in Western Europe }\end{array}$ & \multirow{3}{*}{$\begin{array}{l}\text { Regional-level (West- } \\
\text { ern-Europe, and EU) }\end{array}$} \\
\hline & $\begin{array}{l}\text { Chapter } 5 \text { Climate change and infectious disease risk in Western } \\
\text { Europe: A survey of Dutch expert opinion on adaptation re- } \\
\text { sponses and actors }\end{array}$ & \\
\hline & Chapter 6 Climate change adaptation for health in Europe & \\
\hline & Chapter 7 Conclusions and reflection & \\
\hline
\end{tabular}

Table 1.1 Graphical representation of dissertation outline 


\section{CHAPTER 2 \\ RESEARCH CONTEXT, KEY CONCEPTS, AND METHODOLOGICAL APPROACH}


This chapter provides some clarifications and definitions of key concepts used throughout this dissertation which will be related to the context of climate change and health. As a second objective this chapter clarifies the methods and approach to the research presented in this dissertation.

\subsection{Global (environmental) change, globalisation, and human health}

Today, many interacting global changes are taking place at an unprecedented rate often related to human activities. These changes impact our ecological as well as societal systems. Climate change is one of the significant examples of such (mostly) human-induced global changes with already noticeable but also future consequences (IPCC, 2013; Scholte, 2000; Steffen et al., 2007).

The Anthropocene is a term coined by Paul J. Crutzen and describes the current time within which human activity has changed the Earth in unprecedented and long-lasting (at times irreversible) ways (Steffen et al., 2007). The term Anthropocene has become widely used in the global change research community (Steffen et al., 2011). It describes the shift in the relationship between humans and the global environment (Steffen et al., 2011). The impacts of human activities are rooted in the underlying human-driven global changes that are taking place. These global changes manifest itself in a wide range of global-scale phenomena including biophysical and socioeconomic changes such as in atmospheric composition, nitrogen and carbon cycles, physical climate changes, and resource and energy use, amongst others (Steffen et al., 2007; Zalasiewicz et al., 2010). We are now facing challenges of excessive resource use and environmental deterioration, and at the same time no significant reductions in greenhouse gas emissions have materialised; the Anthropocene, starting from the mid-twentieth century onwards, is reaching criticality (Steffen et al., 2007).

It is clear that global anthropogenic climate change is one of the major human-induced global environmental changes characterising the Anthropocene. These climatic changes (besides other global changes) create significant threats to human health and well-being (McMichael, 2013). Climate change can be seen as an example of how human activities towards nature have current and future consequences for human health. Human activities are leading to the disruption of Earth's biophysical and life-supporting systems, which will ultimately result in a significant reduction in population health (McMichael, 2014b). Global climate change is mainly caused by human activities and in the second stage of the Anthropocene, together with other global changes, this leads to great (positive and negative) consequences for human health (McMichael, 2014b). 


\subsubsection{Globalisation and human health}

The concept of globalisation, a central concept to this dissertation, serves as an overarching umbrella to the many processes of global change that can be observed in the Anthropocene. There are various definitions and understandings of the concept of globalisation, and it therefore needs some clarification for the purpose of this dissertation. From the brief discussion on the Anthropocene it becomes evident that there are a multitude of global changes taking place. In order for the concept of globalisation to capture this, comprehensive integrative definitions are needed. It should encompass economic, political, technological, but also the socio-cultural and environmental changes taking place at a global level (Dreher et al., 2008; Rennen \& Martens, 2003). In Chapter 3 of this dissertation, a definition of the concept of globalisation is employed which attempts to capture the complexity of the various global changes taking place, applying an integrative perspective on global change and the concept of globalisation. The following definition by Rennen and Martens (2003) (p.143) provides such an integrated pluralistic conceptualisation, defining contemporary globalisation as: "[...] an intensification of crossnational cultural, economic, political, social and technological interactions that lead to the establishment of transnational structures and the global integration of cultural, economic, environmental, political and social processes on global, supranational, national, regional and local levels" (Martens et al., 2010). This definition makes clear that globalisation embodies many different simultaneous change processes, taking place at different levels and within different domains (Rennen \& Martens, 2003).

Globalisation or the global changes that are taking place create wide-ranging impacts on (public) health (Lee, 2009). Global changes and globalisation influence human health, and amongst these relevant global changes is also climate change as a driver for human health outcomes (McMichael, 2013). Many have conceptualised the links between global change and/or globalisation and human/population health. These frameworks all make different conceptual assumptions on what globalisation or global change processes entail and they therefore represent different perspectives on the relationship at hand ((see for a discussion on this (Huynen, 2008; Huynen, Martens, et al., 2005)). McMichael (2013) provides a figure illustrating the human health impacts of systemic global changes and globalisation, see Figure 2.1 for a representation of this figure. 


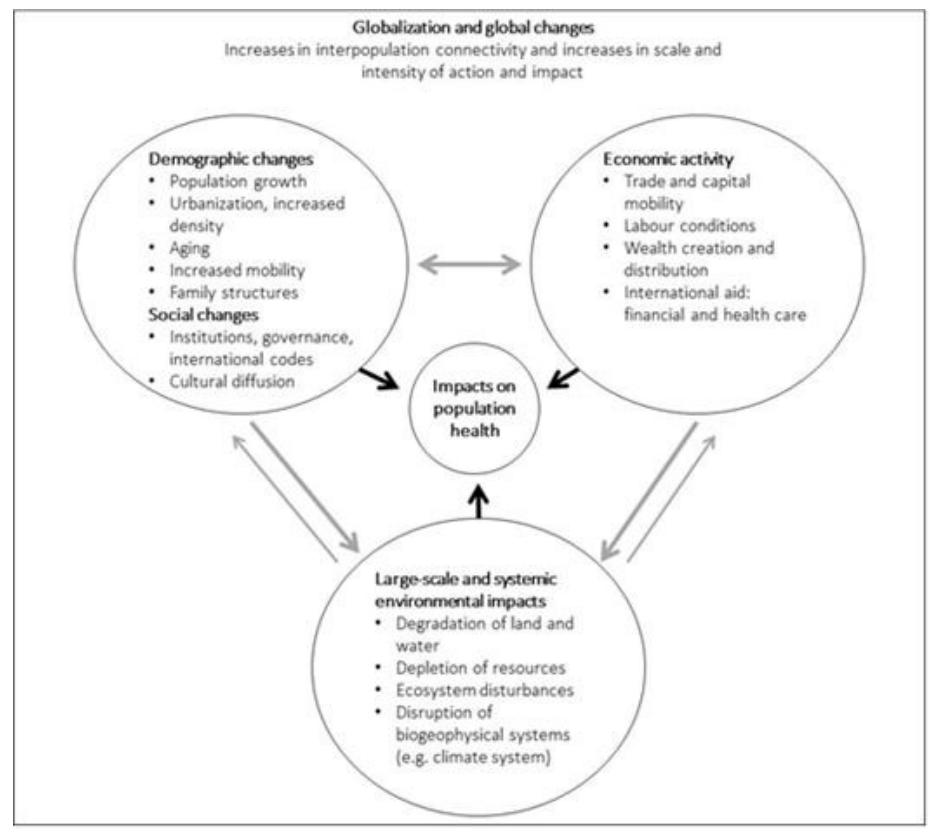

Figure 2.1 Globalisation, global changes and health, adapted from McMichael (2013)

Global change and globalisation for the purpose of this figure has been defined as "increases in interpopulation connectivity and increases in scale and intensity of action and impact (p.1336, figure 1) (McMichael, 2013)"'2. What should be noted is that the figure emphasises the relevance of all change processes in the different domains for health as well as the interactions or feedbacks that take place between the change processes (illustrated by the arrows). It becomes clear that global changes influence health outcomes jointly and in interaction with each other. This interrelatedness of global changes is also relevant for the relationship between climate changes and health (McMichael, 2013). Globalisation or global change can have positive and negative effects on human health (Martens et al., 2010; McMichael, 2013).

\footnotetext{
${ }^{2}$ This figure is not based on the definition of globalisation that is used for Chapter 3 , however, it illustrates very well the environmental changes amongst which are climatic changes and its relation to population health, which is the focus of this dissertation.
} 


\subsection{Health}

In this dissertation an integrated perspective on the concept of health is taken. The focus of this dissertation is on human health and well-being (and not e.g. animal or plant health) ${ }^{3}$. (Human) health has no universal definition ${ }^{4}$. The global nature of change processes amongst which climate change is a key focus in this dissertation impact upon health determinants and outcomes and therefore pose current and future challenges which require population-level and integrated perspectives on health in order to research the topic of global change, and specifically climate change and health (McMichael, 2014b).

Both concepts of population health and public health apply to the way the term (human) health is used and understood throughout this dissertation. The difference between the two concepts is subtle. Population health is a concept that supports us to think about why some populations or subsets of populations are healthier than others. Population health places a focus on an entire population rather than on individuals. Moreover, population health aims to address the entire range of factors that determine health (rather than individual-level health risks). Due to the comprehensive and integrated nature of the concept of population health, it requires interdisciplinary research resting in disciplines such as epidemiology and social sciences (Kue Yong, 2005). Analysis of population health issues can serve as a source of information for the development of policy and governance of these issues. Population health can be defined as: "The health of population measured by health status indicators; it is influenced by physical, biological, social, and economic factors in the environment, by personal health behaviour, and by access to and effectiveness of health care services". An alternative definition emphasizing the idea of determining the current and/or desired level of health in a given population is: "The prevailing or aspired level of health in the population of a specified country or region or in a defined subset of that population" (Porta, 2014). For some of the studies presented in this dissertation, the concept of population health is a useful way of understanding what (human) health means or how it is defined in the context of the analyses conducted. Chapter 3 presents a study on globalisation as a determinant for human health outcomes. Human health in this study is defined as the health of populations being subject to a wide array of globalisation-related determinants. Therefore the concept of population health fits well with the conceptual point of departure and the analysis of that study. In Chapter 4, climatic and non-climatic determinants of infectious

\footnotetext{
${ }^{3}$ Zoonoses are taken into account for the survey conducted as a research component of the ERA-NET ENVHEALTH ENHanCE research project, and reported on in Chapter 4, but only to the extent that these impact upon human health and well-being. For a definition of zoonoses, please see Chapter 4.

${ }^{4}$ The definition for (human) health formulated by the WHO most commonly quoted is: "Health is a state of complete physical, mental and social well-being and not merely the absence of disease or infirmity" (WHO, 1948).
} 
disease outcomes in a Western-European context are assessed. This is also a study where the concept of population health is appropriate as the focus lies on a broad range of determinants of the health of a population and the aim is to gain more understanding of the importance and (future) uncertainty of these determinants. It should be noted that of course both of these studies result in information that may be useful for health policy and/or governance, however, these aspects are not the explicit focus of the analyses at hand.

The concept of public health is another core concept to the studies presented in this dissertation. Public health places a focus on systems, programs, policies, procedures, institutions, and disciplines that are required to achieve the aspired level of status of population health. This focus shows how the concepts of public health and population health can be distinguished (even if, as mentioned earlier, the distinction may be somewhat subtle) (Kue Yong, 2005; Porta, 2014). A widely accepted definition is "Public health is the science and art of preventing disease, prolonging life, and promoting health through the organized efforts of society" (Detels, 2009; Porta, 2014). Another more elaborate definition of public health is the following, which emphasises the aim of meeting the health needs of a population: "The combination of sciences, skills, and beliefs that is directed to the maintenance and improvement of the health of all the people through collective or social actions. The programs, services, and institutions involved emphasize the prevention of disease and the health needs of the population as a whole. Public health activities change with changing technology and social values, but the goals remain the same: to reduce the amount of disease, premature death and diseaseproduced discomfort and disability in the population. Public health is thus a social institution, a discipline, and a practice" (Porta, 2014). As with population health, the concept of public health focuses not on individual-level health, but rather on the aggregate level of health of the public (Detels, 2009). The focus on the aggregate or population level of health that is inherent to both concepts makes them useful to study global changes, globalisation, and specifically climate change consequences for (human) health at a global and/or European level, as is done in this dissertation. Public health has several key functions of which the promotion and protection of a healthy environment, as well as planning and preparing for natural and manmade disasters, seems to be key functions relating to the topic of climate change and health of focus in this dissertation. Climate change and the resulting global warming is a major public health issue of this time (Detels, 2009). The concept of public health is appropriate for the studies presented in Chapter 5 and 6 . Chapter 5 explicitly focuses on (the assessment of) potential responses to climate change-induced infectious disease risk. Chapter 6 provides an overview of the policies in place for adaptation to climate change impacts on health and reflects on possible future development as well as mainstreaming of these policy efforts. It can be seen that the broad scope as well as the focus on health at an aggregate level, and of course the essential focus on policies, institutions, systems, and programs that the public health concept encompasses is fitting in the context of these studies. 
Another health concept that should be mentioned briefly in addition to what has been described is global health. Since the determinants of health and its outcomes for health transcend national boundaries, the type of health challenges focused on in this dissertation may be called global health challenges (Lee, 2009; Skolnik, 2008).

The research focus throughout this dissertation in line with the conceptualisation of health explained is consistently on the population-level rather than the individual level. In order to examine and gain understanding of health threats from global environmental changes, and climate change in particular, in interaction with other change processes (socio-economic, institutional, demographic), a population-level approach to the research is necessary to capture these dynamics. This focus also allowed to understand and assess the health of entire populations, or communities, which is the focus throughout the studies presented in this dissertation (McMichael, 2014b).

\subsection{Climate change and health in Europe, and the ENHanCE Research Project}

"The climate", as a sources of threats to health [...] is a dynamic and changeable system with many local and regional manifestations, most of which can influence rates and patterns of health outcomes. It is often referred to as a health 'risk multiplier'. Of course, it can also act as a 'risk divider' [...] (p.9) (McMichael, 2014b)." Most, but not all, of the effects of climate change on health will be adverse (McMichael, 2014b).

Climatic changes work together with (global) non-climatic drivers, such as land use change, the movement of people, to result in health outcomes. The simultaneous influence of such non-climatic driver makes it difficult to determine the climate change effects on health (Akin \& Martens, 2014; EEA, 2012; McMichael, 2013, 2014a; Semenza \& Menne, 2009).

In short there are three causal pathways in which climate change affects health (McMichael, 2013, 2014a): “1) Primary, direct-acting, climatic-environmental exposures. For example, the health consequences of exposure to excessive heat and the physical hazards of extreme weather events; 2) Secondary health risks resulting from less direct

\footnotetext{
5 "Climate change refers to a change in the state of the climate that can be identified (e.g., by using statistical tests) by changes in the mean and/or the variability of its properties, and that persists for an extended period, typically decades or longer. Climate change may be due to natural internal processes or external forcings such as modulations of the solar cycles, volcanic eruptions, and persistent anthropogenic changes in the composition of the atmosphere or in land use. Note that the Framework Convention on Climate Change (UNFCCC), in its Article 1, defines climate change as: 'a change of climate which is attributed directly or indirectly to human activity that alters the composition of the global atmosphere and which is in addition to natural climate variability observed over comparable time periods.' The UNFCCC thus makes a distinction between climate change attributable to human activities altering the atmospheric composition, and climate variability attributable to natural causes (p.39) (IPCC, 2014f)."
} 
pathways involving disruptions/changes to ecosystems and inter-species relationshence to harvest yields, livestock health, and infectious disease transmission, and 3) Tertiary risks to physical and mental health from social and economic disruptions, job losses/changes, and the more ominous risks of health damage from conflict situations driven by climate-related resource shortages (water, food, habitable land) (p.10) (McMichael, 2014a)" (also see Ebi et al. (2006)). The health consequences of climate change will mostly be negative with some positive outcomes e.g. from milder winters in some regions (EEA, 2012; McMichael, 2013).

Within a European context, which is the level of analysis for the studies on climate change and health presented in Chapters 4, 5, and 6, climate change influences on health can be summarized as the following (based on some of the main evidence provided by the latest IPCC report (IPCC, 2014c)). Climate change is likely to have a wide range of health effects in Europe and is already contributing to the burden of disease and premature deaths in Europe (EEA, 2012; IPCC, 2014c). The health consequences from climate change differ depending on the vulnerability of the people affected, their ability to adapt, and ecological, socio-economic and cultural factors (EEA, 2012). Southern European regions show vulnerability to hot weather and will experience highest heat exposures. In Continental and Northern European regions also vulnerability to heat waves events has been found. Climate change is likely to increase future heatrelated mortality and morbidity, and to reduce future cold-related mortality (which causes a greater mortality in most European countries). Evidence of future climate change impact on infectious disease risk remains limited. The Asian tiger mosquito Aedes Albopictus (a vector of dengue and Chikungunya) is found to be present in Southern Europe, and may move eastward and northward due to climate change (IPCC, 2014c).

\subsubsection{The ENHanCE - ERA-NET Health and Climate in Europe - research project}

As mentioned in Chapter 1, the ENHanCE research project, part of the ERA-ENVHEALTH project, has been essential for the research conducted in for this dissertation. Chapters 4 and 5 present research outcomes directly resulting from the research conducted for the ENHanCE project. Understanding the project will help to gain a better view on the context within which the research of this dissertation is placed.

The ENHanCE project aimed to assess the potential impact of future climate change on infectious disease risk in Europe, and its outcomes for human health and well-being (the latter via effects of animal health). The research aimed to gain more understanding of the disease consequences of climate change and communicate insights necessary for climate change action to policy-makers. For the project the unit of analysis was "all those pathogens of humans and domestic animals that are known to occur in, or threaten, Western Europe; are of major impact to human health or well-being; and have epidemiological linkages to temperature or moisture levels in air or the environment and, hence, 
are expected to be most susceptible to the effects of climate change" (ENHanCE project proposal (ENHanCE). The geographical focus of the project was Western Europe, with a strong emphasis on the partner countries involved in the project. The map in Figure 2.1 illustrates the geographical focus of the project research. In red the partner countries of the ENHanCE project are shown: the United Kingdom, France, and the Netherlands. These formed the core geographical focus of the research. The neighbouring countries are shown in orange, and the other countries of interest are green. This map however should not be seen as an exclusive list of countries that the project's research concerned; as the nature of climate change and infectious diseases is transboundary this makes a strict geographical demarcation unrealistic (ENHanCE).

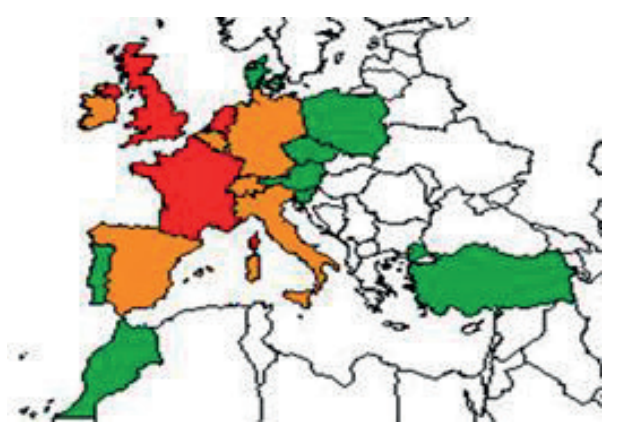

Figure 2.1 Map of geographical research focus of the ENHanCE Research Project (from ENHanCE project proposal (ENHanCE))

There are some core elements to the project research which also characterize the work that was done for ENHanCE. The state-of-the-art is advanced by using an integrated approach to address the complexity of infectious disease risk in Europe, which ensures that interactions, feedbacks, and effects are taken into account in the analysis. Thus the different pieces of the puzzle are not examined in isolation but rather integrated to increase our understanding as well as gain insights for the related policy field. The integrated approach also encompasses a wide variety of methods ranging from epidemiological analysis, to quantitative modelling, to qualitative scenario development. Related to this is another key characteristic of the project research, namely multidisciplinary, or one might even call it transdisciplinary. As researchers from different disciplinary backgrounds work together to address the aims of the project (epidemiologists, veterinarians, climatologists, sustainability scientists etc.) and at the same time, the project research and outcomes are developed with the engagement of stakeholders from the policy field. The participatory approach, which is related to this engagement of stakeholders, is another key characteristic of the project. Problems such as infectious disease risk from climate change which are complex and plagued with many uncertainties are best tackled using participatory approached. Participatory Integrated Assessment methods are discussed in further detail later in this chapter. But these methods make it possi- 
ble to include stakeholders and decision-makers in the research process. Moreover, the multidisciplinary approach is key for conducting a Participatory Integrated Assessment. The participation of stakeholders makes the integration of non-scientific knowledge, values, and preferences possible into the research process, which improves the quality of the project research by giving access to practical knowledge and experiences and different perspectives. The participatory approach therefore meant that the project assessment methods were designed by taking into consideration the needs of stakeholders and end-users, including the knowledge and experiences of stakeholders in the research process, and finally to communicate research approaches and outcomes effectively to these stakeholders and end-users. Therefore the participatory method is a key aspect of the research done running throughout the entire project. Finally, the project explicitly aimed to communicate to European policy and decision-makers what the key future infectious disease risks from climate change are. This explicit link to European policy for climate change and infectious disease outcomes is also a key aspect of the project research (see ENHanCE project proposal (ENHanCE)).

The ENHanCE research project consisted of several work packages (WPs), which are illustrated in Figure 2.2.

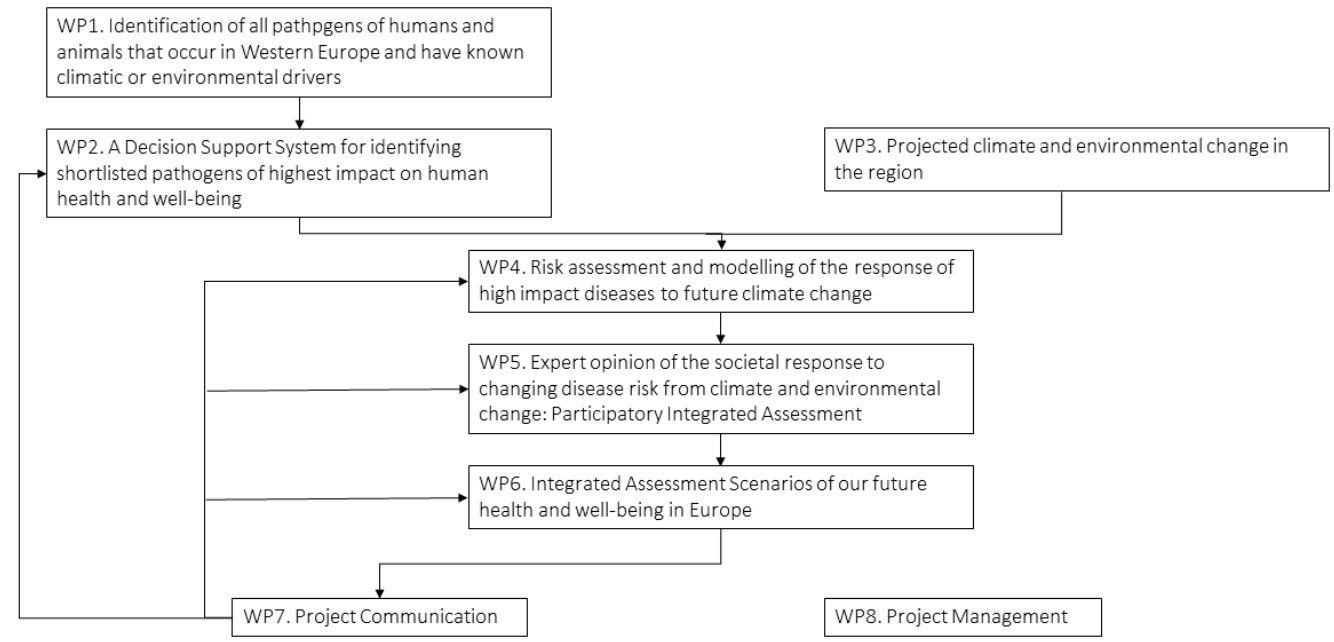

Figure 2.2 ENHanCE Research Project graphical representation of Work Packages (from ENHanCE research proposal (ENHanCE))

ICIS lead two Work Packages:

Work Package 5 "Expert opinion of the societal response to changing disease risk from climate and environmental change: Participatory Integrated Assessment", which in brief involved a participatory integrated assessment of responses to climate change-induced infectious disease risks, using expert opinion, and 
Work Package 6 "Integrated Assessment Scenarios of our future health and well being in Europe", which concerned the participatory development of integrated assessment scenarios to visualize the future climate change impacts on human health \& well-being in Western Europe.

The studies presented in Chapters 4 and 5 show the results of a large part of the Integrated Participatory Assessment conducted for Work Package 5.

Work Package 5 aimed to assess the likely response of stakeholders, decision makers and other end-users to the threat to human health and well-being from future climate and environmental change. More specifically, the capacity of response of different stakeholders is assessed and the management options available to deal with the problem are evaluated. The survey results presented in Chapters 4 and 5 come from the work done for this work package. Work Package 6 aimed to provide a visualization of our possible disease-future by integration of the threat of climate change on disease (coming from WP4) and our potential societal response to that threat (coming from WP5) in terms of potential measures of adaptation and mitigation; and secondly to develop a range of consistent, coherent \& multiform scenarios for changes in infectious disease risk in Europe in time periods centred on 2030 \& 2070 (ENHanCE).

\subsection{Responses to climate change impacts on health: Adaptation and mitigation}

Another key aspect of the studies presented in this dissertation is the possible response to climate impacts on health. Responding to climate change impacts on health is dealt with in Chapters 5 and 6, and this dissertation focuses on adaptation (rather than mitigation) as a response to climate change impacts on health (while acknowledging the benefits that can come from mitigation efforts for climate change impacts on health).

\subsubsection{Responding to climate change impacts on health: The global governance context}

Global change processes and in particular climate change and its consequences for health pose a great governance challenge. Climate governance comprises of mitigation of global warming, as well as adaptation to the consequences of global warming, as mitigation alone will not completely prevent global warming and its consequences (Biermann et al., 2010). In relation to the health consequences of global change and in particular climate change, mitigation is an important response strategy however, the immediate health threats from climate change make adaptation measures to lessen these risks a priority for the health sector (McMichael, 2013). The research presented in this dissertation emphasises adaptation to climate change-induced health outcomes, rather than mitigation. Even through mitigation efforts are a necessary task to combat 
climate change and in addition the effects of mitigation can benefit health as well. Mitigation efforts that improve transportation, housing and urban design, energy generation, and agricultural production can benefit health as well (McMichael, 2013).

Responses to climate change impacts on health can take place at various levels (ranging from global to local action), in different sectors, and by various actors (Adger, 2001; Biermann et al., 2010; McMichael, 2013). In the face of global ecological changes, both local- but also global-level measures are necessary to manage population health outcomes (McMichael, 2013). At a global scale, responses to climate change are mainly governed under the United Nations Framework Convention on Climate Change (UNFCCC) (Adger, 2001). The global climate governance architecture ${ }^{6}$ can be characterized by four spheres which range from being climate-related to more universal or crosscutting institutions; see Figure 2.4 for an illustration of this. The global governance architecture is made up of a broad variety of actors, differing in "[...] their character (organizations, regimes, and implicit norms), their constituencies (public and private), spatial scopes (from bilateral to global) and subject matters (from specific policy fields to universal concerns)[...] (p.16)" (Biermann et al., 2010).

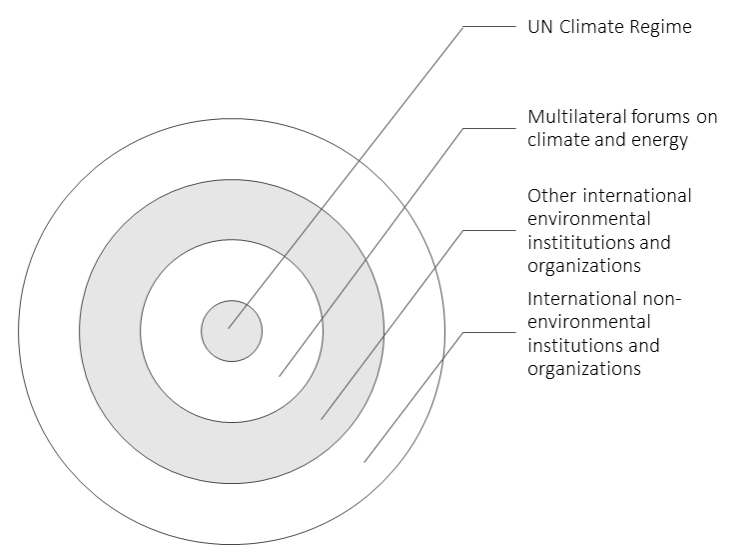

Figure 2.4 Spheres of global climate governance, adapted from Biermann et al. (p. 307) (2010)

The governance of climate change also involves many non-state actors, including private actors such as environmentalist groups, businesses, other public actors such as city municipalities, provinces. Governance beyond the state is increasingly believed to be necessary in order to tackle global changes processes such as climate change and its consequences, thus responding to climate change has become more and more a joint effort of

\footnotetext{
${ }^{6}$ The concept of global governance architecture is defined by Biermann et al. (2010) as "the overarching system of public and private institutions- that is, principles, norms, regulations, decision-making procedures and organizations - that are valid or active in a given issue areas of world politics (p.306-307)". This can be described as the meta-level of governance (Biermann et al., 2010).
} 
state and non-state actors. Global health governance is rather centralized around the World Health Organisation, and some additional, related institutions such as the World Bank (Biermann et al., 2010).

Embedded in this global governance architecture is the European Union and its governance of climate change and health, which is the level of focus for the Chapters 5 and 6 dealing with climate change adaptation. The national-level, thus the member states of the European Union, is also acknowledged and briefly discussed in Chapter 6, however, is not the central focus of the studies presented.

\subsubsection{Climate change adaptation and mitigation}

As mentioned earlier responding to climate change impacts on health (or any other sector) involves mitigation and adaptation measures. These response measures need some clarification as their definitions and differences are not immediately evident. Greater attention will be paid to the concept of climate change adaptation as this is the central focus of the studies presented in this dissertation.

The concept of climate change mitigation can be defined as "a human intervention to reduce the sources or enhance the sinks of greenhouse gases (p.1769) (IPCC, 2014d)." Climate change mitigation can produce health co-benefits, however may also create harmful health effects (IPCC, 2014a; WHO, 2011a). Co-benefits from climate change mitigation for health can comprise of reduced emissions of health-damaging pollutants; increased access to reproductive health services; decreased meat consumption, increased active transport, and increased urban green spaces (IPCC, 2014a).

The concept of climate change adaptation is not a well-demarcated concept (Füssel, 2007). Climate change adaptation is defined by the IPCC as "[t]he process of adjustment to actual or expected climate and its effects. In human systems, adaptation seeks to moderate or avoid harm or exploit beneficial opportunities. In some natural systems, human intervention may facilitate adjustment to expected climate and its effects (p.1758) (IPCC, 2014d)". Based on this definition (IPCC, 2014d), adaptation for climate change-induced health outcomes specifically can be understood as the adjustment to actual or expected climate change effects on human health, where it is also aimed to moderate harm to health or to take advantage of beneficial opportunities (MEA, 2005a). Ebi et al. (2006) provide another formal definition of the concept of climate change adaptation for health:“[...] the strategies, policies, and measures [...] undertaken now and in the future to reduce the burden of climate-sensitive health determinants and outcomes (p.1913)." Adaptation measures can encompass a great variety of actions, and come in different forms (institutional, technical, legal, educational, behavioural measures) (Füssel, 2007; Füssel \& Klein, 2006). Climate change adaptation measures for health can be for instance the adjustment of care facilities in order to be able to cope with increased patient volumes due to extreme weather events, or the development of 
programs for infectious disease surveillance (McMichael, 2013). These adaptation response measures and more are explained and addressed in the study in Chapter 5.

For adaptation measures not only climatic conditions and changes are the focus, but also the interactions with other non-climatic (environmental, socio-cultural, economic, political) factors determine the context within which adaptation takes place. For adaptation measures to be effective it is necessary to integrate and take into account climatic and relevant non-climatic factors. Adaptation can be autonomous, where an affected individual reacts to climatic variability or changes, or planned where governments or institutions respond to such climatic variability or changes. Planned adaptation can be reactionary or precautionary (anticipatory) (Adger, 2001; Ebi et al., 2006; Füssel, 2007). Füssel (2007) points out that in practices this distinction between reactive and anticipatory actions is at times difficult to make. The studies in this dissertation deal specifically with planned adaptation, as the focus is consistently placed on public health policy and climate change policy in Europe. Adaptation involves a wide range of actors or stakeholders at different level and representing different public and private sectors (Biermann et al., 2010; Füssel, 2007). In practice, adaptation efforts are mostly limited by financial constraints, insufficient technical skills, or lack of political will (Füssel, 2007).

When examining adaptation responses to climate change and health the concepts of adaptive capacity as well as the related concept of vulnerability are relevant. The concept of vulnerability is defined by the IPCC as: "[t]he propensity or predisposition to be adversely affected. Vulnerability encompasses a variety of concepts including sensitivity or susceptibility to harm and lack of capacity to cope and adapt (p.39) (IPCC, 2014f)." Ebi et al. (2006) elaborate on the concept of vulnerability within the context of human health. "Human health vulnerability to climate can be defined as a function of a) sensitivity, which includes the extent to which health, or the national or social systems on which health outcomes depend, are sensitive to changes in weather and climate (the exposureresponse relationship) and the characteristics of populations, such as its demographic structure; b) the exposure to the climate-related hazard, including the character, magnitude, and rate of climate variation; and c) the adaptation measures and actions in place to reduce the burden of a specific adverse health outcomes (the adaptation baseline), the effectiveness of which may influence the exposure-response relationship (p.1931)." Adaptive capacity in the context of climate change and health can be understood as "the general ability of institutions, systems, and individuals to adjust to potential harm, to take advantage of opportunities, or to cope with the consequences of climate variability and change (p.1931) (Ebi et al., 2006)". So, adaptive capacity aims at reducing the vulnerability to climatic variability or change; and when adaptive capacity decreases, vulnerability will increase. One can speak of an inverse relationship between the concepts of vulnerability and adaptive capacity (Adger, 2001; Ebi et al., 2006).

The two concepts of climate change mitigation and adaptation differ, in theory, in many of their characteristics. The key differences between climate change mitigation and adaptation have been summarized very well by Füssel and Klein (2006) and Füssel 
(2007); Table 2.1 provides an overview of these differences, compiled and adapted from these studies.

\begin{tabular}{lll}
\hline $\begin{array}{l}\text { Table } 2.1 \text { Key differences between climate change mitigation and adaptation (compiled and adapted from } \\
\text { Füssel (2007); Füssel and Klein (2006)) }\end{array}$ & Response measure \\
\hline \multicolumn{4}{l}{ Characteristic } & Climate change mitigation & Climate change adaptation \\
\hline Target systems & All systems & Selected systems \\
Scale of effect & Global & Local to regional \\
Life time & Centuries & Year to centuries \\
Lead time & Decades & Immediate to decades \\
Effectiveness & Certain & Generally less certain \\
Co-benefits & Sometimes & Often \\
Polluter pays & Typically yes & Not necessarily \\
Actor benefits & Only little & Almost fully \\
Monitoring & Relatively easy & More difficult \\
\hline
\end{tabular}

It can be gathered from the overview in Table 2.1 that mitigation when implemented, affects all climate-sensitive systems. Adaptation measures are often context-specific and thus limited in their application in some systems. There are also scalar and temporal differences between the two measures (Füssel, 2007; Füssel \& Klein, 2006; Martens et al., 2012). Mitigation is usually a more global-level effort, whereas adaptation mainly takes place at local or regional levels (Adger, 2001; Füssel \& Klein, 2006; Keessen, 2014; Martens et al., 2012). However, due to the multi-level nature of the issue of climate change mitigation and adaptation measures are integrated across these scales, and adaptation can have feedback effects for mitigation (Adger, 2001). Biermann et al. (2010) discuss the concept of global adaptation governance besides adaptation that takes place at local and national levels, which they relate to global level consequences of climate change for issues such as food security and health. Based on these sources it can be seen that adaptation can take place at different levels. Adaptation measures, when compared to mitigation, take relatively more immediate effect, whereas the effects of greenhouse gas reductions takes longer to be noticeable. Adaptation measures, however, may have a relatively shorter life time than mitigation measures. These temporal differences also have implications from a generational equity point of view. Mitigation has more long-term targets and therefore values the interests of future generations more. Therefore mitigation could be seen as a more altruistic response by society. Adaptation, on the other hand, is more focused on responding to immediate climate change consequences and may be characterized as being a more self-interested response (Martens et al., 2012). As mitigation aims to reduce greenhouse gases causing global warming, the effectiveness of these measures is certain. For adaptation responses the effectiveness is not so certain, as the latter depends on the accuracy of regional climate projections (Füssel, 2007; Füssel \& Klein, 2006). Adaptation measures have co-benefits relatively more often, which means that adaptation measures can create positive effects 
for other purposes which e.g. lessening the risk of climate variability, beyond the original purpose of the adaptation measure (Füssel, 2007; Füssel \& Klein, 2006; IPCC, 2014d). Mitigation mostly relies on the polluter-pays principle; adaptation measures, however, are most needed in those countries that have historically contributed least to global warming. The benefits of implementing adaptation measures are usually experienced by the actor(/-s) implementing the measures. Monitoring is significantly easier for mitigation than for adaptation. For mitigation, greenhouse gas reductions can be measured or estimated quantitatively. This also ties in the certainty of the effectiveness of the measure. For adaptation, monitoring is more difficult. Assessment of the effectiveness would have to be done in terms of future impacts avoided which can be more difficult to express in quantitative terms (Füssel, 2007; Füssel \& Klein, 2006). In practice, adaptation responses that have been adopted have not much been monitored or evaluated yet, which also makes it difficult to assess the effectiveness of the adaptation measures in place (IPCC, 2014a, 2014b, 2014c). The lack of monitoring done can also be related to the difficulty of doing so for adaptation (Füssel, 2007; Füssel \& Klein, 2006).

Historically, mitigation has received more policy and scientific attention, globally and at a European level, than adaptation (Biesbroek et al., 2010; Füssel, 2007; Füssel \& Klein, 2006; Martens et al., 2012), which could be related to the differences in the characteristics of the two response options relating to the applicability of mitigation to all systems, the certainty of the long-term effects of mitigation, the reliance on the polluter-pays principle of mitigation, and the ease of monitoring mitigation responses (Füssel, 2007; Füssel \& Klein, 2006).

Of course the differences explained in this section are conceptual and cannot always be applied strictly when looking at different cases of adaptation and mitigation responses (Keessen, 2014). Adaptation and mitigation measures are complementary, even though they may sometimes be mutually reinforcing and at other times conflicting. It is a policy priority to integrate the two measures to tackle climate change and its consequences, but their inherent differences make this a challenging task (Füssel, 2007; Martens et al., 2012).

\subsection{Participatory integrated assessment methods}

Many of the problems of today's society are complex, and therefore cannot be addressed by disciplinary approaches or conventional decision-making methods. Complex problems possess features such as encompassing many interlinked problems at the same time, covering different disciplines, exiting at different scales, and lastly involving many different stakeholders (Valkering et al., 2006). In these circumstances, Integrated Assessment (IA) methods serve as a valuable approach, since an integrated approach to analysis can provide insights which cannot be gained only from studies merely addressing specific parts of the entire phenomenon (Martens, 2006; Valkering et al., 2006). For 
the types of problems often studied in sustainability science, such as climate change and health, IA has been found to be a suitable umbrella method for making the inherent complexities explicit (Valkering, 2009). Over time, IA has evolved towards addressing more complex chains of analysis, integrating more quantitative research, being policydriven, and involving users in the assessment (Füssel \& Klein, 2006; Rothman \& Robinson, 1997).

IA can be seen as an umbrella method, encompassing different research methods and approaches which can come together under IA, such as integrated scenario assessment, integrated assessment modelling, or participatory integrated assessment. Participatory assessment tools are used in decision-making processes, at different levels of governance, and aim to involve stakeholders (de Ridder et al., 2007; Kloprogge \& van der Sluijs, 2006). The involvement of stakeholders in an IA can be done in many different ways thus all kinds of methods and approaches are used for a participatory assessment (de Ridder et al., 2007; Kloprogge \& van der Sluijs, 2006). Participatory approaches are often used in the context of response option assessments (Kloprogge \& van der Sluijs, 2006) which is comparable to the study presented in Chapter 5 where adaptation responses are assessed through the involvement of experts. In this study IA has been conducted in a participatory manner; involving expert stakeholders through a survey method.

Participatory IA is used when there is such a degree of complexity that there are fundamentally unknowable issues at hand, and the goal is to use the assessment in policymaking (Rothman \& Robinson, 1997). The involvement of stakeholders is a way to address the complexities, uncertainties, and the diversity in values that can be related to global environmental risks. Thus participatory methods allow for the researcher to include stakeholders' knowledge, views, and/or preferences into the IA process (de Ridder et al., 2007; Kloprogge \& van der Sluijs, 2006).

For the assessment of climate change and related adaptive responses the involvement of stakeholders as a part of participatory integrated assessment is deemed important (Ebi et al., 2006; Füssel, 2007; Füssel \& Klein, 2006; Kloprogge \& van der Sluijs, 2006). Kloprogge and van der Sluijs (2006) argue that the inclusion of stakeholders in an IA is important both due to the nature of the climate change problem, and in light of the development in the policy field of climate change.

\subsection{In summary}

This chapter provides a clarification of the following key concepts and relationships to this dissertation: global change; globalisation; health; the relationship between globalisation and health; the relationship between climate change and health; and climate change adaptation and mitigation. Additionally some key aspects to the research approach throughout this dissertation are discussed, such as an integrated understanding of the relationships between globalisation, climate change, and health; the ENHanCE 
Research Project; an aggregate, population-level research focus, and integrated participatory assessment methods. The concepts and research approach introduced and clarified in this chapter reappear in the different studies in this dissertation. Moreover, the final chapter offers some related discussion and reflection on the concepts and research approach used. 


\section{CHAPTER 3 \\ GLOBALISATION AND HEALTH: A STATISTICAL \\ INDICATOR ANALYSIS}




\section{Abstract}

It is clear that globalisation is something more than a purely economic phenomenon manifesting itself on a global scale. Among the visible manifestations of globalisation are the greater international movement of goods and services, financial capital, information and people. In addition, there are technological developments, more transboundary cultural exchanges, facilitated by the freer trade of more differentiated products as well as by tourism and immigration, changes in the political landscape and ecological consequences. In this paper, we link the Maastricht Globalisation Index with health indicators to analyse if more globalised countries are doing better in terms of infant mortality rate, under-five mortality rate, and adult mortality rate. The results indicate that a high level of globalisation is associated with low mortality rates. In view of the arguments that globalisation provides winners and losers, and might be seen as a disequalizing process, we should perhaps be careful in interpreting the observed association as simple evidence that globalisation is mostly good for our health. It is our hope that a further analysis of health impacts of globalisation may help in adjusting and optimising the process of globalisation on every level in the direction of a sustainable and healthy development for all.

Published as:

Martens, P., Akin, S., Huynen, M., and Raza, M. (2010). Is globalization healthy: a statistical indicator analysis of the impacts of globalization on health. Globalization and Health, 6 (16). http://www.globalizationandhealth.com/content/6/1/16 


\subsection{Introduction}

In the past, globalisation has often been seen as a more or less economic process characterized by increased deregulated trade, electronic communication, and capital mobility. However, globalisation is becoming increasingly perceived as a more comprehensive phenomenon that is shaped by a multitude of factors and events, and that is reshaping our society rapidly; it encompasses not only economic, political, and technological forces, but also social-cultural and environmental aspects. This increased global economic integration, global forms of governance, and globally inter-linked social and environmental developments are often referred to as globalisation. However, depending on the researcher or commentator, globalisation is interpreted as growing integration of markets and nation-states and the spread of technological advancements (Friedman, 1999); receding geographical constraints on social and cultural arrangements (Walters, 1995); the increased dissemination of ideas and technologies (Albrow, 1996); the threat to national sovereignty by trans-national actors (Beck, 2004); or the transformation of the economic, political and cultural foundations of societies (Mittelman, 2000). In our view, globalisation is an overarching process encompassing many different processes that take place simultaneously in a variety of domains (e.g., governance structures, markets, communication, mobility, cultural interactions, and environmental change). The pluralistic definition of globalisation by Rennen and Martens (2003) offers a conceptualization capturing the complexity of different dimensions; processes; scale-levels; and linkages and pathways; characterizing the relationship between globalisation and health. Hence, contemporary globalisation is defined as the intensification of cross-national interactions that promote the establishment of trans-national structures and the global integration of cultural, economic, ecological, political, technological and social processes on global, supra-national, national, regional and local levels (Rennen \& Martens, 2003).

Looking at the health of populations, Martens (2002) and Huynen (2008), amongst others, argue that changes in drivers of disease are brought about not only by economic changes, but also by changes in the social, political, and environmental domains at local, regional, and global levels. Health improvements experienced in developed countries over the past centuries are mainly vested in social and environmental changes, whereas more recent health improvements in developing countries can be broadly related to knowledge transfer and socio-cultural determinants. Nowadays, global processes influence all these important health determinants. Hence, globalisation and its underlying processes have brought about vast changes in both health determinants and related health outcomes. As a result, the geographical scale of important health issues is significantly increasing (Huynen, Martens, et al., 2005). The link between global mobility and the spread of infectious diseases is perhaps the best-known health effect of globalisation. However, it is only one of the many possible health implications of globalisation. Many scholars have tried to conceptualize the possible linkages between globalisation and health. Woodward et al. (2001), for example, propose a framework based on three 
component circular processes of globalisation: openness; cross-border flows; and rules and institutions. However, their conceptualization mainly focused on the health effects of economic globalisation. Labonte and Torgerson (2003) review different conceptualizations of the globalisation-health relationship, resulting in a diagrammatical synthesis that mainly focuses on governmental policy changes as well as economic determinants of health, but with the inclusion of an environmental pathway. Hence, many of these approaches primarily emphasize the economic and institutional side of globalisation, defining globalisation in a rather narrow way. Labonte and Schrecker $(2007,2009)$ took a somewhat different approach in their framework for the Commission of Social Determinants of Health, conceptualizing how globalisation affects disparities in access to social determinants of health.

Because of the multitude of underlying processes shaping the globalisation-health link, ideas about globalisation, health determinants and possible outcomes should be broadened. The causality of human health is multi-factorial and many population health problems are invariably embedded in a global context (Huynen, 2008). Taking this broader view on globalisation and global health, Huynen, Martens et al. (2005) developed an integrated conceptual framework for the health implications of globalisation. We can conclude that a variety of both negative and positive effects are expected to influence our health in the (near) future (Huynen, 2008; Huynen, Martens, et al., 2005) (see Table 3.1 for examples), but it is still very uncertain what the overall health outcomes will be. Academic literature shows an ongoing polarized debate (Lee, 2001). The limited empirical evidence on the multiple links between globalisation and health poses a problem (Lee \& Collin, 2001). Many scholars urge for elaboration and possible quantitative evidence to support the hypothesized relationships (Beaglehole \& Bonita, 2000; Dollar, 2001; Drager \& Beaglehole, 2001; Huynen, Martens, et al., 2005; Lee, 2001; Lee \& Collin, 2001; Martens et al., 2000; Smith et al., 2004; WHO, 2001; Woodward et al., 2001). In this paper we try to answer the question if the process of globalisation improves the health of populations (or not). 


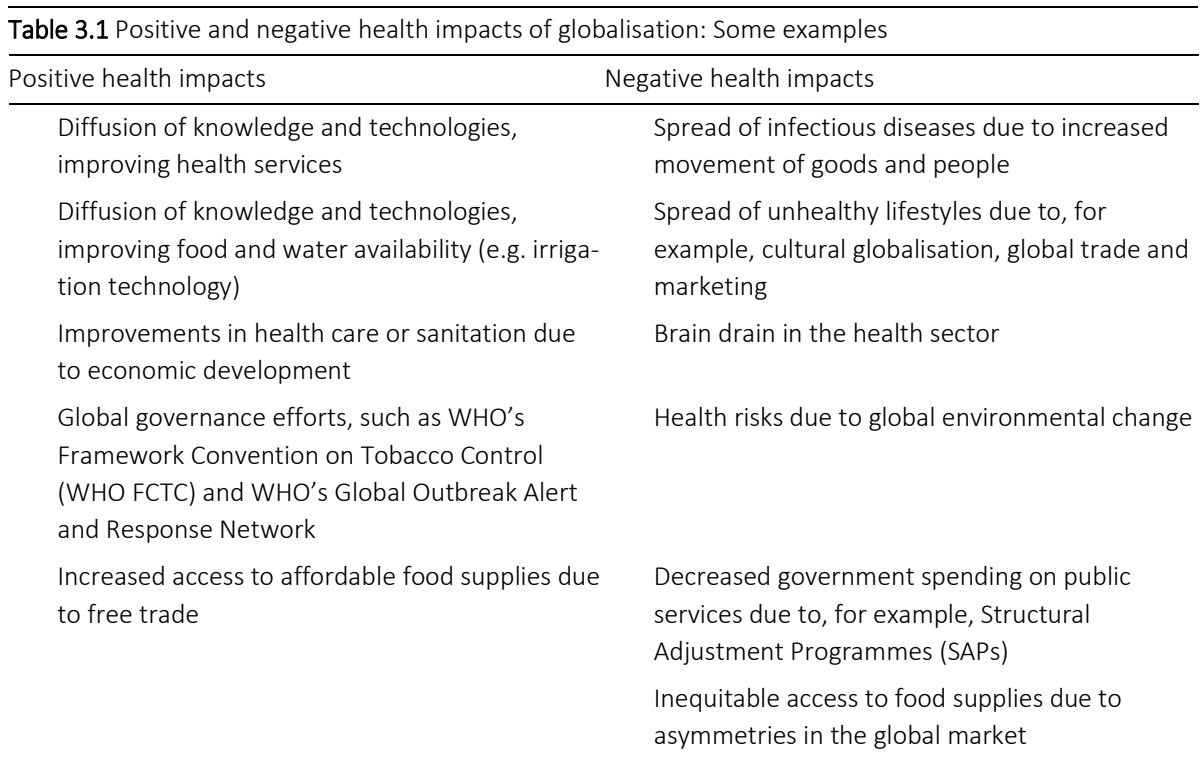

Note: (Huynen, 2008; Huynen, Martens, et al., 2005)

\subsection{Methodology}

In this paper we use an indicator-based approach (Dreher et al., 2008) linking the Maastricht Globalisation Index (MGI) (a measure of globalisation) to important health indicators, correcting for possible confounding factors. The MGI as well as the selected health indicators and confounders will be discussed in the following sections. Subsequently, the performed statistical analyses will be clarified.

\subsubsection{The Maastricht Globalisation Index}

In this section, we briefly describe the Maastricht Globalisation Index (MGI) (Dreher et al., 2008). The MGI was developed by Martens and Zywietz (2006) and Martens and Raza (2009) to improve upon existing globalisation-indices. The need for a balance between broad coverage, data availability and quality motivated the following choice of indicators (see Table 3.2), with data for 117 countries (see Figure 3.1). 


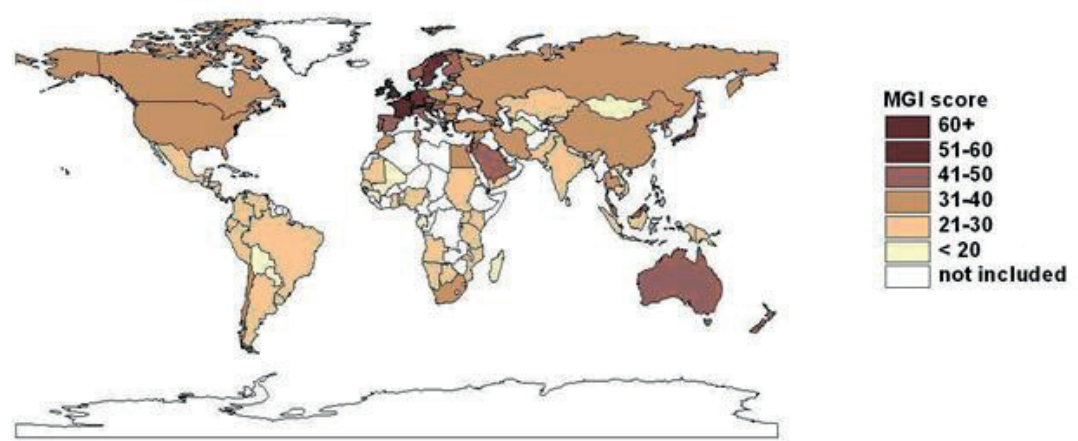

Figure 3.1 Map of the Maastricht Globalisation Index (MGI) 2008 (www.globalisationindex.info)

\begin{tabular}{|c|c|c|}
\hline Category & Variable name & Variable definition \\
\hline \multirow[t]{3}{*}{ Political domain } & Embassies & $\begin{array}{l}\text { Absolute number of in-country embassies and high } \\
\text { commissions }\end{array}$ \\
\hline & Organizations & $\begin{array}{l}\text { Absolute number of memberships in } \\
\text { international organizations }\end{array}$ \\
\hline & Military & $\begin{array}{l}\text { Trade in conventional arms as a share of military } \\
\text { spending }\end{array}$ \\
\hline \multirow[t]{3}{*}{ Economic domain } & Trade & $\begin{array}{l}\text { Imports + exports of goods and services as a share of } \\
\text { GDP }\end{array}$ \\
\hline & FDI & Gross foreign direct stocks as a share of GDP \\
\hline & Capital & Gross private capital flows as a share of GDP \\
\hline \multirow[t]{2}{*}{$\begin{array}{l}\text { Social \& Cultural } \\
\text { Domain }\end{array}$} & Migrants & $\begin{array}{l}\text { Those who changes their country of usual residence } \\
\text { per } 100 \text { inhabitant }\end{array}$ \\
\hline & Tourism & $\begin{array}{l}\text { International arrivals + departures per } 100 \\
\text { inhabitants }\end{array}$ \\
\hline \multirow[t]{2}{*}{$\begin{array}{l}\text { Technological } \\
\text { Domain }\end{array}$} & Phone & $\begin{array}{l}\text { Incoming + outgoing international telephone traffic in } \\
\text { minutes per capita }\end{array}$ \\
\hline & Internet & Internet users as a share of population \\
\hline Ecological Domain & Eco footprint & Ecological deficit in global ha \\
\hline
\end{tabular}

Note: (Martens \& Raza, 2009; Martens \& Zywietz, 2006)

The MGI is constructed in a four-stage process (see also UNDP (2002)). The first stage is conceptual and choices are made about which variables are most relevant and should be included in the index. In the second stage, suitable quantitative measures are identified for these variables. In the third stage, following Dreher (2006), each variable is transformed to an index with a zero to one hundred scale (this differs from earlier calculations constructing the MGI (Martens \& Zywietz, 2006). Higher values denote more globalisation. The data are then transformed-on the domain level-according to the percentiles of the base year (2000) distribution (using the formula $\left(\left(V_{i}-V_{\min }\right) /\left(V_{\max }-V_{\min }\right) \times\right.$ 
$100)^{7}$. In the last and final stage, a weighted sum of the measures is calculated to produce the final score, which is then used to rank and compare countries. The 'most globalised' country has the highest score. Within each domain, every variable is equally weighted. The MGI scores are simply added, i.e., all domains receive the same weight. In this paper, we use the MGI calculated for 2008 (www.globalisationindex.info).

Several limitations in using the MGI (and in general globalisations indices) exist. Since there are missing data on the share of international linkages that are regional rather than global, it is impossible to distinguish globalisation from internationalisation and regionalisation with complete certainty. Therefore, there is an underlying assumption that countries with many international links have a correspondingly greater number of global linkages. As expected, international statistics on eleven different indicators ranging from politics and military to the environment have widely varying degrees of data quality, reflecting the different capabilities and priorities of the organisations collecting the data. Of particular concern are the domains in which the underlying data have not been collected by official international bodies like the World Bank, IMF and/or other UN organizations, but by private or semi-public organisations. In addition, many countries are reluctant to share information about activities related to their national security, which creates data gaps that are not easily filled.

The fact that countries with fewer international linkages tend to publish less data and are less likely to be included in international statistics biases against states that are less globalised (Rosendorff \& Vreeland, 2006). Additionally, despite being members of the UN and most other international bodies, countries with totalitarian or communist regimes (e.g., North Korea, Cuba) are often excluded in international financial statistics. Therefore, this also leads to their exclusion due to lack of data. Finally, yet importantly, countries that are too small to collect internationally coherent statistics and/or are strongly integrated into the economies of their big neighbours (e.g., Luxembourg, Monaco, and Swaziland) are also missing from the statistics and therefore excluded from the MGI.

Both the sensitivity to extreme values and year-to-year variations are a major concern for the robustness of other indices for globalisation. With the methodology used to construct the MGI, the sensitivity of the index to extreme values has been sharply reduced since the distribution is now centred on the mean of a component rather than just lying somewhere between the extreme values. Similarly, the strongest year-to-year variations are filtered by the averaging process for the highly volatile components, sharply decreasing the dependence on the choice of base year in some of the component indicators. Furthermore, several weighting methods for composite indicators - like the MGI-exist; all with their own pros and cons. Regardless which weighting method is used, weights are in essence value judgments. For maximum transparency, we have relied on equal

\footnotetext{
${ }^{7}$ Where $V=$ value of the variable, ranging on a scale from 0 to 100
} 
weighting (OECD, 2008). Next, we have tested the sensitivity of the weighting scheme at the domain level. With respect to the weights for the five domains tested in the sensitivity analysis, the country rankings are consistent for approximately half of the countries. The allocation of the weights must be evaluated with care according to its analytical rationale, globalisation relevance, and implied value judgments.

\subsubsection{Health Indicators}

In order to link the extent that a country is globalised with the status of population health in a country, several indicators for mortality have been selected, based on the World Health Statistics (WHO, 2009b):

- Infant mortality rate (per 1000 live births, both sexes): "[...] the probability of a child born in a specific year or period dying before reaching the age of one, if subject to age-specific mortality rates of that period (WHO, 2009a)".

- Under-five mortality rate (probability of dying by age 5 per 1000 live births, both sexes): "the probability of a child born in a specific year or period dying before reaching the age of five, if subject to age-specific mortality rates of that period (WHO, 2009a)".

- Adult mortality rate (probability of dying between 15 to 60 years per 1000 population, both sexes): "probability that a 15-year-old person will die before reaching his/her 60th birthday (WHO, 2009a)".

According to the World Health Organization (WHO, 2009a), indicators representing such mortality rates provide an accurate view of overall population health. The infant mortality rate and under-five mortality rate are principal indicators used to assess child health, and overall health and development in a country (WHO, 2008b). The WHO uses these indicators to measure progress on the Millennium Development Goals (UN, 2007; WHO, 2008b, 2009a). Low levels of life expectancy are inherently related to higher levels of child mortality. The adult mortality rate has become a widely used indicator for assessing the overall patterns of mortality in a country's population. The growing importance of this indicator is particularly stressed by the increasing disease burden from noncommunicable diseases among adults (economically productive age categories) by ageing trends and health transitions (WHO, 2008b). The selected mortality indicators are available for all 117 countries in the MGI-indicator dataset.

\subsubsection{Confounding factors}

The association between the process of globalisation (MGI) and the selected health outcomes cannot be isolated from other, possibly related developments. Therefore, possible confounding factors in the MGI-health association have been identified based on existing literature: income level and income growth (often represented by GDP per 
capita; GNP per capita; or Growth of GDP per capita) (Burns et al., 2003; Cornia et al., 2009; Martens, 2002); water quality (Burns et al., 2003); Health expenditures and financing (Burns et al., 2003; Cornia et al., 2009); Smoking (Cornia et al., 2009); secondary education (Burns et al., 2003); and availability of public health resources (such as vaccinations) (Burns et al., 2003). Table 3.3 provides an overview of the selected indicators associated with these confounding factors (including sample size, year and source).

\begin{tabular}{|c|c|c|c|c|}
\hline Indicator & Definition & $\begin{array}{l}\mathrm{n} \\
\text { (sample } \\
\text { size) }\end{array}$ & Year(s) & Source \\
\hline $\begin{array}{l}\text { GDP per capita } \\
\text { growth (annual \%)* }\end{array}$ & $\begin{array}{l}\text { "Annual percentage growth rate } \\
\text { of GDP per capita based on con- } \\
\text { stant local currency. GDP per } \\
\text { capita is gross domestic product } \\
\text { divided by midyear population. } \\
\text { GDP at purchaser's prices is the } \\
\text { sum of gross value added by all } \\
\text { resident producers in the econ- } \\
\text { omy plus any product taxes and } \\
\text { minus any subsidies not included } \\
\text { in the value of the products. It is } \\
\text { calculated without making de- } \\
\text { ductions for depreciation of fab- } \\
\text { ricated assets or for depletion } \\
\text { and degradation of natural re- } \\
\text { sources (WB, 2010)" }\end{array}$ & 114 & 2008 & $\begin{array}{l}\text { World Data- } \\
\text { Bank, World } \\
\text { Development } \\
\text { Indicators and } \\
\text { Global Devel- } \\
\text { opment Fi- } \\
\text { nance (WB, } \\
\text { 2010) }\end{array}$ \\
\hline $\begin{array}{l}\text { Prevalence of un- } \\
\text { dernourishment (\% } \\
\text { of population) }\end{array}$ & $\begin{array}{l}\text { "[...] the percentage of the popu- } \\
\text { lation whose food intake is insuf- } \\
\text { ficient to meet dietary energy } \\
\text { requirements continuously. Data } \\
\text { showing as } 2.5 \text { signifies a preva- } \\
\text { lence of undernourishment be- } \\
\text { low } 2.5 \%(W B, 2010) . "\end{array}$ & 116 & 2006 & $\begin{array}{l}\text { World Data- } \\
\text { bank, World } \\
\text { Development } \\
\text { Indicators and } \\
\text { Global Devel- } \\
\text { opment Fi- } \\
\text { nance (WB, } \\
\text { 2010) }\end{array}$ \\
\hline $\begin{array}{l}\text { Total expenditure } \\
\text { on health as a per- } \\
\text { centage of gross } \\
\text { domestic product }\end{array}$ & $\begin{array}{l}\text { "Level of total expenditure on } \\
\text { health (THE) expressed as a per- } \\
\text { centage of gross domestic prod- } \\
\text { uct (GDP)(WHO, 2009a)." }\end{array}$ & 117 & 2006 & $\begin{array}{l}\text { WHO (WHO, } \\
\text { 2009a, 2009b) }\end{array}$ \\
\hline $\begin{array}{l}\text { Health expenditure, } \\
\text { public ( } \% \text { of GDP) }\end{array}$ & $\begin{array}{l}\text { "Public health expenditure con- } \\
\text { sists of recurrent and capital } \\
\text { spending from government (cen- } \\
\text { tral and local) budgets, external } \\
\text { borrowings and grants (including } \\
\text { donations from international } \\
\text { agencies and nongovernmental } \\
\text { organizations), and social (or } \\
\text { compulsory) health insurance } \\
\text { funds (WB, 2010)" }\end{array}$ & 117 & 2007 & $\begin{array}{l}\text { World Data- } \\
\text { bank, World } \\
\text { Development } \\
\text { Indicators and } \\
\text { Global Devel- } \\
\text { opment Fi- } \\
\text { nance (WB, } \\
\text { 2010) }\end{array}$ \\
\hline
\end{tabular}


Health expenditure, total (\% of GDP)

Literacy rate, adult total (\% of people ages 15 and above)

Total enrolment, primary (\% net) 2000-2008

School enrolment, secondary (\% net)

Total fertility rate (per woman)
"Total health expenditure is the sum of public and private health expenditure. It covers the provision of health services (preventive and curative), family planning activities, nutrition activities, and emergency aid designated for health but does not include provision of water and sanitation (WB, 2010)."

"Adult literacy rate is the percentage of people ages 15 and above who can, with understanding, read and write a short, simple statement on their everyday life (WB, 2010)."

"Total enrollment is the number of pupils of the school-age group for primary education, enrolled either in primary or secondary education, expressed as a percentage of the total population in that age group (WB, 2010)."

"Net enrollment ratio is the ratio of children of official school age based on the International Standard Classification of Education 1997 who are enrolled in school to the population of the corresponding official school age. Secondary education completes the provision of basic education that began at the primary level, and aims at laying the foundations for lifelong learning and human development, by offering more subject- or skill-oriented instruction using more specialized teachers (WB, 2010)."

"The average number of children a hypothetical cohort of women would have at the end of their reproductive period if they were subject during their whole lives to the fertility rates of a given period and if they were not subject to mortality. It is expressed as children per woman (WHO,

\begin{tabular}{|c|c|c|}
\hline 117 & 2007 & $\begin{array}{l}\text { World Data- } \\
\text { bank, World } \\
\text { Development } \\
\text { Indicators and } \\
\text { Global Devel- } \\
\text { opment Fi- } \\
\text { nance (WB, } \\
\text { 2010) }\end{array}$ \\
\hline 97 & $\begin{array}{r}2000- \\
2008^{* *}\end{array}$ & $\begin{array}{l}\text { World Data- } \\
\text { bank, World } \\
\text { Development } \\
\text { Indicators and } \\
\text { Global Devel- } \\
\text { opment Fi- } \\
\text { nance (WB, } \\
\text { 2010) }\end{array}$ \\
\hline 109 & $\begin{array}{r}2000- \\
2008^{* *}\end{array}$ & $\begin{array}{l}\text { World Data- } \\
\text { bank, World } \\
\text { Development } \\
\text { Indicators and } \\
\text { Global Devel- } \\
\text { opment Fi- } \\
\text { nance (WB, } \\
\text { 2010) }\end{array}$ \\
\hline 94 & $\begin{array}{r}2000- \\
2008^{* *}\end{array}$ & $\begin{array}{l}\text { World Data- } \\
\text { bank, World } \\
\text { Development } \\
\text { Indicators and } \\
\text { Global Devel- } \\
\text { opment Fi- } \\
\text { nance (WB, } \\
\text { 2010) }\end{array}$ \\
\hline
\end{tabular}

1172006 WHO (WHO, 2009a, 2009b) 
Smoking prevalence, females ( \% of adults)

Improved water source (\% of population with access)

Improved sanitation facilities $(\%$ of population with access)

Immunization, DPT (\% of children ages 12-23 months)
"[...] the percentage of women ages 15 and over who smoke any form of tobacco, including cigarettes, cigars, and pipes, and excluding smokeless tobacco. Data include daily and non-daily smoking (WB, 2010)."

"[...] the percentage of the population with reasonable access to an adequate amount of water from an improved source, such as a household connection, public standpipe, borehole, protected well or spring, and rainwater collection. Unimproved sources include vendors, tanker trucks, and unprotected wells and springs. Reasonable access is defined as the availability of at least 20 liters a person a day from a source within one kilometer of the dwelling (WB, 2010)."

"Access to improved sanitation facilities refers to the percentage of the population with at least adequate access to excreta disposal facilities that can effectively prevent human, animal, and insect contact with excreta. Improved facilities range from simple but protected pit latrines to flush toilets with a sewerage connection. To be effective, facilities must be correctly constructed and properly maintained (WB, 2010)."

"Child immunization measures the percentage of children ages 12-23 months who received vaccinations before 12 months or at any time before the survey. A child is considered adequately immunized against diphtheria, pertussis (or whooping cough), and tetanus (DPT) after receiving three doses of vaccine (WB, 2010)."

$95 \quad 2006 \quad \begin{aligned} & \text { World Data- } \\ & \text { bank, World } \\ & \\ & \text { Development } \\ & \text { Indicators and } \\ & \text { Global Devel- } \\ & \text { opment Fi- } \\ & \text { nance (WB, } \\ & \text { 2010) } \\ & \text { World Devel- } \\ & \text { 2000- } \\ & \text { opment Indi- } \\ & \text { cators and } \\ & \text { Global Devel- } \\ & \text { opment Fi- } \\ & \text { nance (WB, } \\ & \text { 2010) }\end{aligned}$
102 2000- World Devel- 2006** opment Indi- cators and Global Devel- opment $\mathrm{Fi}$ - nance (WB, 2010)

$1162008 \quad \begin{aligned} & \text { World Devel- } \\ & \text { opment Indi- } \\ & \text { cators and } \\ & \text { Global Devel- } \\ & \text { opment Fi- } \\ & \text { nance (WB, } \\ & \text { 2010) }\end{aligned}$


Immunization, measles (\% of children ages 12-23 months)

\begin{abstract}
"Child immunization measures the percentage of children ages 12-23 months who received vaccinations before 12 months or at any time before the survey. A child is considered adequately immunized against measles after receiving one dose of vaccine
\end{abstract}

World Development Indicators and Global Development Finance(WB, 2010) (WB, 2010)."

opment Indi-
cators and
Global Devel-
opment Fi-
nance(WB,
2010)

Notes: * Other GDP measures (including GDP per capita (PPP)) have not been included for the following reasons: a) the GDP measure shows multicollinearity with the other confounders and/or b) the GDP measure when tested does not function as a confounder in the MGI-health indicator relationship.

** Data for most recent year available in this range has been selected for each country. It should be noted that all compiled datasets largely exist of data stemming from the latest years that the set covers, and only few cases from earlier years have been added to meet the sampled countries in the MGI dataset. Confounders that did not have any or much current data available for the sampled countries did not qualify for a compilation of data over several years, and were therefore not included in this study.

Many other possible confounders have been considered for this analysis, but could not be included for different reasons. A large group of confounders has been excluded based on lack of data availability for the sampled countries and/or a lack of current data ${ }^{8}$. Other variables could not be selected for this study because when tested not all criteria for confounding could be met ${ }^{9}$.

\subsubsection{Statistical methods and analysis}

Correlation analysis has been conducted as a first step, in order to obtain the crude associations between the indicators used. For this we applied the non-parametric

\footnotetext{
${ }^{8}$ The variables excluded from the analysis based on these reasons are: from WHOSIS (WHO, 2009a, 2009b): adult literacy rate (\%); adolescent fertility rate (\%); antenatal care coverage - at least four visits (\%); births attended by skilled health personnel (\%); prevalence of HIV among adults aged $\geq 15$ years (per 100000 population); population with sustainable access to improved drinking water sources (\%) total; population with sustainable access to sanitation (\%) total; prevalence of current tobacco use amongst adolescents (13-15 years (\%) both sexes; prevalence of current tobacco use amongst adults ( $\geq 15$ years) (\%) both sexes; deaths amongst children under 5 years of age due to malaria (\%); deaths due to HIV/Aids (per 100000 population per year). Confounders assessed and excluded for the same reasons from the World DataBank (WB, 2010) include: malnutrition prevalence, weight for age (\% of children under 5 ); literacy rate adult female (\% of females ages 15 and above); literacy rate adult male (\% of males ages 15 and above); total enrolment, primary, female (\% net); total enrolment, primary, male (\% net); pregnant women receiving prenatal care (\%); and births attended by skilled health staff (\% of total).

${ }^{9}$ Variables that did not satisfy the criteria of functioning as a confounder on the MGI-health indicator relationships are: 'Smoking prevalence, males (\% of adults) 2006'; and 'Prevalence of HIV, total (\% of population ages 15-49), 2007' (WB, 2010).
} 
Spearman's correlation analyses, as not all variables showed a normal distribution (Shapiro \& Wilk, 1965) ${ }^{10}$.

Next, least squares (LS) simple linear regression analysis has been performed to gain an insight into the possible associations between the MGI and the mortality indicators, as well as the strength of these associations for each of the underlying MGI Domains (all without controlling for possible confounding). Subsequently, LS multiple linear regression analysis has been performed, in order to assess if and to what extent the MGI can explain a proportion of the variance in the dependent variables 'infant mortality rate'; 'under-five mortality rate'; and 'adult mortality rate'; whilst controlling for the selected confounding factors (Garson, 2009). It has been tested whether the models meet the regression model assumptions and are not subject to outliers (Garson, 2009; Huynen et al., 2004; McClave et al., 2001b) ${ }^{11}$. Based on the results, a transformation of the mortality indicators into a natural logarithm (Ln) was required for a proper regression analysis. First, the correlation coefficients between the independent/confounding variables and the dependent variable have been used as a criterion to prioritize the different confounding variables for inclusion in the multiple regression model (i.e. variables showing a higher correlation coefficient with the dependent variable have precedence over variables showing lower correlation coefficients). Moreover, the correlation coefficients have been used to identify possible cases of multicollinearity between the independent and confounding variables. Here, the common threshold of not having a correlation coefficient higher than 0.80 has been applied (Garson, 2009). When a possible case of multicollinearity has been detected, one of the two variables involved has not been included in the model, where the variable with the lower Spearman's correlation with the dependent variable has been excluded over the other variable.

\footnotetext{
${ }^{10}$ The following tests have been used to assess whether the indicators used display a normal distribution: Frequency histograms (for a graphical assessment of normality of distribution); P-P plots and Q-Q plots (have been used as a complementary graphical assessment tool for the normality of the distribution of the variable, thus in addition to the frequency histograms); Boxplots (to graphically check for outliers and skewness); the Shapiro-Wilk's W-test (as a formal test for normality has been used (Shapiro \& Wilk, 1965). However, results of the $\mathrm{W}$-test have been treated with care and placed within the context of the insights gained from all the other normality tests performed); descriptive statistics have been used to numerically assess skewness and kurtosis (criterion used for skewness: the skewness-statistic must lie between +2 and -2; criterion used for kurtosis: the kurtosis-statistic must lie between +2 and -2 ) (Garson, 2009).

${ }^{11}$ All assumptions of least squares regression analysis have been checked and could be met by the models. The assumption of linearity has been checked with scatterplots and linear curve estimation. The normality of the probability distribution of the error terms of prediction have been tested by generating frequency histograms of the standardized residuals. To test for homoscedasticity, the standardized residuals and the standardized predicted values have been plotted in a scatterplot to observe a random pattern. For the assumption of mean independence, residual statistics and scatterplots of the residual against the predicted values have been used to verify that the mean of the residuals would be approximately zero. In addition, all models have been checked for multivariate outliers by generating Cook's Distances (McClave et al., 2001a). When the Cook's Distance is higher than 1.0, a case is considered an outlier and is deleted from the analysis.
} 
To construct the final multiple regression models, step-wise backward linear regression has been used. During the step-wise backward linear regression, the R-square and the Fstatistic (as a test for the global usefulness of the model) have been used to determine the final model (Garson, 2009; McClave et al., 2001b) ${ }^{12}$. All analyses have been performed in SPSS 15.0 .

\subsection{Results}

\subsubsection{Results: Spearman correlation}

To give an indication of the crude associations between the MGI, and the MGI Domains, with the health indicators, the Spearman's correlations are given in Table 3.4.

\begin{tabular}{|c|c|c|c|}
\hline$n=117$ & $\begin{array}{l}\text { Infant mortality rate } \\
2007\end{array}$ & $\begin{array}{c}\text { Under-five mortality } \\
\text { rate } 2007\end{array}$ & $\begin{array}{l}\text { Adult mortality rate } \\
2007\end{array}$ \\
\hline MGI 2008 & $-.798 *$ & $-.803^{*}$ & $-.717^{*}$ \\
\hline \multicolumn{4}{|l|}{ MGI domains } \\
\hline Political 2008 & $-.440 *$ & $-.445^{*}$ & $-.487 *$ \\
\hline Economic 2008 & $-.421 *$ & $-.428^{*}$ & $-.270^{*}$ \\
\hline Social \& cultural 2008 & $-.706^{*}$ & $-.712^{*}$ & $-.556^{*}$ \\
\hline Technological 2008 & $-.891^{*}$ & $-.892 *$ & $-.805^{*}$ \\
\hline Ecological 2008 & $-.397 *$ & $-.400 *$ & $-.390^{*}$ \\
\hline
\end{tabular}

*Significant at the 0.01 level (2-tailed)

The results show that the MGI has a statistically significant ${ }^{13}$ negative correlation (at $\alpha=$ $0.01)$ with all selected mortality indicators $(-0.798,-0.803,-0.717$, respectively). When taking a closer look at the individual domains of the $\mathrm{MGl}$, the results in Table 3.4 reveal that all underlying domains have a significant negative correlation (at $\alpha=0.01$ ) with the mortality indicators. The correlations between the mortality rates and the socio-cultural, and technological domains are particularly strong.

\subsubsection{Results: Simple linear regression models}

Tables 3.5 and 3.6 and Figure 3.2 show the simple linear regression outcomes of the mortality indicators (Ln transformed) with the MGI and the MGI Domains, respectively,

\footnotetext{
${ }^{12}$ Note: The step-wise backward linear regression analyses have been performed manually.

${ }^{13}$ When reporting on statistical results, the term 'significance' refers to 'statistical significance'.
} 
as dependent variables; without correction for confounding factors. The associations between the MGI/MGI Domains and the mortality indicators suggested by the Spearman's correlation outcomes logically correspond with the associations that can be ascertained from these univariate regression analyses. All results are significant (at $\alpha=0.01$ ) in the expected direction. From the R-squares, it follows that the variation in the MGI partly explains the variation in all mortality indicators. Similar to the correlation results, the R-squares in Table 3.6 indicate that the 'social \& cultural' and the 'technological' domains of the MGI show a stronger association with the mortality indicators.

\begin{tabular}{|c|c|c|c|}
\hline$n=117$ & $\begin{array}{c}\text { Ln Infant mortality } \\
\text { rate } 2007\end{array}$ & $\begin{array}{c}\text { Ln Under-five mortality } \\
\text { rate } 2007\end{array}$ & $\begin{array}{l}\text { Ln Adult mortality rate } \\
\qquad 2007\end{array}$ \\
\hline Constant $\left(\beta_{0}\right)$ & $4.941^{*}$ & $5.263^{*}$ & $6.103^{*}$ \\
\hline MGI $2008\left(\beta_{1}\right)$ & $-.064 *$ & $-.067 *$ & $-.030 *$ \\
\hline R-square & .616 & .596 & .502 \\
\hline
\end{tabular}

\begin{tabular}{|c|c|c|c|}
\hline \multicolumn{4}{|c|}{ *Significant at the 0.01 level (2 tailed) } \\
\hline \multicolumn{4}{|c|}{$\begin{array}{l}\text { Table } 3.6 \text { Linear regression coefficients ( } \beta \text { ) for the Maastricht Globalisation Index (MGI) domains and } \\
\text { selected mortality indicators. }\end{array}$} \\
\hline$n=117$ & $\begin{array}{l}\text { Ln Infant mortality } \\
\text { rate } 2007\end{array}$ & $\begin{array}{l}\text { Ln Under-five mortality } \\
\text { rate } 2007\end{array}$ & $\begin{array}{l}\text { Ln Adult mortality rate } \\
\qquad 2007\end{array}$ \\
\hline Constant $\left(\beta_{0}\right)$ & $3.752^{*}$ & $4.021^{*}$ & $5.609 *$ \\
\hline Political $2008\left(\beta_{1}\right)$ & $-.024 *$ & $-.026 *$ & $-.013^{*}$ \\
\hline R-square & .217 & .210 & .237 \\
\hline Constant $\left(\beta_{0}\right)$ & $3.506 *$ & $3.772^{*}$ & $5.362^{*}$ \\
\hline Economic $2008\left(\beta_{1}\right)$ & $-.030 *$ & $-.031 *$ & $-.011^{*}$ \\
\hline R-square & .178 & .177 & .090 \\
\hline Constant $\left(\beta_{0}\right)$ & $3.491^{*}$ & $3.748^{*}$ & $5.406^{*}$ \\
\hline $\begin{array}{l}\text { Social \& Cultural } \\
2008\left(\beta_{1}\right)\end{array}$ & $-.037 *$ & $-.038^{*}$ & $-.016^{*}$ \\
\hline R-square & .400 & .388 & .294 \\
\hline Constant $\left(\beta_{0}\right)$ & $3.744^{*}$ & $4.003^{*}$ & $5.542 *$ \\
\hline $\begin{array}{l}\text { Technological } 2008 \\
\left(\beta_{1}\right)\end{array}$ & $-.039 *$ & $-.041^{*}$ & $-.019 *$ \\
\hline R-square & .667 & .633 & .551 \\
\hline Constant $\left(\beta_{0}\right)$ & $3.978^{*}$ & $4.272^{*}$ & $5.676^{*}$ \\
\hline Ecological $2008\left(\beta_{1}\right)$ & $-.017^{*}$ & $-.018^{*}$ & $-.008^{*}$ \\
\hline R-square & .085 & .085 & .077 \\
\hline
\end{tabular}

\footnotetext{
*Significant at the 0.01 level (2 tailed)
} 

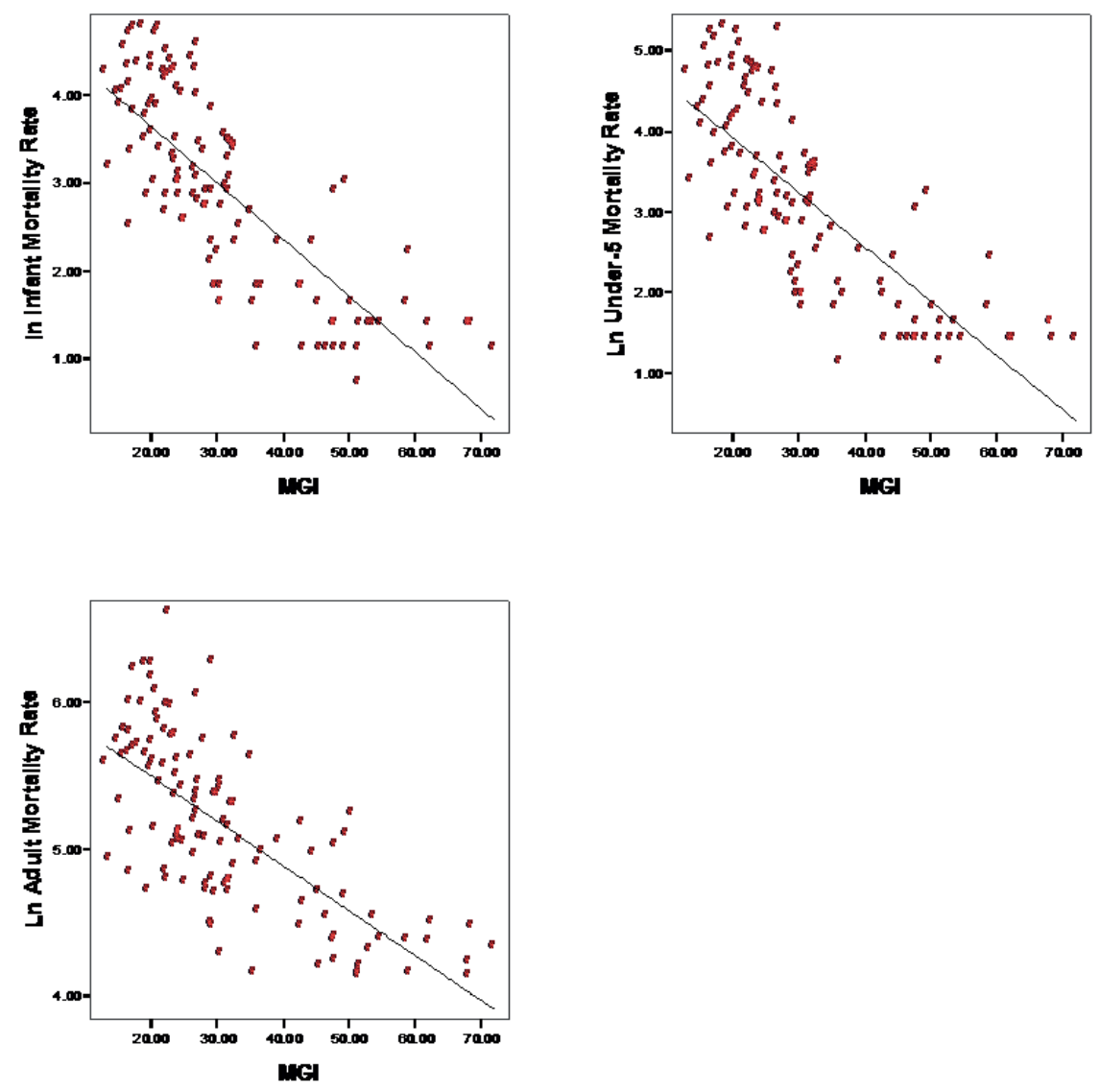

Figure 3.2 Scatterplots and linear regression between the Maastricht Globalisation (MGI) and the selected mortality indicators

\subsubsection{Results: Multiple regression models}

Table 3.7, 3.8, and 3.9 show the results of the multiple regression models for Ln Infant mortality rate, Ln Under-five morality rate, and Ln Adult mortality rate. Overall, it can be observed that the R-squares are higher in all instances, in comparison to the results of the simple linear regression analyses in Table 3.5. This indicates that the models for all three mortality indicators have been improved in explanatory power by adding the confounding factors.

For all three models, the confounders 'Total expenditure on health as a percentage of gross domestic product 2006' and 'Health expenditure, total (\% of GDP) 2007' were not 
included because of multicollinearity and conceptual overlap with 'Health expenditure, public (\% of GDP) 2007'. Similarly, the confounder 'Immunization, DTP (\% of children 1223 months) 2008' has not been included in any of the models due to multicollinearity with 'Immunization, measles (\% of children 12-23 months) 2008'.

\begin{tabular}{|c|c|c|c|}
\hline $\begin{array}{l}\text { Number of countries } \\
\qquad \begin{array}{l}(\mathrm{n}) \\
\end{array} \\
\end{array}$ & R-Square & $\begin{array}{l}\text { F-statistic } \\
130.544 \\
\end{array}$ & $\begin{array}{l}\text { Significance F-test } \\
.000 \\
\end{array}$ \\
\hline & $\begin{array}{c}\text { Regression coefficient } \\
\beta\end{array}$ & t-statistic & Significance t-test \\
\hline Constant $\left(\beta_{0}\right)$ & 7.142 & 13.875 & .000 \\
\hline MGI $2008\left(\beta_{1}\right)$ & -.022 & -4.539 & .000 \\
\hline $\begin{array}{l}\text { School enrollment, } \\
\text { secondary }(\% \quad \text { net }) \\
2000-2008\left(\beta_{2}\right)\end{array}$ & -.021 & -6.454 & .000 \\
\hline $\begin{array}{l}\text { Health Expenditure, } \\
\text { public (\% of GDP) } 2007 \\
\left(\beta_{3}\right)\end{array}$ & -.131 & -3.725 & .000 \\
\hline $\begin{array}{l}\text { Total enrollment, } \\
\text { primary (\% net) 2000- } \\
2008\left(\beta_{4}\right)\end{array}$ & -.018 & -2.700 & .009 \\
\hline
\end{tabular}

\begin{tabular}{|c|c|c|c|}
\hline Number of countries ( $n$ ) & R-Square & F-statistic & Significance F-test \\
\hline 80 & .885 & 144.099 & .000 \\
\hline & $\begin{array}{c}\text { Regression coefficient } \\
\beta\end{array}$ & $\mathrm{t}$-statistic & Significance t-test \\
\hline Constant $\left(\beta_{0}\right)$ & 7.469 & 14.126 & .000 \\
\hline MGI $2008\left(\beta_{1}\right)$ & -.026 & -5.922 & .000 \\
\hline $\begin{array}{l}\text { School enrollment, } \\
\text { secondary (\% } \quad \text { net), } \\
2000-2008\left(\beta_{2}\right)\end{array}$ & -.024 & -7.021 & .000 \\
\hline $\begin{array}{l}\text { Smoking prevalence, } \\
\text { females (\% of adults) } \\
2006\left(\beta_{3}\right)\end{array}$ & -.019 & -3.506 & .001 \\
\hline $\begin{array}{l}\text { Total enrollment, } \\
\text { primary (\% net) 2000- } \\
2008\left(\beta_{4}\right)\end{array}$ & -.019 & -2.781 & .007 \\
\hline
\end{tabular}




\begin{tabular}{|c|c|c|c|}
\hline Number of countries ( $\mathrm{n}$ ) & R-Square & F-statistic & Significance F-test \\
\hline 90 & .612 & 78.124 & .000 \\
\hline & $\begin{array}{c}\text { Regression coefficient } \\
\beta\end{array}$ & t-statistic & Significance t-test \\
\hline Constant $\left(\beta_{0}\right)$ & 6.389 & 62.523 & .000 \\
\hline MGI $2008\left(\beta_{1}\right)$ & -.012 & -3.044 & .003 \\
\hline $\begin{array}{l}\text { Improved sanitation } \\
\text { facilities (\% of popula- } \\
\text { tion with access) 2000- } \\
2006\left(\beta_{2}\right)\end{array}$ & -.012 & -7.069 & .000 \\
\hline
\end{tabular}

\subsubsection{Multiple regression model for Infant mortality rate}

For the model of Ln Infant mortality rate, the confounders 'Literacy rate, adult total (\% of people ages 15 and above) 2000-2008'; 'Total fertility rate (per woman) 2006'; 'Improved water source (\% of population with access) 2000-2006'; and 'Improved sanitation facilities (\% of population with access) 2000-2006' were not included because of multicollinearity with 'School enrollment, secondary (\% net) 2000-2008'. During the process of stepwise backward regression, the following confounders have been removed from the model based on an insignificant association with Ln Infant mortality rate (meaning a significance higher than $\alpha=0.01$ ) to create the final model: 'GDP per capita growth (annual \%) 2008'; 'Immunization, measles (\% children ages 12-23 months) 2008'; 'Prevalence of undernourishment (\% of population) 2006'; and 'Smoking prevalence, females (\% of adults) 2006'.

The results from final model of Ln Infant mortality rate (Table 3.7) shows significant tvalues for all variables included. The coefficients for the MGI and the confounders all show the expected signs/direction. In addition, a high R-square (0.880) and a significant and high F-statistic is reached. The decrease in regression coefficients for the MGI compared to the results of the simple linear regression analysis indicates that the confounders play a significant role in the posed relationship. When controlling for the confounding factors, however, the MGI still remains significantly associated with the Ln Infant mortality rate.

\subsubsection{Multiple regression model for Under-five mortality rate}

For the final model of Ln Under-five mortality rate (Table 3.8), the same confounders were excluded based on multicollinearity with 'School enrollment, secondary (\% net) 2000-2008' as described for the previous model of Ln Infant mortality rate. During the process of stepwise backward regression, contrary to the model of Ln Infant mortality rate, 'Health expenditure, public (\% of GDP) 2007' has been removed based an insignificant association with Ln Under-five mortality rate (higher than $\alpha=0.01$ ), but 'Smoking prevalence, females (\% of adults), 2006' could be included in the final model. 
The results from the final model (Table 3.8) show that all resulting coefficients display the expected signs, and all t-values are significant at the $\alpha=0.01$ level. The R-square is high (0.885) and the F-statistic is high and significant. The significance of the confounding factors indicates that these factors do play a relevant role in the association between the MGI and the Ln Under-five mortality rate. Hence, the higher MGI coefficient found for the simple linear regression might have been an overestimation of the association between the MGI and the Ln Under-five mortality rate, and this association has now been corrected for relevant confounding factors. When controlling for the confounding factors, however, the MGI still remains significantly associated with the Ln Infant mortality rate.

\subsubsection{Multiple regression model for Adult mortality rate}

For the final model of Ln Adult mortality rate, the confounder 'School enrollment, secondary (\% net) 2000-2008' has not been included in the model due to multicollinearity with 'Improved sanitation facilities (\% of population with access) 2000-2006' (amongst other confounders). During the process of stepwise backward regression, all confound$\mathrm{ers}^{14}$ had to be eliminated from the model due to an insignificant association with the $\mathrm{Ln}$ Adult mortality rate $(\alpha=0.01$ ) except for 'Improved sanitation facilities (\% of population with access) 2000-2006'. The insignificant associations of all other confounders with the Ln Adult mortality rate is a departure from what could be seen for the other models. This could be an indication that the selected confounders are not as relevant in the association between the MGI and the Ln Adult mortality rate.

The results from the final model (Table 3.9) show that all coefficients have the expected signs, and the t-values are significant (at $\alpha=0.01$ ). The R-square is relatively high $(0.612$ ) and the F-statistic is significant. The decrease in regression coefficients for the MGI compared to the results of the simple linear regression analysis indicates that 'Improved sanitation facilities (\% of population with access) 2000-2006' plays a significant role in the posed association. When controlling for this confounding factor, however, the MGI still remains significantly associated with the Ln Infant mortality rate.

\subsection{Discussion}

As this research focuses on indicators of mortality to highlight an important side of global health outcomes, it is interesting to look at some of the drivers directly related to

\footnotetext{
14 'GDP per capita growth (annual \%) 2008'; 'Health expenditure, public (\% of GDP), 2007'; 'Prevalence of undernourishment (\% of population) 2006)'; Immunization, measles (\% of children ages 12-23 months, 2008'; 'Improved water source (\% of population with access) 2000-2006'; 'Total enrolment, primary (\% net) 20002008'; 'Smoking prevalence, females (\% of adults) 2006'; 'Literacy rate, adult total (\% of people ages 15 and above) 2000-2008'; 'Total fertility rate (per woman), 2006'.
} 
mortality (or factors linking globalisation and mortality) identified in the current body of research in this field. Martens (2002) claims that increased income levels can result in a decrease in mortality rates, which ultimately impacts life expectancy rates positively. Burns et al. (2003) focus on infant mortality and discuss a country's level of internal development and the related dependencies on the world economy (affecting domestic institutional structures) as a main driver. However, the level of a country's development and the resulting impact on infant mortality is not fully uncovered. Other factors they found to be related to infant mortality are the macro level effect of export commodity concentration, GDP per capita, health expenditures per capita, secondary education, and organic water pollution. They identified several mediating factors between global dependence and infant mortality: quality of water and health care, level of internal development such as GNP per capita, the role of ecology (pollution and misuse of land) as well as public health factors (lack of resources for public health can be seen with indicators such as scarcity of inoculation to childhood diseases, and the lack of trained medical personnel for pre-and post-natal care and for assistance with birth process itself (Burns et al., 2003).

Cornia et al. (2009) associate globalisation mainly with economic changes, such as economy policy, protectionism, costs of technological transfer, privatization, market liberalization, trade and financial liberalization. Looking at the slow progress in infant mortality rates over the past decades, the authors suggest that many factors can be responsible for these slow improvements such as slow growth of household incomes, greater income volatility, shifts in health financing, amongst others. In this study, the effects of globalisation are captured by comparing the timeframe of 1980-2000 (the era of globalisation) with other timeframes, indicating changes in the following indicators: growth of GDP per capita, economic stability, income inequality, inflation and prices of basic goods, taxation and public health expenditure and health financing, migration and family arrangements, technical progress in health, smoking drinking and obesity, and random shocks (Cornia et al., 2009).

The results of our analysis (Spearman's correlations, and simple and multiple linear regression analyses) indicate that the infant mortality rate, under-five mortality rate and adult mortality rate all show a negative association with the process of globalisation (as measured by the MGI). Specifically, technological globalisation and socio-cultural globalisation are shown to have strong associations with the selected health indicators. The multivariate analyses show that different confounders have been found to be significant in the three final models. Specifically, for Ln Infant mortality rate confounders accounting for primary and secondary education and public health expenditures have been found to be significant. For the Ln Under-five mortality rate, next to the confounders for primary and secondary education, smoking prevalence among women have shown to be significant in the final model. Lastly, for the model of Ln Adult mortality rate, only a confounder on access to improved sanitation facilities has been significant. These factors thus can possibly function as confounders in the associations between the respective 
mortality rates with the MGI. However, the confounders in the final models could also be important mediating/causal factors in the association between the mortality rates and the MGI. Either way, in all multivariate models, the association between globalisation and the mortality indicators remains significant after controlling for confounding factors.

Given the limited existing quantitative information on the association between globalisation and health, the results might provide a crude initial indication of the potential advantageous effect of globalisation on health. In view of the arguments that globalisation provides winners and losers, and might be seen as a disequalizing process, we should perhaps be careful in interpreting the observed positive association between the MGI and health, as simple evidence that globalisation is mostly good for our health. Important to note is that all indicators and data are on the country level, without a specific spatial dimension. Globalisation interacts with health at levels that make measurement difficult, e.g., trans-border environmental issues, cultural transformations and a so-called 'global consciousness'. For example, the data do not show us that the most globalised countries might have lower mortality rates because they have exported their unhealthy pollution and other externalities of the production of goods and services they enjoy (and which contribute to their health) to people and environments in other parts of the world. Hence, some of the winners might be benefiting from their high levels of globalisation at the expense of others. Importantly, it should also be noted that the MGI represents actual levels of globalisation across different domains, rather than the mere implementation of neoliberal policies.

\subsection{Conclusion}

In this paper, we consider the impact of the recent process of globalisation on the health of populations. Looking at the results, globalisation can be characterised as both more complicated and more surprising than was anticipated. One clear lesson can be learned from the many global assessments that have been produced over the past decades: dogmatic predictions regarding the earth's future are unreliable, ill-founded and misleading, and can be politically counterproductive. So, this analysis is beset with the uncertainties and assumption that apply to any global statistical indicator analysis (De Lombaerde \& Lelio lapadre, 2008). For example, if consumerism and global economic processes do have polluting and other unhealthy negative side-effects for some, it needs to be asked which direction these dynamics need to take for sustainable health for all. Furthermore, this analysis is based on 'present day data'. As the globalising processes intensify over time, the indirect impacts of human-induced disruption of global biogeochemical cycles and global climate change, and their impacts on human health, may start to become more apparent (Martens \& Huynen, 2003; Martens \& Rotmans, 2005). Borghesi and Vercelli (2003) also state that the available empirical evidence suggests 
that the current process of globalisation is unsustainable in the long run unless we introduce new institutions and policies able to govern it, a similar claim being made by Tisdell (2001) and Watanabe (2004) looking at economic globalisation only. Schrecker et al. (2008) reject furthermore the presumption that globalisation will yield health benefits as a result of its contribution to rapid economic growth and associated reduction in poverty.

Hence, for future research we hypothesize that a country's performance might be classified into four categories (adopted from Ranis (2006)): vicious cycle (low globalisation, high mortality), globalisation-lopsided (high globalisation, high mortality), healthlopsided (low globalisation, low mortality) or virtuous cycle (high globalisation, low mortality). In the vicious cycle, any efforts to properly integrate into the global process are yet unsuccessful, but might even result in (temporary) adverse health effects (e.g. Ghana). Globalisation-lopsided may happen when integration into the globalisation process has not yet resulted in major health benefits, or might have even resulted in increasing health problems (e.g. Egypt). Health-lopsided might happen, when health improvements occur that are not related to any globalisation benefits, but due to other domestic policies or developments (e.g. Peru). In a virtuous cycle, countries might have benefited from their integration into the globalisation process, while averting any associated health risks. It is important to note, however, that for some countries the virtuous cycle could be the result of bias due to causal sequence (i.e. did all the major improvements in health already occur prior to the modern-day globalisation process?) (e.g. the Netherlands).

Example countries:

- Vicious cycle (low globalisation, high mortality): Since the 1980s, Ghana has implemented the macro-economic policy prescriptions and Structural Adjustment Programs of the Bretton Woods Institutions (BWI), but with limited success. The commitment to privatisation and cuts in public spending have, however, resulted in users fees in health care and, subsequently, to restricted access for the poor, especially in rural areas (Smith, 2006). In the Upper Volta region, health care use is believed to have decreased by 50 percent (Hong, 2000). An additional health problem is, for example, the out-migration of doctors and nurses (Mensah et al., 2005). Ghana has experienced an increase in adult mortality rate from 272 per 1000 population in 1990 to 331 per 1000 population in 2006 (WHO, 2009b).

- Health-lopsided (low globalisation, low mortality): Peru has experienced important health improvements in the past decades (although the gap between rich and poor remains a problem) (Huynen, Vollebregt, et al., 2005) and in 1990, Peru's adult mortality rate had already declined to 178 per 1000 population (WHO, 2009b). Hence, many of Peru's health improvements occurred before President Fujimori started to push for integration into the global market via extensive macro-economic policies in the early 1990s. There has been macroeco- 
nomic growth since, but limited increase in development. In 2006, adult mortality rate had declined further to 136 per 1000 population (WHO, 2009b), but Peruvians have a lower health status compared to the continental average and some are concerned about the possible adverse globalisation impacts, such as increasing inequality and decreasing labour standards (Béjar, 2001, 2006).

- Globalisation-lopsided (high globalisation, high mortality): Since the mid-1970s, Egypt has been going through a process of increasing integration into the world economy. Even though Egypt implemented further macro-economic policies and structural adjustment programs in the 1980s and 1990s, the associated impacts on economic growth and development have been disappointing and uneven (UNDP, 2005), for example resulting in increasing unemployment. Egypt also faced many health challenges such as low formal health coverage and poor quality of many health facilities. This resulted in an increased need for health reform, increasing public health expenditure and pro-poor health care (Anwar \& Sallam, 2003; UNDP, 2005). Although adult mortality rate has declined over recent years, it is still relatively high at 186 per 1000 population in 2006 (WHO, 2009b).

- Virtuous cycle (high globalisation, high mortality): In the Netherlands, mortality started to decrease progressively in the late nineteenth century. Although this decline happened decades before the start of modern-day globalisation, the diffusion of knowledge about, for example, sanitation probably played an important role besides improved overall living conditions (Huynen, 2008). Adult mortality rate was 92 per 1000 population in 1990, declining further to 70 per 1000 population in 2006 (WHO, 2009b).

The important issue for policy purposes, of course, is how a country may move towards the virtuous cycle and several important research questions can be identified. How have countries changed their location over time and due to which underlying mechanisms? If countries find themselves in a viscous cycle, should they first focus on enhancing their health status or on enhancing their integration into the globalisation process? Looking at the health-lopsided countries and the globalisation lop-sided countries, which have a higher chance of reaching a virtuous circle and which are most at risk from shifting to a vicious circle? How can health-lopsided countries make sure that their health status is not compromised by any efforts to improve their integration in the globalisation process? How can globalisation-lopsided countries increase their health benefits of globalisation? And finally, will the countries that now experience a virtuous cycle also remain in this category in the future?

What is clear is that the increasing complexity of our global society means that sustainable health cannot be addressed from a single perspective, country, or scientific discipline. Changes in human health in the context of globalisation are far more complex than health issues that had to be tackled in the past. As addressed by others (e.g. Borghesi and Vecelli, 2003), it is our hope that a further analysis of health impacts of 
globalisation may help in adjusting and optimising the process of globalisation on every level in the direction of a sustainable and healthy development (Martens \& Raza, 2010). To this end, extensive empirical work is needed to identify the relevant causal mechanisms underlying the influence of globalisation on human health. 


\section{CHAPTER 4 \\ A SURVEY OF DUTCH EXPERT OPINION ON CLIMATIC DRIVERS OF INFECTIOUS DISEASE RISK IN WESTERN EUROPE}




\section{Abstract}

Climate change is considered to be a significant influence for infectious disease risk in Western Europe. Climatic and non-climatic developments act together resulting in current and future infectious disease risk. This study uses a survey to explore Dutch expert perspectives on climate change-induced infectious disease risk. The results show that the experts consider temperature change, precipitation change, humidity change, and climate change-induced habitat change to be relatively important for water-related infectious disease risk, vector-borne disease risk excluding zoonoses, and the risk of zoonoses. The climatic drivers are seen as relatively less important for food-related infectious disease risk. The experts rate many non-climatic drivers to be highly important for infectious disease risk. Comparatively, the majority of the non-climatic drivers assessed are seen as more important than climate change drivers. The degree of uncertainty in the future development of climatic drivers is viewed as moderate to high, and for non-climatic drivers mostly as moderate. An analysis of subsamples based on professional backgrounds reveals differences in experts' opinions for e.g., socio-cultural drivers, and similarities. Diversity and consensus amongst expert perspectives on climate change and infectious diseases can have implications for policy. Further research to uncover and compare prevailing perspectives is necessary.

Published as: Akin, S., \& Martens, P. (2014). A survey of Dutch expert opinion on climatic drivers of infectious disease risk in Western Europe. Climate, Special Issue Climate Impacts on Health, 2(4), p.310-328, doi:10.3390/cli2040310. 


\subsection{Introduction}

Today, many interacting global changes are taking place at an unprecedented rate, often interrelated with human activities. These changes impact our ecological as well as societal systems. Climate change is one of the significant examples of these types of predominantly human-induced global changes, with already noticeable and anticipated consequences (IPCC, 2013; Scholte, 2000; Steffen et al., 2007).

In Europe, climate change will become an increasing burden, socio-economically and in terms of health. Climate change directly and/or indirectly affects health. Specifically, there is growing scientific evidence of its effects on infectious disease risk in Europe (Alcamo et al., 2007; EEA, 2012; Menne et al., 2008; Semenza \& Menne, 2009). Climate change can bring about changes in the distribution and transmission of communicable diseases, and relating to this, the number of disease cases by influencing e.g., the disease pathogen directly, the suitability of environments, or human behaviours leading to exposure (ECDC, 2005-2009; EEA, 2012; Menne et al., 2008; Semenza \& Menne, 2009).

Many population health problems are embedded in a global context (Huynen, Martens, et al., 2005; Martens et al., 2011). When trying to understand the infectious disease reality that Europe is facing today and in the future due to climate change, other relevant non-climatic mediating developments at the global but also local level need to be taken into account, such as urbanization, the movement of people (travel and migration), land use, and socio-economic inequalities (Abrahams et al., 2012; Cohen, 2000; Menne et al., 2008; Semenza \& Menne, 2009). Climatic and non-climatic developments and their infectious disease risk outcomes will play out differently across countries and regions. This is true on a global scale, but also within Europe. Moreover, adaptive capacities differ amongst European countries, and varying climate change impacts can in turn influence the ability to adapt to and control infectious disease risk (EC, 2009a, 2013a; Menne et al., 2008; Senior, 2008). The relevance of the global context for health outcomes encompassing multiple drivers contributes to complexities and uncertainties with regard to the relationship between climate change and infectious disease risk.

It is integral for healthy and sustainable development that a priority is placed on understanding and tackling climate change and its health impacts (EC, 2013c; Griggs et al., 2013; UN, n.d./2009). Many studies have been done to find evidence for the effects of climate change on infectious disease risk, taking into consideration other non-climatic drivers (see e.g. EEA (2012); Epstein (2001); McMichael et al. (2006); Patz et al. (2005); Semenza \& Menne (2009)). However, the relationship between climate change and infectious disease risk in a European context requires further research (EEA, 2012; Semenza \& Menne, 2009). Besides the necessity to gain more understanding and knowledge of this complex relationship, it is also important to recognize that there will most likely always be uncertainty and therefore imperfect predictions of how climate change together with other factors will result in infectious disease risk (Senior, 2008; Wardekker et al., 2012). Stakeholder involvement using participatory research methods can be a 
way to address complexities and uncertainties, common to environmental and specifically climate change problems (de Ridder et al., 2007; Kloprogge \& van der Sluijs, 2006). In this study, the perspectives of experts on the relationship between climate change and infectious disease risk in Western Europe are investigated with a survey. Potentially relevant non-climatic drivers of infectious disease risk in Western Europe are also addressed in this survey, and compared in terms of importance with climatic drivers by the experts. The analysis integrates multiple drivers and takes on an overall holistic view on the causation of infectious disease risk.

\subsection{Methodology and research design}

This study has been conducted to shed more light on the views Dutch experts have on the causation of infectious disease risk in Western Europe, integrating climatic and nonclimatic drivers. Surveying expert stakeholders is a way to uncover existing perspectives (and the possible diversity amongst these) in the Netherlands, concerning the relationship between climate change and infectious disease outcomes in Western Europe. For this purpose, a qualitative survey was executed. In preparation of this, a stakeholder analysis has been performed for the identification of experts and selection of an expert sample for the survey.

\subsubsection{Stakeholder analysis and sampling}

A stakeholder analysis was conducted to identify stakeholders for the selection of potential respondents for the expert survey used in this study (Prell et al., 2013; Reed et al., 2009). A broad definition of stakeholders was assumed for this analysis: individuals and organizations that are likely to be affected by or can influence climate change and related health impacts; the latter e.g., through the implementation of adaptation measures (Allen \& Kilvington, 2003; Davie et al., 2006; Freeman \& McVea, 2001; Reed et al., 2009). The analysis was performed in the Netherlands, being a priority research focus of the ERA-ENVHEALTH ENHanCE research project. The stakeholder approach aimed to map out Dutch stakeholders in relation to the topic of climate change and infectious disease risk in Western Europe; to create a useful inventory for potential participants for the participatory elements in the broader research setup of the project; and to facilitate the collection of expert knowledge and perspectives on climate change and health impacts. This approach can be characterized as descriptive and instrumental (Reed et al., 2009).

The stakeholder analysis yielded a stakeholder matrix where detailed information was stored for each stakeholder, such as the stakeholder's expertise and professional background. The stakeholder matrix could then be used for the selection of an expert sample of respondents for the survey. The guiding criterion for selecting a sample of experts 
from the stakeholder matrix was that the individuals possess expertise relevant for the survey's topic and scope; i.e., expertise on climate change/environment, and health/infectious diseases. Information on the expertise of each stakeholder was documented in the stakeholder matrix and could therefore be retrieved for the purpose of sampling. Since a guiding criterion was used as a base for sample selection, this sampling method can be called judgment sampling, a non-probabilistic sampling method (Cooper \& Schindler, 2003; Garson, 2012). From the stakeholder matrix a sample of 56 experts on climate change/environment, and health/infectious diseases could be drawn. Based on the information collected about each stakeholder's professional background, the expert sample included mostly scientists and policy advisors. The survey was conducted in 2012 and yielded a useful response of 29 (out of the 56 experts that were approached as respondents for the survey) ${ }^{15}$.

The survey included a section where respondents could indicate their professional background, using predefined categories with the possibility of adding additional categories in an open section. This data was used to divide the sample into groups. This was done to explore potential differences and similarities in opinions of experts with different professional backgrounds in the analysis. The sample groups were formed in the following manner: first, all respondents who indicated a professional background in policy were placed in one sample group labelled "Policy" and thereafter removed from the full list of respondents. After that, the respondents who indicated a professional background in science were included in another sample group labelled "Science"; finally, the remaining three respondents were added to the group "Policy" as the indicated professional backgrounds seemed to allow for such a compilation. This process resulted in two sample subgroups: "Policy" consisting of 12 experts, and "Science" consisting of 17 experts. As explained earlier, based on information collected in the stakeholder matrix on professional backgrounds of the selected sample, the sample could be characterized as comprising scientists and policy advisors. The self-indicated professional backgrounds of the respondents leading to the formation of the sample subgroups, confirms the initial characterization made of the composition of the selected sample. In this respect, the sample subgroups also seem to be a sensible division of the aggregate sample.

Additional information on the stakeholder analysis and sample are given in Appendix 1.

\subsubsection{Survey design and content}

The survey aimed to have experts assess the importance and uncertainty of climatic and non-climatic drivers of infectious disease risk in Western Europe. A survey was used as this is a suitable and efficient method for a qualitative assessment based on expert opin-

\footnotetext{
${ }^{15} 33$ respondents, out of the sample of 56 experts that were invited to participate, started the survey, but 4 of the 33 surveys were returned incomplete, and therefore had to be removed prior to analysis which resulted in a useful response of 29 .
} 
ions and perceptions (Cooper \& Schindler, 2003). The survey design included closed questions, predominantly in a Likert-scale format, and optional open questions. Each closed question provided a possibility to leave it open ("no opinion/do not know") and to add more items which could then be assessed as well. All definitions could be viewed by the respondents at all times during the survey process. The survey was administered online, and generated descriptive information, nominal, ordinal and some ratio/interval data. Survey methods are prone to several common limitations, which were taken into account during the design and implementation of this study. For instance, the risk of misunderstanding of the wording used (Cooper \& Schindler, 2003) was reduced by using vocabulary familiar to experts and making definitions available at all times during the survey process. The lower quality of responses received is another potential risk of surveys, which was limited by offering a "no opinion/do not know" option.

The survey structure was the following: the assessment of

(a) the relative importance of climatic drivers of infectious disease risk, for each type of infectious disease risk;

(b) the degree of uncertainty in the future development of each climatic driver;

(c) the relative importance of non-climatic drivers of infectious disease risk;

(d) the uncertainty in the future development of each non-climatic driver; and lastly

(e) the relative importance of each non-climatic driver compared to climate change as a driver of infectious disease risk.

In part (a) for the assessment of the importance of climatic drivers for infectious disease risk, "importance" is defined as: the relative impact/importance of each driver for future infectious disease risk. Does the way in which the driver evolves make a major difference in increasing or decreasing the overall infectious disease risk, or does it make a relatively minor difference? (Jäger et al., 2007). The following climatic drivers were included in the survey: temperature change, precipitation change, humidity change, climate changeinduced habitat change, and increase in frequency of extreme weather events. Infectious disease risk is specified in broad types: water-related infectious disease risk, foodrelated infectious disease risk, vector-borne disease risk excluding zoonoses, and risk of zoonoses (Jäger et al., 2007). Here a zoonosis is defined as: "[...] any disease or infection that is naturally transmissible from vertebrate animals to humans. Animals thus play an essential role in maintaining zoonotic infections in nature. Zoonoses may be bacterial, viral, or parasitic, or may involve unconventional agents (WHO, 2011b)."

In the next part, experts assessed the degree of uncertainty in the future development of each climatic driver for infectious disease risk. For the purpose of this question, uncertainty has been defined as: Degree of uncertainty in each driver. How much variation is there in the range of possible ways in which the driver could evolve? Is there a great deal of uncertainty in this, or relatively little? (Jäger et al., 2007). 
For the following parts of the survey (c) and (d), non-climatic drivers were assessed. A conceptual analysis for the identification of potential non-climatic drivers of infectious disease risk was conducted using relevant background studies and literature (see amongst others Cohen (2000); McMichael (2004); Semenza \& Menne, (2009); Sutherst (2004); Van Lier et al. (2007)). After that a selection of non-climatic drivers was made for inclusion in the survey, according to their potential importance in a European context. The non-climatic drivers are organized in domains: ecological, economic and agricultural, technological, institutional, and socio-cultural. The survey included the same questions as for the climatic drivers, using the same definitions for importance and uncertainty.

Finally, the non-climatic drivers were compared to climate change as an aggregate driver for infectious disease risk in terms of relative importance, using the same definition for importance.

\subsubsection{Survey analysis}

The resulting survey data were analysed using descriptive statistics. The statistics performed are appropriate for the ordinal data obtained from Likert-scale questions. Thus, for the analysis of central tendency and variability median, mode, range, and interquartile range are used (see e.g., Cooper \& Schindler (2003)). Moreover, the smaller sample size and non-probabilistic sampling method were taken into account for the analysis. Uncompleted surveys were excluded from the analysis. For the analysis, the "no opinion/do not know" responses were assumed to be distributed proportionally amongst the respondents, and therefore were excluded in order to circumvent an inflation of the actual resulting responses (Cooper \& Schindler, 2003).

In order to explore the experts' opinions according to the experts' self-indicated professional background, all descriptive analyses were done for the aggregate sample as well as for the two sample groups "Policy" and "Science", described earlier.

\subsection{Results of the survey}

In this section, the results of the survey analysis are presented in the form of descriptive statistics.

\subsubsection{Expert assessment of the relative importance of climatic drivers for infectious disease risk}

Through analysis of the survey results the perspectives of the expert sample on the relative importance of climatic drivers for infectious disease risk types could be obtained. The results are first presented of the aggregate sample analysis in Figure $4.1 \mathrm{a}-\mathrm{d}$, and thereafter of the two sample groups "Policy" and "Science" in Figure $4.2 \mathrm{a}-\mathrm{h}$. 
Figure $4.1 \mathrm{a}-\mathrm{d}$ shows the results of the aggregate expert sample's assessment of the relative importance of the climatic drivers for each type of infectious disease risk.

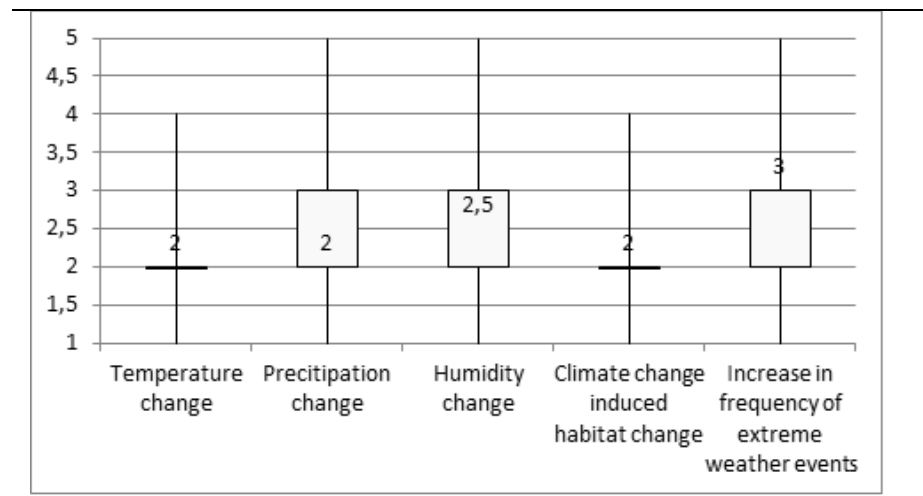

a. Water-related infectious disease risk

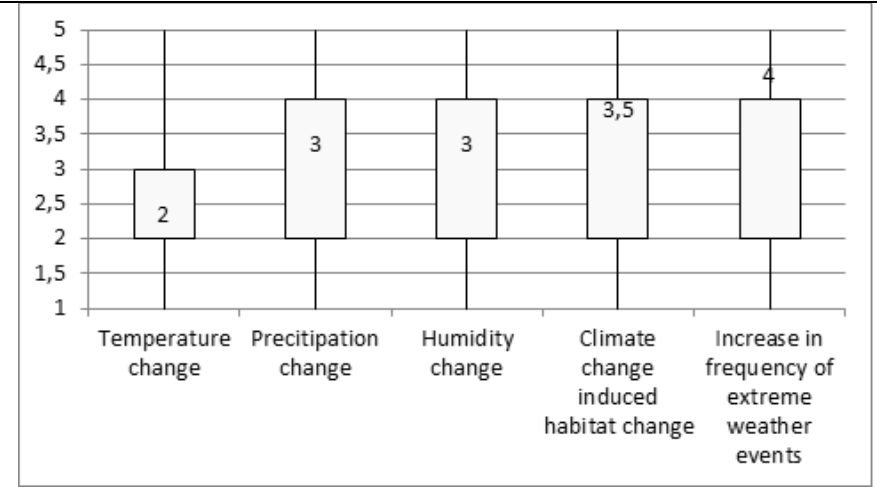

b. Food-related infectious disease risk

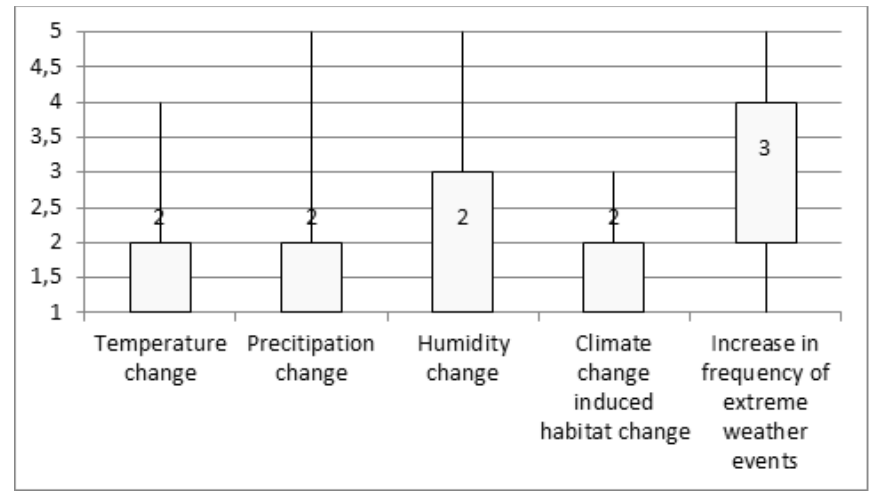

c. Vector-borne disease risk (excluding zoonoses) 


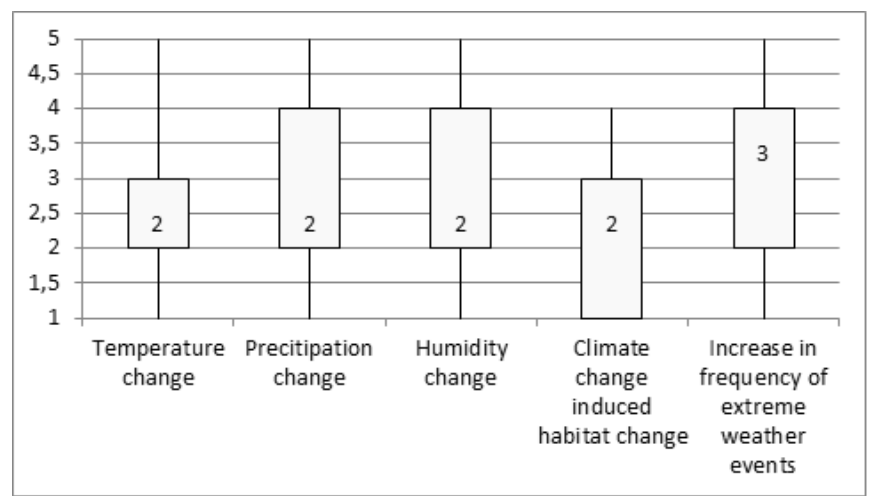

d. Risk of zoonoses

Figure 4.1 a-d Box plots of the aggregate sample assessment of the relative importance of climatic drivers for each type of infectious disease risk

Notes: Medians are given as numbers in each box plot

Interpretation of the median values for importance: 1=very high importance [high importance, moderate importance, low importance] 5=very low importance

Range $=$ maximum value - minimum value

Interquartile range $(I Q R)=3^{\text {rd }}$ quartile $-1^{\text {st }}$ quartile $=$ length of box

It can be seen that the aggregate expert sample views temperature change as highly important for all types of infectious disease risk. In addition, precipitation change and climate change-induced habitat change are seen as highly important, except for foodrelated infectious disease risk, where these drivers are rated with moderate and little importance respectively. Increase in frequency of extreme weather events is overall rated to be least relevant; expert assessments show moderate importance for waterrelated and vector-borne infectious diseases and zoonoses, and even little importance for food-related infectious disease risk. With use of the interquartile range (hereafter IQR) a closer look can be taken at the variability of the expert opinions. The experts show little variance in their opinions on temperature change, precipitation change, humidity change, and habitat change, as well as for water-related infectious disease risk and vector-borne disease risk excluding zoonoses. Overall, most variation amongst expert assessments, based on the IQR, can be found for the climatic driver increase in frequency of extreme weather events, and the infectious disease type risk of zoonoses.

The same analysis was done for the two sample groups "Policy" and "Science". In Figure $4.2 \mathrm{a}-\mathrm{h}$, the assessment of the relative importance of climatic drivers for each type of infectious disease risk given by the two sample groups can be found. 


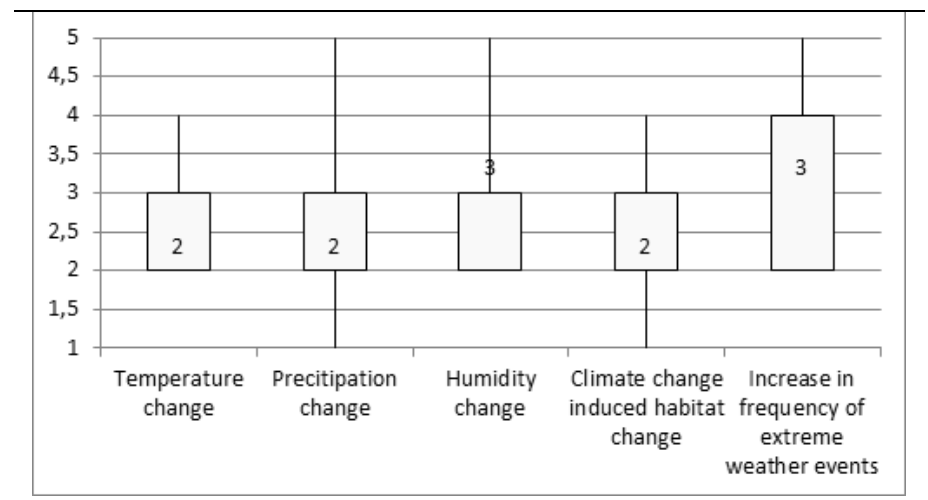

a. Water-related infectious disease risk, sample group "Policy"

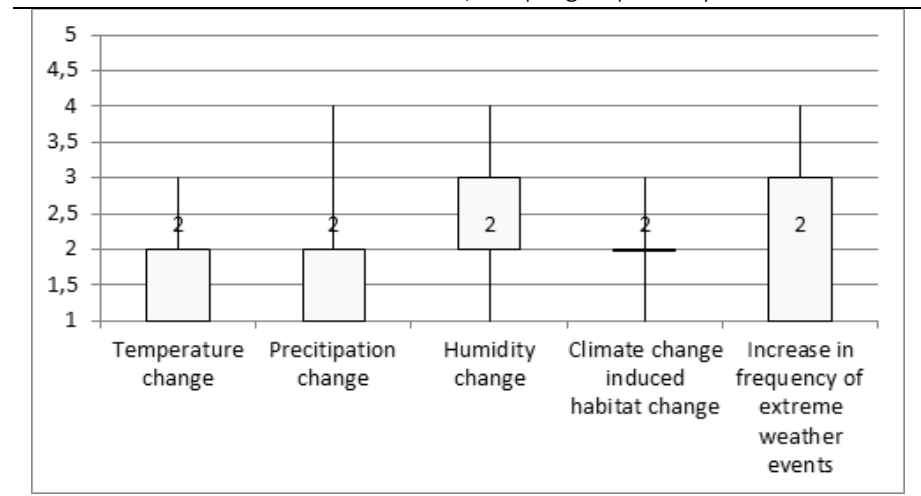

b. Water-related infectious disease risk, sample group "Science"

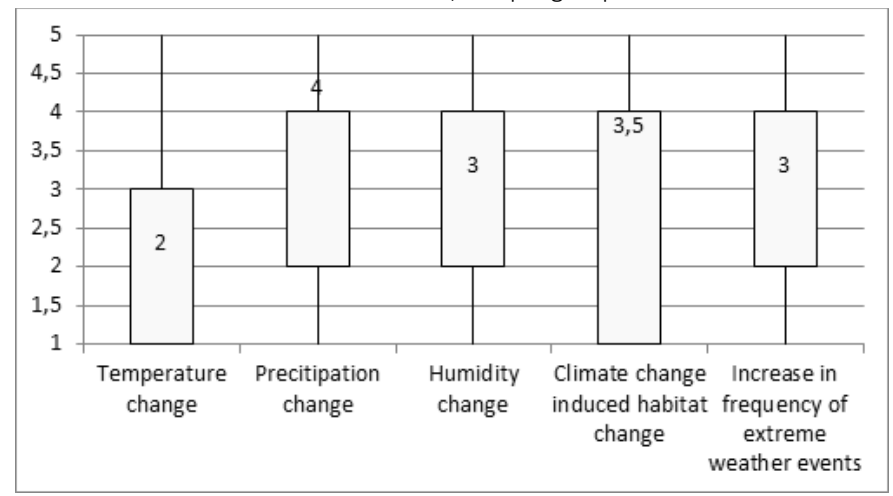

c. Food-related infectious disease risk, sample group "Policy" 


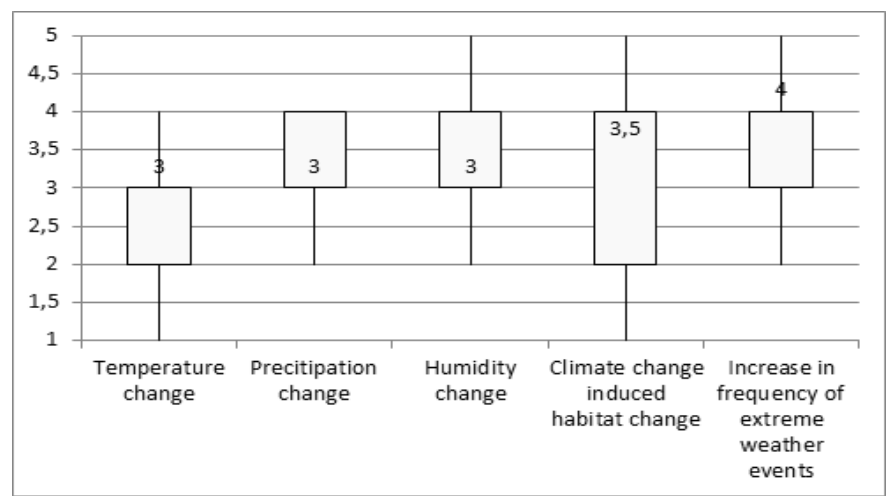

d. Food-related infectious disease risk, sample group "Science"

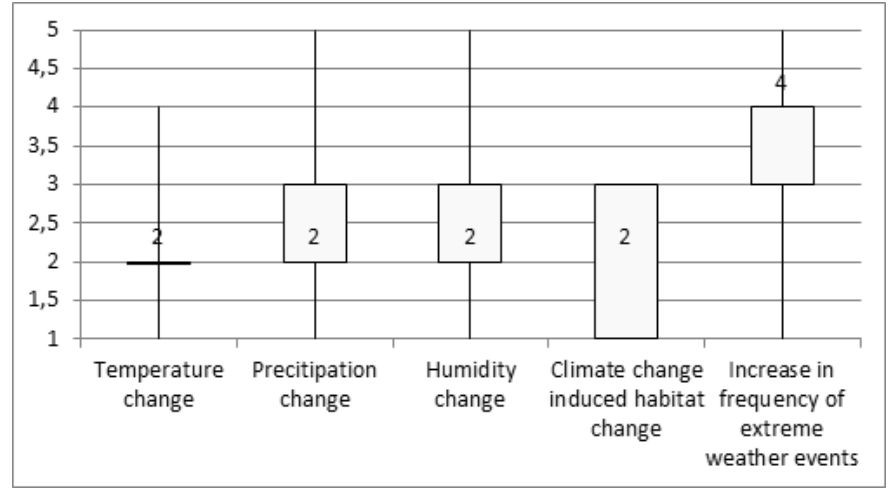

e. Vector-borne disease risk (excluding zoonoses), sample group "Policy"

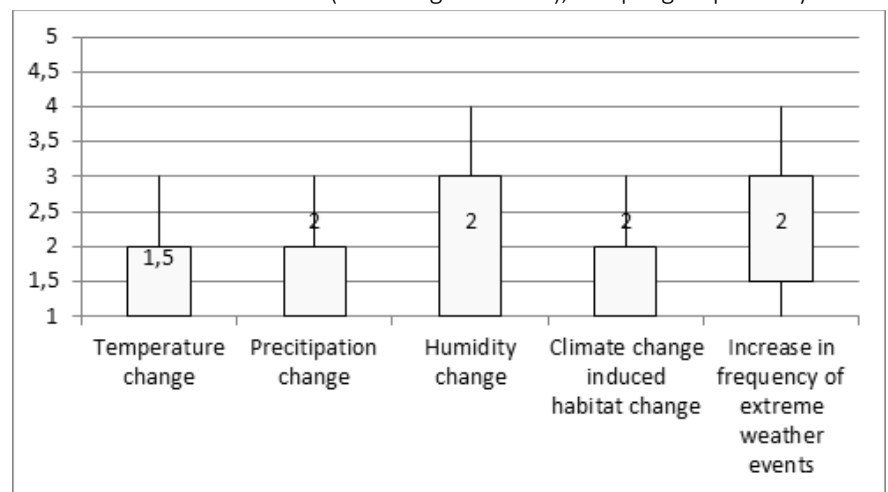

f. Vector-borne disease risk (excluding zoonoses), sample group "Science" 


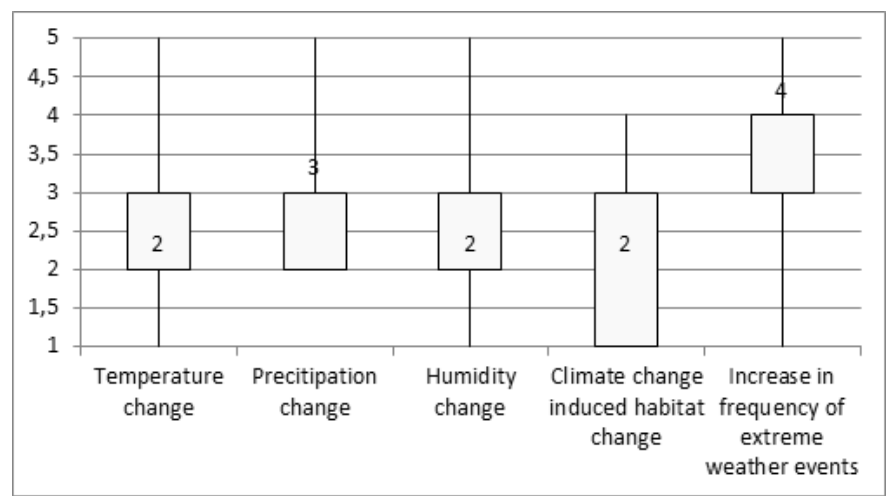

g. Risk of zoonoses, sample group "Policy"

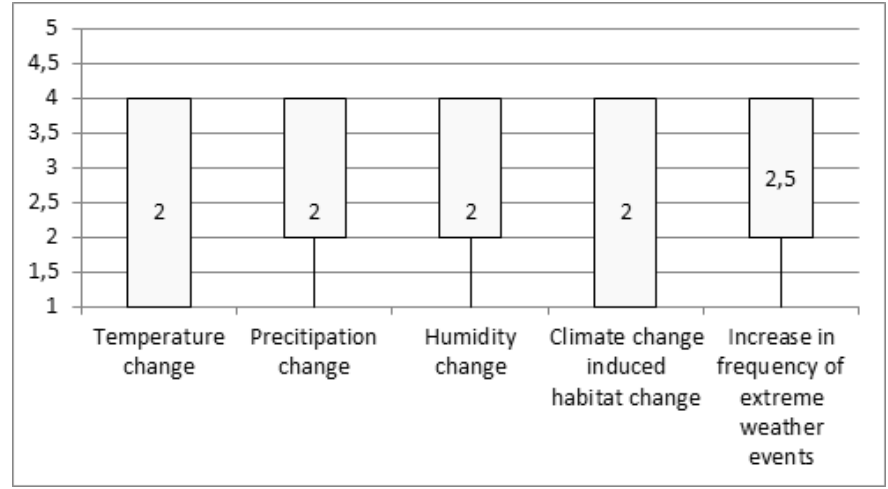

h. Risk of zoonoses, sample group "Science"

Figure 4.2 a-h Box plots of the assessments of the two sample groups "Policy" and "Science" of the relative importance of climatic drivers for each type of infectious disease risk Notes: Medians are given as numbers in each box plot Interpretation of the median values for importance: 1=very high importance [high importance, moderate importance, low importance] $5=$ very low importance

Range $=$ maximum value - minimum value

Interquartile range $(\mathrm{IQR})=3^{\text {rd }}$ quartile $-1^{\text {st }}$ quartile $=$ length of box

Several differences between the groups "Science" and "Policy" can be found. Humidity change and increase in frequency of extreme weather events as drivers of water-related infectious disease risk are seen as moderately important by the "Policy" group but as highly important by the "Science" group. For food-related infectious disease risk the two groups are in disagreement regarding the importance of temperature change ("Policy": high importance; "Science": moderate importance); precipitation change ("Policy": little importance; "Science": moderate importance); and increase in frequency of extreme weather events ("Policy": moderate importance; "Science": little importance). The importance of temperature change for vector-borne disease risk excluding zoonoses is assessed to be high by the "Policy" group; and high to very high by the "Science" group. Moreover, the importance of increase in frequency of extreme weather events for this 
disease risk is rated to be of little importance by the "Policy" group, and of high importance by the "Science" group. For the risk of zoonoses the two groups differ in their assessment of the importance of precipitation change: "Science" rates this to be high, and "Policy" to be moderate. Lastly, for the importance of increase in extreme weather events the results of the two groups differ quite notably: "Science" rating this to be of high to moderate importance, and "Policy" viewing this as having little importance. For all other values, which are the majority, the same assessments result from the two groups. This means that both groups assess the following climatic drivers to be highly important: temperature change for water-related infectious disease risk and zoonoses; precipitation change for water-related infectious disease risk and vector-borne disease risk; humidity change for vector-borne disease risk and zoonoses; and finally, climate change-induced habitat change for water-related infectious disease risk, vector-borne infectious disease risk, and zoonoses. In sum, it can be seen that the opinions on the importance of increase in frequency of extreme weather events differ mostly for all disease types between the two groups. Most agreement between the two groups' assessments can be found for the importance of climate change-induced habitat change, where all the ratings are the same between groups for all disease types, and the importance of humidity change where the ratings are the same for all but one disease type, namely water-related infectious disease risk.

The IQRs indicate that both the groups "Science" and "Policy" show much agreement within each group regarding water-related infectious disease risk and vector-borne disease risk excluding zoonoses. The variation in expert opinions for food-related infectious disease risk is high for the group "Policy". For zoonoses, the group "Science" shows greater variations.

\subsubsection{Expert assessment of the degree of uncertainty in the future development of each climatic driver}

Next, the degree of uncertainty in the future development of each climatic driver was assessed. The analyses for both the aggregate sample as well as the two sample groups

"Science" and "Policy" are presented in Table 4.1. 


\begin{tabular}{|c|c|c|c|c|c|c|}
\hline \multirow[b]{3}{*}{ Climatic drivers } & \multicolumn{6}{|c|}{ Assessment of uncertainty } \\
\hline & \multicolumn{2}{|c|}{ Aggregate sample } & \multicolumn{2}{|c|}{$\begin{array}{l}\text { Sample Group } \\
\text { "Policy" }\end{array}$} & \multicolumn{2}{|c|}{$\begin{array}{l}\text { Sample Group } \\
\text { ence" }\end{array}$} \\
\hline & Median & $\mathrm{IQR}^{\mathrm{a}}$ & Median & IQR & Median & IQR \\
\hline Temperature change & 3 & 1 & 3 & 2 & 3 & 1 \\
\hline Precipitation change & 3 & 1 & 3 & 1 & 3 & 1 \\
\hline Humidity change & 2 & 1 & 3 & 1 & 2 & 1 \\
\hline $\begin{array}{l}\text { Climate change-induced habitat } \\
\text { change }\end{array}$ & 2 & 1 & 2 & 1 & 2 & 1 \\
\hline $\begin{array}{l}\text { Increase in frequency of extreme } \\
\text { weather events }\end{array}$ & 3 & 1 & 2 & 2 & 3 & 1 \\
\hline
\end{tabular}

Notes: Interpretation of the median values for uncertainty: 1=very high uncertainty [high uncertainty, moderate uncertainty, little uncertainty] $5=$ virtually certain

$\mathrm{IQR}^{\mathrm{a}}=$ Interquartile range $=3^{\text {rd }}$ quartile $-1^{\text {st }}$ quartile

From the analysis of the aggregate sample, it can be gathered that temperature change, precipitation change, and increase in frequency of extreme weather events are seen as being moderately uncertain in their future development. Experts assign high uncertainty in future development for the climatic drivers humidity change and climate changeinduced habitat change. The IQR's are low for these results, pointing to relatively little variability in expert opinions in the aggregate sample.

The same analysis was done for the two sample groups "Science" and "Policy". It can be seen that the two groups "Science" and "Policy" agree with regards to the degree of uncertainty in the future development of temperature change, precipitation change, and climate change-induced habitat change. The group "Policy" sees the increase in frequency of extreme weather events as being more uncertain (high uncertainty) than the group "Science" (moderate uncertainty). The opposite holds for the uncertainty of humidity change (group "Science": high uncertainty, group "Policy": moderate uncertainty).

The IQRs for the group "Science" are low, indicating high agreement amongst experts on uncertainty. The group "Policy" has relatively high IQRs, thus a higher variability in their responses on uncertainty. Particularly, a high degree of divergence can be found in their opinions on temperature change and frequency of extreme weather events.

\subsubsection{Expert assessment of the relative importance of non-climatic drivers for infectious disease risk}

The expert survey also included selected non-climatic drivers of infectious disease risk, which were assessed in terms of their relative importance for infectious disease risk.

Table 4.2 shows the results of the expert assessment of the relative importance of nonclimatic drivers of infectious disease risk, both for the aggregate sample and the two sample groups "Science" and "Policy". 


\begin{tabular}{|c|c|c|c|c|c|c|}
\hline & \multicolumn{6}{|c|}{ Assessment of importance } \\
\hline & $\begin{array}{l}\text { Aggregate } \\
\text { ple }\end{array}$ & sam- & $\begin{array}{l}\text { Sample } \\
\text { "Policy" }\end{array}$ & group & $\begin{array}{l}\text { Sample } \\
\text { "Science" }\end{array}$ & group \\
\hline Ecological (non-climatic) drivers & Median & $I Q R^{b}$ & Median & IQR & Median & IQR \\
\hline Land use change & 2 & 1 & 2 & 1 & 2 & 1 \\
\hline Microbial evolution & 2 & 1 & 2.5 & 2 & 2 & 1 \\
\hline Pollution & 3 & 2 & 4 & 1 & 3 & 2 \\
\hline Urban greening & 3 & 0 & 3 & 0 & 3 & 0 \\
\hline Economic and agricultural drivers & Median & IQR & Median & IQR & Median & IQR \\
\hline Increased movement of goods & 2 & 1 & 2 & 1 & 2 & 1 \\
\hline Increased farm scale and scope & 2 & 1 & 2 & 1 & 2 & 1 \\
\hline Increased organic farming & 3 & 1 & 3 & 1 & 3 & 1 \\
\hline Technological drivers & Median & IQR & Median & IQR & Median & IQR \\
\hline Globalised food supply chains & 2 & 1 & 2 & 1 & 2 & 1 \\
\hline Widespread use of antibiotics & 2 & 1 & 2 & 1 & 2 & 1 \\
\hline Capacity to detect, prevent, and treat diseases & 2 & 1 & 2 & 1 & 2 & 1 \\
\hline Institutional drivers & Median & IQR & Median & $\mathrm{IQR}$ & Median & $\mathrm{IQR}$ \\
\hline Decreased public health care structures & 2 & 2 & 2 & 1 & 2 & 2 \\
\hline $\begin{array}{l}\text { Limitations to and reduction in prevention } \\
\text { programs }\end{array}$ & 2 & 0 & 2 & 0 & 2 & 1 \\
\hline Move towards privatization of health sector & 3 & 2 & 3 & 2 & 3 & 1 \\
\hline Socio-cultural drivers & Median & IQR & Median & IQR & Median & IQR \\
\hline Increased movement of people & 2 & 0 & 2 & 1 & 2 & 0 \\
\hline Aging population & 2 & 2 & 2 & 2 & 2.5 & 2 \\
\hline Incidence of chronic diseases & 3 & 2 & 3 & 2 & 3 & 1 \\
\hline Sexual behaviour & 3 & 1 & 3 & 0 & 2 & 1 \\
\hline Intravenous drug use & 3 & 1 & 4 & 2 & 3 & 0 \\
\hline
\end{tabular}

Notes: Interpretation of the median values for importance: 1=very high importance [high importance, moderate importance, low importance] $5=$ very low importance

$I Q R^{\mathrm{b}}=$ Interquartile range $=3^{\text {rd }}$ quartile $-1^{\text {st }}$ quartile

From the results for the aggregate sample in Table 4.2 it can be seen that a large part of the non-climatic drivers are rated to be of high importance for infectious disease risk. Drivers such as pollution, urban greening, and increased organic farming are seen as having moderate importance. When looking at the relating IQRs, it can be seen that more variability in the aggregate expert sample's responses can be ascertained for the importance of pollution, move towards privatization of health sector, aging population, and incidence of chronic diseases.

The same analyses were performed for the two groups "Science" and "Policy". The median results for both groups for relative importance of non-climatic drivers are largely similar. Some main differences can be observed. The group "Policy" rates pollution to 
have little importance as opposed to moderate importance resulting from the group "Science". The group "Science" considers sexual behaviour as being highly important as opposed to moderately important resulting from the group "Policy". Moreover, the group "Policy" also indicates intravenous drug use to be of little importance, whereas the group "Science" views this as moderately important. The IQRs for the responses given by the two sample groups are relatively low, indicating high agreement amongst the experts within each group. More variability in experts' responses of the sample group "Science" could be found for pollution, decreased public health care structures, and aging population. For the group "Policy" more variability can be seen for microbial evolution, increased movement of goods, move towards privatization of health sector, aging population, chronic diseases, and intravenous drug use. So overall, for more nonclimatic drivers a higher variability could be found in the responses of the group "Policy".

\subsubsection{Expert assessment of the degree of uncertainty in the future development of each non-climatic driver}

The expert sample also assessed the degree of uncertainty in the future development of each non-climatic driver. Table 4.3 presents these results for the aggregate sample and the two sample groups "Science" and "Policy".

Regarding the results of the aggregate sample, in Table 4.3 it can be found that only microbial evolution is indicated to be highly uncertain in its future development. Many drivers are rated to be moderately uncertain in their future development, amongst which are land use change, increased farm scale and scope, and limitations to and reduction in prevention programs. Moreover, quite a significant amount of drivers received a rating of little uncertainty, including widespread use of antibiotics, decreased public health care structures, aging population, and incidence of chronic diseases. The IQR's and thus the differences in expert opinions within the aggregate sample are relatively higher for the uncertainty of increased movement of goods, increased organic farming, globalised food supply chains, and capacity to detect, prevent, and treat diseases.

When taking a look at the assessment of uncertainty by the two sample groups "Policy" and "Science", the following can be seen. The groups show notably different results in their median uncertainty ratings for increased movement of goods, decreased public health care structures, limitations to and reductions in prevention programs, and incidence of chronic diseases. For all technological drivers the two groups agree in their assessments. The IQRs for the group "Science" are low, indicating much agreement in expert opinion in this group. An exception is found for the uncertainty of the move towards privatisation of the health sector which has a higher IQR and therefore larger variability amongst expert opinions in the group "Science". With regards to the IQRS found for the group "Policy", it becomes clear that the experts show less consensus on 
the uncertainty of the increased movement of goods, globalised food supply chains, aging population, sexual behaviour, and intravenous drug use.

\begin{tabular}{|c|c|c|c|c|c|c|}
\hline & \multicolumn{6}{|c|}{ Assessment of uncertainty } \\
\hline & $\begin{array}{l}\text { Aggregate } \\
\text { ple }\end{array}$ & sam- & $\begin{array}{l}\text { Sample } \\
\text { "Policy" }\end{array}$ & group & $\begin{array}{l}\text { Sample } \\
\text { "Science" }\end{array}$ & group \\
\hline Ecological (non-climatic) drivers & Median & $I Q R^{C}$ & Median & IQR & Median & IQR \\
\hline Land use change & 3 & 1 & 3 & 1 & 3 & 0 \\
\hline Microbial evolution & 2 & 1 & 2 & 1 & 2.5 & 1 \\
\hline Pollution & 3 & 1 & 3 & 2 & 3.5 & 1 \\
\hline Urban greening & 3 & 1 & 3 & 1 & 3 & 1 \\
\hline Economic and agricultural drivers & Median & IQR & Median & IQR & Median & IQR \\
\hline Increased movement of goods & 4 & 2 & 3 & 2 & 4 & 1 \\
\hline Increased farm scale and scope & 3 & 1 & 3 & 1 & 3 & 1 \\
\hline Increased organic farming & 3 & 2 & 2.5 & 1 & 3 & 1 \\
\hline Technological drivers & Median & IQR & Median & IQR & Median & IQR \\
\hline Globalised food supply chains & 3 & 2 & 3 & 2 & 3 & 1 \\
\hline Widespread use of antibiotics & 4 & 1 & 4 & 1 & 4 & 1 \\
\hline Capacity to detect, prevent, and treat diseases & 3 & 2 & 3 & 1 & 3 & 1 \\
\hline Institutional drivers & Median & IQR & Median & IQR & Median & IQR \\
\hline Decreased public health care structures & 4 & 1 & 3 & 1 & 4 & 1 \\
\hline $\begin{array}{l}\text { Limitations to and reduction in prevention } \\
\text { programs }\end{array}$ & 3 & 1 & 4 & 1 & 3 & 1 \\
\hline Move towards privatization of health sector & 3 & 1 & 2.5 & 1 & 3 & 2 \\
\hline Socio-cultural drivers & Median & IQR & Median & IQR & Median & IQR \\
\hline Increased movement of people & 4 & 1 & 4 & 1 & 4 & 1 \\
\hline Aging population & 4 & 1 & 4 & 2 & 4 & 1 \\
\hline Incidence of chronic diseases & 4 & 1 & 3 & 1 & 4 & 1 \\
\hline Sexual behaviour & 4 & 1 & 3.5 & 3 & 4 & 1 \\
\hline Intravenous drug use & 4 & 1 & 4 & 2 & 3.5 & 1 \\
\hline
\end{tabular}

Notes: Interpretation of the median values for uncertainty: 1=very high uncertainty [high uncertainty, moderate uncertainty, little uncertainty] $5=$ virtually certain

$\operatorname{IQR} R^{\mathrm{c}}=$ Interquartile range $=3^{\text {rd }}$ quartile $-1^{\text {st }}$ quartile

\subsubsection{Expert assessment of the relative importance of non-climatic drivers compared to climate change}

Finally, the experts assessed the relative importance of each non-climatic driver compared to climate change as an aggregate driver for infectious disease risk. The results of this assessment are shown in Table 4.4 for the aggregate sample and the two sample group "Science" and "Policy". 


\begin{tabular}{|c|c|c|c|c|c|c|}
\hline & \multicolumn{6}{|c|}{$\begin{array}{l}\text { Importance of non-climatic drivers compared to climate } \\
\text { change }\end{array}$} \\
\hline & $\begin{array}{l}\text { Aggregate } \\
\text { ple }\end{array}$ & sam- & $\begin{array}{l}\text { Sample } \\
\text { "Policy" }\end{array}$ & group & $\begin{array}{l}\text { Sample } \\
\text { "Science" }\end{array}$ & group \\
\hline Ecological (non-climatic) drivers & Median & $\operatorname{IQR}^{\mathrm{d}}$ & Median & IQR & Median & IQR \\
\hline Land use change & 1 & 1 & 1 & 0 & 1 & 1 \\
\hline Microbial evolution & 1 & 1 & 1.5 & 1 & 1 & 1 \\
\hline Pollution & 2 & 1 & 2 & 0 & 2 & 1 \\
\hline Urban greening & 2 & 0 & 2 & 0 & 2 & 0 \\
\hline Economic and agricultural drivers & Median & IQR & Median & IQR & Median & IQR \\
\hline Increased movement of goods & 1 & 1 & 1 & 1 & 1 & 1 \\
\hline Increased farm scale and scope & 1 & 1 & 1 & 1 & 1 & 1 \\
\hline Increased organic farming & 2 & 1 & 2 & 1 & 2 & 1 \\
\hline Technological drivers & Median & IQR & Median & IQR & Median & IQR \\
\hline Globalised food supply chains & 1 & 1 & 1 & 1 & 1 & 1 \\
\hline Widespread use of antibiotics & 1 & 0 & 1 & 0 & 1 & 0 \\
\hline Capacity to detect, prevent, and treat diseases & 1 & 1 & 2 & 1 & 1 & 1 \\
\hline Institutional drivers & Median & IQR & Median & IQR & Median & IQR \\
\hline Decreased public health care structures & 1 & 1 & 1 & 1 & 1 & 0 \\
\hline $\begin{array}{l}\text { Limitations to and reduction in prevention } \\
\text { programs }\end{array}$ & 1 & 1 & 1.5 & 1 & 1 & 1 \\
\hline Move towards privatization of health sector & 2 & 0 & 2 & 0 & 2 & 1 \\
\hline Socio-cultural drivers & Median & IQR & Median & IQR & Median & IQR \\
\hline Increased movement of people & 1 & 1 & 1 & 1 & 1 & 0 \\
\hline Aging population & 1 & 1 & 1.5 & 1 & 1 & 1 \\
\hline Incidence of chronic diseases & 2 & 1 & 2 & 0 & 1 & 1 \\
\hline Sexual behaviour & 1.5 & 1 & 2 & 1 & 1 & 1 \\
\hline Intravenous drug use & 2 & 0 & 2 & 0 & 2 & 0 \\
\hline
\end{tabular}

Notes: Interpretation of the median values for comparative importance: $1=$ more important than climate change, 2 = less important than climate change

$\operatorname{IQR}^{\mathrm{d}}=$ Interquartile range $=3^{\text {rd }}$ quartile $-1^{\text {st }}$ quartile

The aggregate sample's results show that climate change is seen as a more important driver for infectious disease risk than the following non-climatic drivers: pollution, urban greening, increased organic farming, incidence of chronic diseases, intravenous drug use, and the move towards privatization of the health sector. According to the aggregate sample, most non-climatic drivers are more important than climate change. For the technological domain, all drivers tested are rated as more important than climate change. The results of the aggregate sample show low to very low IQRs, meaning that the experts' opinions vary little. 
The same analysis was done for the two groups "Policy" and "Science". The two sample groups mostly agree in their assessment of the importance of non-climatic drivers compared to climate change. With regards to capacity to detect, prevent, and treat diseases, the group "Policy" sees this as less important than climate change, and the group "Science" as more important than climate change. The same disagreement can be found for incidence of chronic diseases and sexual behaviour. For both sample groups the IQRs are low, pointing towards much agreement amongst expert opinions within each group.

\subsection{Discussion and conclusions}

The results of the survey reveal information on the opinions of the expert sample on the importance, uncertainty, and comparative importance of climatic and non-climatic drivers for infectious disease risk in Western Europe. Moreover, the expert opinions were further explored by conducting all analyses for two sample subgroups "Science" and "Policy".

The aggregate sample and sample group analyses in summary yield several key results. The aggregate sample views all climatic drivers as highly important for all types of infectious disease risk, except for the driver increase in extreme weather events which is rated to have moderate to little importance. For food-related infectious disease risk, the climatic drivers receive relatively lower ratings for importance. For this disease type, the experts might perceive non-climatic drivers of potential importance for explaining foodrelated infectious disease risk. Regarding this, in an open section, one of the respondents remarks that the control on food production, as well as the preservation of food are relevant for food-related disease outcomes, and can prevent the climatic effects. Related research also emphasizes the significance of non-climatic factors such as food safety standards, food handling and storage, and food production and processing for food-borne disease outcomes besides climate change. Non-climatic drivers might even counteract the effects of climatic drivers such as temperature change (Cohen, 2000; Semenza \& Menne, 2009; Wardekker et al., 2012). The aggregate expert sample opinions converge greatly for temperature change, precipitation change, and humidity change, but less so for the climatic driver increase in frequency of extreme weather events. For water-related and vector-borne disease risks, high agreement amongst experts is found. The experts agree less on the importance of the climatic drivers for zoonoses and food-related disease types. The relationships between climate change and zoonoses as well as climate change and food-related infectious diseases are shown to be complex as impacts of climatic and non-climatic developments, such as human behaviour and regulations, act together. More research on the role climate change plays in these disease outcomes is needed (Semenza \& Menne, 2009; Vorou et al., 2007). This lack of knowledge and the remaining uncertainties on these relationships might be an underlying cause for the variations found amongst expert opinions. One respondent also 
confirms this in a comment, stating that many climatic and non-climatic factors impact zoonoses, which makes it difficult to assess the impact of climatic drivers.

The assessment of importance of climatic drivers for infectious disease risk has also been analysed for the two sample groups "Policy" and "Science". The groups show much agreement in their assessments. Most disagreement is found for the importance of frequency of extreme weather events for all disease types. Most agreement between the two groups is found for the importance of climate change-induced habitat change and humidity change. Within each sample group, there is much agreement in assessments for water-related and vector-born infectious disease risks.

Regarding the degree of uncertainty in the future development of each climatic driver, the aggregate sample's assessment shows that temperature change, precipitation change, and increase in frequency of extreme weather events are viewed as moderately uncertain in their future development, and humidity change and climate change-induced habitat change as highly uncertain. Expert's opinions vary little regarding the uncertainty assessments given, based on the IQRs. When looking into the opinions given by the two sample groups, agreement is found for temperature change, precipitation change, and climate change-induced habitat change. More variation amongst the opinions of the group "Policy" can be found in particular for the uncertainty of the future development of temperature change and the increase in frequency of extreme weather events. The group "Science" shows high agreement amongst expert opinions.

An integrative perspective is taken on the relationship between climate change and infectious disease risk, and therefore non-climatic drivers with potential relevance for the causation of infectious disease risk in Western Europe were included for expert assessment as well. It can be seen that the aggregate expert sample assesses many nonclimatic drivers to be highly important, such as land use change, increased movement of goods, and widespread use of antibiotics. Some non-climatic drivers are rated to be moderately important, such as pollution, urban greening, and the incidence of chronic diseases. The related IQRs point towards less agreement amongst expert opinions on the importance of pollution, move towards privatization of health sector, aging population, and incidence of chronic diseases. The analyses of the two sample groups' assessments of importance show overall similar results between the two groups. Key differences between the two groups are found for pollution, sexual behaviour, and intravenous drug use. The IQRs show that within both sample groups high agreement amongst experts exist. The group "Policy" shows relatively more cases of higher variation in their assessment of importance of non-climatic drivers, particularly for some of the socio-cultural drivers.

With regards to the degree of uncertainty in the future development of each nonclimatic driver only microbial evolution is rated to be highly uncertain by the aggregate expert sample. Most non-climatic drivers are rated to be moderately uncertain, such as land use change, pollution, and increased organic farming. In addition, some nonclimatic drivers are seen as having little uncertainty, including all socio-cultural drivers. 
These results might partly be related to differences in the temporal scale of change in a driver, in other words, whether a driver can change relatively fast or slow. Microbial evolution can take place relatively fast possibly giving rise to more perceived uncertainty in its future development due to this dynamism, whereas the socio-cultural drivers assessed such as ageing population, and the incidence of chronic diseases, can only structurally change over a longer period of time, and thus making it arguably easier to predict and anticipate in the nearer future and therefore reducing their perceived uncertainty in future development (Huynen, 2008). The analysis of the two sample groups shows that the two groups differ in their assessments of increased movement of goods, decreased public health care structures, limitation to and reductions in prevention programs, and incidence of chronic diseases. For all technological drivers, the two groups are in agreement. The IQRs show that within the group "Science", relatively high agreement amongst experts can be found. For the group "Policy" generally the IQRs are also low, except for a small number of non-climatic drivers including a significant amount of sociocultural drivers.

Lastly, the aggregate expert sample analyses reveal that a large part of the non-climatic drivers are seen as more important than climate change as a driver for infectious disease risk. The non-climatic drivers that are found to be less important than climate change are: pollution, urban greening, increased organic farming, incidence of chronic diseases, intravenous drug use, and move towards privatization of health sector. Within the aggregate sample, experts have high agreement on this assessment. The analysis of the two sample groups "Science" and "Policy" shows high agreement within and between groups. Most disagreement is found once again for socio-cultural drivers. In addition, in this context it should be noted that the comparative importance of non-climatic and climatic drivers might vary when focusing on shorter or longer temporal scales, which is also noted by one of the respondents in a related open section. The question of the relative importance of climate change for infectious diseases and broader health outcomes in comparison to other drivers is often raised (McMichael et al., 2006; J. A. Patz et al., 2005). The results give an indication of how this relative importance between climatic and non-climatic drivers is viewed by the expert sample and the sample groups "Science" and "Policy".

The results of the survey should be seen as an indication of the perspectives of Dutch experts on the importance and uncertainty of climatic and non-climatic drivers for infectious disease risk in Western Europe, based on the Dutch expert sample that participated in this study. The inherent complexity of the relationship between climate change and infectious disease outcomes makes analysis difficult and as a result research gaps remain (McMichael et al., 2006; Semenza \& Menne, 2009). For the investigation of issues of greater complexity and uncertainty such as climate change impacts on infectious diseases, the involvement of experts for the exploration of their perspectives can be a useful approach to gain more insights into this complexity and discover underlying values. This approach is not only deemed constructive because of this complex nature of 
climate change and other environmental problems, but also in relation to policy in this area (de Ridder et al., 2007; Kloprogge \& van der Sluijs, 2006). For the interpretation of the results of this study it should be noted that a Dutch expert sample has been surveyed. It would be interesting to conduct similar studies involving experts from other countries in order to compare and contrast potentially prevailing perspectives on climate change and infectious disease risk in Western Europe. Another issue that should be considered for the interpretation of results is the focus on Western Europe, as disease outcomes from climate change vary across geographical locations.

The analyses of expert opinions of the two sample groups "Science" and "Policy" can point towards possible differing perspectives held in the two professional environments regarding certain drivers and/or their uncertainty and importance for infectious disease risk. The differences found between the two sample groups could be due to diversity in underlying values within each professional environment. Such a difference between experts' views from the policy or academic field is also suggested in a study analysing expert opinions on climate change (Nordhaus, 1994). Further exploration of expert opinions on climate change and infectious disease risk and comparisons across professional backgrounds would be necessary in order to shed more light on possible differences and identify prevailing perspectives on this topic. In addition, the influence of other issues on the diversity of opinions should be considered, such as potential existing information asymmetries between scientific and policy communities.

Differences in opinions found between sample groups and within the aggregate sample and each sample group, can have practical implications. The findings can point towards a lack of consensus with regards to the importance or uncertainty of some of the drivers of infectious disease risk in Western Europe. Differences in expert views can play out in decision-making and policy contexts with regards to climate change and infectious disease risk. Awareness and recognition of the diversity of values creating the variety in expert opinions as well as potential other issues of influence such as information asymmetries can facilitate decision- and policy-making processes for the governance of climate change-induced infectious disease risk. Policy and societal responses to climate change-induced infectious disease risk which accommodate the different perspectives of a broad range of stakeholders could benefit from greater support and robustness. 


\section{CHAPTER 5}

CLIMATE CHANGE AND INFECTIOUS DISEASE RISK IN WESTERN EUROPE: A SURVEY OF DUTCH EXPERT OPINION ON ADAPTATION RESPONSES AND ACTORS 


\section{Abstract}

There is growing evidence of climate change affecting infectious disease risk in Western Europe. The call for effective adaptation to this challenge becomes increasingly stronger. This paper presents the results of a survey exploring Dutch expert perspectives on adaptation responses to climate change impacts on infectious disease risk in Western Europe. Additionally, the survey explores the expert sample's prioritization of mitigation and adaptation, and experts' views on the willingness and capacity of relevant actors to respond to climate change. An integrated view on the causation of infectious disease risk is employed, including multiple (climatic and non-climatic) factors. The results show that the experts consider some adaptation responses as relatively more cost-effective, like fostering interagency and community partnerships, or beneficial to health, such as outbreak investigation and response. Expert opinions converge and diverge for different adaptation responses. Regarding the prioritization of mitigation and adaptation responses expert perspectives converge towards a 50/50 budgetary allocation. The experts consider the national government/health authority as the most capable actor to respond to climate change-induced infectious disease risk. Divergence and consensus among expert opinions can influence adaptation policy processes. Further research is necessary to uncover prevailing expert perspectives and their roots, and compare these.

Published as: Akin, S., Martens, P., \& Huynen, M. (2015). Climate change and infectious disease risk in Western Europe: A survey of Dutch expert opinion on adaptation responses and actors. International Journal of Environmental Research and Public Health, Special Issue Cumulative and Integrated Health Impact Assessment, 12(8), p. 9726-9749, doi: 10.3390/ijerph120809726. 


\subsection{Introduction}

Warming in the climate system is unequivocal and human influence on the climate system is clear (IPCC, 2013). Climate change is impacting all areas of life, including human health. Also, within a European context, climate change will have impacts in nearly all sectors and all regions. In addition, the health effects of global warming are increasingly evident (EEA, 2012; Kovats et al., 2014; Menne et al., 2008; Semenza \& Menne, 2009; WHO-Europe, 2010a). Among the anticipated health impacts, climate change-induced infectious disease risks pose a significant (future) health as well as social and economic burden on Europe (EEA, 2012; WHO-Europe, n.d.). The prospect of even further global warming (IPCC, 2013) only increases concerns for these potential impacts. Climate change can bring about changes in the distribution and transmission of communicable diseases and, related to this, the number of disease cases by influencing e.g., the disease pathogen directly, the suitability of environments, or human behaviours leading to exposure (ECDC, 2005-2009; EEA, 2012; Menne et al., 2008; Semenza \& Menne, 2009). Tickborne encephalitis, leishmaniasis, and salmonellosis, are for example relevant for Europe in this context of climate change impacts (EEA, 2012; Semenza \& Menne, 2009).

Climate change and the related health impacts pose a great challenge on our societies, and are therefore gaining increasing scientific and policy attention (EC, 2007a, 2009a, 2010a, 2013a; Martens et al., 2012; Wardekker et al., 2012; WHO-Europe, 2010c). Subsequently, the call for adequate (policy) responses to address this challenge is becoming increasingly stronger, as illustrated by, for example, the European Commission White Paper "Adapting to climate change: Towards a European framework of action"; the "Declaration of the European Commission Fifth Ministerial Conference on Environment and Health", and the recent European Commission Staff Working Document "Adaptation to climate change impacts on human, animal and plant health" (EC, 2009a, 2010a, 2013a; WHO-Europe, 2010c). Some of the observed and anticipated (health) effects from climate change in Europe (e.g., increased mortality due to high temperature extremes) have initiated the development and implementation of adaptation strategies (Kovats et al., 2014). The (future) health risks and vulnerabilities arising from climate change, in interaction with other non-climatic drivers, can be reduced by adaptation responses. Current adaptation efforts should be improved and extended to reach this potential of risk reduction to its fullest. More understanding and research regarding responses and their effectiveness and health implications is necessary (EC, 2009a, 2013a; Menne et al., 2008; Smith et al., 2014).

It is clear that a more effective (policy) response and an overall strengthening of health systems in Europe are needed to address climate change and the resulting health impacts (EC, 2009a, 2013a; Menne et al., 2008). A broad range of necessary aspects of such a response are discussed and put forward in related studies and literature, such as climate-sensitive surveillance and monitoring systems; outbreak investigation, response, and control; raising awareness and education of policy-makers, health professionals and 
public; information and communication systems for awareness raising; emergency preparedness and planning; research; access to health care and preventive measures; and cooperation and partnerships (see e.g., EEA (2012); Kovats et al. (2014); MEA (2005b); Menne et al. (2008); Semenza \& Menne (2009); WHO-Europe (2010a)).

In this study, conducted as a part of the ERA-ENVHEALTH ENHanCE research project, the perspectives of Dutch experts on such responses to climate change-induced infectious disease risk in Western Europe are explored. Moreover, experts' views on the willingness and capacity of potentially relevant actors in this response effort as well as the priorities placed on mitigation and adaptation responses are examined (see Mclntyre et al. (2010)). The study has been conducted as a part of a participatory integrated assessment where the involvement of stakeholders (in this case, experts) is a way to address complexities and uncertainties that are common to environmental and specifically climate change problems (de Ridder et al., 2007; Kloprogge \& van der Sluijs, 2006). The study, therefore, makes use of a stakeholder analysis for the identification and selection of the Dutch expert sample. For the analysis, an integrated view on the causality of infectious disease risk is taken on by including multiple climatic as well as non-climatic factors as drivers (see Akin and Martens (2014)). Based on this study, other results on Dutch expert opinion on climatic and non-climatic drivers of infectious disease risk in Western Europe have also been published (see Akin and Martens (2014)).

\subsection{Methodology}

This study was conducted to gain an insight into Dutch expert views on responses to climate change-induced infectious disease risk in Western Europe. A qualitative survey was used to uncover existing perspectives (and the possible diversity among them) in the Netherlands, by targeting a Dutch expert sample. In preparation for this, a stakeholder analysis was done to sample Dutch experts. The obtained data were analysed descriptively. (For the methodology of this study, also see Akin and Martens (2014), where the survey results on climatic and non-climatic drivers of infectious disease risk are presented.)

\subsubsection{Stakeholder analysis and sampling}

A stakeholder analysis was done to identify experts for the selection of potential respondents for the survey used in this study (Prell et al., 2013; Reed et al., 2009). A broad definition of stakeholders was assumed for this analysis: individuals and organisations that are likely to be affected by or can influence climate change and related health impacts; the latter e.g., through the implementation of adaptation measures (Allen \& Kilvington, 2003; Davie et al., 2006; Freeman \& McVea, 2001; Reed et al., 2009). The analysis was restricted to the Netherlands, being a priority research focus of the ERA- 
ENVHEALTH ENHanCE research project. The stakeholder analysis aimed to map out Dutch stakeholders in relation to the topic of climate change and infectious disease risk in Western Europe; to create a useful inventory for the potential participants for the participatory elements in the broader research setup of the project; and to facilitate the collection of expert knowledge and perspectives on climate change and health impacts. This approach to a stakeholder analysis can be characterized as descriptive and instrumental (Reed et al., 2009).

The stakeholder analysis yielded a stakeholder matrix storing detailed information for each stakeholder, such as the stakeholder's expertise and professional background. Based on the stakeholder matrix an expert sample of respondents for the survey could be selected. The guiding criterion for selecting a sample of experts from the stakeholder matrix was that the individuals possess expertise relevant for the survey's topic and scope; i.e. expertise on climate change/environment, and health/infectious diseases. Information on the expertise of each stakeholder was documented in the stakeholder matrix and could therefore be retrieved for the purpose of sampling. Since a guiding criterion was used as a base for sampling selection, this sampling method can be called judgment sampling, a non-probabilistic sampling method (Cooper \& Schindler, 2003; Garson, 2012). From the stakeholder matrix a sample of 56 experts on climate change/environment, and health/infectious diseases could be drawn. Based on the information collected about each stakeholder's professional background, the expert sample included mostly scientists and policy advisors. The survey was conducted in 2012 and yielded a useful response of 29 (out of the 56 experts who were approached as respondents for the survey) ${ }^{16}$.

The survey included a section where respondents could indicate their professional background, using predefined categories with the possibility of adding additional categories in an open section. This data was used to divide the sample into groups. This was done to explore potential differences and similarities in opinions of experts with different professional backgrounds in the analysis. The sample groups were formed in the following manner: first, all respondents who indicated a professional background in policy were placed in one sample group labelled "Policy" and thereafter removed from the full list of respondents. After that, the respondents who indicated a professional background in science were included in another sample group labelled "Science"; finally, the remaining three respondents were added to the group "Policy" as the indicated professional backgrounds seemed to allow for such a compilation. This process resulted in two sample subgroups: "Policy" consisting of 12 experts, and "Science" consisting of 17 experts. As explained earlier, based on information collected in the stakeholder matrix on the professional backgrounds of the selected sample, the sample could be characterized as

\footnotetext{
${ }^{16} 33$ respondents, out of the sample of 56 experts that were invited to participate, started the survey, but 4 of the 33 surveys were returned incomplete, and therefore had to be removed prior to analysis which resulted in a useful response of 29.
} 
comprising scientists and policy advisors. The self-indicated professional backgrounds of the respondents leading to the formation of the sample subgroups confirms the initial characterization made of the composition of the selected sample. In this respect, the sample subgroups also seem to be a sensible division of the aggregate sample.

Additional information on the stakeholder analysis and sample can be found in Appendix 1.

\subsubsection{Survey design}

This study aimed to have experts assess responses to climate change-induced infectious disease risk in Western Europe, and the capacity and willingness of potentially relevant actors in this context. A survey was used to accomplish this as this is a suitable and efficient method for a qualitative assessment based on expert opinions and perceptions (Cooper \& Schindler, 2003). The survey design included closed questions, mostly in a Likert-scale format, and optional open questions. Each closed question provided a possibility to leave it open ("no opinion/do not know") and to add more items that could then be assessed as well. All definitions could be viewed by the respondents at all times during the survey process. The survey was administered online and generated descriptive information, nominal, ordinal and some ratio/interval data.

Using a survey method involves several common limitations, which were taken into account during the design and implementation phases of this study. For instance, the risk of misunderstanding of wording (Cooper \& Schindler, 2003) was reduced by using vocabulary familiar to experts and making definitions available at all times during the survey process. Research design measures, such as using an expert sample and offering a "no opinion/don't know" option, could help to safeguard the quality of responses, which can be another potential risk of survey methods.

\subsubsection{Survey content}

The survey content was structured in the following manner: the assessment of

a) Adaptation responses to climate change-induced infectious disease risk in Western Europe;

b) The priorities under budgetary constraints for mitigation or adaptation responses to climate change-induced infectious disease risk; and

c) The willingness and the capacity of potentially relevant actors to respond to climate change-induced infectious disease risk.

In part a) of the survey, experts assessed adaptation responses to climate changeinduced infectious disease risk in Western Europe, using pre-defined policy assessment criteria. Based on descriptive research and background literature, possible and mostrelevant adaptation responses to climate change impacts on infectious disease risk could 
be selected (MEA, 2005b; Semenza \& Menne, 2009). The responses assessed in the survey are also acknowledged (in the same or a similar form) in relevant European policy documents (EC, 2009a, 2010a, 2013a; WHO-Europe, 2010d). In Table 5.1 an overview of the responses used in the survey is given.

Table 5.1 Descriptions/definitions of the responses to climate change-induced infectious disease risk, used in the survey

\begin{tabular}{|c|c|}
\hline Response & Description \\
\hline Monitoring & $\begin{array}{l}\text { Includes both indicator-based surveillance and event-based } \\
\text { epidemic intelligence. Indicator-based surveillance refers to } \\
\text { data collection, (trend) analysis, and interpretation of data. } \\
\text { Indicator-based surveillance is conducted based on data } \\
\text { from infectious disease notifications at the European Union } \\
\text { level, pharmacy-based monitoring, sentinel surveillance, } \\
\text { vector distribution monitoring, real-time surveillance, moni- } \\
\text { toring cause-specific deaths from infectious diseases, and } \\
\text { syndrome surveillance. Event-based epidemic intelligence } \\
\text { refers to the early identification of climatic change-induced } \\
\text { infectious disease threats, through screening of news media, } \\
\text { scientific reports, clinical case reports, and interdisciplinary } \\
\text { reporting (such as from related industrial sectors) (Semenza } \\
\text { \& Menne, 2009). }\end{array}$ \\
\hline
\end{tabular}

Outbreak investigation and response

Dissemination of information, and health education

Foster interagency and community partnerships

Enforce laws and regulations

Access to health care, and prevention

Strengthen capacity of public health work-
The diagnosis and investigation of new/emerging infectious diseases, as well as responding effectively to (potential) outbreaks involving the cooperation of multiple sectors. For effective response adequate supplies (such as medication and vaccinations) and distributive infrastructures are required and thus need to be included in this sort of policy option (Semenza \& Menne, 2009).

The communication of information, health education and health promotion; all relating specifically to human (risk) behaviour in the context of work, recreational activities, food handling, but also personal preventive measures for vector control and minimisation of exposure (Semenza \& Menne, 2009).

Fostering interagency and community partnerships, thus establishing partnerships between stakeholders across different sectors, disciplines, and levels (e.g., local community, municipality, national) (Semenza \& Menne, 2009).

Enforcing laws and regulations regarding reporting climate change-induced health events, setting up and enforcing conventions relating to e.g., water resources and sanitation, and regulation to e.g., minimise harmful exposures (Semenza \& Menne, 2009).

Providing access to health services, prevention of outbreak propagation through treatment of infected patients, and prevention (such as vaccination, prophylaxis, travel medicine) (Semenza \& Menne, 2009).

Strengthening of the capacity (in terms of quality and quan- 
force and implement emergency preparedness training

Research

Environmental management/modification

Direct control methods tity) of public workforce for instance through training focused on diagnosis of specific infectious diseases. In addition, this policy option includes the implementation of emergency preparedness training (Semenza \& Menne, 2009).

Fostering research focused on the relationship between infectious diseases and climate change, risk mapping of climate sensitive vectors and pathogens, development of diagnostic tests and vaccines, burden-of-disease studies, and climate as well as policy scenarios, amongst other related research activities (Semenza \& Menne, 2009).

The practice of using environmental management to reduce the capacity of local habitats to maintain pathogens and/or populations of disease vectors (e.g., reducing reservoir host abundance, removing larval breeding sites), thus resulting in a decrease of spread of a disease to humans/animals (MEA, 2005b).

The use of chemical or biological control methods in order to reduce pathogen or vector abundance. Chemical control methods consist of, for example, the use of insecticides or water treatment chemicals. Biological control methods consist of the utilisation of biological toxins and natural enemies include e.g. bacteria and larvivorous fish (MEA, 2005b).

In order for experts to assess the selected responses, eight policy assessment criteria were defined, partly based on a previous relevant study by the World Health Organization (WHO-Europe, 2010b). These criteria are given in Table 5.2. In the survey, therefore, each response was assessed using all eight assessment criteria. 


\begin{tabular}{|c|c|}
\hline Assessment criterion & Description \\
\hline Potential health gain & $\begin{array}{l}\text { The "potential magnitude of the health gain" of the policy option (WHO- } \\
\text { Europe, 2010b) (p.23). }\end{array}$ \\
\hline $\begin{array}{l}\text { Uncertainty of potential health } \\
\text { gain }\end{array}$ & $\begin{array}{l}\text { The extent to which the potential health impact (i.e. gain) of the policy } \\
\text { option is uncertain. Uncertainty refers to the predictability of the health } \\
\text { outcomes that can result from the policy option (WHO-Europe, 2010b). }\end{array}$ \\
\hline Monetary costs & $\begin{array}{l}\text { Direct and indirect monetary costs of the policy option (WHO-Europe, } \\
2010 b \text { ). }\end{array}$ \\
\hline Non-monetary costs & $\begin{array}{l}\text { The potential (non-monetary) imposition on the health system and society } \\
\text { at large that this policy option can create }\end{array}$ \\
\hline Positive spill-over effects & $\begin{array}{l}\text { The potential that this policy option can bring about positive side-effects } \\
\text { for other policy areas, sectors, and/or for society }\end{array}$ \\
\hline Flexibility & $\begin{array}{l}\text { The degree of ease for modification of the policy option should this be- } \\
\text { come necessary in the future (WHO-Europe, 2010b). }\end{array}$ \\
\hline Urgency of implementation & $\begin{array}{l}\text { The rapidity at which the policy option needs to be implemented for it to } \\
\text { still have an effect, and if it is not to run into any implementation barriers } \\
\text { (WHO-Europe, 2010b). }\end{array}$ \\
\hline $\begin{array}{l}\text { Regret if climate change does } \\
\text { not turn out as expected }\end{array}$ & $\begin{array}{l}\text { The extent that the policy option will still be effective in terms of health } \\
\text { gain if climate change trends turn out differently than expected (WHO- } \\
\text { Europe, 2010b). }\end{array}$ \\
\hline
\end{tabular}

In part b) of the survey the priorities placed by the expert sample on mitigation and adaptation measures as part of an overall response strategy were assessed. Responses to climate change impacts can be broadly grouped into the two categories adaptation or mitigation measures. For the purpose of the survey the following definitions were assumed: Mitigation responses are measures to reduce greenhouse gas emissions and enhance sinks in order to mitigate anthropogenic climate change; and adaptation responses are initiatives and measures to reduce climate change-induced infectious disease risk (IPCC, 2007).

Finally, in part c), the survey aimed to obtain expert views on the willingness and the capacity of potentially relevant actors to respond to climate change-induced infectious disease risk. For this, the following actor categories were formulated: national government/health authority; local health authority; policy-advice, policy-maker; NGO, advocacy, funders, charity; science; health care provider/health practitioner; veterinary profession; pharmaceutical industry; farmer union; food supply sector; environmental management, conservation; trade and tourism sector; other business/private sector actors (ENHanCE Research Project, see (ENHanCE)).

\subsubsection{Survey analysis}

The resulting survey data were analyzed using descriptive statistics. The statistics performed are appropriate for the ordinal data obtained from Likert-scale questions. Thus, for the analysis of central tendency and variability median, mode, range, and inter- 
quartile range were used. For the ratio data obtained from part c) of the survey, the median and standard deviation were used for the analysis of central tendency and variability (see e.g., Cooper and Schindler (2003)).

Moreover, the smaller sample size and non-probabilistic sampling method were taken into account for the analysis. Uncompleted surveys were excluded from the analysis. For the analysis, the "no opinion/do not know" responses were assumed to be distributed proportionally amongst the respondents, and therefore were excluded in order to circumvent an inflation of the actual resulting responses (Cooper \& Schindler, 2003).

In order to explore the experts' opinions according to the experts' self-indicated professional background, all descriptive analyses were done for the aggregate sample as well as for the two sample groups "Policy" and "Science", described earlier.

\subsection{Results}

In this section the results of the survey are presented in the form of descriptive statistics, following the structure of the survey, part a), b), and c), as explained earlier in the methodology.

\subsubsection{Expert assessment of the responses to climate change-induced infectious disease risk}

Through analysis of the survey data, the expert sample's assessment of the adaptation responses to climate change-induced infectious disease risk in Western Europe (defined in Table 5.1), making use of the predefined eight assessment criteria (defined in Table 5.2 ), could be obtained. The results of the aggregate sample analysis are presented first in Figure $5.1 \mathrm{a}-\mathrm{j}$, and thereafter of the two sample groups "Policy" and "Science" in Figure $5.2 \mathrm{a}-\mathrm{t}$.

Figure 5.1 a-j shows the results of the aggregate expert sample's assessment of the adaptation responses using the eight criteria. 


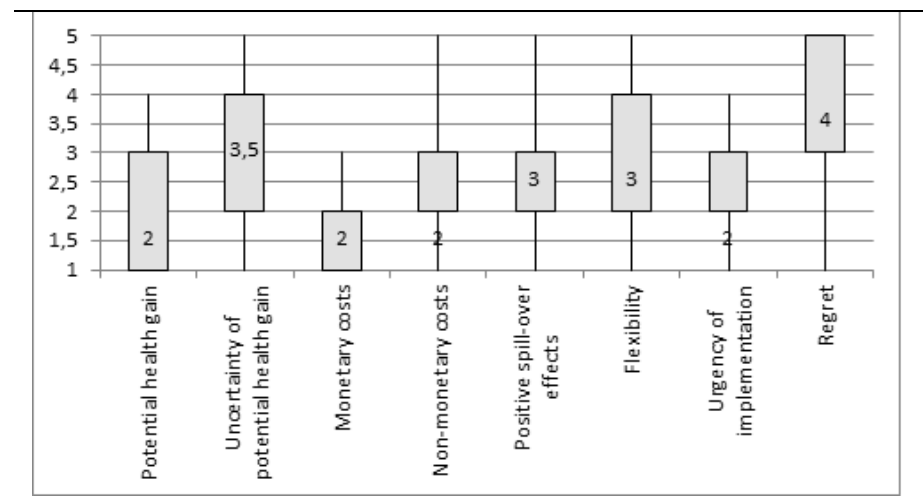

a. Monitoring

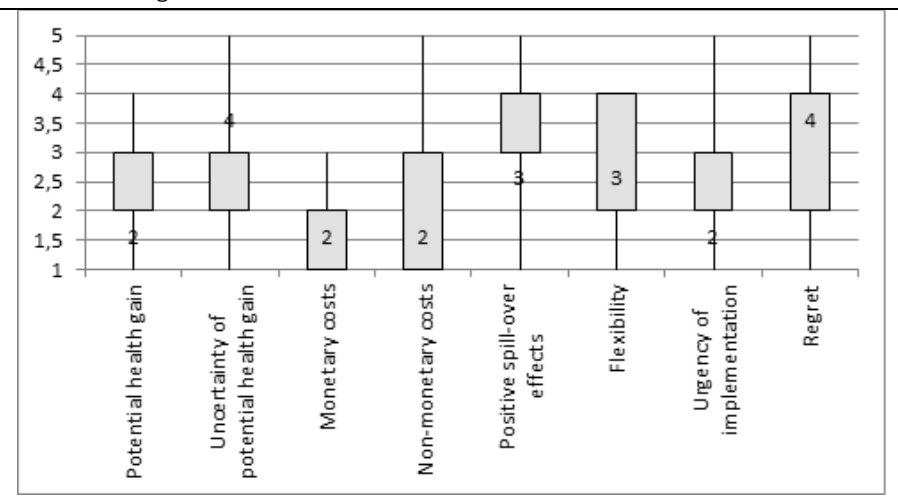

b. Outbreak investigation and response

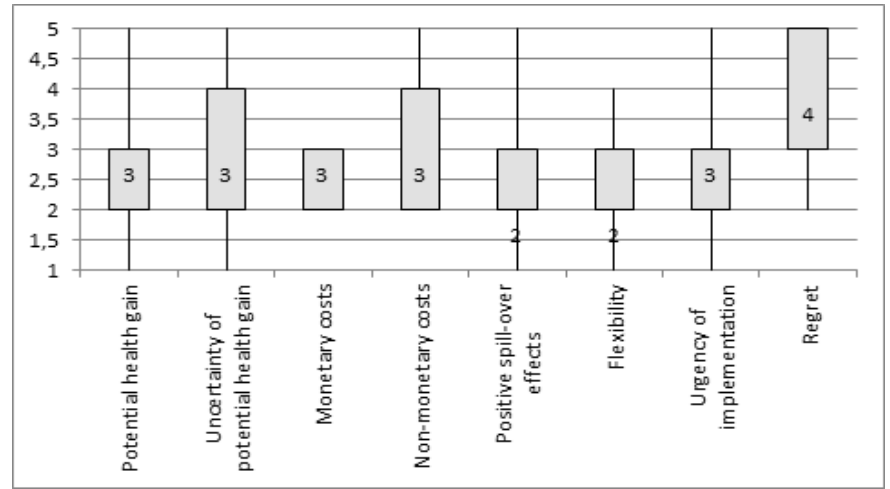

c. Dissemination of information, and health education 


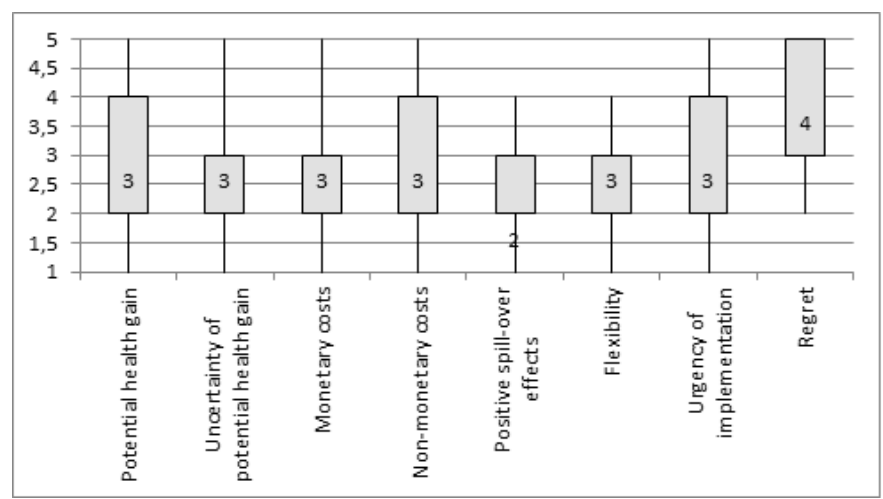

d. Foster interagency and community partnerships

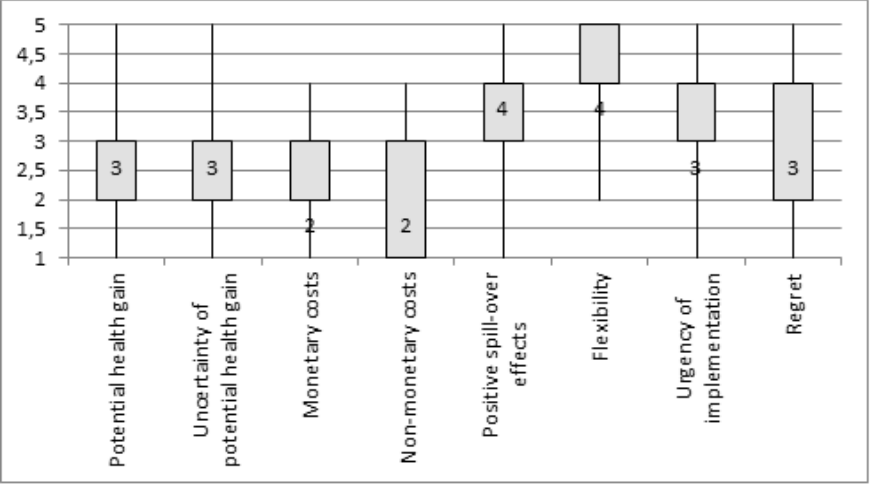

e. Enforce laws and regulations

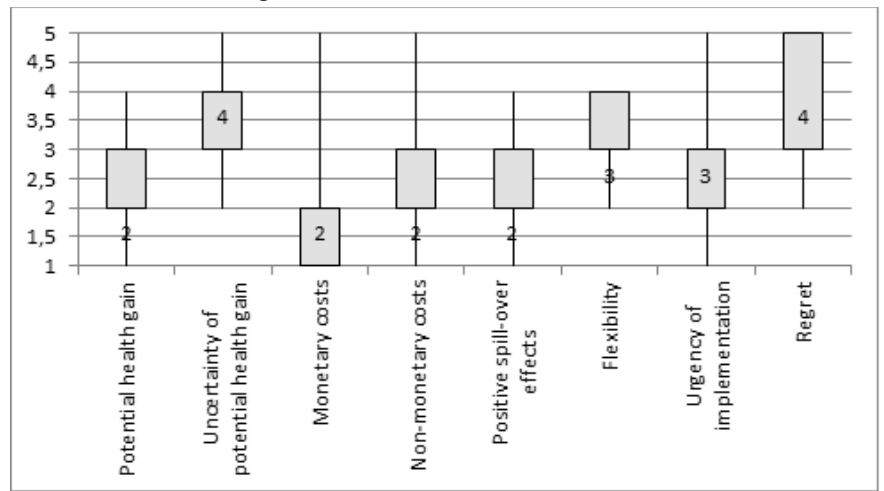

f. Access to health care, and prevention 


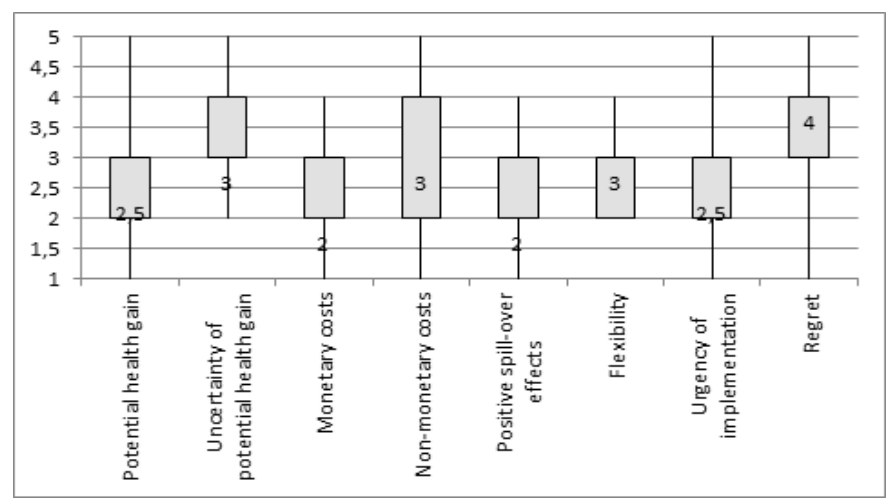

g. Strengthen capacity of public health workforce and implement emergency preparedness training

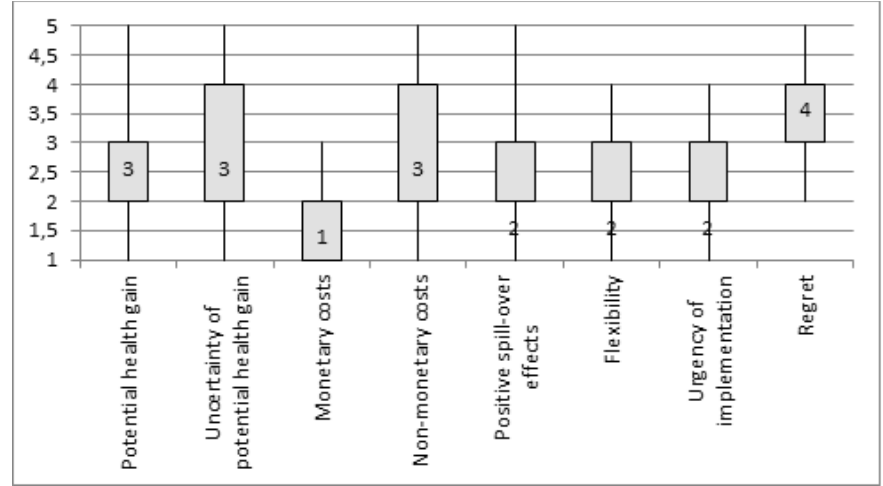

h. Research

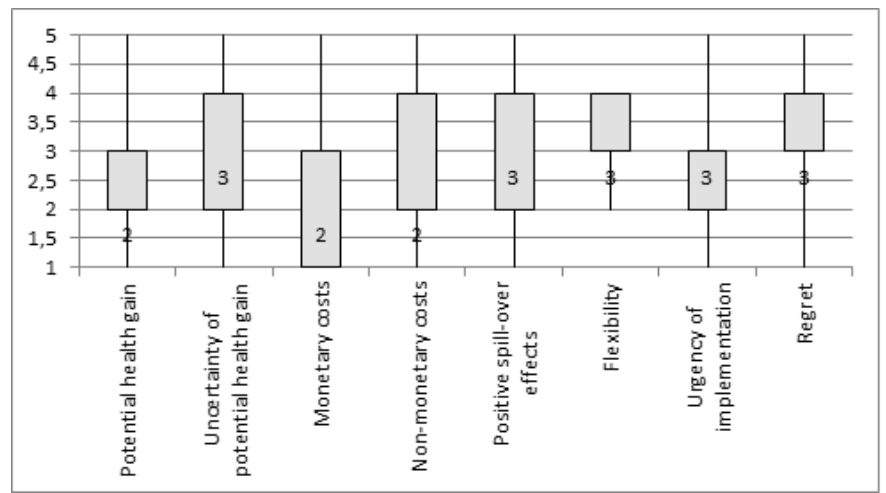

i. Environmental management 


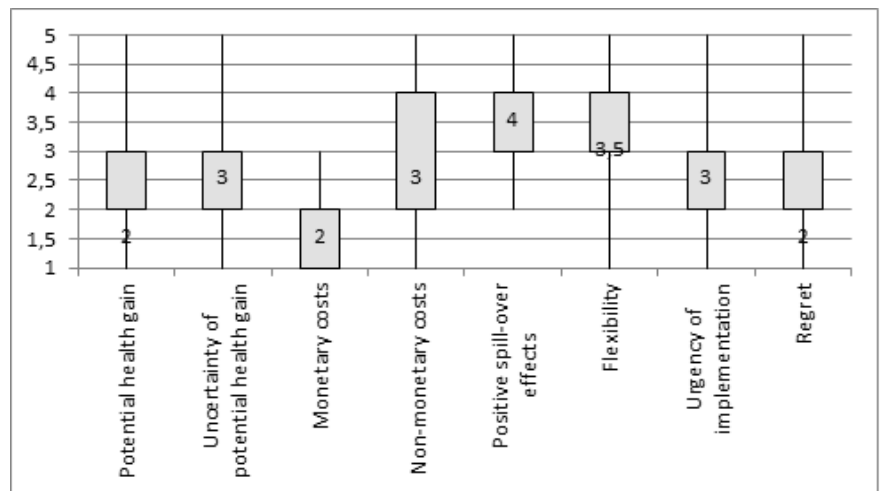

j. Direct control methods

Figure 5.1 a-j Box plots of the aggregate expert sample assessment of the responses to climate change-induced infectious disease risk in Western Europe, using the eight assessment criteria Notes: Medians are given as numbers in the box plots

Range $=$ maximum value - minimum value Interquartile range $(I Q R)=3^{\text {rd }}$ quartile $-1^{\text {st }}$ quartile $=$ length of box Interpretation of median values for each assessment criterion: Potential health gain: 1=very high [high, moderate, low] 5=very low Uncertainty of potential health gain: $1=$ very high uncertainty [high, moderate, little] $5=$ virtually certain

Monetary costs: $1=$ high costs [moderate costs, low costs, no or negligible costs] $5=$ net benefits Non-monetary costs: 1=high costs [moderate costs, low costs, no or negligible costs] $5=$ net benefits Positive spill-over effects: 1=very high [high, moderate, low] 5=very low to none Flexibility: 1=very high flexibility [high, moderate, low] 5=no flexibility Urgency of implementation: 1= very high urgency [high, moderate, little] 5=no urgency Regret if climate change does not turn out as expected: 1=very high potential regret if climate change does not turn out as expected [high, moderate, little] $5=$ no regret if climate change does not turn out as expected

Several notable results can be gathered from the box plots in Figure $5.1 \mathrm{a}-\mathrm{j}$. The following responses are rated by the aggregate sample as having high potential health gains: "monitoring", "outbreak investigation and response", "access to health care and prevention", "environmental management", and finally "direct control methods". However, only for "outbreak investigation and response" and "access to health care and prevention", there is little uncertainty of this potential health gain according to the expert sample. For "monitoring", "environmental management", and "direct control methods", the IQRs for the uncertainty of the potential health gain are relatively high, indicating that the responses of the aggregate sample vary.

A number of responses are believed by the experts to involve low costs. "Dissemination of information and health education" and "foster interagency and community partnerships" have low monetary and non-monetary costs according to the experts. For "strengthen capacity of public health workforce and implement emergency preparedness training" and "direct control methods" low non-monetary costs are found. The 
experts view "research" as having high monetary costs, but low non-monetary costs. The IQRs are relatively high in most instances for non-monetary costs, indicating that there is quite some variance in the responses of the experts on this criterion.

For "dissemination of information and health education", "foster interagency and community partnerships", "access to health care and prevention", "strengthen capacity of public health workforce and implement emergency preparedness training" and "research" the positive spill-over effects are seen by the expert sample as high. Positive spill-over effects are rated as low for "direct control methods" and "enforce laws and regulations". Generally, the IQRs for the results on positive spill-over effects are relatively low, indicating less variability amongst the responses of the expert sample on this criterion. One exception is "environmental management", where the IQR and thus the variation in the answers for positive spill-over effects are relatively high.

With regards to flexibility, the results show that "dissemination of information and health education" and "research" are seen as highly flexible, but "enforce laws and regulations" has low flexibility. "Monitoring", "outbreak investigation and response", and "research" are rated as highly urgent by the expert sample. Finally, when taking a look at the results for regret if climate change does not turn out as expected, the expert sample assesses all responses to have little regret, except for "environmental management" and "direct control methods", where the latter is even seen as having high regret. It should be noted that the IQRs for regret are relatively high for the majority of the responses, which indicates that the aggregate sample's answers vary for regret.

The same analysis was done for the two sample groups "Policy" and "Science". Figure 5.2 a-t shows the assessment of adaptation responses to climate change-induced infectious disease risk in Western Europe using the eight assessment criteria, according to the sample groups "Policy" and "Science".

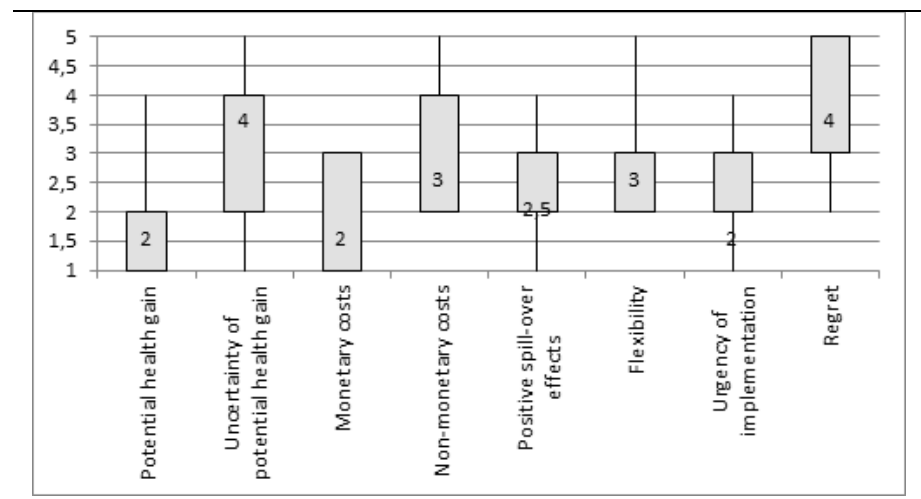

a. Monitoring, sample group "Policy" 


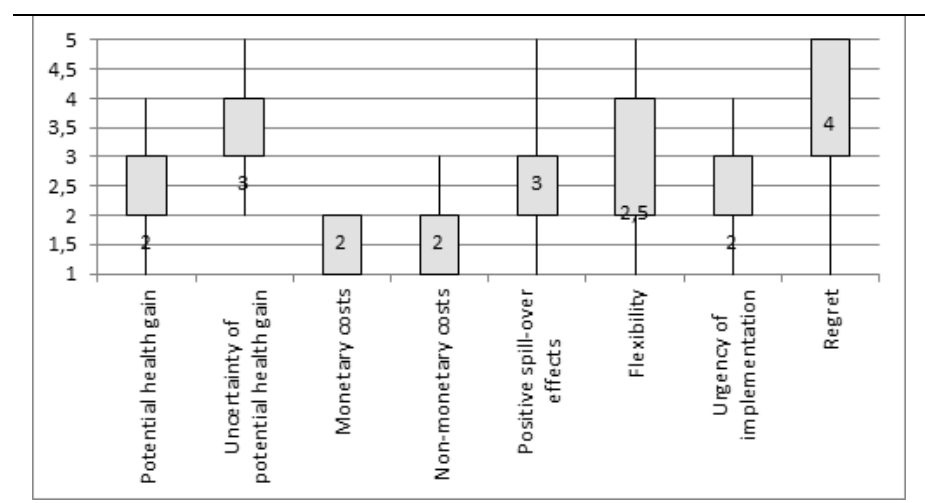

b. Monitoring, sample group "Science"

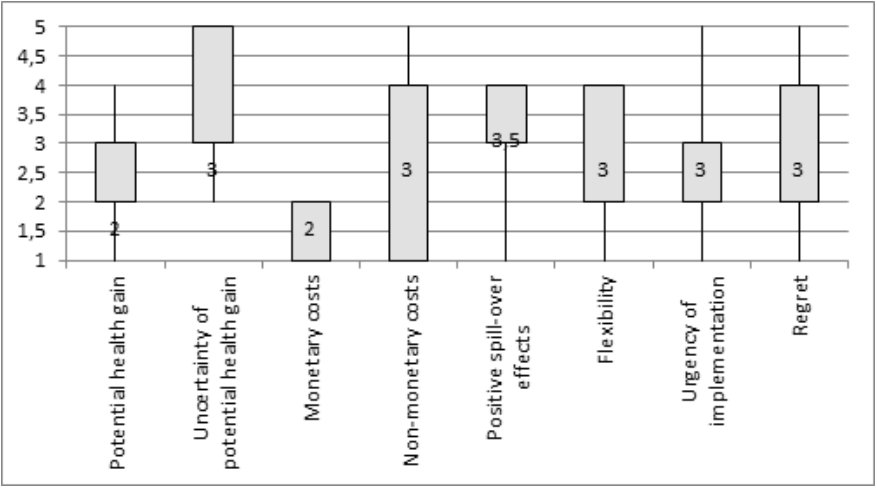

c. Outbreak investigation and response, sample group "Policy"

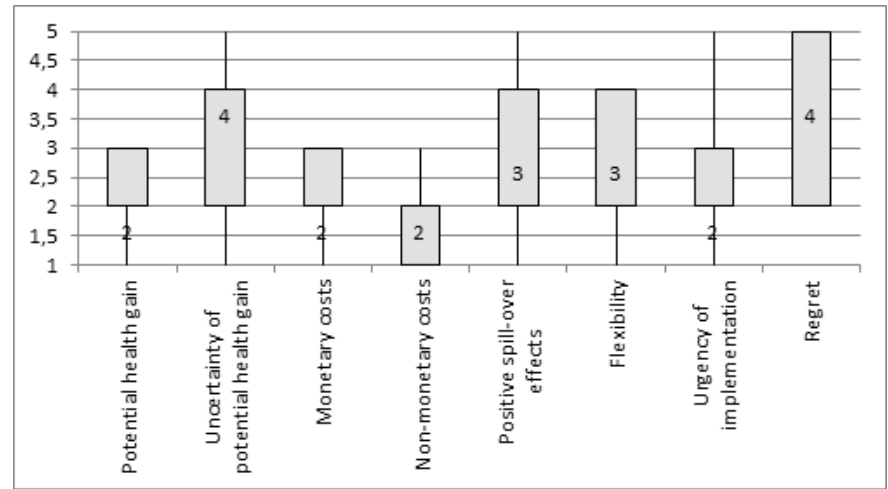

d. Outbreak investigation and response, sample group "Science" 


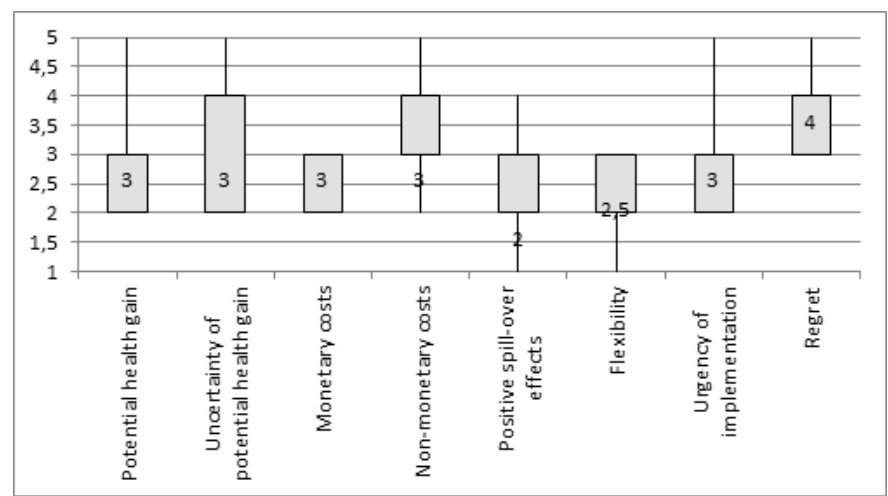

e. Dissemination of information, and health education, sample group "Policy"

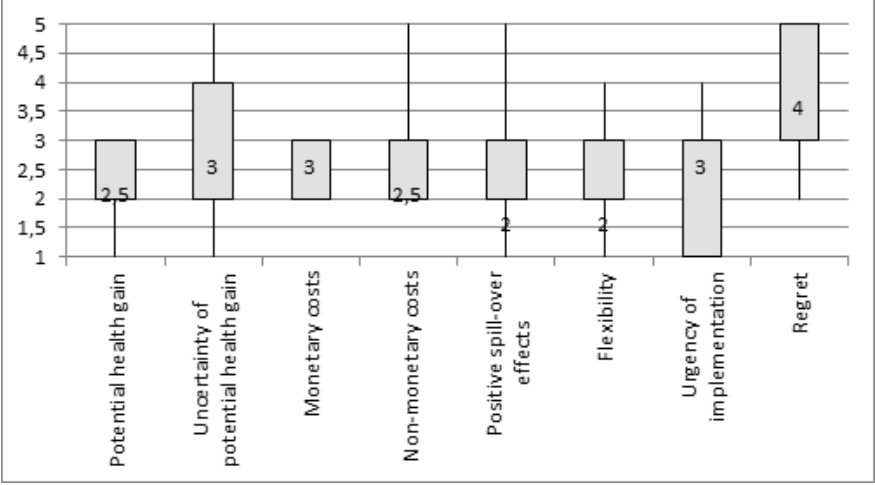

f. Dissemination of information, and health education, sample group "Science"

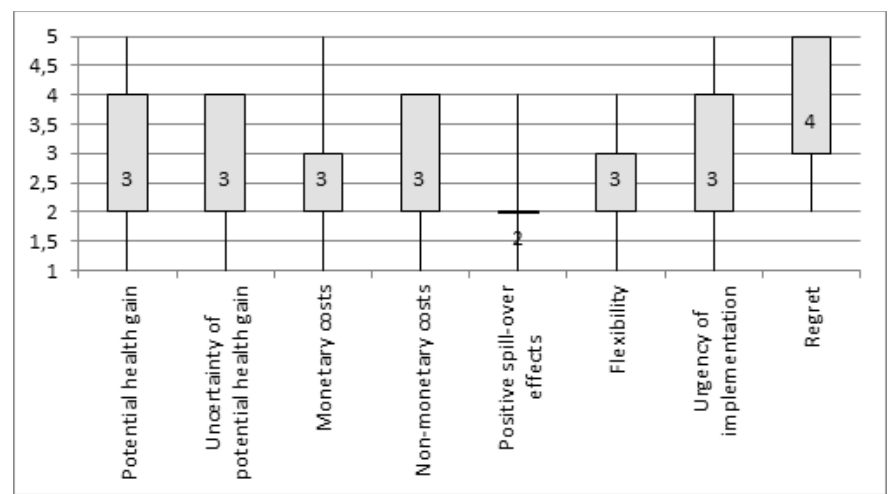

g. Foster interagency and community partnerships, sample group "Policy" 


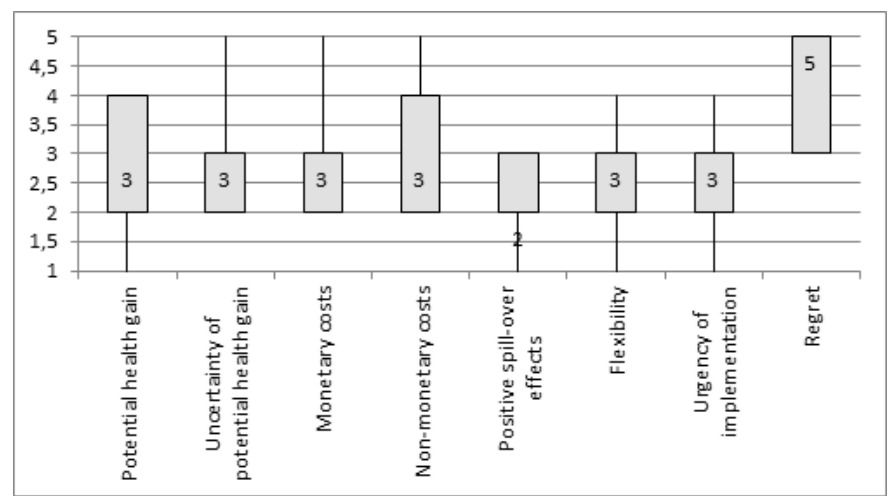

h. Foster interagency and community partnerships, sample group "Science"

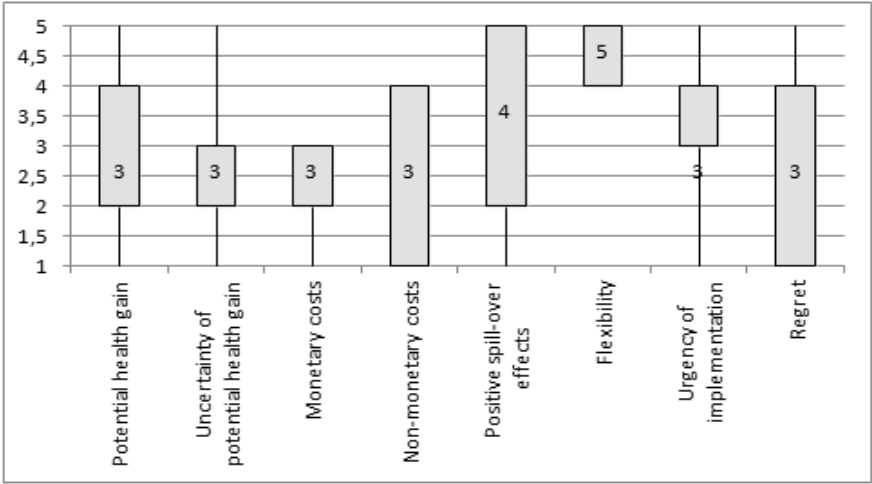

i. Enforce laws and regulations, sample group "Policy"

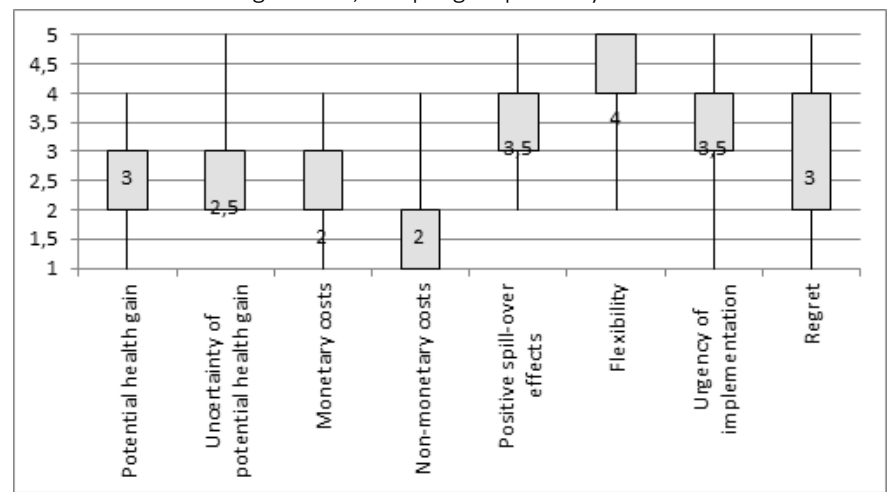

j. Enforce laws and regulations, sample group "Science" 


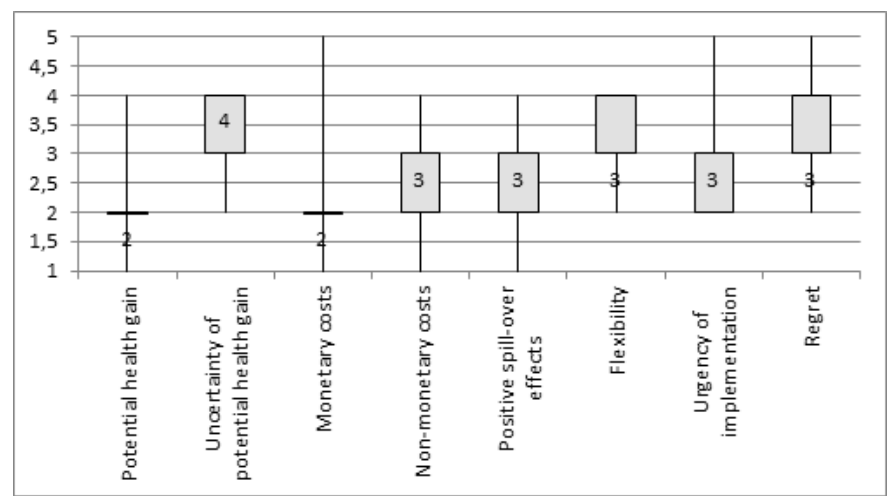

k. Access to health care, and prevention, sample group "Policy"

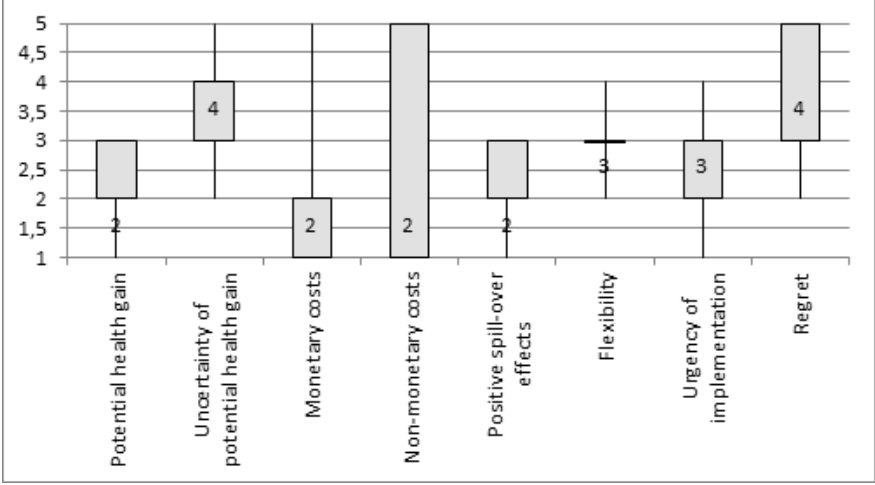

I. Access to health care, and prevention, sample group "Science"

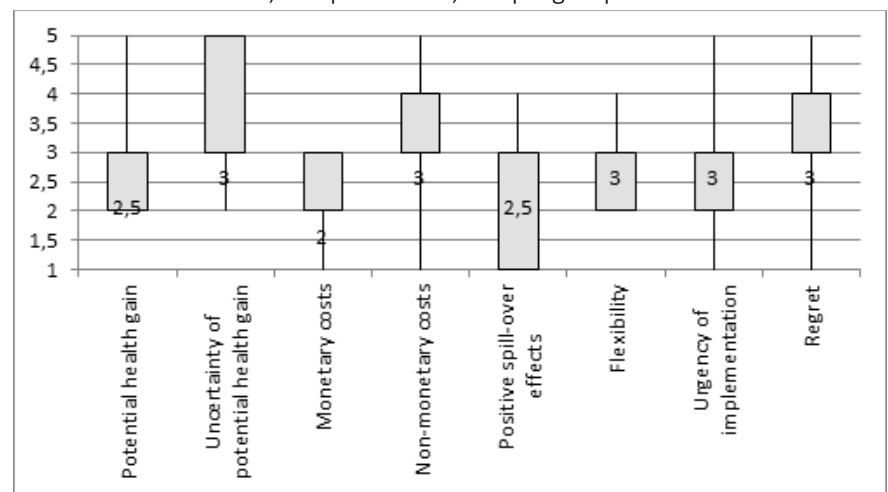

$\mathrm{m}$. Strengthen capacity of public health workforce and implement emergency preparedness training, sample group "Policy" 


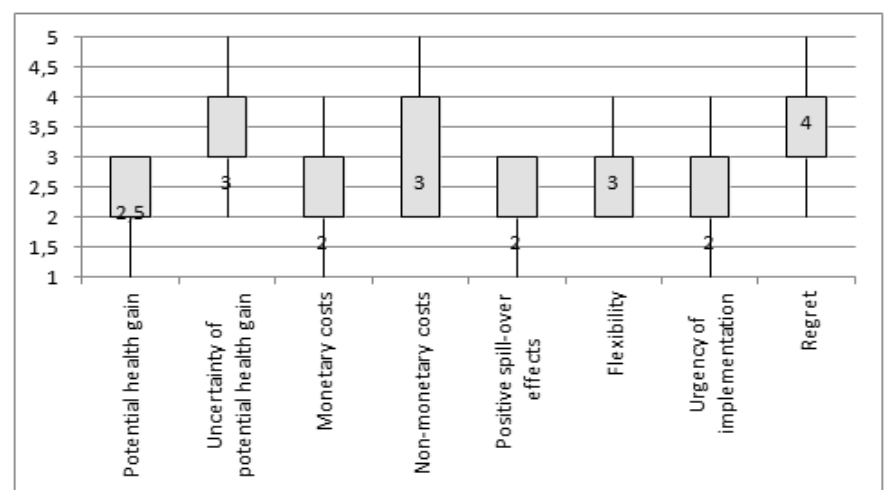

$\mathrm{n}$. Strengthen capacity of public health workforce and implement emergency preparedness training, sample group "Science"

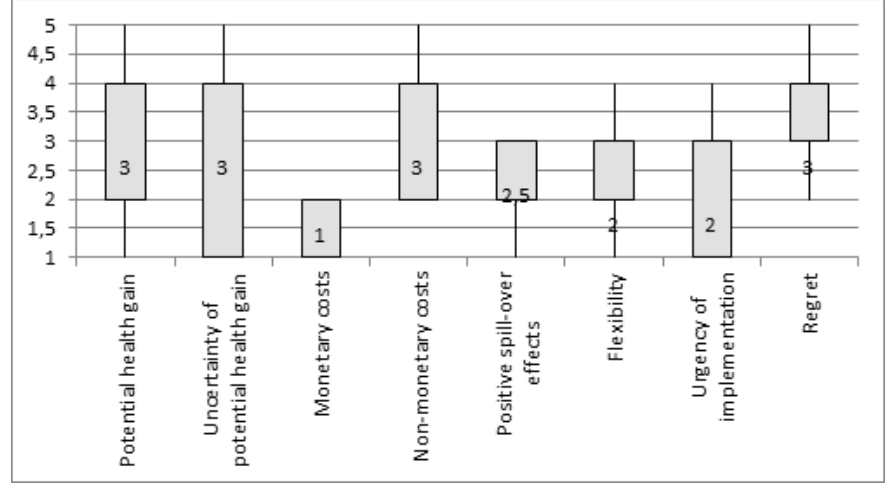

o. Research, sample group "Policy"

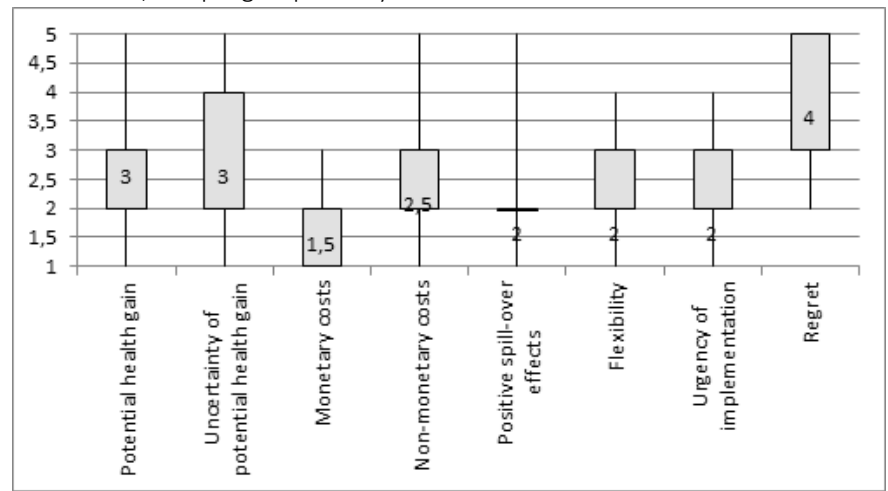

p. Research, sample group "Science" 


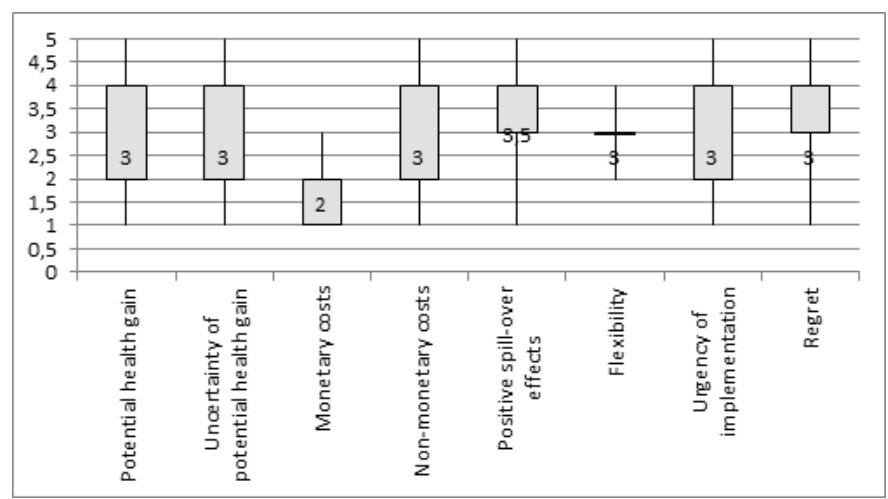

q. Environmental management, sample group "Policy"

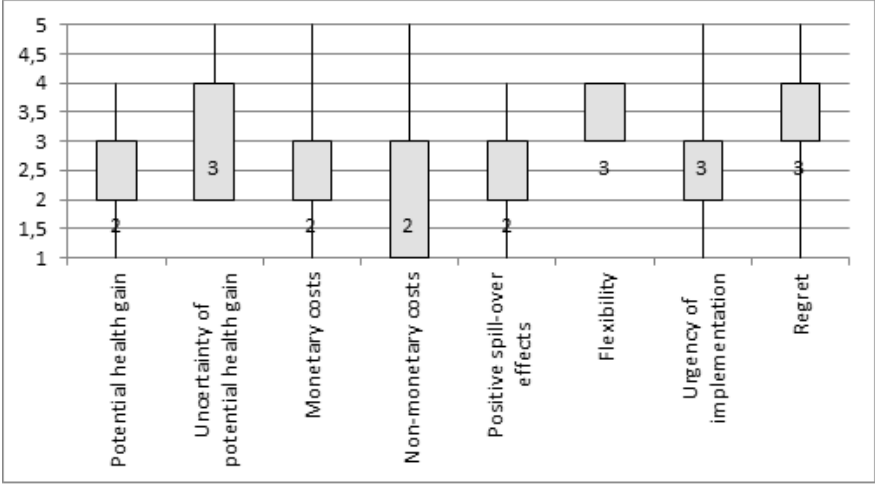

r. Environmental management, sample group "Science"

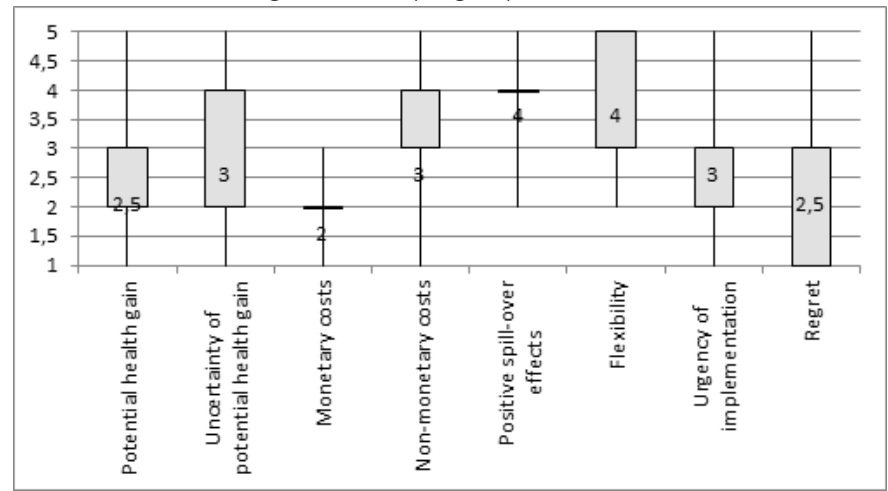

s. Direct control methods, sample group "Policy" 


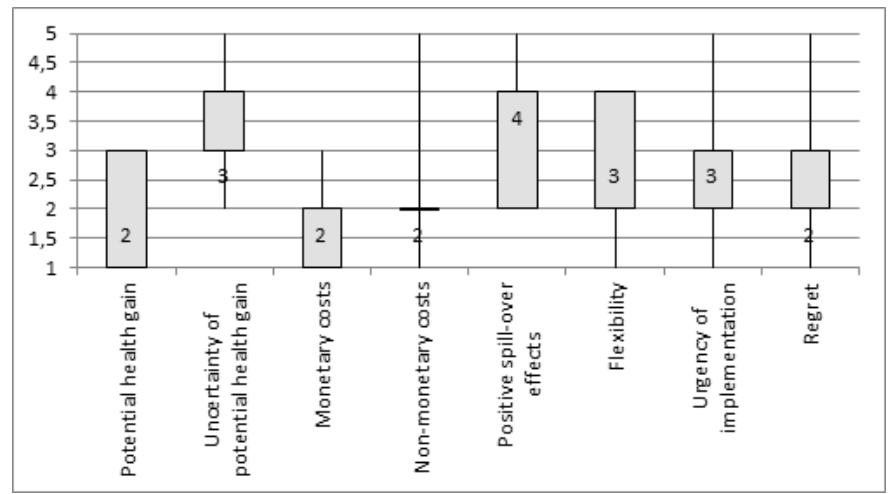

t. Direct control methods, sample group "Science"

Fig 5.2 a-t Box plots of the assessment of the two sample groups "Policy" and "Science" of the responses to climate change-induced infectious disease risk in Western Europe, using the eight assessment criteria

Notes: Medians are given as numbers in the box plots

Range = maximum value - minimum value

Interquartile range $(I Q R)=3^{\text {rd }}$ quartile $-1^{\text {st }}$ quartile $=$ length of box

Interpretation of median values for each assessment criterion:

Potential health gain: 1=very high [high, moderate, low] 5=very low

Uncertainty of potential health gain: $1=$ very high uncertainty [high, moderate, little] 5=virtually certain

Monetary costs: $1=$ high costs [moderate costs, low costs, no or negligible costs] $5=$ net benefits Non-monetary costs: $1=$ high costs [moderate costs, low costs, no or negligible costs] $5=$ net benefits Positive spill-over effects: $1=$ very high [high, moderate, low] $5=$ very low to none

Flexibility: 1=very high flexibility [high, moderate, low] 5=no flexibility

Urgency of implementation: 1= very high urgency [high, moderate, little] 5=no urgency

Regret if climate change does not turn out as expected: $1=$ very high potential regret if climate change does not turn out as expected [high, moderate, little] $5=$ no regret if climate change does not turn out as expected

The results in the box plots in Figure 5.2 a-t show that the sample groups "Policy" and "Science" mostly agree when it comes to the following assessment criteria: potential health gain, uncertainty of potential health gain, monetary costs, flexibility, and urgency of implementation. Most differences between the two sample groups in terms of assessment criteria can be seen for non-monetary costs, positive spill-over effects, and regret if climate change turns out differently than expected. A greater difference between the assessments of the sample groups can be seen for the responses "outbreak investigation and response" and "enforce laws and regulations". Much agreement between the assessments of the two groups can be found for "dissemination of information, and health education", "foster interagency and community partnerships", "access to health care, and prevention", "strengthen capacity of public health workforce and implement emergency preparedness training", and "environmental management". 
The group "Policy" shows greater IQRs for potential health gain, uncertainty of health gain, and non-monetary costs, which means that greater variation in the responses for these criteria is found within this sample group. For the group "Science" greater IQRS and thus more variation in responses could be found for the criteria uncertainty of health gain, non-monetary costs, and regret if climate change turns out differently than expected. The group "Policy" shows a greater amount of relatively higher IQR values in the assessment of the response "foster interagency and community partnerships". The group "Science" shows a greater amount of relatively higher IQR values in the assessment of the response "outbreak investigation and response".

\subsubsection{Expert prioritization of mitigation and adaptation response strategies}

The respondents were asked to divide (in percentages adding up to a total of 100\%) a fictional limited budget between mitigation and adaptation responses to address climate change-induced infectious disease risk in the most optimal manner. In Table 5.3 the results of the analyses of the responses of the aggregate sample as well as the sample groups "Policy" and "Science" are shown.

\begin{tabular}{llllll}
\hline $\begin{array}{l}\text { Table } 5.3 \text { Assessment of the percentage committed to mitigation and adaptation response strategies under } \\
\text { budgetary constraints, by the aggregate sample and the two sample groups "Policy" and "Science" }\end{array}$ \\
\hline
\end{tabular}

Note: In part c) of the survey the respondents could give their answers in percentages resulting in ratio data. Therefore the mean and standard deviation are used for the analysis of central tendency and variation, which are appropriate measures for ration/interval data (see e.g. (Cooper \& Schindler, 2003)) (as described in the methodology).

The mean percentage assigned by the aggregate sample to mitigation is $50.52 \%$ and to adaptation is $49.48 \%$. Based on these results it would seem that there is no clear priority placed on either mitigation or adaptation measures, so a (policy) response strategy including an equally proportioned mix of the two is shown in the results. When taking a closer look at the data resulting from the aggregate sample's responses it can be seen that indeed a large part of the sample opted for a 50/50 budgetary division between mitigation and adaptation options. But also the priorities $70 \% / 30 \%$ and $80 \% / 20 \%$ (for mitigation and adaptation, respectively) have been opted for relatively more frequently by the expert sample.

Additionally, the mean results for mitigation and adaptation were assessed for the groups "Policy" and "Science". Here a slight difference in emphasis between mitigation and adaptation results between the two sample groups can be found. The group "Policy" 
allocates a higher mean percentage of the budget to adaptation, whereas the group "Science" devotes a slightly higher mean percentage to mitigation (47.92\% and 52.35\% for mitigation, and $52.08 \%$ and $47.65 \%$ for adaptation, respectively). The standard deviations reveal that the sample group "Science" shows greater variance in their responses in comparison to the group "Policy". Again, when taking a closer look at the dataset resulting from this question, the group "Policy" showed the same frequency of responses for the budgetary divisions of $30 \% / 70 \%, 50 \% / 50 \%$, and $70 \% / 30 \%$ (for mitigation and adaptation, respectively). For the sample group "Science", a large portion of the respondents chose $50 \% / 50 \%$, but $80 \% / 20 \%$ (mitigation/adaptation) also received considerable support.

\subsubsection{Expert assessment of the willingness and the capacity to respond of relevant actors}

Next, the survey had the expert sample assess the willingness and the capacity to respond to climate change-induced infectious disease risk in Western Europe of potentially relevant actors (earlier defined as: national government/health authority; local health authority; policy-advice, policy-maker; NGO, advocacy, funders, charity; science; health care provider/health practitioner; veterinary profession; pharmaceutical industry; farmer union; food supply sector; environmental management, conservation; trade and tourism sector; other business/private sector actors). The results of the survey are first presented for the analysis of the assessment of the willingness to respond of the actors by the aggregate sample and the two sample groups "Policy" and "Science" in Table 5.4 and thereafter the results will be shown for the capacity to respond of the actors in Table 5.5 .

Table 5.4 shows the results of the aggregate expert sample's assessment and the assessments of the two sample groups "Policy" and "Science" of the willingness to respond of the actors. 


\begin{tabular}{|c|c|c|c|c|c|c|}
\hline \multirow[b]{3}{*}{ Actors } & \multicolumn{6}{|c|}{ Assessment of willingness to respond } \\
\hline & \multicolumn{2}{|c|}{ Aggregate sample } & \multicolumn{2}{|c|}{$\begin{array}{l}\text { Sample group } \\
\text { "Policy" }\end{array}$} & \multicolumn{2}{|l|}{$\begin{array}{l}\text { Sample } \\
\text { ence" }\end{array}$} \\
\hline & Median & IQR & Median & IQR & Median & IQR \\
\hline $\begin{array}{l}\text { National government/health author- } \\
\text { ity }\end{array}$ & 3 & 2 & 3 & 1 & 3 & 2 \\
\hline Local health authority & 3 & 2 & 3 & 2 & 2 & 2 \\
\hline Policy-advice, policy-maker & 3 & 1 & 3 & 0 & 3 & 1 \\
\hline NGO, advocacy, funders, charity & 2 & 1 & 2 & 1 & 2 & 1 \\
\hline Science & 2 & 2 & 2 & 1 & 2 & 2 \\
\hline $\begin{array}{l}\text { Health care provider/health practi- } \\
\text { tioner }\end{array}$ & 3 & 2 & 3 & 2 & 3 & 1 \\
\hline Veterinary profession & 3 & 2 & 3 & 2 & 3 & 1 \\
\hline Pharmaceutical industry & 3 & 2 & 2 & 2 & 4 & 2 \\
\hline Farmer union & 4 & 1 & 4 & 1 & 4 & 2 \\
\hline Food supply sector & 4 & 1 & 3 & 2 & 4 & 0 \\
\hline $\begin{array}{l}\text { Environmental management, con- } \\
\text { servation }\end{array}$ & 2 & 1 & 2 & 0 & 3 & 1 \\
\hline Trade and tourism sector & 3 & 2 & 2 & 2 & 4 & 1 \\
\hline Other business/private sector actors & 4 & 1 & 3 & 2 & 4 & 0 \\
\hline
\end{tabular}

Notes: IQR $=$ Interquartile range $=3^{\text {rd }}$ quartile $-1^{\text {st }}$ quartile. Interpretation of median values for willingness to respond: 1 = very high willingness to respond (high, moderate, low) $5=$ no willingness to respond

From the results in Table 5.4 it can be gathered that the aggregate sample rates the following actors as having a high willingness to respond: "NGO, advocacy, funders, charity", "science", and "environmental management, conservation". The IQRs are also relatively smaller for the assessment of willingness of "NGO, advocacy, funders, charity" and "environmental management, conservation", indicating that the responses of the aggregate sample for these two types of actors have relatively little variation. The aggregate sample's responses yield low willingness to respond for the actors "farmer union", "food supply sector", and "other business/private sector actors", all with relatively low IQRs and thus relatively little variation in the responses of the aggregate sample.

The sample group "Policy" associates a high willingness to respond with the actors "NGO, advocacy, funders, charity", "science", "pharmaceutical industry", "environmental management, conservation", and "trade and tourism sector". In the cases of "NGO, advocacy, funders, charity", "science", and "environmental management, conservation" also lower IQRs are found, thus the sample group has relatively little variance in its responses. The group "Policy" indicates "farmer union" to have a low willingness to respond. This response also has a lower IQR.

The actors "local health authority", "NGO, advocacy, funders, charity", and "science" are rated as having high willingness to respond by the sample group "Science". For "NGO, advocacy, funders, charity", a lower IQR could be found. It can been seen that the two sample groups agree with regards to "NGO, advocacy, funders, charity", and "science" 
being actors with high willingness to respond, but differ in their assessment with regards to "local health authority", "pharmaceutical industry", "environmental management, conservation", and "trade and tourism sector". The sample group "Science" rates a greater number of actors as having low willingness to respond: "pharmaceutical industry", "farmer union", "food supply sector", "trade and tourism sector", and "other business/private sector actors", of which the latter two also receive a lower IQR. In comparison to the group "Policy", the group "Science" sees more actors as having a low willingness to respond; the two groups agree on the low willingness to respond of the actor "farmer union".

In Table 5.5 the results of the assessments of the aggregate sample and the sample groups "Policy" and "Science" of the capacity to respond of the actors can be found.

\begin{tabular}{|c|c|c|c|c|c|c|}
\hline \multirow[b]{3}{*}{ Actors } & \multicolumn{6}{|c|}{ Assessment of capacity to respond } \\
\hline & \multicolumn{2}{|c|}{ Aggregate sample } & \multicolumn{2}{|c|}{$\begin{array}{l}\text { Sample group } \\
\text { "Policy" }\end{array}$} & \multicolumn{2}{|c|}{$\begin{array}{l}\text { Sample group "Sci- } \\
\text { ence" }\end{array}$} \\
\hline & Median & IQR & Median & IQR & Median & IQR \\
\hline $\begin{array}{l}\text { National government/health author- } \\
\text { ity }\end{array}$ & 2 & 1 & 3 & 1 & 2 & 1 \\
\hline Local health authority & 3 & 2 & 3 & 2 & 3 & 1 \\
\hline Policy-advice, policy-maker & 3 & 1 & 3 & 2 & 3 & 1 \\
\hline NGO, advocacy, funders, charity & 3 & 1 & 4 & 2 & 3 & 1 \\
\hline Science & 3 & 1 & 3 & 1 & 3 & 1 \\
\hline $\begin{array}{l}\text { Health care provider/health practi- } \\
\text { tioner }\end{array}$ & 3 & 2 & 2 & 1 & 3 & 2 \\
\hline Veterinary profession & 3 & 2 & 2 & 1 & 3 & 2 \\
\hline Pharmaceutical industry & 3 & 2 & 3 & 1 & 3 & 2 \\
\hline Farmer union & 3 & 2 & 3 & 1 & 3 & 2 \\
\hline Food supply sector & 3 & 2 & 3 & 2 & 3.5 & 2 \\
\hline $\begin{array}{l}\text { Environmental management, con- } \\
\text { servation }\end{array}$ & 3 & 2 & 3 & 4 & 3 & 1 \\
\hline Trade and tourism sector & 3 & 2 & 2 & 1 & 3.5 & 1 \\
\hline Other business/private sector actors & 3 & 1 & 4 & 3 & 3 & 1 \\
\hline
\end{tabular}

Notes: IQR $=$ Interquartile range $=3^{\text {rd }}$ quartile $-1^{\text {st }}$ quartile. Interpretation of median values for capacity to respond: 1 = very high capacity to respond (high, moderate, low) $5=$ no capacity to respond

From the results in Table 5.5 it becomes clear that the aggregate sample rates the "national government/health authority" as an actor with high capacity to respond. For this also a lower IQR can be found, which indicates that the aggregate sample's responses vary relatively little.

The sample group "Policy" associates a high capacity to respond with the following actors: "health care provider/health practitioner", "veterinary profession", and "trade and tourism sector". All these responses are also accompanied by a relatively low IQR. The group "Policy" views the actors "NGO, advocacy, funders, charity" and "other busi- 
ness/private sector actors" as having a low capacity to respond. However, the IQRs for the assessment of the capacity of "environmental management, conservation" and "other business/private sector actors" are slightly greater, thus showing that the sample group "Policy" has some variation in their responses for this item.

The group "Science" rates the "national government/health authority" as an actor with high capacity to respond. Also, a lower IQR could be found here, so the sample group "Science" has little variation in their response. The two sample groups show no agreement on which actors have high or low capacity to respond (but are in agreement for some actors that are viewed as having a moderate capacity to respond).

\subsection{Discussion and conclusions}

The survey presented in this paper aimed to shed light on the perspectives of Dutch experts on responses to climate change-induced infectious disease risk in Western Europe, the willingness and capacity of potentially relevant actors in this response effort, and finally the prioritization of mitigation and adaptation responses. The results of the survey and the analyses of the responses of the aggregate sample as well as the two sample groups "Policy" and "Science" reveal some information about the perspectives the experts hold. In summary, several key results have surfaced from the analyses.

The results show that the expert sample views the assessed responses differently in terms of the given criteria. There are two responses that are perceived by the experts as having both a high potential health gain and little uncertainty of this potential health gain: "outbreak investigation and response" and "access to health care and prevention". Additionally, "access to health care and prevention" is seen by the aggregate sample as having high positive spill-over effects. According to the expert sample "dissemination of information and health education" and "foster interagency and community partnerships" have low monetary and non-monetary costs. It should be noted that the IQRs for non-monetary costs are relatively high, and therefore there may be less consensus among the experts in the aggregate sample as to the non-monetary costs for each of the responses assessed. Next to the low costs, "dissemination of information and health education" is also viewed as a highly flexible response with high positive spill-over effects. Also for "foster interagency and community partnerships" high positive spill-over effects result from the survey. "Research" is viewed as a high monetary cost response but at the same time one with high positive spill-over effects, flexibility, and urgency. However, the majority of the results for "research" come with higher IQR values, indicating that the aggregate sample shows variations in their responses for "research". Overall, relatively high IQRs for the criteria uncertainty of potential health gain, nonmonetary costs, and regret if climate change does not turn out as expected can be found. This can indicate that the aggregate expert sample has fewer shared opinions on the issues of uncertainty, non-monetary cost, and regret. The assessments of some re- 
sponses show overall more variation than others: "foster interagency and community partnerships", "research", and "environmental management". Thus the experts seem to have more diverging perspectives on these responses. The experts show the greatest consensus on their assessment of the responses "access to health care, and prevention" and "strengthen capacity of public health workforce and implement emergency preparedness" (based on the IQRs). The larger variations regarding several criteria and responses may also possibly relate to the idea that more understanding of response measures is needed as argued by some (see Menne et al. (2008), amongst others).

When analysing the results of the two sample groups "Policy" and "Science" it can be noted that much agreement between the assessments of the two groups can be found for "dissemination of information, and health education", "foster interagency and community partnerships", "access to health care, and prevention", "strengthen capacity of public health workforce and implement emergency preparedness training", and "environmental management". The two groups seem to have differences in their assessments of the responses "outbreak investigation and response" and "enforce laws and regulations". The perspectives within the group "Policy", based on the resulting IQRs, seem to diverge most for the response "foster interagency and community partnerships". For the group "Science" this is the case for "outbreak investigation and response". Within the group "Policy", the greatest consensus could be found for the responses sample "dissemination of information and health education", "access to health care, and prevention" and "strengthen capacity of public health workforce and implement emergency preparedness training". Within the group "Science", the greatest consensus could be found for the responses: "monitoring", "enforce laws and regulations", "access to health care, and prevention", "strengthen capacity of public health workforce and implement emergency preparedness training", "research", and "environmental management"..

Based on these analyses one cannot deem one response to be better or worse than another. Important to note are those cases where the experts seem to show great divergence or consensus (based on the IQRs), which can indicate to what extent the results show a more or less shared perspective on the assessed response in question. In practice, adaptation responses are highly context-specific, and should ideally take into account both relevant climatic and non-climatic developments (Füssel, 2007). The priorities characterising a decision-making context will influence which responses will be most fitting for the situation at hand. The criteria used in the survey can be translated to such possible decision-making priorities. For instance, when low monetary costs and high flexibility are important criteria for the decision on a response, then the "dissemination of information and health education" would, in the views of the aggregate expert sample, be a relatively more effective response in such a decision-making context. In this case, the answers for monetary costs and flexibility have relatively small ranges/IQRs, thus indicating greater agreement amongst the experts in the aggregate sample. When these guiding priorities change for another situation, this may lead to other choices in terms of response. The assessment criteria used in the survey cover a broad range of 
possible priorities for responses. In practice, some criteria for making decisions on adaptation measures might take precedence over others. For example, monetary costs are recognized as a key barrier to adaptation (EC, 2009a; Füssel, 2007). Due to this, more weight may be given to the criterion of low monetary costs, affecting the choice for an adaptation response strategy. In related studies it is argued that cost-effectiveness as well as no or little regret of adaptation response options can be priority characteristics in a decisions-making context on adaptation (Ebi et al., 2006; Füssel, 2007).

Part (b) of the survey focussed on prioritising mitigation and adaptation responses under a fixed budget. The analysis of the results of the aggregate sample and the two sample groups "Policy" and "Science" all seem to indicate that a 50/50 budgetary allocation between mitigation and adaptation responses is the most optimal approach to tackle climate change-induced infectious disease risk in Western Europe. For the sample group "Policy", however, the budgetary allocations of 30\%/70\% and 70\%/30\% (between mitigation and adaptation respectively) were also opted for with the same frequency as a $50 \% / 50 \%$ division. Overall, relatively more variation in the responses of the sample group "Science" could be found. A response strategy including both mitigation and adaptation measures is acknowledged to be crucial for tackling (future) climate change consequences optimally (Kovats et al., 2014).

The results on the assessment of the willingness and the capacity to respond, displayed in Tables 5.4 and 5.5, show that the aggregate expert sample views the "national government/health authority" as the most capable actor to respond to climate changeinduced infectious disease risk, and the lower IQR indicates that the experts show high agreement on this. The aggregate expert sample sees the actors "NGO, advocacy, funders, charity", "environmental management, conservation", and "trade and tourism sector" as having a high willingness to respond. The results on "NGO, advocacy, funders, charity", and "environmental management, conservation" are also accompanied by lower IQRs, indicating that there is greater consensus among the expert opinions on the willingness of these actors. Lower willingness to respond is associated by the aggregate sample with the actors "farmer union", "food supply sector", and "other business/private sector actors", also with lower IQRs. The sample groups "Policy" and "Science" show no agreement with regards to which actors have a high or low willingness to respond. For high and low capacity to respond the two sample groups show some agreement but also some differences.

The survey results should be seen as an indication of the perspectives of Dutch experts on the responses to climate change-induced infectious disease risk in Western Europe, and the willingness and capacity of the actors in such a response effort, based on the Dutch expert sample that participated in this study. The approach to conduct a participatory integrated assessment for the ERA-ENVHEALTH ENHanCE research project, of which this survey was a key research component, allowed for the involvement of stakeholders (the expert sample) to address the complexities and uncertainties inherent to the topic of climate change and infectious disease risk. The exploration of expert perspectives can 
provide insights into the complexity of climate change (and other environmental topics), as well as the related policy field (Akin \& Martens, 2014; de Ridder et al., 2007; Kloprogge \& van der Sluijs, 2006). The involvement of stakeholders, specifically for the assessment of adaptation responses, is seen as a necessary approach, also for future research efforts in this area (Ebi et al., 2006; Füssel, 2007). Currently there is a lack of guidelines for the assessment of policy options for climate adaptation decision-making (WHO-Europe, 2010b). The use of expert perspectives to gain more insight into the responses assessed according to a broad range of criteria can help to address this need. In addition to the set of criteria used in this study, other criteria for the assessment of adaptation responses can be formulated.

The survey only relied on the answers provided by the Dutch expert sample, which should be kept in mind for the interpretation of the results of this study. Similar studies involving experts from different countries could be conducted to compare and contrast potentially prevailing perspectives on responses to climate change-induced infectious disease risk in Western Europe and the willingness and capacity of relevant actors in such a response (Akin \& Martens, 2014). Moreover, the composition of the aggregate sample, including scientists and policy advisors, could have influenced the results, and further studies incorporating various stakeholders could help to establish whether the responses are influenced by the composition of the sample. It should be noted that this study focussed on Western Europe as a geographical area. The disease burden and the role of climate change and infectious disease risk in this varies greatly across regions and countries and is often tied in with income-levels and other non-climatic conditions. The disease burden in Western Europe from climatic drivers for infectious disease risk is comparatively limited (WHO, 2008a). The results of the study should be interpreted with this background in mind.

The results of the analyses of the two sample groups "Science" and "Policy" can indicate that the two professional environments possibly have differing opinions when it comes to certain responses, assessment criteria, and the willingness and capacity of the actors. These differences could be related to the diversity in underlying values held in the two professional environments (Akin \& Martens, 2014; Nordhaus, 1994). To establish prevailing perspectives on responses to climate change and infectious disease risk and make comparisons across professional backgrounds, more research involving experts needs to be done. In addition, the potential role of other factors contributing to differences in perspectives should be considered as well, such as possible information asymmetries between scientific and policy communities (Akin \& Martens, 2014). Differences in perspectives within and between sample groups can indicate a lack of consensus with regards to several responses and the assessed actors, which can have implications for policy processes for climate change adaptation. Increasing our awareness of the diversity in values and related perspectives as well as understanding the underlying (other) drivers of the perspectives can support policy processes for the adaptation to climate change-induced infectious disease risk. Responses that accommodate the prevailing 
perspectives of a broad range of stakeholders could benefit from greater support (Akin \& Martens, 2014). It would be therefore interesting to perform the same survey targeting samples of other relevant stakeholder groups, such as NGOs, veterinary and health professionals, and relevant businesses and private actors, in order to uncover a great variety of perspectives and possibly gain more insights into the differences between the views of different stakeholder groups.

In addition, greater awareness of the capacity and willingness of potentially relevant actors to respond to climate change-induced infectious disease risk can facilitate cooperative and multi-stakeholder policy processes in this sector. A cooperative and integrated approach towards climate adaptation for health under the coordination of the European Union appears to be an important element of European governance of climate change and adaptation for health (EC, 2009a, 2013a).

The call for responses to the health and also in particular infectious disease outcomes of climate change is becoming increasingly stronger at a European level (EC, 2009a, 2010a, 2013a). In response to this, this study focused on adaptation responses addressing climate change-induced infectious disease risk in Western Europe. A clear need for response strategies to climate change-induced infectious disease risk (and broader health outcomes) is emphasised at a European policy level. Yet, the remaining uncertainties on the effective use of adaptation (and mitigation) responses demonstrate that decisionmaking regarding this can prove to be a difficult task. The exploration of expert perspectives on adaptation responses using assessment criteria, as well as relevant actors' willingness and capacity to respond can contribute to our understanding and the governance of the complex issue of climate change and its health outcomes. In order to address existing research gaps, a continued effort integrating multiple disciplines and research methods complementing participatory research approaches (such as modelling and scenarios analysis) will be necessary. 
CHAPTER 6

CLIMATE CHANGE ADAPTATION FOR HEALTH

IN EUROPE 


\section{Abstract}

Climate change and its current and potential future consequences for human health, as well as for other sectors, have become a large governance challenge of our time. Mitigation and adaptation are complementary strategies to tackle climate change and reduce our vulnerabilities to occurring health impacts. Adaptation mechanisms are put into place at local, regional, national, and global levels. However, not to the extent necessary yet to achieve adequate adaptation to current and prospective climate change-induced health outcomes. Moreover, the effectiveness of those adaptation responses that are implemented is largely not known (yet), as more research on this is needed. In this chapter, climate change adaptation policy for health currently in place at the European level is discussed. Specifically this chapter aims to shed light on the role of health in EU climate adaptation policy and at the same time reflecting on key EU health policy and its relation to climate adaptation. This is followed by a discussion on the potential necessary and future development of such adaptation policy in order to better meet and tackle current and future consequences of climate change for health in Europe. Thereafter a reflection on mainstreaming as well as the role of the EU with regards to its Member States for climate change adaptation for health is given. The review of policy shows that climate change adaptation increasingly prioritises health as a key area. At the same time, the increasing attention paid to adaptation in key health policy documents can be seen as well. Enhancing efforts to mainstream climate adaptation and health policies can contribute to the achievement of more effective and efficient adaptation responses for health. This is also an objective in the policy documents on adaptation and health. In practice more implementation and mainstreaming of adaptation and health needs to take place, as well as more monitoring and evaluation to enhance the evidence base on effective adaptation options for health. 


\subsection{Introduction}

Climate change poses a significant public threat, with potentially large implications for human and natural systems. In all regions in Europe, climate change has current and expected future impacts on a wide range of sectors, including human health and wellbeing (IPCC, 2014a, 2014c). Specifically, injuries and deaths from heat, health consequences from extreme weather events, as well as climate change-induced changes in the distribution and seasonal patterns of infectious diseases are examples of the key challenges that can occur due to climate change in Europe (IPCC, 2014c). The exact health burden from climate change is difficult to estimate and depends on factors such as public health status, socio-economic conditions, and the implementation of adaptation measures (EC, 2013a; IPCC, 2014a).

Governing climate change has become an important challenge of our time (Biermann et al., 2010). Climate governance involves the mitigation of global warming, but also the adaptation to climate change impacts, as mitigation will not prevent us from experiencing some degree of global warming and its consequences. These instruments are complementary, and can be mutually supportive depending on the case at hand (Biermann et al., 2010). Climate governance therefore needs to incorporate adaptation (Biermann et al., 2010; EC, 2013d; IPCC, 2014f).

Despite the clear necessity of adaptation, in a European context, implementation of adaptation strategies as well as monitoring of effectiveness of adaptation have progressed slowly and are at times limited (EC, 2013e; IPCC, 2014c; Keessen, 2014). With regards to adaptation to health impacts specifically, the World Health Organization estimated in a study conducted in 2012 that, at a global level, the commitment to health adaptation is estimated to be less than $1 \%$ of the annual health costs attributable to climate change in 2030 (IPCC, 2014a). In Europe, adaptive capacity is overall comparatively high relative to other regions, but, within Europe there are significant differences in the climate change impacts borne and the adaptive capacity available to respond to these impacts (IPCC, 2014c).

In past decades a priority on mitigation dominated European Union (EU) policy-making to govern climate change, however in recent years also adaptation to climate change has entered the European governance sphere (Biesbroek et al., 2010). The EU recognizes the necessity of climate change adaptation, including a specific emphasis on climate change adaptation for human health outcomes (EC, 2013a, 2013d). Moreover, adaptation to climate change supports the objective of reaching a climate-resilient economy and enhancing capacities for disaster prevention and response as set out in the Europe 2020 Strategy (EC, 2010b; Keessen, 2014). At the EU, but also Member State and local levels, adaptation policies are developed (EC, 2013e; IPCC, 2014c). However, the information on the status quo of the implementation of adaptation measures and polices and their effectiveness is limited (EC, 2013e; IPCC, 2014c). An issue related to this is that there is a lack of guidance for effective adaptation to climate change impacts including to current 
and future health impacts. The inherent complexity of adaptation and its specific information needs (what to adapt to and how to adapt) feeds into these difficulties in decision-making (Ebi \& Burton, 2008; Füssel \& Klein, 2006; IPCC, 2014b).

In light of this, this chapter aims to give an overview the development and status quo of the climate change adaptation to health outcomes in the EU, with attention for the role of health in EU adaptation policy as well as the role of climate change adaptation in EU health policy. Thereafter, opportunities for further development of EU climate change adaptation and mainstreaming are discussed.

Previous chapters of this dissertation report, in brief, on research on climate changeinduced infectious disease risk in Western Europe and an assessment of potential adaptation responses to these risks with reference to relevant EU adaptation policy. This chapter therefore takes on the purpose of providing an overview of EU climate change adaptation for health in Europe. This broader perspective placed on the issue of climate change adaptation to health consequences provides a complementary context to the research presented in earlier chapters.

\subsection{Conceptualization and research background}

Even though humans have a long history of dealing with climate- and weather-related consequences, current climate changes pose new risks and uncertainties (Adger et al., 2007; Füssel, 2007). Climate change is recognized as one of the major governance challenges we are facing today, relevant for multiple levels (local, regional, and global), sectors, and stakeholders (Biermann et al., 2010). Climate governance (or policy) involves a choice between or rather a combination of mitigation and adaptation instruments (Biermann et al., 2010; Mechler \& Kundzewicz, 2010).

In the context of climate governance, adaptation can be defined as "the process of adjustment to actual or expected climate and its effects. In human systems, adaptation seeks to moderate harm or exploit beneficial opportunities. In natural systems, human intervention may facilitate adjustment to expected climate and its effects (p.1758) (IPCC, 2014d)". Thus based on this definition (IPCC, 2014d), adaptation for climate changeinduced health outcomes specifically can be understood as the adjustment to actual or expected climate change effects on human health, where it is also aimed to moderate harm to health but to take advantage of beneficial opportunities (MEA, 2005a).

It should be noted however, that adaptation is not a well-demarcated concept (Füssel, 2007). Adaptation responses can vary in their form including e.g. technical, institutional, legal, educational, or behavioural measures (Füssel, 2007). Also, adaptation is inherently a multi-level governance issue, involving multiple public and private stakeholders (Adger et al., 2007; Biesbroek et al., 2010; Martens et al., 2012). Moreover, adaptation practices can be placed along a temporal scale, as it can be in response to past, current, medium, 
long-term, or projected climate change impacts. As such adaptation can range from expost, reactionary to anticipatory, precautionary ${ }^{17}$ action (Adger et al., 2007; Füssel, 2007; MEA, 2005a).

Mitigation of climate change can be defined as "a human intervention to reduce the sources or enhance the sinks of greenhouse gases (p.19) (IPCC, 2014d)". Mitigation policies can have co-benefits for health, e.g. changes to housing, energy, and/or transport policies can also indirectly improve overall population health and resilience (IPCC, 2014c).

Mitigation has great priority in (global and European) climate governance, as further global warming should be avoided. Despite these mitigation efforts, there will be unavoidable warming or climate change and related current and future consequences, therefore adaptation is a necessary strategy besides mitigation for optimal climate governance (Adger et al., 2007; Biermann et al., 2010; EC, 2013d; Füssel \& Klein, 2006; IPCC, 2014f; Mechler \& Kundzewicz, 2010). In order to combat climate change, massive mitigation needs to take place, and relating to this of course the question of who takes responsibility for this arises. Both the scope of mitigation responses as well as the issue of responsibility bring about some controversy. As a consequence insufficient resources may be committed to climate change mitigation, which contributes to the (complementary) necessity of adaptation (Keessen, 2014).

Also at a European level there has been a clear initial priority placed on the development and implementation of mitigation policy and only recently part of the focus also moved towards the development of an adaptation strategy (Biesbroek et al., 2010; Keessen, 2014). Füssel and others (Füssel, 2007; Füssel \& Klein, 2006; Martens et al., 2012) explain that traditionally this emphasis on mitigation over adaption has been a tendency in both the policy and the scientific world. The differences in development and implementation of the two response strategies to climate change, can (partly) be related to their different characteristics (Füssel, 2007; Keessen, 2014; Martens et al., 2012) ${ }^{18}$. One of the key differences lies in the spatial scales of the two responses. Mitigation is usually a more global-level effort, whereas adaptation mainly takes place at local or regional levels (Füssel \& Klein, 2006; Keessen, 2014; Martens et al., 2012). Keessen (2014) argues that this scalar difference could be related to the faster development and implementa-

\footnotetext{
${ }^{17}$ Despite the lack of a commonly agreed definition or related criteria, the main idea behind the precautionary principle is that one can act in the face of scientific uncertainty in order to prevent harm to the environment. Cost-effectiveness (or proportionality of response), and taking a longer temporal scale into account for decision making are additional central concerns when applying a precautionary approach. Precaution or the precautionary principle is accepted by national governments and supra-national bodies, such as the UN and the EU, as a guide for policy-making (O'Riordan \& Jordan, 1995). As the problem of climate change and climate science is prone to some degree of scientific uncertainty, the application of the precautionary principle is necessary to facilitate timely and adequate decision-making and governance of climate adaptation (Adger et al., 2007; Barnett, 2001; Dessai et al., 2009).

${ }^{18}$ For further discussion on mitigation and adaptation responses and their differences, please see Chapter 2.
} 
tion of a mitigation policy at the EU-level as opposed to the rather slow development of an equivalent EU policy for adaptation. Another difference between mitigation and adaptation is that mitigation will reduce climate change impacts on all climate-sensitive systems. Adaptive responses are often specific to a local context and therefore their potential for tackling climate change impacts is limited for many contexts or systems. The broad applicability of mitigation might have contributed to it receiving more policy attention than adaptation (Füssel, 2007; Füssel \& Klein, 2006). Another important difference is that monitoring of effectiveness and results is often easier for mitigation than for adaptation (Füssel, 2007; Füssel \& Klein, 2006). Because of their inherent differences, adaptation and mitigation are complementary strategies. There is much political interest in the integration of both responses, but their differences at the same time make this challenging (Füssel, 2007; Martens et al., 2012).

In this chapter, EU climate change adaptation to health outcomes will be studied in order to gain an understanding of the status quo and progress of the development and implementation of adaptation strategies to date. A review of relevant EU policy documents was done, and related publications and empirical studies of EU adaptation are also included. A focus is placed on the role of health in climate adaptation efforts in the EU and a reflection is also offered on key relevant health policy documents and their link to climate adaptation efforts. The review focuses specifically on EU-level climate change adaptation for health, with some reference to international and member state levels where appropriate.

\subsection{European Union climate change adaptation for health}

In this section the status quo and progress of EU climate change adaptation to health will be discussed in order to gain an insight into the policies in place for adaptation to climate change and health. Based on policy documents and related literature the main developments of EU policy for climate change adaptation and its relation to health as well as EU health policy with a relevance for climate change adaptation are mapped out.

\subsubsection{EU climate change adaptation policy and its relation to health}

Until recently, Europe's primary focus was on mitigation of climate change and adaptation played a small role. However, in 2007 with the publication of the Green Paper 'Adapting to climate change in Europe - Options for EU action' and thereafter in 2009 the White Paper 'Adapting to climate change: Towards a European framework for action' the European Commission made it clear that adaptation is important and Member States should develop national strategies to adapt to climate change (Biesbroek et al., 2010). Thus, since 2007 there has been a change in Europe's governance of climate 
change (IPCC, 2014c), however, the development of an adaptation strategy has generally progressed slowly (Keessen, 2014).

At an EU-level, and also at the Member State level, adaptation plans have been developed (Biesbroek et al., 2010; IPCC, 2014c, 2014e; Keessen, 2014). The EU has moreover created next to policy on adaptation, an information sharing platform called ClimateADAPT (see EC (2014b)). However, research on the extent of implementation of adaptation policies and plans is limited and there is an overall lack of monitoring and evaluation of the effectiveness of adaptation practices in light of current and potential future climate change impacts (IPCC, 2014b, 2014c).

In 2009, the White Paper 'Adapting to climate change: Towards a European framework for action' was published (EC, 2009a; Keessen, 2014). In this White Paper the necessity of adaptation is stressed, in order to tackle climate change and its impacts that cannot be avoided with mitigation efforts. The White Paper expresses a first decisive step towards the development of an EU adaptation strategy according to Keessen (2014), endorsed both by the Council and the European Parliament (Keessen, 2014). Moreover, a more strategic approach is found to be necessary in order to develop more effective adaptation measures and reduce the EU's vulnerability to climate change impacts but also to ensure consistency across sectors and governance levels (EC, 2009a). In the White Paper the effects of changing weather and climate on human health is discussed and has been accompanied by a sector paper on health (amongst other papers on different sectors), which outlines the main health issues associated with climate change (EC, 2009a, 2009b). The White Paper proposes an EU Framework for Adaptation which aims to improve the resilience of the EU to climate change impacts, and plans the preparation of a comprehensive EU adaptation strategy. The need for more knowledge on how to adapt best to climate change impacts is expressed as well (EC, 2009a). Moreover, the White Paper emphasizes the need to mainstream adaptation into key EU policy areas (EC, 2009a; Keessen, 2014). The paper also points out that early action on adaptation is crucial especially concerning key EU policy sectors. The actions that are specifically defined with relevance for human health are: the development of guidelines and surveillance mechanisms on the health impacts of climate change by 2011; and stepping up existing animal disease surveillance and control. The document also draws a (brief) link with the EU Health Strategy (EC, 2007a), stating that also there, adaptation action has been foreseen (EC, 2009a).

In 2013, the European Commission published 'An EU Strategy on adaptation to climate change' which aims to contribute to a more climate-resilient Europe in line with the objective of the EU framework for adaptation proposed in the White Paper and the Europe 2020 Strategy (EC, 2009a, 2013d). This should be achieved by enhancing preparedness and capacity to respond to the impacts of climate change at the local, regional, and EU level. The document acknowledges the priority placed on mitigation but also the necessity of adaptation to cope with unavoidable climate change impacts. The strategy sets out several key points of action, which describe amongst others that the EU will 
encourage all Member States to adopt adaptation strategies; the provision of funding for adaptation; and enhancing knowledge and making information available on adaptation (EC, 2013d). As an accompanying document to the EU Strategy on adaptation to climate change, a Commission Staff Working Document on 'Adaptation to climate change impacts on human, animal and plant health' has been published (EC, 2013a), which is one of several accompanying documents and it explicitly places a focus on adaptation to climate change impacts on human health. This policy document shows the explicit prioritization of human health within climate adaptation policy, and ties in with the framework set out by the White Paper on adapting to climate change which argues for more resilience of health and social systems to climate change impacts and emphasizes the need for adequate surveillance and monitoring of climate change-induced human, animal, and plant health outcomes (EC, 2009a, 2013a). The Commission Staff Working Document discusses in detail the legal and policy base that underpins the capacity of the EU to react to the impacts of climate change for human health. The document brings to attention that there are still some substantial knowledge gaps regarding the influences of climate change on human health outcomes which need to be addressed. In conclusion the document mentions that the implementation of the Commission's proposal on serious cross-border threats to health will require "the identification of Member States' preparedness, early warning and surveillance, risk assessment and risk management existing structures for different serious cross-border threats to health including climate change (p.29)" (EC, 2013a). In summary this document, which is one of the most recent key policy documents published by the European Commission on climate change adaptation specifically focused on human health discusses the potential impacts of climate change on human health, the legal and policy context for the EU to react to these impacts, and touches on some tools for action.

\subsubsection{Key EU health policy and the relation to climate change adaptation}

There is a range of international and EU level health policies and regulations which show relevance and provide a base for adaptation to climate change health outcomes ${ }^{19}$. First of all, at an international level, all EU Member States have adopted the International Health Regulations (see WHO (2008c)) which entered into force in 2007 (EC, 2013a). The International Health Regulations provide an international legally binding instrument aimed to prevent and respond to acute global health risks, which includes the protection of public health from effects of weather and climate change events (EC, 2013a; Menne

\footnotetext{
${ }^{19}$ See also the Commission Staff Working Document on Adaptation to climate change impacts on human, animal and plant health (EC, 2013a) which discusses the relevant policy and legal context of climate change adaptation to human health, amongst others, of these the most key documents relevant to the study at hand are also discussed in this section.
} 
et al., 2008; WHO, 2014). In the 'Council Conclusions on Environment and Health' the Commission and the Member States are urged to "develop tools for anticipating, preventing and responding to potential threats from identified emerging and re-emerging [environment and health] issues, such as climate change [amongst others] (p.18) (Council, 2007; EC, 2013a)". In the Fifth Ministerial Conference on Environment and Health in Parma in 2010, the Commission recognizes that climate change impacts on health and the related policies are a key environment and health challenge, and supports the commitment to act on this challenge (EC, 2010a; WHO-Europe, 2010c).

The EU Health Strategy, White Paper 'Together for Health: A Strategic Approach for the EU 2008-2013' (EC, 2007a) has been adopted in 2007. The EU Health Strategy identifies several key health challenges that require a new strategic approach, which includes amongst others the recognition of climate change as a potential major health threat and the necessity to respond rapidly to such global health threats. Overall, the capacity to respond should be enhanced in order to achieve the Commission's overall strategic objective of security. In order to meet the major health challenges identified, the Health Strategy sets out several objectives. Of these, objective 2 is 'protecting citizens from health threats' and also refers to the focus the Commission would like to place on challenges that have not been fully addressed yet, such as the actions needed on emerging health threats from climate change, and the related impacts for public health and health care systems. For this objective an action point has been formulated specifically on adaptation: 'Health aspects on adaptation to climate change (Commission) (p.9)' (EC, 2007a). It should be noted that the EU Health Strategy provides a strategic framework for public health. Under such a framework, the Member States are responsible to provide health care and formulate health policy, and the Commission's role is to coordinate cooperative action relating to cross-border health threats and the prevention of illness. This implies working on health issues across all sectors (EC, 2007a; PHEIAC, 2011).

In the third EU Health Programme 2014-2020, published in 2014, the following regulation shows the relationships between health and climate change and adaptive action. Article 16 states, in summary, that action under the EU Health Programme can cover cross-border health threats caused, amongst others, by climate change. This article also refers to the Commission's Communication 'A Budget for Europe 2020' where the Commission has committed to the mainstreaming of climate change into the EU's spending programmes, directing at least $20 \%$ of the budget towards climate change related objectives. This budget should also cover health threats from climate change. Under Annex I thematic priorities for actions under the Health Programme are provided of which one is "protecting Union citizens from serious cross-border health threats". Here also actions required for the implementation of Union legislation with regards to health threats from climate change (amongst others) are included (EU, 2014). In the previous EU Health Programme 2008-2013, such articles and/or priorities have not been specified including climate change as a health threat requiring action (EU, 2007). 


\subsection{A discussion on progress and mainstreaming of EU climate change adaptation for health}

In this section, the policy documents on climate change adaptation and health described earlier will be discussed and reflected upon in terms of the progress made on climate change adaptation and issues of mainstreaming. The final section will take a glance at the way EU climate adaptation for health can move forward.

\subsubsection{Discussion of EU climate change adaptation policy}

When examining the development of EU-level policy on climate change adaptation for human health it can be seen that first of all a gradual greater focus is placed on climate change adaptation besides mitigation and a priority is placed on adaptation to climate change impacts on human health specifically and worked out in more detail over time (Biesbroek et al., 2010; EC, 2013a, 2013d; Keessen, 2014). According to Keessen (2014), the vision of the European adaptation policy is unclear as both the White Paper and the European Adaptation Strategy aim to improve resilience in the face of climate change, but lack a definition of resilience.

It is important to note that even though policy and legislation have been developed over recent years in the area of adaptation to climate change, the EU does not set any binding rules for adaptation to climate change. Therefore even in light of the fact that the Commission urges Member States to develop and adopt national adaptation strategies (EC, 2013d), this action point is dependent on the initiatives Member States take themselves at the national level with regards to the development of national adaptation responses. Despite the absence of any binding rules, many European Member States have put regional and national level adaptation strategies into place (Keessen, 2014).

There is no Adaptation Directive yet, but the Commission might propose one (Keessen, 2014). In the EU Strategy on adaptation to climate change it is stated that in 2017 the Commission will assess the sufficiency of the actions taken by Member States towards the adoption of a comprehensive adaptation strategy. If this progress is deemed to be insufficient, the Commission will consider proposing a legally binding instrument (EC, 2013d). Therefore whether the EU will continue to have Member States commit voluntarily to adaptation to climate change or instead will resort to the instilment of binding rules remains to be seen (Keessen, 2014).

An Adaptation Directive could oblige Member States to develop adaptation plans. From a legal point of view, according to Keessen (2014), such a Directive would be limited, as Member States can still determine for themselves to what extent they will adapt. And related to this, the Directive could also not provide enough guidance or incentive for the adoption of adaptation measures in different policy fields and the mainstreaming of 
these. In any case, a Directive is not a guarantee for successful and effective adaptation to climate change (Keessen, 2014).

Thus at this moment the sufficiency of the development and adoption of adaptation strategies by Member States still stands to be evaluated. However, it is worthwhile taking a look at Member States' actions with regards to the development and implementation of national adaptation strategies, based on the information provided on the European Climate Adaptation Platform 'Climate-Adapt' and the Commission Staff Working Document 'Guidelines on developing adaptation strategies' (EC, 2013e, 2014a, 2014b). This will give an insight into the progress that is potentially made. Even though in order to address these issues a full evaluation should be undertaken. Moreover, it should be noted that in this discussion the focus is placed on the National Adaptation Strategies and not on other local or regional adaptation initiatives in place at the Member State level. Further research would be necessary in order to also capture these initiatives and actions.

Since the turn of the century, Member States at national or local governance levels have begun to develop and put into practice adaptation practices in order to cope with climate change impacts. Since 2005, National Adaptation Strategies (NASs) started to be developed and implemented in EU Member States, with the aim of enhancing national coordination and facilitation of adaptation activities (Biesbroek et al., 2010). The Member States are all at different stages with regards to the development and implementation of an NAS. To date, the following countries have adopted an adaptation strategy: Austria, Belgium, Denmark, Finland, France, Germany, Hungary, Ireland, Lichtenstein, Lithuania, Malta, the Netherlands, Portugal, Slovakia, Spain, Sweden, Switzerland, Turkey, and the United Kingdom (EC, 2013b, 2014a). In these countries no adaptation strategy has been adopted: Bulgaria, Croatia, Cyprus, Czech Republic, Estonia, Greece, Iceland, Italy, Latvia, Luxemburg, Norway, Poland, Romania, and Slovenia (EC, 2014a). It should be noted that, the implementation at the Member State level should be evaluated on a country-by-country basis taking into account the differences in vulnerabilities that the respective country faces. Action or inaction can be a reflection of a country's specific situation, therefore progress on national adaptation strategies cannot be compared well between European countries (Wolf et al., 2014).

According to a study conducted in 2010 by Biesbroek et al. (2010), NASs generally all cover a wide range of issues and vulnerable sectors. The authors show that of the countries' NASs that they have analysed Denmark, Finland, Spain, Germany, and the UK show that human health is a vulnerable sector that will be dealt with in the NASs. France has made a clear prioritization of human health in their NAS, as the only country of those included in this study. The Netherlands does not identify human health as a vulnerable sector or priority in their NAS (Biesbroek et al., 2010). To date, according to the information gathered from the Climate-Adapt Platform, of the countries that have adopted an adaptation strategy, there are several that emphasize human health as a priority sector 
for their national adaptation efforts: Austria, Denmark, Finland, France, Germany, Hungary, Lichtenstein, Lithuania, Malta, Portugal, Slovakia, Spain, Switzerland, and the United Kingdom. The priority areas of Belgium were not as explicitly including human health. The Belgian national adaptation strategy emphasizes the impacts of climate change on the health sector, mainly focusing on heat-effects, and delineate 5 categories for action, of which the first appears to be most directly related to climate adaptation for health 'reducing human and natural vulnerabilities and improving building resilience'. (Other action categories can arguably be related indirectly to adaptation for health, covering such issues as technological and institutional change). So, it appears that Belgium includes human health in its strategy but it is not as explicitly stressed on the Climate-Adapt Platform as for the other countries mentioned before. Ireland has, for the moment, not identified health as a key priority area, but state that the identification of priorities is an ongoing process as a part of their national adaptation strategy. The Dutch description of their adaptation strategy does not explicitly discuss health as a priority area. It should be noted that the Climate-Adapt Platform offers limited information on what each Member State has done in terms of their national adaptation strategy; it does not become clear to what extent adaptation is developed and implemented for health specifically (EC, 2014a). ${ }^{20}$

A recent study on the implementation of action to counter health impact of climate change in the WHO European area by Wolf et al. (2014) confirms that vulnerability and impact assessments, strengthening of health systems, and raising awareness are more strongly developed. However, the level of governmental approval and uptake of national health adaptation plans is still low. They found that implementation of national health adaptation plans (amongst others) could benefit from more support (Wolf et al., 2014). Research conducted for the evaluation of European national adaptation strategies shows that many strategies were rather agendas for further research, or aiming at awareness raising, coordination, or communication for implementation. Thus actual implementation is found to be limited, and restricted to sectors such as water resource management, disaster risk reduction, environmental protection, and spatial planning (IPCC, 2014c).

Generally speaking, more evaluation and monitoring of the implementation of adaptation strategies needs to be done (EC, 2013d; IPCC, 2014b, 2014c) in order to determine what progress is made, what the effectiveness is of adaptation measures adopted, and what the role of the EU is in guiding and coordinating adaptation efforts at all levels in Europe. When looking back at the European policy documents on climate change adaptation (for health), it can be recognized that the Commission aims to coordinate the

\footnotetext{
${ }^{20}$ The adaptation strategy of the following countries could not be examined in detail, as information is not (yet) available: Sweden and Turkey. Therefore for these countries the priority areas are not included in this discussion.
} 
implementation of the EU strategy on adaptation, as well as ensure the integration and coherence of adaptation measures on all levels. Moreover, the Commission facilitates the exchange of best practices, and aims to fill knowledge and action gaps. Financial support through the LIFE funding will be provided for adaptation (EC, 2009a, 2013d). This coordinating role is specifically relevant when addressing cross-border threats from climate change as can be the case for human health. In such cases well-coordinated and consistent actions are important. Thus even though there are no EU-level binding regulations in place, the coordinating function of the $\mathrm{EU}$ is highly relevant in the field of climate change adaptation for human health impacts. When comparing different regions globally, according to the IPCC (2014c) the EU has been an important force in the development of climate policy and governance for countries in the European region. The governance structure present in Europe is important in reducing or exacerbating Europe's vulnerabilities to climate change, as the region is so highly regulated compared to other regions globally (IPCC, 2014c).

\subsubsection{Discussion of EU health policy in relation to climate adaptation}

In 2011 a Mid-Term Evaluation of the EU Health Strategy was published. This evaluation was commissioned by the Directorate General for Health and Consumers with the aim of evaluating the implementation and impacts of the EU Health Strategy for the period of 2008-2010, also with the purpose of guiding the future implementation of the EU Health Strategy (PHEIAC, 2011). The evaluation states that progress has been made on each of the principles and objectives set out in the EU Health Strategy, however to a varying extent (PHEIAC, 2011). The impact of the EU Health Strategy on other EU policies has been evaluated and shows that EU policies, activities and funding programs in other areas take health into account adhering to the principles and objectives of the EU Health Strategy, however, no direct impact of the EU Health Strategy on other EU policies could be found (PHEIAC, 2011). This conclusion could also apply to the development of climate change adaptation policy. Health has been incorporated increasingly in the EU policy area of climate change adaptation, and in acknowledgement of the EU Health Strategy (EC, 2013a). The evaluation shows that Member State outputs directly related to the EU Health Strategy are taken in a range of action areas, where Member States' actions taken on environment/climate change is relatively smaller than for other areas making up $2.2 \%$ of all actions taking place in all action areas. The same evaluation has been done for EC's actions, and here environment/climate change make up $2.9 \%$ of all actions in all action areas. The Senior Level Working Party created by the Council to support the implementation of the EU Health Strategy has discussed specific priorities and actions amongst which is climate change and specifically the health aspects of adaptation to climate change. Indicators are proposed in order to monitor progress of Member States in terms of the EU Health Strategy's principles and objectives. Here for the purpose of monitoring objective 2 of the EU Health Strategy, also climate change is a proposed 
indicator referring to "the number of [member states] that have adopted a specific strategy to deal with / mitigate the likely effects of climate change on human health (before / after the adoption of the [Health Strategy]) (p.158)" (PHEIAC, 2011). Here it seems that mitigation is at least explicitly included, and adaptation is not mentioned but might still be included under the activities of dealing with the likely effects of climate change on human health. It would seem from this that more explicit attention is paid to mitigation in this indicator to monitor progress on objective 2. The members of the EUHPF, the European Union Health Policy Forum, which is the other coordinating mechanism responsible for supporting the implementation of the EU Health Strategy, points out that there are some principles and objectives of the EU Health Strategy on which more work remains to be done, and in general the strategy is too ambitious to be achieved in 2013. Also climate change (part of objective 2) is mentioned as an area where more work needs to be done. International organizations and partners, have also been included through stakeholder interviews for the evaluation, and indicated that climate change has not been sufficiently covered in the EU Health Strategy (amongst other issues). The publication of the Commission Staff Working Document on 'adaptation to climate change impacts on human, animal and plant health', addressing health aspects to climate change adaptation, is mentioned as an action that has led to some progress with regards to achieving objective 2 of the EU Health Strategy based on the Commission's inventory of EC output (PHEIAC, 2011).

Moreover, in the examination of relevant health policy documents, it could also be seen that the third EU Health Programme 2014-2020 incorporates that action under the programme can cover cross-border health threats caused by climate change (amongst others) (Art. 16). Also under the actions formulated in the EU Health Programme 20142020 the protection of Union citizens from serious cross-border health threats is prioritized, thus here again actions required also in light of climate change as a driver for health threats are included. In the previous EU Health Programme 2008-2013 such articles or actions incorporating the necessity of action to protect health from climate change are not explicitly included (EU, 2007, 2014).

Overall, it can be seen that the development of EU policy for the governance of adaptation to climate change-induced health outcomes is also gradually and increasingly reflected in key EU health policy documentation. Priorities placed on the necessity to act upon climate change threats for health seem to be stressed more, and from the MidTerm Evaluation of the EU Health Strategy is can be seen that some of the stakeholders involved in this evaluation process point to the importance of incorporating climate change and health and/or specifically adaptation. The publication of the Commission Staff Working Document on 'adaptation to climate change impacts on human, animal and plant health' is seen as a step towards achieving objective 2 of the EU Health Strategy (PHEIAC, 2011), and at the same time is it a key document for making progress on EU policy on climate change adaptation with specific attention for health outcomes, as could be seen earlier in the discussion of climate change adaptation policy. 


\subsubsection{Mainstreaming}

In order to tackle climate change and its consequences, a more integrated, holistic approach is necessary to meet the complexity at hand (Martens et al., 2012). Mainstreaming, or in other words, integrating the climate adaptation agenda into health policy, and the other way around integrating health priorities into climate adaptation policy, is a way to find synergies and opportunities in existing(/or newly created) instruments, structures, and policies in order to cope more effectively with climate change-induced health outcomes (EC, 2013a, 2013e; Menne et al., 2008).

The necessity of mainstreaming adaptation efforts into other policy domains, including health, is recognized and discussed in EU policy documents on climate change adaptation. The White Paper on adapting to climate change published in 2009 (EC, 2009a) clearly states the necessity of mainstreaming adaptation into EU policies, and discusses sectors with high EU policy involvement where this would be relevant, including health policy. In this context, the document points to the fact that the EU Health Strategy also foresees action on adaptation, and that the EU Health Programme provides for the EU to assist Member States in this. Specifically the following areas are pointed out in need of further exploration in order to take action on climate change impacts on health: epidemiological surveillance, control of communicable diseases, and the effect of extreme events (EC, 2009a).

In the EU Strategy on adaptation to climate change (EC, 2013d) the Commission prioritises and takes responsibility over mainstreaming adaptation into EU policies and programmes, and undertakes a legislative proposal to integrate adaptation into the area of health (amongst others) (EC, 2013d). In the relating Council Conclusions, the Council "emphasises the importance of mainstreaming adaptation into all relevant policies at all levels of government [...] and welcomes initiatives to integrate adaptation in [...amongst others] health (p.5) (Council, 2013)".

The Commission Staff Working Document specifically focussing on adaptation to climate change impacts on human health (EC, 2013a) shows through the CEHAPSIS Project (Climate, Environment and Health Action Plan and Information System) the need to on the one hand integrate climate change into health policies in order to enhance the ability of the health sector and systems to take action on climate change, and on the other hand integrate health into climate change adaptation and mitigation policies with the aim to enable adaptation and mitigation measures to better achieve health benefits (EC, 2013a).

The Commission Staff Working Document providing guidelines for developing adaptation strategies (EC, 2013e) explains that mainstreaming adaptation with existing programmes and policies is a common aspect of 'good adaptation'. Mainstreaming can be accomplished by making use of existing instruments, structures, and policies which can create synergies and reduce costs; but there can also be a need to develop new instruments to reach mainstreaming objectives. Moreover, the document shows that health is identified as one of the key areas for initiatives on mainstreaming adaptation (EC, 2013e). 
From a health policy perspective, the importance of mainstreaming health concerns into other policy areas is clearly illustrated by the fundamental principle for EU's action on health 'Health in all Policies (HIAP)', provided in the EU Health strategy. This principle, in short, aims to strengthen the integration of health concerns in all policies at EU, Members State, and Regional levels (EC, 2007b). Based on the HIAP principle, the EU Health Strategy formulates the action of strengthening the integration of health concerns in all policies at all levels (EC, 2007b). In the Declaration of the European Commission to the Fifth Ministerial Conference on Environment and Health in Parma (EC, 2010a) the Commission commits to integrate health issues in all mitigation and adaptation policies at all levels and in all sectors (WHO-Europe, 2010c). Thus, from a health policy perspective the importance of mainstreaming is recognized, also specifically with respect to climate change adaptation policies.

According to the EU Strategy on adaptation to climate change, progress has been made to integrate adaptation into several EU (sector specific) policy documents (such as e.g. biodiversity), EU legislation for e.g. forestry, and financial programmes. The Commission plans legislative proposals in order to integrate adaptation in key vulnerable sectors amongst which health is one (EC, 2013d). With regards to EU health policy it is stated that "[...] most human, animal and plant health measures and systems are already in place, but they need to be adjusted to whatever new challenges climate change will bring (p.8)" (EC, 2013d). When looking at the adaptation planning at the Member State level Biesbroek et al. (2010) explain that some NASs also emphasize the interconnectedness of different areas. For instance, France defines health as a cross-cutting issue. The recognition of these sectoral interconnections in NASs can be a way to mainstream adaptation actions across different issues.

The progress in enhancing mainstreaming between climate change adaptation and health depends according to Keessen (2014) also on the role the EU has in that sector, and its competence in that policy area. Thus, for instance for the EU to impose binding obligations to ensure the integration of climate change concerns in a policy area depends on the role the EU has in the area at hand. For health, she clarifies that the EU does not have the competence to e.g. prescribe adaptation to climate change in the implementation of health policies; the EU is only competent to take supplementary action (Keessen, 2014) (action supplementary to the actions taken by the Member States themselves regarding health and the integration of climate change adaptation in these policies).

Globally speaking, mainstreaming of adaptation has also been challenging especially when having to take into account different structures in place at national, subnational, and local levels (IPCC, 2014b). There are much more opportunities to mainstream climate change and health for more effective adaptation that are not yet exploited to their full potential (Abrahams et al., 2012).

A clear commitment to mainstreaming climate change adaptation and health can be found through the analysis of EU policy documentation on climate change adaptation 
and health. However, it is difficult to gather to what extent mainstreaming is actually implemented with the aim of improving adaptation to climate change impacts on health, and what still needs to be done in terms of mainstreaming to optimize this. The lack of evaluation and monitoring of adaptation efforts and the difficulties in measuring its effectiveness (discussed earlier in this chapter) might feed into these unknowns, as well as the fact that the policy implementation in the areas of health and climate change for a large part happens at the Member State level which would require more research at the national level in order to gain further insight into the extent of mainstreaming of adaptation and health taking place in the EU at the national level.

\subsubsection{Moving forward}

In the actions proposed in the EU Strategy on adaptation to climate change (EC, 2013d) some key future steps are identified. All Members States are expected to adopt comprehensive adaptation strategies. In light of this the European Commission plans to develop an adaptation preparedness scoreboard by 2014 as well as a Monitoring Mechanism Regulation in 2017, in order to assess the progress Member States have made with respect to the adoption of national adaptation strategies. If Member States' progress is insufficient, the Commission will consider to propose a legally binding instrument in 2017 (EC, 2013d).

From a health policy perspective, Menne et al. (2008) stress that in the years to come the extent to which health systems can incorporate and implement adaptation and mitigation strategies will be crucial for the ability to protect health from climate change. The health sector can be an example for other sectors when it takes on a proactive attitude in dealing with climate change (Menne et al., 2008). According to the IPCC (2014c), in Europe adaptation in the health sector has been mostly reduced to the development of heat health warning systems, however this is also related to the lack of research done on effective adaptation options in this context. An expert study identified necessary institutional changes for the improvement of responses to climate change risks for the future in a European context: "ongoing surveillance programs, collaboration with veterinary sector and management of animal disease outbreaks, national monitoring and control of climate-sensitive infectious diseases, health services during an infectious disease outbreak and diagnostic support during an epidemic (p. 24)" (IPCC, 2014c).

The extent to which health systems need to be adapted to climate change impact is also influenced by a whole range of other determinants for health (also non-climatic and non-environmental) and depends on the existing health burden (IPCC, 2014a).

Proactive and concerted action is needed in order to cope with climate change impacts on health (Semenza \& Menne, 2009). A proactive approach to adaptation or early adaptation is also encouraged in the EU Strategy on Adaptation as well as the related earlier White Paper (EC, 2009a, 2013d). However, even though the adaptation strategy sets out for early action, the implementation of adaption strategies (also at the Member State 
level) has not been a fast process and whether this can be typified as early adaptation or as more of a reactionary approach is arguable. This also depends on more monitoring and evaluation that is to be done on the status of the adoption of adaptation mechanisms and their actual effectiveness.

More evidence is needed to assess how much progress has exactly been made in terms of adaptation to climate change-induced health impacts, and this can also support the future development of adaptation governance at an EU level and national and local levels as well. Moreover, the elaboration of guidelines on how to adapt best to health impacts from climate change would meet information needs in this context.

\subsection{Conclusions}

This chapter aims to shed light on the development and status of EU adaptation to climate change-induced health outcomes, by reviewing and reflecting on EU climate adaptation policy documents and EU health policy documents. Moreover, progress and mainstreaming have been discussed. As previous chapters in this dissertation report on research relating to climate change impacts on health (infectious diseases specifically) and potential responses to these risks, this chapter gives a complementary overview of the EU climate change adaptation relevant as a contextual background for these chapters.

From the review and discussion of EU climate adaptation policy it follows that over the years a growing emphasis is placed on adaptation action for health impacts from climate change. However, even though this prioritisation of health appears, the actual adoption and implementation of adaptation at an EU and Member State level is at times limited and varies greatly across Member States. In relation to this, monitoring and evaluation of adaptation results is lacking which makes the successfulness and effectiveness of such adaptation efforts unclear.

To date the EU does not set any legally binding rules for adaptation to climate change there is no Adaptation Directive; so Member States develop NASs at their own initiative and in their own way. Nevertheless, many Member States have put NASs into place (Keessen, 2014). In light of this, it will be interesting to see how (in 2017) the Commission will assess the progress Member States have made towards the adoption of NASs, and whether a legally binding instrument will be proposed as a result of it (EC, 2013d; Keessen, 2014).

From the discussion of some key EU health policy documents it can be seen that increasing attention is paid to the role of climate change and at times specific reference is made to adaptation. For instance, the third EU Health Programme 2014-2020 incorporates that action under the programme can cover cross-border health threats caused by climate change (amongst others) (Art. 16). Moreover, under actions, the protection of Union citizens from serious cross-border health threats is prioritised. In the previous EU Health Programme 2008-2013 such articles and actions to protect health from climate 
change have not been explicitly incorporated. Here a clear progression in making climate change increasingly more explicit and important in health policy is shown. The recent publication of the Commission Staff Working Document on 'Adaptation to climate change impacts on human, animal and plant health' (EC, 2013a) is a clear step towards placing specific attention on climate change adaptation for health outcomes in EU policy. The review of EU policy documentation on climate change adaptation and health shows that there is a strong commitment to mainstream climate change adaptation and health. Enhanced mainstreaming efforts can contribute to the effectiveness and efficiency of adaptation responses for health. However, it is difficult to gather to what extent mainstreaming is actually implemented with the aim of improving adaptation to climate change impacts on health, and what still needs to be done in terms of mainstreaming to optimize this.

It should be acknowledged that it is not clear whether the EU strategy on adaptation to climate change and the related documents are a true driver behind actions taken at the Member State level. For the EU Health Strategy a mid-term evaluation has been conducted in 2011, and here it became clear that the outputs at Member State level cannot be attributed directly and exclusively to the EU Health Strategy. Moreover, in most Member States the influence of the EU Health Strategy on national health strategies was found to be limited. The EU Health Strategy's main value is to act as a guiding framework and as a catalyst for actions at the EU level (PHEIAC, 2011). A similar evaluation to see to what extent the EU Strategy for Adaptation is of influence on Member States' actions would be interesting. This can also shed light on the role of the EU in guiding and coordinating adaptation efforts at all levels. This coordinating function of the EU is of great importance for the field of climate change adaptation for human health impacts, in order to govern integrated and well-coordinated responses that reduce overall vulnerabilities in the European regions.

More monitoring and evaluation to increase the evidence base on effective climate change adaptation for health needs to take place, which will also support the future development of EU adaptation to climate change-induced health impacts. In addition, adaptation guidelines specifically focussing on health impacts are needed. 



\section{CHAPTER 7 \\ CONCLUSIONS AND REFLECTION}


In this chapter conclusions and a reflection are offered based on the studies presented in this dissertation. In order to do so, the main conclusions for each research objective of this dissertation, as introduced in Chapter 1, are summarized. Finally, some general conclusions and reflections on the research done for this dissertation are given.

\subsection{The relationship between globalisation and health}

The first research objective introduced in Chapter 1 and addressed by the study in Chapter 3 was: To analyse the relationship between globalisation and health. The study in Chapter 3 analysed the relationship between globalisation and health making use of a statistical indicator analysis where the Maastricht Globalisation Index (MGI), a measure of globalisation, was linked to mortality indicators as measures for population health. The aim of this analysis was to find out if more globalised countries, as measured by the $\mathrm{MGI}$, are experiencing better health, as measured by the health indicators used in the study, correcting for confounding factors.

The pluralistic conceptualisation of globalisation assumed for this study is reflected in the wide range of domains (political, economic, social and cultural, technological, and ecological) incorporated in the MGI, which is a weighted index. Higher values of the MGI denote more globalisation. The MGl dataset includes 117 countries (Akin et al., submitted; Martens \& Raza, 2009; Martens \& Zywietz, 2006; www.globalisationindex.info). The MGI for 2008 was used in the analysis.

In order to link a country's globalisation with the status of population health in that country, several mortality indicators were selected, based on the World Health Statistics (WHO, 2009b): Infant mortality rate (per 1000 live births, both sexes), under-five morality rate (probability of dying by age 5 per 1000 live births, both sexes), and adult mortality rate (probability of dying between 15 to 60 years per 1000 population, both sexes). For the statistical analysis the following methods were used: correlation analysis, least squares (LS) simple linear regression analysis, and multiple regression analysis.

The results of the analyses (Spearman's correlations, simple and multiple linear regression analyses) indicate that the infant mortality rate, under-five mortality rate and adult mortality rate all show a negative association with the process of globalisation (as measured by the MGI). Specifically, technological globalisation and socio-cultural globalisation show strong associations with the selected health indicators. In all multivariate models, the association between globalisation and the mortality indicators remains significant after controlling for confounding factors. The multivariate analyses show that different confounders are found to be significant in the three final models. Specifically, for Ln Infant mortality rate confounders accounting for primary and secondary education and public health expenditures are significant. For the Ln Under-five mortality rate, next to the confounders for primary and secondary education, smoking prevalence among 
women show to be significant in the final model. Lastly, for the model of Ln Adult mortality rate, only a confounder on access to improved sanitation facilities is significant. These factors thus can possibly function as confounders in the associations between the respective mortality rates with the MGI. However, the confounders in the final models could also be important mediating/causal factors in the association between the mortality rates and the $\mathrm{MGI}$. Either way, in all multivariate models, the association between globalisation and the mortality indicators remains significant after controlling for confounding factors.

These results might provide a crude initial indication of the potential advantageous effect of globalisation on health. In other words, high levels of globalisation are associated with low mortality rates. However, in view of the argument that globalisation creates winners and losers, interpretation of the resulting positive association between the MGI and health should be done with care and not taken as a simple confirmation of globalisation being good for our health (also see (Akin et al., submitted).

The results of the statistical analysis of the consequences of globalisation for health show that globalisation and its linkages to health are far more complex. The statistical analysis is a useful method to gain a crude insight into the relationship at hand. The identification of possible confounders is also a step towards understanding which factors are potentially relevant to the globalisation-health relationship. However, for drawing conclusions on such (global) statistical analyses it is important to be cautious and keep the limitations and underlying assumptions in mind (also see (Akin et al., submitted).

Several limitations in using the MGI (and in general globalisation indices) exist. Since there are missing data on the share of international linkages that are regional rather than global, it is impossible to distinguish globalisation from internationalisation and regionalisation with complete certainty. Therefore, there is an underlying assumption that countries with many international links have a correspondingly greater number of global linkages. As expected, the data for the indicators included in the MGI have varying quality, and data collection is limited by data gaps and missing data in some cases. Missing data can found for countries with fewer international linkages, countries with communist or totalitarian regimes, or countries that are too small to collect such statistics (Rosendorff \& Vreeland, 2006). This caused for some countries to not be included in the MGI dataset.

Both the sensitivity to extreme values and year-to-year variations are a major concern for the robustness of (other) indices for globalisation. With the methodology used to construct the MGI, the sensitivity of the index to extreme values has been sharply reduced since the distribution is now centred on the mean of a component rather than just lying somewhere between the extreme values. Similarly, the strongest year-to-year variations are filtered by the averaging process for the highly volatile components, sharply decreasing the dependence on the choice of base year in some of the component indicators. Furthermore, for maximum transparency, we have relied on equal weighting (OECD, 2008). Weights are in essence value judgments. The allocation of the 
weights must be evaluated with care according to its analytical rationale, globalisation relevance, and implied value judgments (see e.g. (Dreher et al., 2008; Martens \& Raza, 2009; Martens \& Zywietz, 2006)).

Besides the limitations to the use of a weighted composite index to measure globalisation, the statistical indicator analysis is beset with the uncertainties and assumption that apply to any global statistical indicator analysis (De Lombaerde \& Lelio lapadre, 2008). All indicators and their underlying data are on the country level, without a specific spatial dimension. Globalisation interacts with health at levels that make measurement difficult, e.g., trans-border environmental issues, cultural transformations and a so-called 'global consciousness'. Furthermore, this analysis is based on 'present day data'. As the globalising processes intensify over time, the indirect impacts of human-induced disruption of global biogeochemical cycles and global climate change, and their impacts on human health, may start to become more apparent (Martens \& Huynen, 2003; Martens \& Rotmans, 2005).

\subsection{Climatic and non-climatic drivers of infectious disease risk in Western Europe}

The second research objective which was addressed in Chapter 4 was: To explore expert views on the importance of climatic and non-climatic drivers for infectious disease risk in Western Europe and their uncertainty in terms of in their future development. The study presented in Chapter 4 addressed this objective by presenting the results of a survey, conducted as a part of an integrated participatory assessment for the ENHanCE research project, which explored Dutch expert perspectives on the relationship between climate change and infectious disease risk. Potentially relevant non-climatic drivers of infectious disease risk in Western Europe are also addressed in this survey, and compared in terms of importance with climatic drivers by the experts. The analysis integrates multiple drivers and takes on an overall holistic view on the causation of infectious disease risk. This study was conducted to shed more light on the views Dutch experts have on the causation of infectious disease risk in Western Europe, integrating climatic and non-climatic drivers. Surveying expert stakeholders is a way to uncover existing perspectives (and the possible diversity amongst these) in the Netherlands, concerning the relationship between climate change and infectious disease outcomes in Western Europe. For this purpose, a qualitative survey was executed. In preparation of this, a stakeholder analysis was performed for the identification of experts and selection of an expert sample for the survey. The resulting survey data were analyzed using descriptive statistics. In order to explore the experts' opinions according to the experts' self-indicated professional background, all descriptive analyses were done for the aggregate sample as well as for the two sample subgroups "Policy" and "Science". 
The results of the survey reveal information on the opinions of the expert sample, and the two sample sub-groups "Science" and "Policy", on the importance, uncertainty, and comparative importance of climatic and non-climatic drivers for infectious disease risk in Western Europe. The results show that the experts consider temperature change, precipitation change, humidity change, and climate change-induced habitat change to be relatively important for water-related infectious disease risk, vector-borne disease risk excluding zoonoses, and the risk of zoonoses. The climatic drivers are seen as relatively less important for food-related infectious disease risk. The experts rate many nonclimatic drivers to be highly important for infectious disease risk. Comparatively, the majority of the non-climatic drivers assessed are seen as more important than climate change drivers. The degree of uncertainty in the future development of climatic drivers is viewed as moderate to high, and for non-climatic drivers mostly as moderate. An analysis of subsamples based on professional backgrounds reveals differences in experts' opinions for e.g., socio-cultural drivers, and similarities.

The results of the survey should be seen as an indication of the perspectives of Dutch experts on the importance and uncertainty of climatic and non-climatic drivers for infectious disease risk in Western Europe, based on the Dutch expert sample that participated in this study. For the investigation of issues of greater complexity and uncertainty such as climate change impacts on infectious diseases and the related policy, the involvement of experts for the exploration of their perspectives can be a useful approach to gain more insights into this complexity and discover underlying values (de Ridder et al., 2007; Kloprogge \& van der Sluijs, 2006). For the interpretation of the results of this study it should be noted that a Dutch expert sample was surveyed. Another issue that should be considered for the interpretation of results is the focus on Western Europe, as disease outcomes from climate change vary across geographical locations.

The analyses of expert opinions of the two sample groups "Science" and "Policy" can point towards possible differing perspectives held in the two professional environments regarding certain drivers and/or their uncertainty and importance for infectious disease risk. The differences found between the two sample groups could be due to diversity in underlying values within each professional environment (Nordhaus, 1994).

Diversity and consensus amongst expert perspectives on climate change and infectious diseases can have implications for policy. Differences in expert views can play out in decision-making and policy contexts with regards to climate change and infectious disease risk. Awareness and recognition of the diversity of values creating the variety in expert opinions can facilitate decision- and policy-making processes for the governance of climate change-induced infectious disease risk. Further exploration of expert opinions on climate change and infectious disease risk and comparisons across professional backgrounds would be necessary in order to shed more light on possible differences and identify prevailing perspectives on this topic. In addition, the influence of other issues on the diversity of opinions should be considered, such as potential existing information asymmetries between scientific and policy communities. 


\subsection{Adaptation responses for climate change-induced infectious disease risk in Western Europe}

The third research objective introduced in Chapter 1 was: To explore expert views on adaptation responses to climate change-induced infectious disease risk in Western Europe, and the willingness and capacity of relevant actors in such a response. This objective was addressed in the study presented in Chapter 5, which aimed to explore the perspectives of Dutch experts on adaptation responses to climate change-induced infectious disease risk in Western Europe, and examine expert's views on the willingness and capacity of potentially relevant actors in this response effort as well as the priorities placed on mitigation and adaptation responses (see Mclntyre et al. (2010)). This study, like the study presented in the previous chapter, reports on part of the results of the survey conducted for the ENHanCE project. The study was conducted as a part of a participatory integrated assessment where the involvement of stakeholders (in this case, experts) was used as a way to address complexities and uncertainties that are common to environmental and specifically climate change problems (de Ridder et al., 2007; Kloprogge \& van der Sluijs, 2006). A survey was used to uncover existing perspectives (and possible diversity amongst these) on responses to climate change-induced infectious disease risk in Western Europe in the Netherlands, by targeting a Dutch expert sample. In preparation of this, a stakeholder analysis was done to sample Dutch experts. The resulting survey data were analysed using descriptive statistics, for the aggregate sample and the two sample groups "Policy" and "Science". The analyses for the sample subgroups were done in order to explore experts' opinions according to the experts' self-indicated professional background. (The broad methodological approach of this study and the study presented in Chapter 4 is the same as both report on different results of the same study).

The results show that the experts view the adaptation responses differently according to the assessment criteria. The experts consider some adaptation responses as relatively more cost-effective, like fostering interagency and community partnerships, or beneficial to health, such as outbreak investigation and response. Expert opinions converge and diverge for different adaptation responses. Based on these analyses one cannot deem one response as better as or worse than another. Important to note are those cases where the experts seem to show much divergence or consensus, which can indicate to what extent the results show a more or less shared perspective on the assessed response in question. Moreover, in practice, the priorities characterising a decision-making context will influence which responses will be most fitting for the situation at hand. Also Füssel (2007) explains that adaptation responses are highly context-specific. In practice, some criteria for making decisions on adaptation measures might take precedence over others. For example, monetary costs are recognized as a key barrier to adaptation, as well as insufficient technical skills, or lack of political will (EC, 2009a; Füssel, 2007). This may affect the choice for an adaptation response strategy. Regarding the prioritization 
of mitigation and adaptation responses, expert perspectives converge towards a 50/50 budgetary allocation. The experts consider the national government/health authority as the most capable actor to respond to climate change-induced infectious disease risk.

The survey results should be seen as an indication of the perspectives of Dutch experts on the responses to climate change-induced infectious disease risk in Western Europe, and the willingness and the capacity of the actors in such a response effort, based on the Dutch expert sample that participated in this study. The approach to conduct a participatory integrated assessment for the ERA-ENVHEALTH ENHanCE research project, of which this survey was a key research component, allowed for the involvement of stakeholders (the expert sample) to address the complexities and uncertainties inherent to the topic of climate change and infectious disease risk. The exploration of expert perspectives can provide insights into the complexity of climate change (and other environmental topics), as well as the related policy field (Akin \& Martens, 2014; de Ridder et al., 2007; Kloprogge \& van der Sluijs, 2006). Currently there is a lack of guidelines for the assessment of policy options for climate adaptation decision-making (WHO-Europe, 2010b). The use of expert perspectives to gain more insight into the responses assessed according to a broad range of criteria can help to address this need. The survey only relied on the answers provided by the Dutch expert sample, which should be kept in mind for the interpretation of the results of this study. The results of the analyses of the two sample groups "Science" and "Policy" can indicate that the two professional environments possibly have differing opinions when it comes to certain responses, assessment criteria, and the willingness and capacity of the actors. These differences could be related to diversity in underlying values held in the two professional environments (Akin \& Martens, 2014; Nordhaus, 1994).

Differences in perspectives within and between sample groups can indicate a lack of consensus with regards to several responses and the assessed actors, which can have implications for policy processes for climate change adaptation. Increasing our awareness of the diversity in values and related perspectives as well as understanding the underlying (other) drivers of the perspectives can support policy processes for the adaptation to climate change-induced infectious disease risk. Responses which accommodate the prevailing perspectives of a broad range of stakeholders could benefit from greater support (Akin \& Martens, 2014).

In addition, greater awareness of the capacity and the willingness of potentially relevant actors to respond to climate change-induced infectious disease risk can facilitate cooperative and multi-stakeholder policy processes in this sector. A cooperative and integrated approach towards climate adaptation for health under the coordination of the European Union appears to be an important element of European governance of climate change and adaptation for health (EC, 2009a, 2013a).

To establish prevailing perspectives on responses to climate change and infectious disease risk and make comparisons across professional backgrounds, more research involving various stakeholders needs to be done. In addition, the potential role of other factors 
contributing to differences in perspectives should be considered as well, such as possible information asymmetries between scientific and policy communities (Akin \& Martens, 2014). The exploration of expert perspectives on adaptation responses using assessment criteria, as well as relevant actors' willingness and capacity to respond can contribute to our understanding and the governance of the complex issue of climate change and its health outcomes.

\subsection{Adaptation to climate change and health in Europe}

The final research objective, central to the study presented in Chapter 6, was: To describe and reflect on current adaptation to climate change-induced health outcomes in Europe, mainstreaming efforts, and possible ways forward. In this chapter, an overview is provided of climate change adaptation to health outcomes currently in place at the European level. Specifically the chapter aimed to shed light on the role of health in EU climate adaptation policy and at the same time reflecting on key EU health policy and its relation to climate adaptation. This was followed by a discussion on the potential necessary and future development of adaptation policy in order to better meet and tackle current and future consequences of climate change for health in Europe. Thereafter a reflection on mainstreaming as well as the role of the EU with regards to its Member States for climate change adaptation for health was offered.

Previous chapters of this dissertation report, in brief, on research on climate changeinduced infectious disease risk in Western Europe and potential adaptation responses to these risks. This chapter therefore also takes on the purpose of providing an overview of adaptation to climate change and health in the EU. This broader policy perspective placed on the issue of climate change adaptation and health provides a complementary context to the research presented in earlier chapters.

A review of relevant EU policy documents was done, and related publications and empirical studies of EU adaptation are also included. A focus in this analysis was placed on the role of health in climate adaptation efforts in the EU and a reflection is also offered on key relevant health policy documents and their link to climate adaptation efforts. The chapter focused specifically on EU-level climate change adaptation for health, with some reference to international and member state levels where appropriate.

The review shows that climate change adaptation increasingly prioritises health as a key area. However, even though this prioritisation of health appears, the actual adoption and implementation of adaptation at an EU and Member State level is at times limited and varies greatly across Member States. In relation to this, monitoring and evaluation of adaptation results is lacking which makes the successfulness and effectiveness of such adaptation efforts unclear. The recent publication of the Commission Staff Working Document on 'Adaptation to climate change impacts on human, animal and plant health' (EC, 2013a) is a clear step to progress towards placing specific attention on climate 
change adaptation for health outcomes in EU policy. To date the EU does not set any legally binding rules for adaptation to climate change, so Member States develop NASs at their own initiative and in their own way. Nevertheless, many Member States have put NASs into place (Keessen, 2014). It should be acknowledged that it is not clear whether the EU strategy on adaptation to climate change and the related documents are a true driver behind actions taken at the Member State level.

From the discussion of some key EU health policy documents it can be seen that increasing attention is paid to the role of climate change and at times specific reference is made to adaptation. For instance, the third EU Health Programme 2014-2020 incorporates that actions under the programme can cover cross-border health threats caused by climate change (amongst others) (Art. 16). Moreover, under actions, the protection of Union citizens from serious cross-border health threats is prioritised. In the previous EU Health Programme 2008-2013 such articles and actions to protect health from climate change are not explicitly incorporated. Here a clear progression in making climate change increasingly more explicit and important in health policy appears.

The discussion of EU policy documentation on climate change adaptation and health shows that there is a strong commitment to mainstream climate change adaptation and health. Enhanced mainstreaming efforts can contribute to the effectiveness and efficiency of adaptation responses for health. However, it is difficult to gather to what extent mainstreaming is actually implemented with the aim of improving adaptation to climate change impacts on health and what still needs to be done in terms of mainstreaming to optimize this. More monitoring and evaluation to increase the evidence base on effective climate change adaptation for health needs to take place, which will also support the future development of EU adaptation to climate change-induced health impacts. In addition, adaptation guidelines specifically focussing on health impacts are needed.

\subsection{Global change, climate change, and health: Some final reflections}

The overall research aim to this dissertation was: to analyse the relationship between global change, specifically focusing on climate change as a global (environmental) change process, and health, and to assess the adaptation response to climatic consequences for health in Europe. This dissertation focused on global changes and in particular climate change, a global environmental change, and its relations to health and infectious disease risk specifically. And in addition, how to respond (adapt) to the challenges posed by climate change for health and infectious disease risk in Europe. A large part of the research presented in this dissertation was undertaken as a part of the ENHanCE (ERA-NET Health and Climate in Europe) research project. Therefore the purpose and scope of the ENHanCE project also largely determined the research context of this dissertation. 


\subsubsection{Globalisation and health}

From the statistical analysis of the relationship between globalisation, a phenomenon encompassing global change processes, and health it can be gathered that globalisation (as measured by the MGI) is negatively associated with the mortality indicators. However, as explained earlier, this crude initial indication of a potential positive effect of globalisation for health should be interpreted with care, and not taken as a confirmation that globalisation is good for health. The statistical indicator analysis contributed to gain some insights, also in terms of which other factors (significant confounders) may play a role in the relationship between globalisation and health.

A reflection on the merits and limitations of the indicator-based statistical analysis makes it clear that by itself such an approach cannot capture the full picture. The relationship between globalisation and health is far more complex. This challenge of complexity is very apparent when dealing with global change issues. The integrated pluralistic conceptualization of globalisation and its relation to health helped as a way to make the complexity of global dynamics explicit. An integrated approach to the analysis of globalisation and health from a conceptual point of view but also including different perspectives, methods, and disciplines will contribute to understanding this relationship and the consequences for health better. At the same time this also requires research which incorporates different perspectives, multiple disciplines and methods (complementary to a statistical indicator analysis). Without being able to state with certainty whether globalisation will be overall beneficial or detrimental for our health, it is important to step away from this and focus on which direction global dynamics should take in order to achieve sustainable health aims. A deeper understanding of the causal relationship between globalisation and health can aid this process. More empirical research for uncovering the causal mechanisms underlying globalisation and health is necessary. The understanding critical for (future) sustainable development and health requires us to embrace greater complexity (Akin et al., submitted; Huynen et al., 2013; Soskolne et al., 2007).

\subsubsection{The ENHanCE research project: Climate change and infectious disease risk in Europe}

For the ENHanCE research project, a survey was conducted as a part of an integrated participatory assessment, targeting a Dutch expert sample. The results of this study give more insights into the perspectives the Dutch expert sample holds on climatic and nonclimatic drivers for infectious disease risk in Western Europe, as well as responses to this infectious disease risk, and the willingness and capacity of potentially relevant actors in this response effort.

An integrated, population-level perspective on the relationship between climate change and infectious disease risk and related adaptation responses, was taken on as a point for departure for the research conducted for the ENHanCE project. Therefore, non-climatic drivers were integrated in the analysis besides climatic drivers of infectious disease risk. 
This approach helped to gain a more complete picture of the causation of infectious disease outcomes in Western Europe. The relative importance of climatic versus nonclimatic drivers remains an important issue for research and policy, which needs further research attention. Especially with a geographical focus on Western Europe, climatic drivers may often not be the most important drivers for a specific disease risk and rather non-climatic drivers may be the determining influence (as for instance could be seen in the discussion of the results on food-related infectious disease risk, see Chapter 4). Therefore, for future research such an integrated approach where different drivers can be included in research efforts will be helpful to better understand where disease outcomes at a population-level stem from. This can also inform policy and related prioritysetting.

One of the key components of the ENHanCE project was the participatory integrated assessment which allowed for the interaction with end-users of the research, through the involvement of stakeholders (as for instance explained in Kloprogge and van der Sluijs (2006)). Participatory methods, as described in Chapter 2, are a component of integrated assessment methods, and are useful for dealing with issues that are complex, are characterised by uncertainties, and involve varying perspectives and values. It is argued that the quality of research in such cases can be improved by allowing for the inclusion of stakeholder perspectives and values (Kloprogge \& van der Sluijs, 2006; Van Asselt \& Rijkens-Klomp, 2002).

For the ENHanCe project research, a participatory integrated assessment, including expert stakeholders by means of a survey (among other participatory research components in the project), was used as a way to explore perspectives and gain more insights into the topic of climate change and infectious disease risk. This topic has inherent uncertainties and complexities and the response to climate change risks involves different values, which are the typical conditions within which integrated participatory assessment methods can be used (de Ridder et al., 2007; Kloprogge \& van der Sluijs, 2006). There is growing support for and use of participatory methods, and thereby the inclusion of stakeholders, in scientific research as well as for decision-support purposes (Van Asselt \& Rijkens-Klomp, 2002). Participatory methods are also used specifically for the assessment of climate change and global environmental risks, climate change (adaptation) response options, and environmental health impacts (Füssel, 2007; Kloprogge \& van der Sluijs, 2006; Knol et al., 2010).

Participatory methods cover a wide range of methods and approaches to involve stakeholders in research and knowledge production (Van Asselt \& Rijkens-Klomp, 2002). Participatory integrated assessment is in an early stage of development especially within the field of climate change and related responses, and the underlying methodologies and research design are often not clearly defined or documented (Kloprogge \& van der Sluijs, 2006; Lang et al., 2012; Van Asselt \& Rijkens-Klomp, 2002). Moreover, different participatory integrated assessment studies are difficult to compare as their processes 
and characteristics vary (Kloprogge \& van der Sluijs, 2006). All this makes it difficult to make design and methodological choices when conducting participatory research.

From a methodological point of view, the use of participatory methods in the context of climate change and health research can be further developed (Van Asselt \& RijkensKlomp, 2002). Guiding principles are missing on how to conduct participatory research (Lang et al., 2012). The further development of the methodological aspects of participation will also help to address some of the concerns that some may have with regards to these methods (for example about its validity, legitimacy, and credibility) (Lang et al., 2012). Also for research on climate change and health impacts, and related adaptation responses these methodological issues of participatory approaches can be addressed. It should be noted that even when guiding principles and methodological underpinnings are more clearly defined, participatory research remains to some extent context- and/or project-specific (Lang et al., 2012).

The uncertainties and complexities inherent to the relationship between climatic change and health are to the root of remaining research gaps and the difficulties in researching this topic (McMichael et al., 2006; Semenza \& Menne, 2009). Further research, implementing more integrated assessment approaches, can contribute to address these gaps. For the adaptation responses in particular, research efforts to assess adaptation measures using different criteria and including various stakeholders (Ebi et al., 2006; Füssel, 2007) should continue in order to increase our understanding of effective and successful adaptation options and to inform policy on climate change adaptation for health.

\subsubsection{Climate change adaptation for health in Europe}

The last part of the dissertation aimed to map out climate change adaptation for health in Europe. This chapter provides a descriptive brief overview of climate change adaptation for health in Europe, however, much more research can be conducted to understand progress and possible future avenues for optimising adaptation measures to achieve the full potential for risk reduction. Further exploration on the developments at an EU-level and at the member state level with regards to climate change adaptation for health will be interesting in order to find more evidence for the level of adoption and implementation of adaptation measures also at the member state level, the successfulness of adaptation efforts, and the extent of mainstreaming. Incorporating stakeholders for the assessment of adaptation responses can be a valuable and necessary research approach, as explained in the previous section (Ebi et al., 2006; Füssel, 2007). Also more country case studies taking into account country-by-country contexts can be a way to examine adaptation efforts further on the member state level. This can inform the way forward in combating climate change consequences for health and other sectors in Europe. 


\subsubsection{Some final remarks}

The topics researched in the studies presented in this dissertation - global change and health, and climate change and health (and specifically, infectious disease risk), and responses to climate change consequences for health - all have inherent complexities and uncertainties. This poses challenges for research and policy on these issues.

The reflection shows that there are some limitations to the studies presented in this dissertation, and the methods used have their merits as well as challenges for researching topics characterised by greater complexity and uncertainty. Also, the integrative understanding of concepts and relationships employed throughout this dissertation is reflected upon as a way to make complexities explicit. Moreover, based on the research conducted for this dissertation, some avenues for further research on global change, climate change, health impacts, and adaptation are raised. In addition, research opportunities to complement or further the methodological aspects of the studies presented are also discussed.

This research experience shows that integrative research approaches for global change, climate change, and health outcomes and responses, which allows for the inclusion of different perspectives, multiple disciplines and methods can be a way to embrace complexities and uncertainties which will be critical in enhancing our understanding (Huynen et al., 2013; Soskolne et al., 2007). Further research building on these approaches but also complementing the approaches of the studies presented in this dissertation will be a way to enhance our knowledge and understanding of global change, climatic change, and health, and to support healthy and sustainable development. Moreover, the future use and documentation of participatory methods involving stakeholders can help to build and expand the methodological foundations of such research approaches for the analysis of global change, climate change, and health topics. 
VALORISATION ADDENDUM 
The valorisation of research findings in terms of its potential societal value and/or impact, besides its scientific justifications, has received increasing attention. Valorisation has also become an important aspect to the research activities at Maastricht University. In line with this, Maastricht University's regulations for the attainment doctoral degrees now require a valorisation addendum (Regulation governing the attainment of doctoral degrees, Maastricht University, 2013). A reflection on the valorisation of the research findings of a dissertation can help to understand better what the related societal value and relevance of the research findings are, and therefore aims to move beyond the scientific relevance and value of the research findings of a dissertation.

In this valorisation addendum, the research presented in this dissertation is used as a basis for the exploration of possible avenues of how the research findings can have societal benefits, besides the scientific value of the research.

\section{Participatory methods and stakeholder analysis}

In this dissertation, the methodological approach of participatory methods was used for several studies as a part of the integrated participatory assessment conducted for the ENHanCE research project. The research and policy community increasingly engage in transdisciplinary processes and knowledge co-creation. For these processes, the identification and involvement of stakeholders and the effective employment of participatory methods and tools are an essential part.

The research experiences and lessons drawn from projects that involve stakeholders or are designed as participatory and/or transdisciplinary projects are valuable to enlarge the methodological body in this field but also enhance the way such projects are designed, implemented, and evaluated in practice. The studies presented in this dissertation, together with similar studies, can make a contribution to the lessons and experiences on these approaches which can lead to the advancement of participatory and/or transdisciplinary projects. Existing studies using participatory methods and stakeholder analysis, such as in this dissertation, can serve as examples and can also be adjusted and improved or tailor-made for particular contexts.

Based on this research and other research in this field, not only the scientific publications resulting from this can be a way to share research experiences and lessons, but also a report or guide dedicated specifically to inform the academic, policy and other relevant actors on experiences, merits and limitations, and lessons can be produced, which should ideally take into account existing reports and papers which already address this issue and should complement and further elaborate on these.

In order to realise such a report or guide, collaboration should be sought with end-users as well as researchers and policy-makers that have worked on similar studies and that would like to contribute to this report. Existing reports relevant for this effort need to be 
collected and reviewed. And finally a report needs to be produced. A timeline that could be suggested for such an effort could be 12 months.

\section{Climate change adaptation for health in Europe}

As became clear in this dissertation, climate change consequences for health and the way we can respond to these in Europe is a topic that receives increasing policy attention. The research findings of this dissertation can therefore be used to inform policy processes on climate change adaptation for health in Europe. The ENHanCE research project already started in this effort, as relevant institutions and policy-makers and advisors were involved in project meetings and workshops, and results of the project were disseminated through such meetings, but also in the form of reports, presentations, and through the project's website.

Besides this, the research in this dissertation together with the growing body of research on climate change adaptation for health in Europe, can help to design courses and trainings for policy-makers and -advisors but also other professionals that are faced with this topic in their day-to-day work and/or are able to affect or influence the way we deal with climate change consequences. The latter could for instance include businesses that are affected by or work on the issue of climate change and health, health (care) professionals and health (care) institutions, or NGO's working on climate change and health issues. Such courses can help to increase awareness and understanding of climate change and health in Europe, the potential risks, and possible strategies to respond to and cope with consequences. This could support the efforts to respond and manage climate change consequences for health in Europe in an effective manner.

If such a course should be developed, it would be necessary to make connections to the relevant target groups and assess what they would need from such a course specifically. Next, a team needs to design such a course based on the collection of relevant information and materials. There could be a core course design, and a part of the course that is tailored to whatever audience it would target. In terms of a timeline for such a project, an estimate could be 18 months. 

REFERENCES

Abrahams, J., Campbell-Lendrum, D., Kootval, H., Love, G., \& Ortmani del Barrio, M. (2012). Atlas of health and climate. Geneva: World Health Organization and World Meteorological Organization.

Adger, W. N. (2001). Scales of governance and environmental justice for adaptation and mitigation of climate change. Journal of International Development, 13(7), 921931. doi: 10.1002/jid.833

Adger, W. N., Agrewala, S., Mirza, M. M. G., Conde, C., O’Brien, K., Pulhin, J., Pulwarty, R., Smit, B., \& Takahashi, K. (2007). Assessment of adaptation practices, options, constraints and capacity. In M. L. Parry, O. F. Canziani, J. P. Palutikof, P. J. van der Linden, \& C. E. Hanson (Eds.), Climate Change 2007: Impacts Adaptation and Vulnerability. Contribution of Working Group II to the Fourth Assessment Report of the Intergovernmental Panel on Climate Change (pp. 717-743). Cambridge: Cambridge University Press.

Akin, S., \& Martens, P. (2014). A survey of Dutch expert opinion on climatic drivers of infectious disease risk in Western Europe. Climate, 2(4), 310-328. doi: 10.3390/cli2040310

Akin, S., Martens, P., \& Huynen, M. (submitted). Globalisation and health: An indicatorbased statistical analysis. Sustainability Science (at ICIS): An Integrative Approach. Book Chapter. International Centre for Sustainable development and Integrated assessment (ICIS), Maastricht University. Maastricht, the Netherlands.

Albrow, M. (1996). The golden age: State and society beyond modernity. Cambridge: Polity.

Alcamo, J., Moreno, J. M., Nováky, B., Bindi, R., Corobov, R., Devoy, R. J. N., Giannakopoulos, C., Martin, E., Olesen, J. E., \& Shvidenk, A. (2007). Europe. In M. L. Parry, O. F. Canziani, J. P. Palutikof, P. J. Van der Linden, \& C. E. Hanson (Eds.), Climate Change 2007: Impacts, Adaptation and Vulnerability. Contribution of Working Group II to the Fourth Assessment Report of the Intergovernmental Panel on Climate Change (pp. 541-580). Cambridge: Cambridge University Press.

Allen, W., \& Kilvington, M. (2003). Stakeholder Analysis. Lincoln, New Zealand: Crown Research Institute, Landcare Research Manaaki Whenua.

Anwar, W. A., \& Sallam, I. (Eds.). (2003). Global governance interfacing with National Policies. The case of health in Egypt. Hamburg: Deutsche Übersee-Institut.

Barnett, J. (2001). Adapting to climate change in Pacific Island countries: The problem of uncertainty. World Development, 29(6), 977-993.

Beaglehole, R., \& Bonita, R. (2000). Reinvigorating public health. The Lancet, 356(9232), 787-788.

Beck, U. (2004). Der kosmopolitische Blick oder: Krieg ist Frieden. Frankfurt am Main: Suhrkamp Verlag. 
Béjar, H. (2001). Peru: Globalisation consolidated poverty and increased inequality Social Watch Annual Report 2001 (pp. 145-146).

Béjar, H. (2006). Peru: Macroeconomic growth and social exclusion Social Watch Annual Report 2006: Impossible Architecture (pp. 238-240).

Biermann, F., Pattberg, P., \& Zelli, F. (Eds.). (2010). Global climate governance beyond 2012: Architecture, agency, and adaptation (1 ed.). Cambridge: Cambridge University Press.

Biesbroek, G. R., Swart, R. J., Carter, T. R., Cowan, C., Henrichs, T., Mela, H., Morecroft, M. D., \& Rey, D. (2010). Europe adapts to climate change: Comparing National Adaptation Strategies. Global Environmental Change, 20(3), 440-450.

Borghesi, S., \& Vercelli, A. (2003). Sustainable globalisation. Ecological Economics, 44(1), 77-89.

Burns, T., Kentor, J., \& Jorgenson, A. (2003). Trade dependence, pollution, and Infant mortality in less-developed countries. In W. Dunaway (Ed.), Emerging issues in the $21^{\text {st }}$ century world-system: Volume I Crises and resistance in the $21^{\text {st }}$ century world-system (1 ed., pp. 14-28). Westport, United States: Greenwood Publishing Group.

Cohen, M. (2000). Changing patterns of infectious disease. Nature, 406(6797), 762-767.

Cooper, D. R., \& Schindler, P. S. (2003). Business research methods ( $8^{\text {th }}$ ed.). New York, US: McGraw-Hill/Irwin.

Cornia, G., Rosignoli, S., \& Tiberti, L. (2009). An empirical investigation of the relation between globalization and health. In R. Labonté, T. Schrecker, C. Packer, \& V. Runnels (Eds.), Globalization and health: Pathways, evidence, and policy (pp. 3464). New York: Routledge.

Council. (2007). Council Conclusions on Environment and Health 2842nd ENVIRONMENT Council meeting. Brussels: Council of the European Union.

Council. (2013). An EU strategy on adaptation to climate change: Council conclusions Communication from the Commission to the European Parliament, the Council, the European Economic and Social Committee and the Committee of the Regions. Brussels: Council of the European Union.

Davie, T., Fenemore, A., Allen, W., \& Phillips, C. (2006). Stakeholder involvement in integrated catchment management - Motueka, New Zealand. Lincoln, New Zealand: Landcare Research.

De Lombaerde, P., \& Lelio lapadre, P. (2008). The world is not flat: Implications for the construction of globalisation indicators. World Economics, 9(4), 159-180.

de Ridder, W., Turnpenny, J., Nilsson, M., \& von Raggamby, A. (2007). A framework for tool selection and use in integrated assessment for sustainable development. Journal of Environmental Assessment Policy and Management, 9(4), 423-441.

Dessai, S., Hulme, M., Lempert, R., \& Pielke, R. J. (2009). Do we need better predictions to adaption to a changing climate? Eos, Transactions American Geophysical Union, 90(13), 111-112.

Detels, R. (2009). The scope and concerns of public health. In R. Detels, R. Beaglehole, M. A. Lansang, \& M. Gulliford (Eds.), Oxford textbook of public health. Volume 1 The scope of public health (5 ed., Vol. 1, pp. 3-19). Oxford: Oxford University Press. 
Dollar, D. (2001). Is globalization good for your health? Bulletin of the World Health Organization, 79(9), 827-832.

Drager, N., \& Beaglehole, R. (2001). Globalization: Changing the public health landscape. Bulletin of the World Health Organization, 79(9), 803.

Dreher, A. (2006). Does globalization affect growth? Evidence from a new index of globalization. Applied Economics, 38(10), 1091-1110.

Dreher, A., Gaston, N., \& Martens, P. (2008). Measuring globalization: Gauging its consequences. New York: Springer.

Ebi, K., Kovats, R. S., \& Menne, B. (2006). An approach for assessing human health vulnerability and public health interventions to adapt to climate change. Environmental Health Perspectives, 114(12), 1930-1934.

Ebi, K. L., \& Burton, I. (2008). Identifying practical adaptation options: An approach to address climate change-related health risks. Environmental Science and Policy, 11(4), 359-369. doi: 10.1016/j.envsci.2008.02.001

EC. (2007a). White Paper Together for Health: A Strategic Approach for the EU 20082013. Brussels, Belgium: European Commission.

EC. (2007b). White Paper: Together for health: A strategic approach for the EU 20082013. Brussels, Belgium: European Commission.

EC. (2009a). Adapting to climate change: Towards a European framework for action White Paper. Brussels, Belgium: European Commission.

EC. (2009b). Human, Animal and Plant Health Impacts of Climate Change Commission Staff Working Document. Accompanying document to the White Paper: Adapting to climate change: Towards a European framework for action. Brussels: European Commission.

EC. (2010a). Declaration of the European Commission, Fifth Ministerial Conference on Environment and Health, Parma, 10-12 March 2010.

EC. (2010b). Europe 2020: A strategy for smart, sustainable and inclusive growth Communication from the Commission. Brussels: European Commission.

EC. (2013a). Adaptation to climate change impacts on human, animal and plant health Accompanying the document Communication from the Commission to the European Parliament, the Council, the European Economic and Social Committee and the Committee of the Regions, An EU Strategy on Adaptation to Climate Change. Brussels, Belgium: European Commission.

EC. (2013b). Commission Staff Working Document, Guidelines on developing adaptation strategies. Accompanying the document: Communication from the Commission to the European Parliament, the Council, the European Economic and Social Committee and the Committee of the Regions, An EU Strategy on adaptation to climate change. Brussels: European Commission.

EC. (2013c). A decent life for all: Ending poverty and giving the world a sustainable future Communication from the Commission to the European Parliament, the Council, the European Economic and Social Committee and the Committee of the Regions. Brussels: European Commission.

EC. (2013d). An EU Strategy on adaptation to climate change Communication from the Commission to the European Parliament, the Council, the European Economic 
and Social Committee and the Committee of the Regions. Brussels: European Commission.

EC. (2013e). Guidelines on developing adaptation startegies Commission Staff Working Document. Accompanying the document Communication from the Commission to the European Parliament, the Council, the European Economic and Social Committee and the Committee of the Regions: An EU strategy on adaptation to climate change. Brussels: European Commission.

EC. (2014a). Countries, regions, and cities, Countries: adaptation strategies. ClimateAdapt, European Climate Adaptation Platform. Retrieved 14 May, 2014, from http://climate-adapt.eea.europa.eu/web/guest/countries

EC. (2014b). European Climate Adaptation Platform. CLIMATE-ADAPT. Retrieved 24 July, 2014, from http://climate-adapt.eea.europa.eu/home

ECDC. (2005-2009). Climate change in Europe. Health Topics, Climate Change. Retrieved 23 April, 2013, 2013, from

http://www.ecdc.europa.eu/en/healthtopics/climate change/Pages/index.aspx

EEA. (2012). Climate change, impacts and vulnerabilty in Europe 2012: An indicatorbased report. Copenhagen, Denmark: European Environment Agency.

ENHanCE. ENHanCE research project. from http://www.liv.ac.uk/enhance/

Epstein, P. R. (2001). Climate change and emerging infectious diseases. Microbes and Infection, 3(0), 747-754.

EU. (2007). Decisions adopted jointly by the European Parliament and the Council, Decision No 1350/2007/EC of the European Parliament and of the Council, of 23 October 2007, establishing a second programme of Community action in the field of health (2008-13).

EU. (2014). Regulation (EU) No 282/2014 of the European Parliament and of the Council, of 11 March 2014, on the establishment of a third Programme for the Union's action in the field of health (2014-2020), and repealing Decision No 1350/2007/EC.

Freeman, R. E., \& McVea, J. (2001). A stakeholder approach to strategic management, Working Paper No. 01-02 Working Paper No. 01-02. Darden Graduate School of Business Administration, University of Virginia.

Friedman, T. L. (1999). The lexus and the olive tree: Understanding globalization. New York: Farrar, Strauss and Giroux.

Füssel, H.-M. (2007). Adaptation planning for climate change: Concepts, assessment approaches, and key lessons. Sustainability Science, 2(2), 265-275. doi: 10.1007/s11625-007-0032-y

Füssel, H.-M., \& Klein, R. J. T. (2006). Climate change vulnerability assessments: An evoltuion of conceptual thinking. Climate Change, 75(3), 301-329. doi: 10.1007/s10584-006-0329-3

Garson, D. (2009). Statsnotes: Topics in mutlivariate analysis Retrieved from http://faculty.chass.ncsu.edu/garson/pa765/statnote.htm

Garson, G. D. (2012). Sampling Blue Book Series

Griggs, D., Stafford-Smith, M., Gaffney, O., Rockström, J., Öhman, M. C., Shyamsundar, P., Steffen, W., Glaser, G., Kanie, N., \& Noble, I. (2013). Sustainable development goals for people and planet. Nature, 495(7441), 305-307. 
Hong, E. (2000, 4-8 December 2000). Globalisation and the impact in health: A third world view. Paper presented at the The Peoples' Health Assembly, Savar, Bangladesh.

Huynen, M. (2008). Future health in a globalising world. Maastricht: Maastricht University Press.

Huynen, M., Martens, P., \& Akin, S. (2013). Climate change: An amplifier of existing health risks in developing countries. Environment, Development and Sustainability.

Huynen, M., Martens, P., \& De Groot, R. S. (2004). Linkage sbetween biodiversity loss and human health: A global statistical indicator analysis. International Journal of Environmental Health Research, 14(1), 13-30.

Huynen, M. M. T. E., Martens, P., \& Hilderink, H. B. M. (2005). The health impacts of globalization: A conceptual framework. Globalization and Health, 1(article 14), 1-12.

Huynen, M. M. T. E., Vollebregt, L., Martens, P., \& Benavides, B. M. (2005). The epidemiological transition in Peru. Pan American Journal of Public Health, 17(1), 51-59.

IPCC. (2007). Appendix I Glossary. In M. L. Parry, O. F. Canziani, J. P. Palutikof, P. J. van der Linden, \& C. E. Hanson (Eds.), Climate change 2007: Impacts, adaptation, and vulnerability. Contribution of Working Group II to the Fourth Assessment Report of the Intergovernmental Panel on Climate Change (pp. 869-884). Cambridge, United Kingdom: Cambridge University Press.

IPCC. (2013). Summary for policymakers. In T. F. Stocker, D. Qin, G.-K. Plattner, M. Tignor, S. K. Allen, J. Boschung, A. Nauels, Y. Xia, V. Bex, \& P. M. Midgley (Eds.), Climate Change 2013: The Physical Science Basis. Contribution of Working Group I to the Fifth Assessment Report of the Intergovernmental Panel on Climate Change (pp. 1-29). Cambridge, United Kingdom and New York, US: Cambridge University Press.

IPCC. (2014a). Chapter 11 Human Health: Impacts, Adaptation, and Co-Benefits. In C. B. Field, V. R. Barros, D. J. Dokken, K. J. Mach, M. D. Mastrandrea, T. E. Bilir, M. Chatterjee, K. L. Ebi, Y. O. Estrada, R. C. Genova, B. Girma, E. S. Kissel, A. N. Levy, S. MacCracken, P. R. Mastrandrea, \& L. L. White (Eds.), Climate Change 2014: Impacts, Adaptation, and Vulnerability. Part A: Global and Sectoral Aspects. Contribution of Working Group II to the Fifth Assessment Report of the Intergovernmental Panel on Climate Change (pp. tbd). Cambridge and New York: Intergovernmental Panel on Climate Change.

IPCC. (2014b). Chapter 15 Adaptation Planning and Implementation. In C. B. Field, V. R. Barros, D. J. Dokken, K. J. Mach, M. D. Mastrandrea, T. E. Bilir, M. Chatterjee, K. L. Ebi, Y. O. Estrada, R. C. Genova, B. Girma, E. S. Kissel, A. N. Levy, S. MacCracken, P. R. Mastrandrea, \& L. L. White (Eds.), Climate Change 2014: Impacts, Adaptation, and Vulnerability. Part A: Global and Sectoral Aspects. Contribution of Working Group II to the Fifth Assessment Report of the Intergovernmental Panel on Climate Change (pp. tbd). Cambridge and New York: Intergovernmental Panel on Climate Change. 
IPCC. (2014c). Chapter 23 Europe. In V. R. Barros, C.B. Field, D.J. Dokken, M.D. Mastrandrea, K.J. Mach, T.E. Bilir, M. Chatterjee, K.L. Ebi, Y.O. Estrada, R.C. Genova, B. Girma, E.S. Kissel, A.N. Levy, S. MacCracken, P. R. Mastrandrea, \& L. L. White (Eds.), Climate Change 2014: Impacts, Adaptation, and Vulnerability. Part B: Regional Aspects. Contribution of Working Group II to the Fifth Assessment Report of the Intergovernmental Panel on Climate Change (pp. tbd). Cambridge and New York: Intergovernmental Panel on Climate Change.

IPCC. (2014d). Glossary. In C. B. Field, V. R. Barros, D. J. Dokken, K. J. Mach, M. D. Mastrandrea, T. E. Bilir, M. Chatterjee, K. L. Ebi, Y. O. Estrada, R. C. Genova, B. Girma, E. S. Kissel, A. N. Levy, S. MacCracken, P. R. Mastrandrea, \& L. L. White (Eds.), Climate Change 2014: Impacts, Adaptation, and Vulnerability. Contribution of Working Group II to the Fifth Assessment Report of the Intergovernmental Panel on Climate Change (pp. tbd). Cambridge and New York: Intergovernmental Panel on Climate Change.

IPCC. (2014e). Summary for Policymakers. In C. B. Field, V. R. Barros, D. J. Dokken, K. J. Mach, M. D. Mastrandrea, T. E. Bilir, M. Chatterjee, K. L. Ebi, Y. O. Estrada, R. C. Genova, B. Girma, E. S. Kissel, A. N. Levy, S. MacCracken, P. R. Mastrandrea, \& L. L. White (Eds.), Climate Change 2014: Impacts, Adaptation, and Vulnerability. Part A: Global and Sectoral Aspects. Contribution of Working Group II to the Fifth Assessment Report of the Intergovernmental Panel on Climate Change (pp. 1-32). Cambridge and New York: Intergovernmental Panel on Climate Change.

IPCC. (2014f). Technical Summary. In C. B. [Field, V.R. Barros, D.J. Dokken, K.J. Mach, M.D. Mastrandrea, T.E. Bilir, M. Chatterjee, K.L. Ebi, Y.O. Estrada, R.C. Genova, B. Girma, E.S. Kissel, A.N. Levy, S. MacCracken, P.R. Mastrandrea, and L.L. White (eds.)]. (Ed.), Climate Change 2014: Impacts, Adaptation, and Vulnerability. Part A: Global and Sectoral Aspects. Contribution of Working Group II to the Fifth Assessment Report of the Intergovernmental Panel on Climate Change (pp. tbd). Cambridge and New York: Intergovernmental Panel on Climate Change.

Jäger, J., Rothman, D., Anastasi, C., Kartha, S., \& Van Notten, P. (2007). Training module 6 Scenario development and analysis. In UNEP/IISD (Ed.), IEA Training Manual: A Training Manual on Integrated Environmental Assessment and Reporting. Winnipeg, Canada: International Institute for Sustainable Development, United Nations Environment Programme.

Keessen, A. (2014). In search of a European legislative approach to adaptation to climate change. In M. Peeters \& R. Uylenburg (Eds.), EU Environmental Legislation: Legal Perspectives on Regulatory Strategies. Cheltenham: Edward Elgar.

Kloprogge, P., \& van der Sluijs, J. P. (2006). The inclusion of stakeholder knowledge and perspectives in integrated assessment of climate change. Climatic Change, 75(3), 359-389. doi: 10.1007/s10584-006-0362-2

Knol, A. B., Slottje, P., van der Sluijs, J. P., \& Lebret, E. (2010). The use of expert elicitation in environmental health impact assessment: A seven step procedure. Environmental Health, 9(19). doi: 10.1186/1476-069X-9-19

Kovats, R. S., Valentini, R., Bouwers, L. M., Georgopoulou, E., Jacob, D., Martin, E., Rounsevell, M., \& Soussana, J.-F. (2014). Europe. In V. R. Barros, C. B. Field, D. J. Dokken, M. D. Mastrandrea, K. J. Mach, T. E. Bilir, M. Chatterjee, K. L. Ebi, Y. O. 
Estrada, R. C. Genova, B. Girma, E. S. Kissel, A. N. Levy, S. MacCracken, P. R. Mastrandrea, \& L. L. White (Eds.), Climate change 2014: Impacts, adaptation, and vulnerability. Part B: Regional Aspects. Contribution of Working Group II to the Fifth Assessment Report of the Intergovernmental Panel on Climate Change (pp. 1267-1326). Cambridge, United Kingdom and New York, US: The Intergovernmental Panel on Climate Change.

Kue Yong, T. (2005). Population health: Concepts and methods (2 ed.). Oxford: Oxford University Press.

Labonte, R., \& Schrecker, T. (2007). Globalization and social determinants of health: Introduction and methodological background (part 1 of 3). Globalization and Health, 3(5).

Labonte, R., \& Schrecker, T. (2009). Introduction: Globalization challenges to people's health. In R. Labonte, T. Schrecker, C. Packer, \& V. Runnels (Eds.), Globalization and health: Pathways, evidence and policy. New York: Routledge.

Labonte, R., \& Torgerson, R. (2003). Frameworks for analyzing the links between globalization and health. Geneva: World Health Organisation.

Lang, D. J., Wiek, A., Bergmann, M., Stauffacher, M., Martens, P., Moll, P., Swilling, M., \& Thomas, C. J. (2012). Transdisciplinary research in sustainability science: practice, principles, and challenges. Sustainability Science, 7(1 Supplement), 2543.

Lee, K. (2001). A dialogue of the deaf? The health impacts of globalisation. Journal of Epidemiology and Community Health, 55(9), 619.

Lee, K. (2009). Globalisation. In R. Detels, R. Beaglehole, M. A. Lansang, \& M. Gulliford (Eds.), Oxford textbook of public health. Volume 1 The scope of public health. (5 ed., Vol. 1, pp. 85-100). Oxford: Oxford University press.

Lee, K., \& Collin, J. (2001). Review of existing empirical research on globalization and health. Geneva: World Health Organization.

Martens, P. (2002). Health transitions in a globalising world: Towards more disease or sustained health? Futures, 34(7), 635-648.

Martens, P. (Ed.). (2006). Integrated assessment models. Maastricht: International Center for Intergrated assessment and Sustainable development (ICIS), European Forum on Integrated Environmental Assessment (EFIEA).

Martens, P., Akin, S., Huynen, M., \& Raza, M. (2010). Is globalization healthy: A statistical indicator analysis of the impacts of globalization on health. Globalization and Health, 6(16).

Martens, P., Chang, C. T., \& McEvoy, D. (2012). Integrating adaptation and mitigation to climatic changes. Regions, 288(4), 18-20.

Martens, P., Huynen, M., Akin, S., Hilderink, H., \& Soskolne, C. L. (2011). Globalization and human health: Complexity, links and research gaps. IHDP Update, January 2011(1), 2-6.

Martens, P., \& Huynen, M. M. T. E. (2003). A future without health? The health dimension in global scenario studies. Buttelin of the World Health Organisation, 81(12), 896-901.

Martens, P., McMichael, A., \& Patz, J. (2000). Globalization, environmental change and health. Global Change and Human Health, 1(1), 4-8. 
Martens, P., \& Raza, M. (2009). Globalisation in the 21st century: Measuring regional changes in multiple domains. The Integrated Assessment Journal, 9(1), 1-18.

Martens, P., \& Raza, M. (2010). Is globalisation sustainable? Sustainability, 2, 280-293.

Martens, P., \& Rotmans, J. (2005). Transitions in a globalising world. Futures, 37(10), 1133-1144.

Martens, P., \& Zywietz, D. (2006). Rethinking globalisation: A modified globalisation index. Journal of International Development, 18(3), 331-350.

Mayers, J. (2005). Stakeholder power analysis Power Tools: International Institute for Environment and Development.

McClave, J., Benson, P., \& Sincich, T. (2001a). Mutliple regression and model building. In J. McClave, P. Benson, \& T. Sincich (Eds.), Statistics for business and economics (8 ed., pp. 533-674). New Jersey: Prentice Hall.

McClave, J., Benson, P., \& Sincich, T. (2001b). Statistics for business and economics. International Edition (8 ed.). Upper Saddle River, New Jersey: Prentice-Hall.

Mclntyre, K. M., Setzkorn, C., Baylis, M., Waret-Szkuta, A., Caminade, C., Morse, A. P., Akin, S., Huynen, M., Martens, P., \& Morand, S. (2010). Impact of climate change on human and animal health. The Veterinary Record, 167(15), 586. doi: 10.1136/vr.c5523

McMichael, A. J. (2004). Environmental and social infleunces on emerging infections: Past, present, and future. Philosophical Transactions of the Royal Society, 359(1447), 1049-1058.

McMichael, A. J. (2013). Globalisation, climate change and human health. The New England Journal of Medicine, 368(14), 1335-1343. doi: 10.1056/NEJMra1109341

McMichael, A. J. (2014a). Earth as humans' habitat: Global climate change and the health of populations. International Journal of Health Policy and Management, 2(1), 9-12. doi: 10.15171/ijhpm.2014.03

McMichael, A. J. (2014b). Population health in the Anthropocene: Gains, losses and emerging trends. The Anthropocene Review, 1(1), 44-56. doi: $10.1177 / 2053019613514035$

McMichael, A. J., Woodruff, R. E., \& Hales, S. (2006). Climate change and human health: Present and future risks. Lancet, 367(9513), 859-869.

MEA. (2005a). Ecosystems and Human Well-being: Health Synthesis. In C. Corvalan, S. Hales, \& A. McMichael (Eds.), A Report of the Millennium Ecosystem Assessment. Geneva: World Health Organization.

MEA. (2005b). Ecosystems and human well-being: Policy responses, Volume 3. In K. Chopra, R. Leemans, P. Kumar, \& H. Simons (Eds.), Findings of the Responses Working Group of the Millennium Ecosystem Assessment (Vol. 3). Washington, DC, US: Island Press.

Mechler, R., \& Kundzewicz, Z. (2010). Assessing adaptation to extreme weather events in Europe. Mitigation and Adaptation Strategies for Global Change, 15(7), 611620.

Menne, B., Apfel, F., Kovats, S., \& Racioppi, F. (2008). Protecting health in Europe from climate change. Copenhagen, Denmark: World Health Organisation Regional Office for Europe. 
Mensah, K., Mackintosh, M., \& Henry, L. (2005). The 'skills drain' of health professionals from the developing world: A framework for policy formulation. London: Medact.

Mittelman, J. H. (2000). The globalization syndrome: Transformation and resistance. Princeton: Princeton University Press.

Nordhaus, W. D. (1994). Expert opinion on climatic change. American Scientist, 82(1), 4551.

O'Riordan, T., \& Jordan, A. (1995). The precautionary principle in contemporary environmental politics. Environmental Values, 4(3), 191-212.

OECD. (2008). Handbook on constructing composite indicators: Methodology and user guide. Paris: OECD and EC.

Patz, J., Campbell-Lendrum, D., Holloway, T., \& Foley, J. (2005). Impact of regional climate change on human health. Nature, 438(7066), 310-317.

Patz, J. A., Campbell-Lendrum, D., Holloway, T., \& Foley, J. A. (2005). Impact of regional climate change on human health. Nature, 438(7066), 310-317.

PHEIAC. (2011). Mid-Term Evaluation of the EU Health Strategy 2008-2013 Final Report. In T. E. P. P. Public Health Evaluation and Impact Assessment Consortium (PHEIAC) including: Economisti Associati (Lead Firm), Liberio Istituto Universitario Carlo Cattaneo - CREMS (Partner), CEMKA-EVAL (Partner) (Ed.), Provision of Evaluation, Impact Assessment and Related Services to the Commission in the Atea of Public Health.

Porta, M. (Ed.) (2014) A dictionary of epidemiology (5 ed.). Oxford: Oxford University Press.

Prell, C., Hubacek, K., \& Reed, M. (2013). Stakeholder analysis and social network analysis in natural resource management. Society and Natural Resources: An International Journal, 22(6), 501-518.

Ranis, G. (2006). Human development and economic growth. In D. Clark (Ed.), The Elgar companion to development studies (pp. 250-256). UK: Edward Elgar Publishing Limited.

Reed, M. S., Graves, A., Norman, D., Posthumus, H., Hubacek, K., Morris, J., Prell, C., Quinn, C. H., \& Stringer, L. C. (2009). Who's in and why? A typology of stakeholder analysis methods for natural resource management. Journal of Environmental Management, 90(5), 1933-1949. doi: 10.1016/j.jenvman.2009.01.001

Rennen, W., \& Martens, P. (2003). The globalization timeline. Integrated Assessment, 4(3), 137-144.

Rosendorff, B. P., \& Vreeland, J. R. (2006). Democracy and data dissemination: The effect of political regime on transparency. New York University and Yale University.

Rothman, D. S., \& Robinson, J. B. (1997). Growing pains: A conceptual framework for considering integrated assessments. Environmental Monitoring and Assessment, 46(1-2), 23-43.

Scholte, J. (2000). What is 'global' about globalization? In J. Scholte (Ed.), Globalisation: A Critical Introduction (1 ed., pp. 41-61). New York: Palgrave.

Schrecker, T., Labonté, R., \& De Vogli, R. (2008). Globalisation and health: The need for a global vision. Lancet, 372(9650), 1670-1676. 
Semenza, J., \& Menne, B. (2009). Climate change and infectious diseases in Europe. The Lancet, 9(6), 365-375.

Senior, K. (2008). Climate change and infectious disease: A dangerous liaison? The Lancet Infectious Diseases, 8(2), 92-93.

Shapiro, S., \& Wilk, M. (1965). An analysis of variance test for normality (complete samples). Biometrika, 52(3/4), 591-611.

Skolnik, R. L. (2008). Essentials of global health. Sudbury: Jones and Bartlett.

Smith, K. R., Woodward, A., Campbell-Lendrum, D., Chadee, D. D., Honda, Y., Liu, Q., Olwoch, J. W., Revich, B., \& Sauerborn, R. (2014). Human health: Impacts, adaptation, and co-benefits. In C. B. Field, V. R. Barros, D. J. Dokken, K. J. Mach, M. D. Mastrandrea, T. E. Bilir, M. Chatterjee, K. L. Ebi, Y. O. Estrada, R. C. Genova, B. Girma, E. S. Kissel, A. N. Levy, S. MacCracken, P. R. Mastrandrea, \& L. L. White (Eds.), Climate Change 2014: Impacts, Adaptation, and Vulnerability. Part A: Global and Sectoral Aspects. Contribution of Working Group II to the Fifth Assessment Report of the Intergovernmental Panel on Climate Change (pp. 709-754). Cambridge, United Kingdom and New York, US: Intergovernmental Panel on Climate Change.

Smith, M. (2006). Neoliberalism? Alphabet soup of policies in Ghana: From SAPs to PRSPS and MDGs. . Paper presented at the Annual Meeting of the International Studies Association, San Diego, California.

Smith, R., Woodward, D., Acharya, A., Beaglehole, R., \& Drager, N. (2004). Communicable disease control: A 'Global Public Good' perspective. Health Policy and Planning, 19(5), 271-278.

Soskolne, C., Butler, C., Ijsselmuiden, C., London, L., \& von Schirnding, Y. (2007). Toward a global agenda for research in environmental epidemiology. Epidemiology and Society, 18(1), 162-166.

Steffen, W., Crutzen, P. J., \& McNeill, J. R. (2007). The Anthropocene: Are humans now overwhelming the great forces of nature. AMBIO: A Journal of the Human Environment, 36(8), 614-621.

Steffen, W., Grinevald, J., Crutzen, P. J., \& McNeill, J. (2011). The Anthropocene: Conceptual and historical perspectives. Philosophical Tranactions of The Royal Society A, 369(1938), 842-867. doi: 10.1098/rsta.2010.0327

Sutherst, R. (2004). Global change and human vulnerabilty to vector-borne diseases. Clinical Microbiology Reviews, 17(1), 136-173.

Tisdell, C. (2001). Globalisation and sustainability: Environmental Kuznets curve and the WTO. Ecological Economics, 39(2), 185-196.

UN. (2007). MDG Monitor. from http://www.mdgmonitor.org/index.cfm

UN. (n.d./2009). End of poverty 2015 - Millennium Development Goals. Retrieved April 6, 2009, from http://www.un.org/millenniumgoals/

UNDP. (2002). Human Development Report. New York: Oxford University Press.

UNDP. (2005). Egypt Human Development Report 2005. In H. Handoussa, M. El Sherif, S. Tawila, H. Sholkamy, \& M. Zaalouk (Eds.), Choosing our future: Towards a new social contract: United Nations Development Programme and The Institute of National Planning, Egypt. 
Valkering, P. (2009). Toddling 'long the River Meuse: Integrated Assessment and participatory Agent-Based Modelling to support River Management. (PhD Dissertation), Maastricht University, Maastricht.

Valkering, P., Amelung, B., Van der Brugge, R., \& Rotmans, J. (Eds.). (2006). Introduction. Maastricht: International Centre for Integrated assessment and Sustainable Development (ICIS), European Forum on Integrated Environmental Assessment (EFIEA).

Van Asselt, M., \& Rijkens-Klomp, N. (2002). A look in the mirror: Reflection on participation in Integrated Assessment from a methodological pespective. Global Environmental Change, 12(3), 167-184.

Van Lier, E., Rahamat-Langendoen, J., \& Van Vliet, J. (2007). Staat van infectieziekten in Nederland 2006. In RIVM (Ed.): Rijksinstituut voor Volksgezondheid en Milieu.

Vorou, R. M., Papavassiliou, V. G., \& Tsiodras, S. (2007). Emerging zoonoses and vectorborne infections affecting humans in Europe. Epipemiology and Infection, 135(8), 1231-1247.

Walters, M. (1995). Globalisation: Key ideas. London: Routledge.

Wardekker, J. A., de Jong, A., van Bree, L., Turkenburg, W. C., \& van der Sluijs, J. P. (2012). Health risks of climate change: An assessment of uncertainties and its implications for adaptation policies. Environmental Health, 11, 67. doi: 10.1186/1476-069X-11-67

Watanabe, K. (2004). The correlation between Economic Globalization and Human Development. Paper presented at the Annual meeting of the Western Political Science Association, Portland, Oregon. http://www.allacademic.com/meta/p87730 index.html

WB. (2010). World DataBank, World Development Indicators \& Global Development Finance. from The World Bank Group

WHO-Europe. (2010a). Climate change and health in Europe: Opportunities for action in partnership. Paper presented at the Fifth Ministerial Conference on Environment and Health, Protecting children's health in a changing environment, Parma, Italy.

WHO-Europe. (2010b). Climate change and health: Policy options for climate change and health. Report on a joint WHO-PBL technical meeting. Bonn, Germany: WHO Europe.

WHO-Europe. (2010c). Parma Declaration on Environment and Health. (EUR/55934/5.1 Rev. 2). Copenhagen, Denmark: WHO Europe Conference Secretariat.

WHO-Europe. (2010d). Protecting health in an environment challenged by climate change: European regional framework for action. (EUR/55934/6 Rev.1). Copenhagen, Denmark: Contribution of the Climate Change and Health Task Force. WHO Regional Office for Europe.

WHO-Europe. (n.d.). Strategic objective 1 To reduce the health, social and economic burden of communicable diseases Technical Programmes in the European Region: Managing the threat of communicable diseases. Copenhagen, Denmark: WHO Region Office for Europe.

WHO. (1948). Preamble to the Constitution of the World Health Organization as adopted by the International Health Conference, New York, 19-22 June, 1946; signed on 
22 July 1946 by the representatives of 61 States (Official Records of the World Health Organization, no. 2, p. 100) and entered into force on 7 April 1948. New York, US: World Health Organisation.

WHO. (2001). Globalization: How healthy? Bulletin of the World Health Organization, 79(9), 902-903.

WHO. (2008a). The global burden of disease: 2004 update. Geneva: UN World Health Organisation.

WHO. (2008b). Indicator definitions and metadata 2008. from WHO Statistical Information System - WHOSIS

WHO. (2008c). International Health Regulations (2 ed.): World Health Organisation.

WHO. (2009a). Definitions health indicators. from World Health Organisation Statistical Information System - WHOSIS

WHO. (2009b). World Health Statistics. Retrieved 23 July, 2009, from http://www.who.int/whosis/whostat/2009/en/index.html

WHO. (2011a). Health co-benefits of climate change mitigation - Housing sector Health in the green economy. Geneva, Switzerland: World Health Organisation.

WHO. (2011b). Health topics: Zoonoses. Retrieved July 4, 2011, 2011, from http://www.who.int/topics/zoonoses/en/

WHO. (2014). International Health Regulations (IHR). Health topics. Retrieved 24 July, 2014, from http://www.who.int/topics/international health regulations/en/

Wolf, T., Sanchez Martinez, G., Cheong, H.-K., Williams, E., \& Menne, B. (2014). Protecting health from climate change in the WHO European Region. International Journal of Environmental Research and Public Health, 11(6), 62656280. doi: 10.3390/ijerph110606265

Woodward, D., Drager, N., Beaglehole, R., \& Lipson, D. (2001). Globalization and health: A framework for analysis and action. Bulletin of the World Health Organization, 79(9), 875-880.

www.globalisationindex.info. Maastricht Globalisation Index.

Zalasiewicz, J., Williams, M., Steffen, W., \& Crutzen, P. J. (2010). The new world of the Anthropocene. Environmental Science and Technology, 44(7), 2228-2231. doi: 10.1021/es903118j 


\section{APPENDIX 1 \\ Additional information stakeholder analysis \\ and expert sample}


This appendix is added to this dissertation to provide additional information to the studies presented in Chapters 4 and 5, specifically regarding the stakeholder analysis, sample selection, communication, and respondents' characteristics. It should be noted that the respondents of the survey are anonymous, so for privacy reasons names of respondents and/or their organizations are omitted.

\section{Stakeholder analysis and sample selection}

As mentioned in Chapters 4 and 5, a stakeholder analysis was performed for the purpose of identifying stakeholders for the selection of potential respondents for the expert survey. This stakeholder analysis was done as a part of the ENHanCE research project, where stakeholders had to be selected for several participatory research components of the project, of which the survey was one. For the stakeholder analysis, a broad definition of stakeholders was assumed: individuals and organizations that are likely to be affected by or can influence climate change and related health impacts; the latter e.g., through the implementation of adaptation measures (Allen \& Kilvington, 2003; Davie et al., 2006; Freeman \& McVea, 2001; Reed et al., 2009). The analysis was performed in the Netherlands, being a priority research focus of the ENHanCE research project. The stakeholder approach aimed to map out Dutch stakeholders in relation to the topic of climate change and infectious disease risk in Western Europe; to create a useful inventory for potential participants for the participatory elements in the broader research setup of the project; and to facilitate the collection of expert knowledge and perspectives on climate change and health impacts.

To collect and organize the stakeholders and their information, a stakeholder matrix was developed $^{21}$. Table A1.1 shows how this stakeholder matrix looked. The original matrix was made in Microsoft Office Excel.

\begin{tabular}{|c|c|c|c|c|c|c|c|}
\hline$A$ & $\mathrm{~B}$ & $\mathrm{C}$ & $\mathrm{D}$ & $E$ & $\mathrm{~F}$ & G & $\mathrm{H}$ \\
\hline \multirow[t]{2}{*}{ Stakeholder } & \multirow{2}{*}{$\begin{array}{l}\text { Name of } \\
\text { institution }\end{array}$} & \multirow[t]{2}{*}{ Country } & \multicolumn{4}{|c|}{ Contact information } & \multirow{2}{*}{$\begin{array}{l}\text { Any } \\
\text { notes }\end{array}$} \\
\hline & & & $\begin{array}{l}\text { Email } \\
\text { address }\end{array}$ & $\begin{array}{l}\text { Alternative email } \\
\text { address }\end{array}$ & Tel. & Address & \\
\hline & & & & & & & \\
\hline & & & & & & & \\
\hline & & & & & & & \\
\hline
\end{tabular}

\footnotetext{
${ }^{21}$ There are many examples of stakeholder analyses conducted for studies and projects. These often make use of matrices, tables, and/or graphs to describe, characterize, and prioritize stakeholders. See for example Reed et al. (2009) and Mayers (2005), amongst others, for similar characterizations and terminology as used for the stakeholder analysis for this study.
} 


\begin{tabular}{l|l|l|l|l|l|l}
\hline \multicolumn{6}{l}{ Table A1.1 Stakeholder matrix continued } \\
\hline I & $\mathrm{J}$ & $\mathrm{K}$ & $\mathrm{L}$ & $\mathrm{M}$ & $\mathrm{N}$ & $\mathrm{O}$ \\
\hline $\begin{array}{l}\text { Type of } \\
\text { Stakeholder } \\
\text { (predefined } \\
\text { categories) }\end{array}$ & $\begin{array}{l}\text { Interest of } \\
\text { stakeholder } \\
\text { in project }\end{array}$ & $\begin{array}{l}\text { Stakeholder } \\
\text { importance to } \\
\text { project } \\
\text { (rating) }\end{array}$ & $\begin{array}{l}\text { Stakeholder } \\
\text { willingness to } \\
\text { participate } \\
\text { (rating) }\end{array}$ & $\begin{array}{l}\text { Certainty } \\
\text { about will- } \\
\text { ingness } \\
\text { (rating) }\end{array}$ & $\begin{array}{l}\text { Type } \\
\text { knowledge/ } \\
\text { expertise }\end{array}$ & $\begin{array}{l}\text { Contact } \\
\text { person }\end{array}$ \\
\hline & & & & & & \\
\hline
\end{tabular}

The stakeholder analysis was performed by the research team. Therefore the matrix was designed in such a way that this was possible and moreover accompanied by a written guide on how to use the matrix and perform the stakeholder analysis.

In Table A1.1, it can be seen that in the first columns the identified stakeholder could be entered, as well as the stakeholder's organization, country, and contact information. Thereafter in column I, the stakeholder could be labelled according to predefined stakeholder types. The following predefined stakeholder categories were defined for this purpose, see table A1.2.

\begin{tabular}{ll}
\hline Table A1.2 Predefined stakeholder categories & \\
\hline Human surveillance & Advocacy \\
Policy advice & Pharmaceutical industry \\
Science/experts & Food supply chains, supermarkets, governmen- \\
& tal food security \\
National government & Funders, charities \\
Local health authority & Trade and tourism \\
Health care providers & Vet profession \\
Farmer unions & Business/enterprises \\
NGOs & (other...) \\
\hline
\end{tabular}

In column J, the key interests of each stakeholder could be described. (The stakeholders' interests could for instance relate to: the use of ENHanCE project outcomes; overlap between stakeholder's expertise and the ENHanCE project's topical focus; scientific interests; policy-making and (policy) agenda setting.) Next in column K, the importance of the stakeholder to the project could be rated on a scale from 1 to 5 , where 1 is most important and 5 least important. A stakeholder could be considered as more important when for instance the stakeholder could be a user of the project's outcomes; the stake-

\footnotetext{
${ }^{22}$ Some examples of disciplines/experts that are included in this category are: entomologists, epidemiologists, meteorologists, biologists (aquatic, field, microbiologic), ecologists, environmental health scientists, sociologists, social geographers, urban and rural engineers/planners, environmental scientists, economists, communication specialists, veterinary specialists, legal specialists, and medical specialists (such as ENT specialists, cardiologists, dermatologists, lung specialists, immunologists, neurologists) (in part suggested by agencies during ENHanCE Project Agency Meeting I, February 25, 2010; London).
} 
holder deals with problems that the project addresses; the stakeholder plays an important role in policy related the project's topic; the stakeholder has relevant expertise; or the stakeholder represents a larger group of stakeholders. In column L, the stakeholder's willingness to participate in the project could be rated on a scale of 1 to 4 ranging from high willingness to low willingness (or unwilling) to participate in the ENHanCE project. In the next column, $M$, the certainty of this information was rated on a scale of 1 to 4 ranging from very sure to wild guess. In column $\mathrm{N}$, the type of expertise of the stakeholder could be described in brief. Some examples that were given in the guide to help with this were: climate change adaptation: general; climate change adaptation: human health; climate change adaptation: animal health; infectious disease risk: human; infectious disease risk: animal; specific disease: Lyme; animal Health: general; health services dealing with infectious disease risk; food (trade) \& infectious disease risk; policy-making: human infectious disease risk; or policy-making environmental health. The scientific disciplines/expertise mentioned in footnote 22 also served as examples for this step. If a stakeholder was already part of a project members' professional network, then in column $\mathrm{O}$ this could be entered. The documentation of existing network connections was done in order to prepare for those cases where the research team had to contact the stakeholders.

Besides the stakeholder matrix, the Excel sheet also provided a participation matrix. In this matrix, different participatory research components of the ENHanCE research project could be entered. For each stakeholder, using checkmarks, it could be indicated in this participation matrix for which research components they were selected to participate. And the information in the stakeholder matrix could be used in order to select stakeholders for a specific research components based on formulated criteria for selection. An illustration of the participation matrix can be found below, in Table A1.3 (Some hypothetical examples were added in the table to show how the entries in the participation matrix could look for each stakeholder.)

\begin{tabular}{l|l|l|l|l}
\hline Table A1.3 Participation matrix \\
\hline & \multicolumn{5}{l}{ Selection for participation in different research components (indicated with $\mathrm{V}$ ) } \\
\hline (Column in Excel) & $\mathrm{Q}$ & $\mathrm{R}$ & $\mathrm{S}$ & $\mathrm{T}$ \\
\hline Stakeholder & Agency Meeting & Survey & Focus group & Scenario workshop \\
\hline Stakeholder $\mathrm{X}$ & $\mathrm{V}$ & $\mathrm{V}$ & & \\
\hline Stakeholder $\mathrm{Y}$ & & & $\mathrm{V}$ & $\mathrm{V}$ \\
\hline$\ldots$ & & & & \\
\hline
\end{tabular}

For the survey, the expert sample could also be selected based on the information that was collected in the stakeholder matrix. As explained earlier, in Chapters 4 and 5, the guiding criterion for selecting a sample of experts from the stakeholder matrix was that the individuals possess expertise relevant for the survey's topic and scope; i.e., expertise on climate change/environment and health/infectious diseases. Information on the 
expertise of each stakeholder was documented in the stakeholder matrix and could therefore be retrieved for the purpose of sampling. From the stakeholder matrix, 56 stakeholders could be drawn for participation in the survey (and entered in the participation matrix).

\section{Additional information communication approach}

Regarding the communication with the selected sample, the following steps were undertaken. First the potential respondents were approached per email. This email explained the purpose and topic of the survey and functioned as a first announcement of the study. This was followed by an email, where the respondents were asked to fill out the survey. This email contained a personalised link to the survey for each respondent and a deadline for responding to the survey. The electronic survey system with personalised links made it possible to track who did not fill out the survey yet (this was an anonymised process). Those people that did not respond, received a reminder after 3 weeks. Another final reminder was sent to those people that did not respond yet after another 2 weeks. After the survey was closed, the respondents received an email to thank them for their participation. All communication was done in Dutch as the sample was Dutch.

\section{Professional background and expertise of survey respondents}

In order to get a better insight into the characteristics of the experts that participated in the survey, the survey included questions on the expert's professional background and expertise. The results of this section of the survey is presented here.

The respondents were asked to self-rate their professional background by ticking predefined categories and/or adding additional descriptions in the open-ended section. The predefined categories used for this question were: national government/health authority; local health authority; policy-advice, policy-maker; NGO, advocacy, funders, charity; science; health care provider/health practitioner; veterinary profession; pharmaceutical industry; farmer union; food supply sector; environmental management, conservation; trade and tourism sector; and other business/private actor. It should be noted that for this question, the experts could tick more than one item to describe their professional background. Figure A1.1 shows the results of the self-rated professional backgrounds of the respondents. The results can help to give a more detailed insight in the professional backgrounds present amongst the expert respondents. 


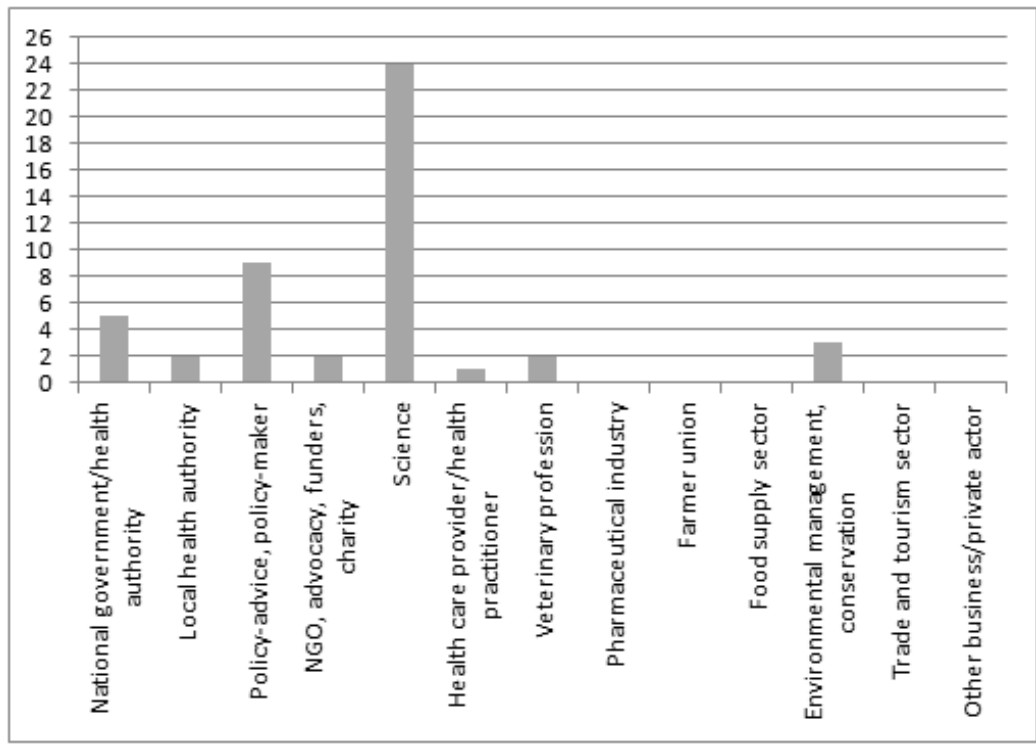

Figure A1.1 Frequencies self-rated professional background $(n=29)$

From the frequencies for each of the professional backgrounds it can be seen that the respondents relatively more often opted for the categories "policy-advice, policy-maker" and "science" to describe their professional backgrounds. Also the professional backgrounds national government/health authority; local health authority; NGO, advocacy, funders, charity; health care provider/health practitioner; veterinary profession; and environmental management/conservation are opted for by the respondents to describe their professional background. In the open-ended section to this question, three additional descriptions of professional backgrounds were added by the respondents: climatologist; communication; and scientific advice (each receiving a frequency of 1 ). As explained in Chapters 4 and 5, the self-rated professional background was used to make two sample subgroups, labelled "Science" and "Policy"23.

Another question was added at the end of the survey which had the respondents selfrate their overall expertise on the topics addressed in the survey. Again some options were predefined for this question: generalist on climate change and/or climate change

\footnotetext{
${ }^{23}$ A description of how the sample subgroups were formed from Chapter 4 \& 5 :

The sample groups were formed in the following manner: first, all respondents who indicated a professional background in policy were placed in one sample group labelled "Policy" and thereafter removed from the full list of respondents. After that, the respondents who indicated a professional background in science were included in another sample group labelled "Science"; finally, the remaining three respondents were added to the group "Policy" as the indicated professional backgrounds seemed to allow for such a compilation. This process resulted in two sample subgroups: "Policy" consisting of 12 experts, and "Science" consisting of 17 experts.
} 
adaptation; expert on climate change and/or climate change adaptation; generalist on health/infectious diseases; expert on health/infectious diseases; generalist on climate change and health; expert on climate change and health; generalist on climate change and infectious diseases; expert on climate change and infectious diseases; generalist on public policy for climate change/health/infectious diseases; expert on public policy for climate change/health/infectious diseases; EU-generalist on climate change/health/infectious diseases; EU-expert on climate change/health/infectious diseases; Netherlands-generalist on climate change/health/infectious diseases; Netherlands-expert on climate change/health/infectious diseases ${ }^{24}$. Also for this question multiple answers were possible and the respondents could add additional descriptions of their expertise in the open-ended section. In Figure A1.2, the results of this question are shown.

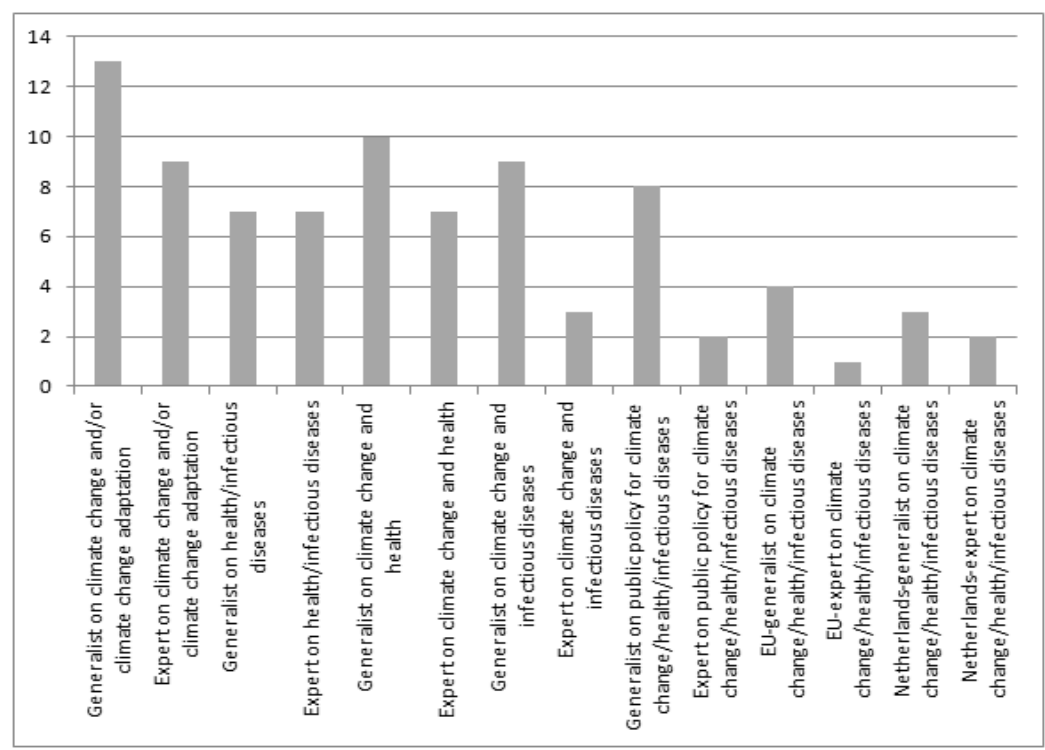

Figure A1.2 Frequencies self-rated expertise $(n=29)$

It can be seen that all predefined categories are opted for at least once to describe the expertise of the respondents. In the open-ended section for this question, also the fol-

\footnotetext{
${ }^{24}$ Expertise categories were adapted from the follow-up work performed by Wardekker \& van der Sluijs on Dessai and Van der Sluijs. (2007). Uncertainty and climate change adaptation: A scoping study. Copernicus Institute and the Netherlands Environmental Assessment Agency. Also see Wardekker et al. 2012.
} 
lowing was added by the respondents: fresh water resources management and climate change; and communication and behaviour change. 


\section{SUMMARY}

This dissertation focuses on global change and in particular climate change, a global environmental change, and its relations to health and infectious disease risk specifically, as well as how we can respond (adapt) to these challenges.

Today, many interacting global changes are taking place at an unprecedented rate often related to human activities. These changes impact our ecological as well as societal systems. Globalisation, or the global changes that are taking place, create wide-ranging impacts on (public) health (Lee, 2009; Steffen et al., 2007). Human-induced global warming and climate change is one of these global changes which threatens human health and well-being, including via its influence on infectious disease risk, at a global level, but also in the European region (EEA, 2012; Kovats et al., 2014; McMichael, 2013; Semenza \& Menne, 2009).

The challenges climate change poses on our health, as well as socio-economic systems, requires an effective response. This dissertation focuses on climate change adaptation responses (rather than climate change mitigation responses). Within a European context, such adaptation responses are developed and implemented. The effectiveness of adaptation strategies for climate change is not evident, also not in the context of health outcomes, moreover, the full potential of risk reduction of adaptation measures is not reached (EC, 2009a, 2013a; IPCC, 2014b, 2014c; Smith et al., 2014).

A large part of the research presented in this dissertation was undertaken as a part of the ENHanCE (ERA-NET Health and Climate in Europe) research project, part of the ERAENVHEALTH project, funded by VROM (Dutch Ministry of Infrastructure and the Environment). The ENHanCE research project aimed to assess the potential impact of future climate change on infectious disease risk in Europe, and its outcomes for human health and well-being (the latter via effects of animal health) (ENHanCE).

The overall research aim of this dissertation is to analyse the relationship between global change, specifically focusing on climate change as a global (environmental) change process, and health, and to assess the adaptation response to climatic consequences for health in Europe.

In Chapter 1, a general introduction to the dissertation is given, including the research objectives and point of departure of the research, and ending with an outline of the structure of the dissertation.

Chapter 2 elaborates on the research context, key concepts and research approach to this dissertation. Concepts such as global change, globalisation, health, and climate change adaptation and mitigation are clarified, as well as the relationships between 
globalisation and health and climate change and health. The research approach to this dissertation is discussed, which is mainly characterised by an integrated understating of the key concepts and their relationships (globalisation, climate change, and health), an aggregate population-level research focus, and the use of participatory integrated assessment methods.

In Chapter 3, the relationship between globalisation and health is analysed by employing a statistical indicator analysis linking globalisation, as measured by the Maastricht Globalisation Index (MGI) with population health, as measured by several mortality indicators, controlling for confounding factors. The aim of the analysis was to find out if more globalised countries are experiencing better health. For the purpose of this study, the following definition for globalisation was assumed: "[...] an intensification of crossnational cultural, economic, political, social and technological interactions that lead to the establishment of transnational structures and the global integration of cultural, economic, environmental, political and social processes on global, supranational, national, regional and local levels (p.143) (Rennen \& Martens, 2003)". This pluralistic conceptualisation is reflected in the range of domains incorporated in the MGI, which is a weighted index. The MGI dataset used was for the year 2008 and included 117 countries (Martens \& Zywietz, 2006; Martens \& Raza, 2009). In order to relate a country's level of globalisation with the status of population health, the following morality indicators were selected: Infant mortality rate (per 1000 live births, both sexes), under-five mortality rate (probability of dying by age 5 per 1000 live births, both sexes), and adult mortality rate (probability of dying between 15 to 60 years per 1000 population, both sexes) (WHO, 2009b). The statistical analysis comprised of the methods: correlation analysis, leastsquares (LS) simple linear regression analysis, and multiple regression analysis.

The results of the statistical analyses indicate that all mortality indicators show a negative association with the process of globalisation. In all multivariate models, the association between globalisation and the mortality indicators remains significant after controlling for confounding factors. High levels of globalisation are associated with low mortality rates. The results might provide a crude initial indication of the potential advantageous effects of globalisation on health. However, in view of the argument that globalisation creates winners and losers, interpretation of the results should be done with care and should not be treated as a simple confirmation for globalisation being good for our health. The limitations and assumptions related to the use of a composite weighted index, and a statistical indicator method for analysing global dynamics should also be taken into account for the interpretation of the results. Further research of the health impacts of globalisation may help in adjusting and optimising the process of globalisation in the direction of healthy and sustainable development.

Chapter 4 presents the results of a survey, conducted as a part of an integrated assessment for the ENHanCE research project, which explored Dutch expert perspectives on 
the relationship between climate change and infectious disease risk. Potentially relevant non-climatic drivers of infectious disease risk in Western Europe are also addressed in this survey, and compared by the experts in terms of importance with climatic drivers. A stakeholder analysis was used to identify and select an expert sample for the survey. The survey data were analysed using descriptive statistics, for the aggregate sample as well as two sample groups "Science" and "Policy" formed based on the expert's professional backgrounds.

The results of the survey show that the experts consider temperature change, precipitation change, humidity change, and climate change-induced habitat change, to be relatively important for water-related infectious disease risk, vector-borne disease risk excluding zoonoses, and the risk of zoonoses. The climatic drivers are seen as relatively less important for food-related infectious disease risk. The experts rate many non-climatic drivers to be highly important for infectious disease risk. Comparatively, the majority of the non-climatic drivers assessed are seen as more important than climate change drivers. The degree of uncertainty in the future development of climatic drivers is viewed as moderate to high, and for non-climatic drivers as mostly moderate. The analyses of the subsamples based on professional backgrounds reveals differences in experts' opinions for e.g., socio-cultural drivers, and similarities.

The results of the survey should be seen as an indication of the perspectives of Dutch experts on the importance and uncertainty of climatic and non-climatic drivers for infectious disease risk in Western Europe, based on the Dutch expert sample that participated in the survey. The analyses of expert opinions of the sample subgroups can point towards possible differing perspectives held in the two professional environments regarding certain drivers and/or their uncertainty and importance for infectious disease risk. To establish and contrast prevailing perspectives held more research is necessary.

The study presented in Chapter 5 aimed to explore the perspectives of Dutch experts on adaptation responses to climate change-induced infectious disease risk in Western Europe, and examine expert's views on the willingness and capacity of potentially relevant actors in this response effort as well as the priorities placed on mitigation and adaptation responses. Chapter 5, like Chapter 4, also reports on part of the results of the survey conducted for the ENHanCE research project. Therefore, the broad methodological approach of this study is the same as in Chapter 4.

The results show that the experts view the adaptation responses differently according to the assessment criteria. The experts consider some adaptation responses as relatively more cost-effective, like fostering interagency and community partnerships, or relatively more beneficial to health, such as outbreak investigation and response. Expert opinions converge and diverge for the different adaptation responses. Based on the analyses one cannot deem one response as better as or worse than another. In practice, the priorities characterising a decision-making context will influence which responses will be most fitting for the situation at hand. Some criteria for making decisions on adaptation meas- 
ures might take precedence over others. This may affect the choice for an adaptation strategy. Regarding the prioritisation of mitigation and adaptation responses, expert perspectives converge towards a 50/50 budgetary allocation. The experts consider the national government/health authority as the most capable actor to respond to climate change-induced infectious disease risk.

The survey results should be seen as an indication of the perspectives of Dutch experts on the responses to climate change-induced infectious disease risk in Western Europe, and the willingness and the capacity of actors in such a response effort, based on the Dutch expert sample that participated in this study. The results of the analyses of the two sample groups "Science" and "Policy" can indicate that the two professional environments possibly have differing opinions when it comes to certain responses, assessment criteria, and the willingness and capacity of the actors. These differences could be related to diversity in underlying values held in the two professional environments (Akin \& Martens, 2014; Nordhaus, 1994). To establish prevailing perspectives on responses to climate change and infectious disease risk and make comparisons across stakeholder groups, more research needs to be undertaken.

Chapter 6 aimed to shed light on the role of health in EU climate adaptation policy and at the same time reflecting on key EU health policy and it's relation to climate adaptation. The chapter also includes a discussion on the potential future development of adaptation policy to meet consequences of climate change for health, and a reflection on mainstreaming efforts. This chapter takes on a broader perspective on climate change adaptation to health outcomes in Europe, in order to complement the previous chapters which touch upon adaptation responses in Western Europe. The chapter shows that climate change adaptation increasingly prioritises health as a key area. However, even though this prioritisation of health appears, the actual adoption and implementation of adaptation at an EU and Member State level is at times limited and varies greatly across Member States. In relation to this, monitoring and evaluation of adaptation results is lacking which makes the successfulness and effectiveness of such adaptation efforts unclear. The recent publication of the Commission Staff Working Document on "Adaptation to climate change impacts on human, animal, and plant health" (EC, 2013a) is a clear step towards placing specific attention on climate change adaptation for health outcomes in EU policy. It is not clear, however, whether the EU strategy on adaptation to climate change and the related documents are a true driver for actions taken at the Member State level.

From the review and discussion of some key EU health policy documents it can be seen that increasing attention is paid to the role of climate change and at times adaptation specifically. For instance, from examining the EU Health Programmes of 2008-2013 and 2014-2020, clear progression can be distinguished in making climate change increasingly more explicit and important. 
Strong commitment is expressed to mainstream climate change adaptation and health. However, it is difficult to gather to what extent mainstreaming is implemented with the aim of improving adaptation to climate change impacts on health and what still needs to be done in terms of mainstreaming to optimize this. More monitoring and evaluation to increase the evidence base on effective climate change adaptation for health needs to take place, which will also support the future development of EU adaptation to climate change-induced health impacts.

Finally Chapter 7 looks back at the chapters included in this dissertation and provides the main findings and conclusions in relation to the research objectives addressed in this dissertation. Moreover, some final reflections are offered. 


\section{SAMENVATTING}

KLIMAATVERANDERING EN GEZONDHEID: CONSEQUENTIES EN ADAPTATIE IN EUROPA.

Deze dissertatie richt zich op mondiale verandering en in het bijzonder klimaatverandering, een mondiale milieuverandering, en de relatie hiervan tot gezondheid en specifiek infectieziekterisico, als ook adaptatiemaatregelen voor deze uitdagingen.

Tegenwoordig vinden veel inter-agerende mondiale veranderingen op een ongekend tempo plaats die vaak verbonden zijn met menselijke activiteiten. Deze veranderingen beïnvloeden onze ecologische en sociale systemen. Mondialisering, of de mondiale veranderingen, creëren een breed scala aan gevolgen voor de volksgezondheid (Lee, 2009; Stenne et al., 2007). Anthropogene mondiale opwarming en klimaatverandering zijn zulk mondiale veranderingen die volksgezondheid en welzijn bedreigen, ook door hun invloed op infectieziekterisico, op mondiaal niveau, maar ook binnen de Europese regio (EEA; 2012; Kovats et al., 2014; McMichael, 2013; Semenza \& Menne, 2009).

De uitdagingen voortkomend uit klimaatverandering voor onze gezondheid en sociaaleconomische systemen vereisen een effectieve aanpak. Deze dissertatie richt zich op adaptatie aan klimaatverandering (en niet mitigatie van klimaatverandering). Binnen een Europese context, wordt adaptatie ontwikkeld en toegepast. De effectiviteit van adaptatiestrategieën voor klimaatverandering is niet duidelijk, ook niet wat betreft gezondheidsgevolgen. Daarenboven wordt het potentieel voor risicoreductie via adaptatiemaatregelen niet volledig gerealiseerd (EC, 2009a, 2013a; IPCC, 2014b, 2014c; Smith et al., 2014).

Het onderzoek voor deze dissertatie is grotendeels uitgevoerd als deel van het ENHanCE (ERA-NET Health and Climate in Europe) (ERA-NET Gezondheid en Klimaat in Europa) onderzoeksproject, onderdeel van het ERA-ENVHEALTH project, gefinancierd door VROM (Ministerie van Infrastructuur en Milieu). Het ENHanCE onderzoeksproject had als doel de assessment van potentiële gevolgen van toekomstige klimaatverandering op infectieziekterisico in Europa en de consequenties voor volksgezondheid en welzijn (dit laatste via uitwerkingen op dierziektes) (ENHanCE).

Het overkoepelende onderzoeksdoel van deze dissertatie is het analyseren van de relatie tussen mondiale verandering, in het bijzonder klimaatverandering als mondiale milieuverandering, en gezondheid, en de assessment van adaptatie aan de gezondheidsgevolgen van klimaatverandering in Europa. 
In Hoofdstuk 1 wordt een algemene introductie gegeven, waarin de onderzoeksdoelen en het uitgangspunt van het onderzoek worden beschreven. Dit hoofdstuk sluit af met een overzicht van de opbouw van deze dissertatie.

Hoofdstuk 2 bespreekt de onderzoekscontext, hoofdconcepten, en onderzoeksaanpak van deze dissertatie nader. Concepten zoals mondiale verandering, mondialisering, gezondheid, en adaptatie aan en mitigatie van klimaatverandering worden verduidelijkt. Ook worden de relaties tussen mondialisering en gezondheid, en klimaatverandering en gezondheid beschreven. De onderzoeksaanpak van deze dissertatie wordt besproken, welke voornamelijk gekenmerkt word door een geïntegreerd begrip van de hoofdconcepten en hun onderlinge relaties (mondialisering, klimaatverandering, en gezondheid), een geaggregeerd perspectief op populatieniveau, en het gebruik van participatieve integrated assessment methoden.

In Hoofdstuk 3 wordt de relatie tussen mondialisering en gezondheid geanalyseerd. Door middel van een statistische indicatoren analyse wordt mondialisering, gemeten door de Maastricht Globalisation Index (Maastricht Mondialiseringsindex) (MGI), verbonden met gezondheid, gemeten door een aantal mortaliteitsindicatoren, verbindt, waarbij wordt gecontroleerd voor confounders. Het doel van de analyse is om te weten te komen of meer gemondialiseerde landen een betere gezondheid genieten. Voor deze studie is de volgende definitie voor mondialisering aangenomen: "[...] an intensification of crossnational cultural, economic, political, social and technological interactions that lead to the establishment of transnational structures and the global integration of cultural, economic, environmental, political and social processes on global, supranational, national, regional and local levels (p.143) (Rennen \& Martens, 2003)". (De intensivisering van grensoverschrijdende culturele, economische, politieke, sociale, en technologische interacties die leiden tot de totstandkoming van transnationale structuren en de mondiale integratie van culturele, economische, ecologische, politieke, en sociale processen op mondiaal, surpanationaal, national, regionaal, en lokaal niveau.) De MGl is een gewogen index waarin een reeks domeinen is opgenomen; dit weerspiegelt deze pluralistische definitie. De MGI dataset van het jaar 2008 is gebruikt en deze bevat 177 landen (Martens \& Zywietz, 2006; Martens \& Raza, 2009). Om het mondialiseringsniveau van een land met de staat van volksgezondheid te verbinden zijn de volgende mortaliteitsindicatoren geselecteerd: Infant mortality rate (per 1000 live births, both sexes) (zuigelingensterfte, per 1000 levendgeborenen, jongens en meisjes), under-five mortality rate (probability of dying by age 5 per 1000 live births, both sexes) (kindersterfte, stervenskans tot het 5 de levensjaar per 1000 levendgeborenen, jongens en meisjes), en adult mortality rate (probability of dying between 15 to 60 years per 1000 population, both sexes) (sterfte, stervenskans tussen de leeftijd van 15 en 60 jaar per 1000 inwoners, mannen en vrouwen) (WHO, 2009b). Voor de statistische analyse zijn de volgende methoden gebruikt: correlatieanalyse, enkelvoudige lineaire 
regressieanalyse (kleinste-kwadrantenmethode) en meervoudige lineaire regressieanalyse.

De resultaten van de statistische analyse duiden erop dat alle mortaliteitsindicatoren een negatieve associatie hebben met het proces van mondialisering. In alle meervoudige regressiemodellen blijft de associatie tussen mondialisering en de mortaliteitsindicatoren significant na het uitsluiten van confounders. Hoge mondialisering wordt geassocieerd met lage mortaliteit. Deze resultaten kunnen een grove eerste indicatie zijn voor een mogelijk voordelig effect van mondialisering voor gezondheid. Maar, met het oog op het argument dat mondialisering winnaars en verliezers teweegbrengt, vergt de interpretatie van de resultaten zorgvuldigheid. De resultaten kunnen niet afgedaan worden als een simpel bewijs dat mondialisering goed voor onze gezondheid is. Ook moet bij het interpreteren van de resultaten rekening worden gehouden met de beperkingen en aannames van het gebruik van een gewogen index en een statistische indicatoren methode voor het analyseren van mondiale dynamiek. Verder onderzoek naar de gezondheidsgevolgen van mondialisering zou de aanpassing en optimalisering van het mondialiseringsproces in de richting van een gezonde en duurzame ontwikkeling kunnen ondersteunen.

Hoofdstuk 4 bevat de resultaten van een enquête uitgevoerd als deel van een integrated assessment voor het ENHanCE onderzoeksproject, welke de perspectieven van Nederlandse experts onderzocht over de relatie tussen klimaatverandering en infectieziekterisico. Mogelijk relevante niet-klimatische drijvende factoren voor infectieziekterisico in West-Europa zijn ook opgenomen in de enquête en door de experts vergleken in mate van belangrijkheid met klimatische drijvende factoren. Een belanghebbendenanalyse is gebruikt om een steekproef van experts te identificeren en selecteren voor de enquête. De data uit de enquête is onderzocht met behulp van descriptieve statistische methoden, waarbij alle analysen voor de hele steekproef maar ook voor twee subgroepen van de steekproef gelabeld "Science" ("Wetenschap") en "Policy" ("Beleid") zijn uitgevoerd. Deze subgroepen zijn gevormd op basis van de professionele achtergrond van de experts.

De resultaten van de enquête laten zien dat de experts temperatuurverandering, neerslagverandering, verandering in luchtvochtigheid, en verandering in de natuurlijke omgeving door klimaatverandering zien als relatief belangrijk voor water-gerelateerd infectieziekterisico, vector-overdragen infectieziektenrisico exclusief zoönosen, en het risico op zoönosen. De klimatische drijvende factoren worden gezien als relatief minder belangrijk voor voedsel-gerelateerd infectieziektenrisico. De niet-klimatische drijvende factoren worden in vergelijk met de klimatische drijvende factoren grotendeels als meer belangrijk bevonden. De mate van onzekerheid in de toekomstige ontwikkeling van de klimatische factoren word gezien als matig tot hoog, en voor de niet-klimatische factoren merendeels als matig. The analyses van de subgroepen van de steekproef, gebaseerd op de professionele achtergrond van de respondenten, laat zien dat er 
verschillen zijn in de meningen van de experts bijvoorbeeld voor de sociaal-culturele drijvende factoren, maar ook gelijkenissen.

De resultaten van de enquête moeten gezien worden als een indicatie van de perspectieven van de Nederlandse experts met betrekking tot de mate van belangrijkheid en onzekerheid van de klimatische en niet-klimatische drijvende factoren voor infectieziekterisico in West-Europa, gebaseerd op de Nederlandse expertsteekproef die deelgenomen heeft aan de enquête. De analyses van de meningen van de experts in de steekproef subgroepen kunnen erop wijzen dat er mogelijk verschil bestaat tussen de perspectieven binnen de twee professionele omgevingen met betrekking tot bepaalde drijvende factoren en/of de onzekerheid of belangrijkheid van deze voor infectieziekterisico. Om zulke algemeen heersende perspectieven vast te kunnen stellen en te vergelijken, is meer onderzoek noodzakelijk.

De studie in Hoofdstuk 5 verkent de perspectieven van Nederlandse experts over adaptatie aan infectieziekterisico ten gevolge van klimaatverandering in West-Europa, en onderzoekt ook de kijk van de experts op de bereidheid en capaciteit van mogelijk relevante actoren in zo een responspoging, alsook de prioriteiten die gehecht worden aan mitigatie- en adaptatiemaatregelen. Hoofdstuk 5 beschrijft, net zoals Hoofdstuk 4, een deel van de resultaten van de enquête die is uitgevoerd voor het ENHanCE onderzoeksproject. Zodoende is de methodologische aanpak van de studie in dit hoofdstuk over het algemeen hetzelfde als die uitgelegd in Hoofdstuk 4.

De resultaten laten zien dat de experts de adaptatiemaatregelen verschillend zien naar gelang de assessment criteria. De experts beschouwen sommige adaptatiemaatregelen als relatief meer cost-effectief, zoals "fostering interagency and community partnerships" (het cultiveren van relaties tussen instellingen en gemeenschappen), of relatief meer voordelig voor gezondheid, zoals "outbreak investigation and response" (het onderzoeken van en reageren op infectieziekteuitbraken). De meningen van de experts convergeren en divergeren voor verschillende adaptatiemaatregelen. Gebaseerd op de analyses kan de ene adaptatiemaatregel niet als beter of slechter aangemerkt worden dan de andere. In de praktijk zullen de prioriteiten die een besluitvormingscontext kenmerken van belang zijn voor welke adaptatiemaatregelen het meest passend zijn voor de gegeven omstandigheden. Sommige criteria voor besluitvorming over adaptatiemaatregelen zouden voorrang kunnen hebben op anderen. Dit zou de keuze voor een adaptatiestrategie kunnen beïnvloeden. Met betrekking tot de prioriteiten die worden gehecht aan mitigatie- en adaptatiemaatregelen blijkt dat de perspectieven van de experts convergeren naar een 50/50 budgettaire toekenning. De experts zien de overheid/landelijke gezondheidsinstellingen als de meest capabele acteur om te reageren op infectieziekterisico ten gevolge van klimaatverandering.

De resultaten van de enquête moeten beschouwd worden als een indicatie van de perspectieven van Nederlandse experts over adaptatie aan infectieziekterisico ten 
gevolge van klimaatverandering in West-Europa, en de bereidheid en capaciteit van de actoren in zo een responsactie, gebaseerd op de Nederlandse expertsteekproef die heeft deelgenomen aan deze studie. De resultaten van de twee steekproefsubgroepen "Science" ("Wetenschap") en "Policy" ("Beleid") kunnen erop duiden dat de twee professionele omgevingen mogelijk verschillende meningen hebben over bepaalde adaptatiemaatregelen, assessment criteria, en de bereidheid en capaciteit van de actoren. Deze verschillen kunnen gerelateerd zijn aan een diversiteit in onderliggende waarden die in de twee professionele omgevingen bestaan (Akin \& Martens, 2014; Nordhaus, 1994). Om heersende perspectieven over adaptatiemaatregelen voor klimaatverandering en infectieziekten vast te stellen en te vergelijken, is het noodzakelijk meer onderzoek te doen.

Hoofdstuk 6 tracht de rol van gezondheid in het klimaatadaptatiebeleid van de EU te verhelderen en tegelijkertijd te reflecteren op de voornaamste EU gezondheidsbeleidsstukken en de relatie hiervan tot klimaatadaptatie. Het hoofdstuk geeft ook een discussie weer over de mogelijke toekomstige ontwikkelingen van adaptatiebeleid om met de gezondheidsgevolgen van klimaatverandering om te gaan, en reflecteerd op het mainstreamen van beleid. Dit hoofdstuk biedt een breder perspectief op klimaatadaptatie en de gezondheidsgevolgen hiervan in Europa om zodoende de voorafgaande hoofdstukken, die over adaptatiemaatregelen in West-Europa gaan, aan te vullen. Het hoofdstuk laat zien dat klimaatadaptatiebeleid steeds vaker gezondheid prioriteert als hoofdthema. Maar ondanks de prioriteit die wordt gegeven aan gezondheid, is de daadwerkelijke toepassing en uitvoering van adaptatie op EU- en lidstatenniveau soms beperkt en varieert sterk van lidstaat tot lidstaat. Dit houdt ook verband met het tekortschieten van het monitoren en evalueren van adapatatieresultaten, wat het succes en de effectivitieit van zulk soort adaptatiemaatregelen onduidelijk maakt. De recente publicatie van het Commission Staff Working Document on "Adaptation to climate change impacts on human, animal, and plant health" (EC, 2013a) (Adaptatie aan de gevolgen van klimaatverandering voor volks-, dier-, en plantengezondheid) is een duidelijke stap om specifiek de aandacht te richten op klimaatadaptatie voor gezondheidsgevolgen in EU beleid. Het is echter niet duidelijk of de EU strategie voor klimaatadaptatie en de gerelateerd beleidsstukken een echte drijfveer zijn voor de actie die genomen wordt op lidstaatniveau.

Uit de bespreking van een aantal belangrijke EU gezondheidsbeleidsstukken blijkt dat hierin toenemend aandacht besteed wordt aan de rol van klimaatverandering en soms specifiek aan adaptatie. Bijvoorbeeld, uit het bestuderen van de EU Health Programmes (EU Gezondheidsprogramma's) voor 2008-2013 en 2014-2020is het duidelijk kenbaar dat klimaatverandering steeds meer expliciet en als zijnde belangrijk wordt weergegeven.

$\mathrm{Er}$ is een sterk engagement voor het mainstreamen van klimaatadaptatie en gezondheid. Het is echter moeilijk vast te stellen tot op welke hoogte mainstreaming wordt 
uitgevoerd met het doel klimaatadaptatie voor gezondheidsgevolgen te verbeteren en wat er nog gedaan moet worden om mainstreaming te optimaliseren. Om meer aanwijzingen te verkrijgen naar effectieve klimaatadaptatie voor gezondheidsgevolgen moet meer monitoren en evaluatie plaatsvinden. Dit kan ook de toekomstige ontwikkeling van EU klimaatadaptatie voor gezondheidsgevolgen bevorderen.

Ten slotte kijkt Hoofdstuk 7 terug naar alle hoofdstukken in deze dissertatie en geeft de hoofdbevindingen en conclusies weer in verband met de onderzoeksdoelen die in deze dissertatie behandeld zijn. Daarnaast worden enkele laatste beschouwingen gegeven. 


\section{ACKNOWLEDGEMENTS}

I would like to thank several institutions and people that have supported me and played an important role during my Ph.D. trajectory.

First of all, I would like to thank my supervisor Prof. Pim Martens for always supporting and encouraging me. I very much appreciate your continued trust in me during my Ph.D. research and employment at ICIS.

I would like to thank the members of the assessment committee, Prof. dr. Pieter Glasbergen (chairman), Prof. dr. Matthew Baylis (Institute of Infection \& Global Health, University of Liverpool), Prof. dr. Martin Beniston (Institute for Environmental Sciences, University of Geneva), and Prof. dr. Wim Passchier, for assessing my manuscript and providing me with constructive comments.

A large part of the research included in this dissertation was conducted as a part of the ENHanCE (ERA-NET Health and Climate in Europe) research project. The project research done by the ICIS-team was funded under the ERA-ENVHEALTH project by VROM (Dutch Ministry of Infrastructure and the Environment). Therefore I would like to gratefully acknowledge VROM for funding this research. I very much enjoyed the collaboration with our ENHanCE colleagues at the University of Liverpool and CIRAD (Centre de coopération internationale en recherché agronomique pour le développement): Dr. Agnès Waret-Szkuta, Prof. Andy Morse, Dr. Christian Setzkorn, Dr. Cyril Caminade, Dr. K. Marie McIntyre, Prof. Matthew Baylis, and Prof. Serge Morand. Thanks to all of you for the fruitful and supportive collaboration.

I would like to thank my former colleagues at ICIS: Alex Baker-Shelly, Alberto Cabral, Annemarie van Zeijl-Rozema, Annet Grol, Astrid Offermans, Atika Wijaya, Bingtao Su, Bram Oosterbroek, Carijn Beumer, Ceren Pekdemir, Chiung Chang, Christian Scholl, Esther Sri Astuti, Hongguang Nie, Jeanine Schreurs, Jing Wang, Joana Mattei Faggin, Joop de Kraker, Julia Backhaus, Laura Kurth, Lukas Figge, Marc Dijk, Marjan Peeters, Mariana Santos, Maud Huynen, Muhammad Ibnu, Nia Hidayat, Nicole Rijkens-Klomp, Paul Wever, Pieter Glasbergen, Pieter Valkering, Reina Pasma, René Kemp, Robbert van Driessche, Sani Kosasih, Sjouke Beemsterboer, Toan Do Thanh, and Véronique Vasseur. During my employment at ICIS I learned a lot from all of you and the ICIS office always had a very friendly and engaging atmosphere for which I am very grateful. I would like to especially thank Anja van Bogaert, Dr. Ron Corvers, and Prof. Pim Martens for giving me the opportunity to work at ICIS and on the ENHanCE project. 
I would also like to thank my former colleagues at the MC4E (Maastricht Centre for Entrepreneurship). It was lovely working together with the MC4E-girls: Ana Mihail, Dr. Carla Costa, and Dr. Jana Thiel. Thank you for the nice times we had together! Thank you Dr. Ing. Wynand Bodewes and Prof. Jan Cobbenhagen for the opportunity to work at the center and move into the field of social \& ecological entrepreneurship.

During my PhD research I was able to go on a research visit to the Robert Schuman Centre for Advanced Studies, European University Institute (EUI). I would like to, first of all, thank ICIS for making this possible. My gratitude goes to Prof. Maduro, who received me as a visiting research fellow at his research school. Many thanks to Prof. Ellerman for his feedback on my work. A special thank you to Federica Parretti and her family for making me feel at home.

I would like to thank all my friends and my family abroad for their interest in my Ph.D., their kindness and thoughtfulness. I am very grateful for always having the love and support from my parents Rose-Marie Akin-Straten and Okan Akin and my sister Cenay Akin in everything I do, not only my Ph.D. And finally, I would like to thank my partner Christoph Aluttis: thank you for your love, empathy, encouragement, and positive attitude.

Thank you! 


\section{LIST OF ABBREVIATIONS AND SYMBOLS}

$\alpha=$ significance level

$\beta=$ regression coefficient

$\beta_{0}=$ constant

$\beta_{1,2, \ldots, x}=$ regression coefficients

CEHAPSIS = Climate, Environment and Health Action Plan and Information System

CIRAD = Centre de coopération internationale en recherché agronomique pour le développement

DPT = Diphtheria, Pertussis (or whooping cough), and Tetanus

$\mathrm{EC}=$ European Commission

$E C D C=$ European Centre for Disease Prevention and Control

$\mathrm{EEA}=$ European Environment Agency

EFIEA = European Forum on Integrated Environmental Assessment

ENHanCE $=$ ERA-NET Health and Climate in Europe (research project)

$\mathrm{EU}=$ European Union

EUHPF = the European Union Health Policy Forum

$\mathrm{FDI}=$ Foreign Direct Investment

GDP $=$ Gross Domestic Product

GNP = Gross National Product

HIAP = Health in all Policies

HIV = Human Immunodeficiency Virus

$\mathrm{IA}=$ Integrated Assessment

$\mathrm{ICIS}=$ International Centre for Integrated assessment and Sustainable development

IPCC = Intergovernmental Panel on Climate Change

$\mathrm{IQR}=$ Interquartile range

$\mathrm{Ln}=$ natural logarithm

$\mathrm{LS}=$ Least Squares

MEA = Millennium Ecosystem Assessment

NAS = National Adaptation Strategy

$\mathrm{n}=$ sample size

$\mathrm{NGO}=$ Non-Governmental Organisation

OECD = Organisation for Economic Co-operation and Development

PHEIAC = Public Health Evaluation and Impact Assessment Consortium

PPP $=$ Purchasing Power Parity

RIVM = Netherlands Institute for Public Health and the Environment; or Rijksinstituut voor Volksgezondheid en Milieu

SAP = Structural Adjustment Programme

THE $=$ Total Expenditure on Health 
UN = United Nations

UNDP = United Nations Development Programme

UNFCCC $=$ United Nations Framework Convention on Climate Change

$V=$ value of the variable, ranging on a scale from 0 to 100

VROM = Dutch Ministry of Infrastructure and the Environment; or Ministerie van

Infrastructuur en Milieu

WB $=$ World Bank

WHO $=$ World Health Organization

WHO FCTC $=$ WHO Framework Convention on Tobacco Control

WHOSIS = WHO Statistical Information System

WP $=$ Work Package 


\section{ABOUT THE AUTHOR}

Su-Mia Fazilet Akin was born on 20 February 1983 in Aachen, Germany. Su-Mia obtained a Master's Degree in International Business in 2006 from Maastricht University, the Netherlands. After her business studies, Su-Mia worked as a research assistant at the Chambers of Commerce in Aachen, Germany. In 2008, she obtained another Master's degree in Public Policy and Human Development also from Maastricht

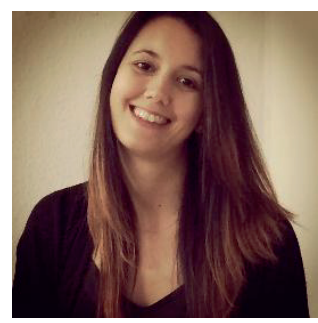
University. During this program she followed the specialization track on Sustainable Development.

In 2008, Su-Mia started working as a tutor for different courses offered by the International Centre for Integrated assessment and Sustainable development (ICIS), Maastricht University. In January 2009, she started to work as a PhD researcher at ICIS. From April 2009-March 2012, Su-Mia worked as a researcher on the European ENHanCE (ERA-NET Health and Climate in Europe) Research Project, part of the ERA-ENVHEALTH Project.

From May to June 2012, Su-Mia stayed at the Global Governance Programme, Robert Schuman Centre for Advanced Studies, European University Institute in San Domanico di Fiesole, Italy, as a visiting research fellow, which was a part of her PhD Research.

From Aug 2014 to Jan 2015, Su-Mia was deployed to the Maastricht Centre for Entrepreneurship (MC4E), Maastricht University, and worked there as an assistant professor of Social and Environmental Entrepreneurship.

During her employment at Maastricht University, Su-Mia co-/coordinated, planned, developed, and taught Bachelor and Master courses and skills trainings, and supervised Bachelor and Master theses. Her teaching activities covered the topics: sustainable development, globalization and environmental change, social and environmental entrepreneurship, and problem-based learning. 


\section{Maastricht University}

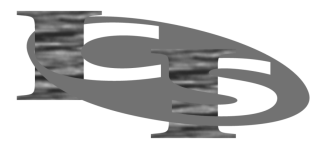

International Centre for

Integrated assessment and Sustainable development

\section{Certificate}

On behalf of Maastricht University, the International Centre for Integrated assessment and Sustainable development (ICIS) - Maastricht University graduate school of SusTainability science (MUST) declares that

\section{Su-Mia Akin}

born

20 February 1983 in

Aachen, Germany

has successfully fulfilled all requirements of the MUST PhD programme.

Maastricht, the Netherlands

17 December 2015 
